\title{
POTASSIUM FERRATE TREATMENT OF RFETS' CONTAMINATED GROUNDWATER
}

\section{Rocky Flats Environmental Technology Site}

\author{
DISCLAIMER
}

This report was prepared as an account of work sponsored by an agency of the United States Government. Neither the United States Government nor any agency thereof, nor any of their employees, makes any warranty, express or implied, or assumes any legal liability or responsibility for the accuracy, completeness, or usefulness of any information, apparatus, product, or process disclosed, or represents that its use would not infringe privately owned rights. Reference herein to any specific commercial product, process, or service by trade name, trademark, manufacturer, or otherwise does not necessarily constitute or imply its endorsement, recommendation, or favoring by the United States Government or any agency thereof. The views and opinions of authors expressed herein do not necessarily state or reflect those of the United States Government or any agency thereof.

\section{U.S Department of Energy Rocky Flats Field Office Golden, Colorado}

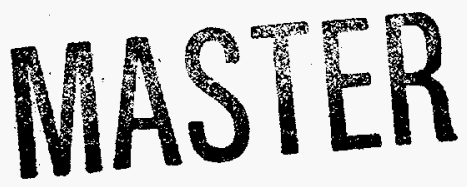

DIBTRIBU $\ldots . . . . . . . . . . .$. OUMENT IS UNLIMTTEO DISTRIBUTION OF THUS DOCUMENT IS UNLIMITEQ WW 


\section{DISCLAIMER}

Portions of this document may be illegible in electronic image products. Images are produced from the best available original document. 


\begin{tabular}{llr}
\hline $\begin{array}{l}\text { Potassium Ferrate Treatment } \\
\text { of RFETS Groundwater }\end{array}$ & Document Number: & RF/ER-94-0028.UN \\
& Section: & Table of Contents, Rev. 0 \\
Page: & i of iii \\
\hline \hline
\end{tabular}

\section{TABLE OF CONTENTS}

\section{SECTION}

1.0

1.1

1.1 .1

1.1 .2

1.2

1.3

1.4

2.0

2.1

2.2

3.0

3.1

3.2

3.3

3.3.1

3.3.2

3.3 .3

3.4

3.4 .1

3.4 .2

3.5

3.6

4.0

4.1

4.1.1

4.2

4.2 .1

4.2 .2

4.2 .3

4.3

4.3.1

4.3.2
INTRODUCTION

Site Description.

Site Name and Description

History of Operations

Groundwater Description

Treatment Technology Description

Previous Studies of Ferrate Water Treatment of RFETS

CONCLUSIONS AND RECOMMENDATIONS

Conclusions

Recommendations

TREATABILITY STUDY APPROACH

Test Objectives and Rationale

Experimental Design

Experimental Equipment, Materials and Procedures

Experimental Equipment

Experimental Materials

Experimental Procedures

Sampling and Analysis

Waste from this Study

Experimental Treatment Process

Data Management

Deviation from the Work Plan

RESULTS AND DISCUSSION

Phase I Results and Discussion

Conclusions from Phase I Tests

Phase II results and Discussion

Determining the Test Conditions to be Used in Phase III Tests

Discussion of Phase II Results with Corrected Radionuclide Data

Conclusions from Phase II Tests

Phase III Results and Discussion

Preliminary Engineering Data

Phase III Potassium Ferrate Treatment Demonstration Results
PAGE

$1-1$

$1-4$

$1-4$

$1-5$

$1-5$

1-6

1-10

2-1

2-1

2-7

3-1

3-1

3-2

3-6

3-6

3-6

3-7

3-9

3-10

3-10

3-11

3-11

4-1

4-1

4-9

4-10

4-16

4-20

4-31

4-32

4-33

4-35 


\begin{tabular}{llr}
\hline $\begin{array}{l}\text { Potassium Ferrate Treatment } \\
\text { of RFETS Groundwater }\end{array}$ & Document Number: & RF/ER-94-0028.UN \\
& Section: & Table of Contents, Rev. 0 \\
& Page: & ii of iii \\
\hline \hline
\end{tabular}

4.3.3 Discussion of the Statistical Implications of Phase III Results ................. 4-38

4.3.4 Conclusion from Phase III Tests ............................................................. 4-39

5.0 QUALITY ASSURANCE / QUALITY CONTROL (QA/QC) .............. 5-1

$5.1 \quad$ Groundwater Sampling .......................................................................... $5-1$

$5.2 \quad$ Chemical Analysis ............................................................................... 5-1

$5.3 \quad$ Computer Modeling ……..................................................................... $5-1$

$5.4 \quad$ Instrumentation ............................................................................... 5

$5.5 \quad$ Laboratory Techniques ....................................................................... $5-3$

\section{FIGURES}
4.1-1
$4.1-2$
4.1-3
4.2.1-1
4.2.2-1
$4.2 .2-2$
4.2.2-3
$4.2 .2-4$
$4.2 .2-5$
$4.2 .2-6$
4.2.2-7
4.3.1-1
Summary of Results of Phase I Tests Using ECHIP Program
$4-4$
Response Surface of Americium
4-6
Summary of the Responses from Modified Phase I Test Program .......... 4. 4-9
Combined Response Surface Using Uncorrected Radionuclide Data ..... 4-18
Summary of Results of Phase II Tests Using ECHIP Program ................ 4. 4-20
Pareto Effect Graph of Americium
4-22
Response Surface of Americium
4-23
Pareto Effects Graph of Uranium
$4-24$
Pareto Effects Graph of Aluminum
4-25
Aluminum Response to Ferrate Treatment
$4-26$
Combined Response Surface of Corrected Phase II Results..
$4-27$
General Flowsheet for Ferrate Treatment of RFETS Groundwater
$4-36$

\section{TABLES}

$1.0-1$

$1.0-2$

$1.2-1$

$1.2-2$

2.1-1

$2.1-2$

CWQCC Discharge Limits

$1-2$

Analytical Methods and Detection Limits Used in This Study ................ 1-3

Approximate Volume of Groundwater from Various Monitoring Wells . 1-6

Analysis of Untreated Water at Beginning of Each Phase of the Study ... 1-7

Results of potassium Ferrate Water Treatment and Comparison to the CWQCC Discharge Limits and the Analytical Detection Limits

Initial Groundwater and Phase III Treated Water Chemical Analysis

Percent Removal

Effect of $\mathrm{pH}$ and Ferrate Addition Upon the Response of Americium .... 
Potassium Ferrate Treatment of RFETS Groundwater
Document Number:

Section:

Page:
RF/ER-94-0028.UN

Table of Contents, Rev. 0

iii of iii

Effect of Alum and Polymer Change on the Response of Some of the

$\mathrm{COCs}$ at the Same $\mathrm{pH}$ and Ferrate Addition

Test Matrix Used for the First Phase of this Study

$3-4$

$3.2-2$

$4.1-1$

4.1-2

$4.1-3$

4.2-1

Phase II Test Matrix

3-5

Analytical Results for Phase I Ferrate Treatment Tests ..

$4-2$

Coefficients for Response of Americium

4-5

Coefficients for Response of Uranium

4-7

Phase II Test Matrix

4-13

Modified Phase II Test Matrix

4-14

Analytical Results for the Modified Phase II Ferrate Treatment Tests

4-15

4.2-3

4.2.1-1

Predicted Contaminant Concentrations at the Optimum Conditions

Using Uncorrected Radionuclide Data

4-19

4.2.2-1

Predicted Contaminant Concentrations at the Optimum Treatment

Conditions

4-28

4.2.2-2 Predicted Results at Phases III Treatment Conditions Using the

Corrected Data Response Surface Model

Results of the Phase III Ferrate Treatment Tests at the Optimum

Conditions

4-37

$5.5-1$

Material Balance Calculations

$5-6$

\section{References}

\section{Appendices}

Appendix A Appendix B Appendix C Appendix D Appendix E Appendix $\mathrm{F}$ Appendix G
Analytical Reports of Treated Water from Phase I Tests. A-1 Analytical Report of Treated Water From Phase II Tests. B-1 Analytical Report of Test Products From Phase III Tests.. C-1 ECHIP Output of Phase I Results. D-1

ECHIP Output of Phase I Modified Test Plan E-1

ECHIP Output of Phase II Modified Test Plan F-1 Acronym List 
Potassium Ferrate Treatment of RFETS Groundwater
Document Number:

Section:

Page:
RF/ER-94-0028.UN

1.0, Rev. 0

1 of 10

\subsection{INTRODUCTION}

The potassium ferrate treatment study of Rocky Flats Environmental Technology Site (RFETS) groundwater was performed under the Sitewide Treatability Studies Program (STSP). This study was undertaken to determine the effectiveness of potassium ferrate in a water treatment system to remove the contaminants of concern (COCs) from groundwater at the RFETS. Potassium ferrate is a simple salt where the iron is in the plus six valence state. It is the iron at the plus six valence state $\left(\mathrm{Fe}^{+6}\right)$ that makes it an unique water treatment chemical, especially in waters where the $\mathrm{pH}$ is greater than seven. In basic solutions where the solubility of the oxides/hydroxides of many of the COCs is low, solids are formed as the $\mathrm{pH}$ is raised. By using ferrate these solids are agglomerated so they can be effectively removed by sedimentation in conventional water treatment equipment.

The objective of this study was to determine the quality of water after treatment with potassium ferrate and to determine if the Colorado Water Quality Control Commission (CWQCC) discharge limits for the COCs listed in Table 1.0-1 could be met (1). Radionuclides in the groundwater were of special concern.

Laboratory work was performed by personnel from the Environmental Technology and Environmental Engineering Technology group of Rocky Flats Plant under the supervision and direction of ACTA Resources, Inc. All potassium ferrate test work was performed in Laboratory 264, Building 881 in accordance with the guide lines of the treatability work plan (2).

Chemical analysis of the untreated and treated water samples generated during this study were done by Accu-Labs Research, Inc. using EPA methods listed in Table 1.0-2. 
Table 1.0-1 CWQCC Discharge Limits

\begin{tabular}{|l|c||}
\hline \multicolumn{1}{|c|}{ Analytes } & Discharge Limits \\
\hline \multicolumn{2}{|c|}{ Radionuclides, pCi/l } \\
\hline Gross alpha (a) & $7-11$ \\
\hline Gross beta (b) & $5-19$ \\
\hline Am 241 & 0.05 \\
\hline Pu 239,240 & 0.05 \\
\hline U total & $5-10$ \\
\hline & Target Metals, mg/ \\
\hline Aluminum & 0.087 \\
\hline Antimony & 0.024 \\
\hline Barium & 1.0 \\
\hline Beryllium & 0.004 \\
\hline Cadmium & 0.0015 \\
\hline Chromium & 0.05 \\
\hline Cobalt & 0.05 \\
\hline Iron & 0.3 \\
\hline Lead & 0.028 \\
\hline Manganese & 0.56 \\
\hline Mercury & 0.00001 \\
\hline Nickel & 0.125 \\
\hline Selenium & 0.01 \\
\hline Silver & 0.00059 \\
\hline Vanadium & 0.1 \\
\hline Zinc & 0.35 \\
\hline
\end{tabular}


Potassium Ferrate Treatment of RFETS Groundwater
Document Number:

Section:

Page:
RF/ER-94-0028.UN

1.0, Rev. 0

3 of 10

Table 1.0-2 Analytical Methods and Detection Limits Used in This Study

\begin{tabular}{|c|c|c|c|}
\hline Analytes & Analytical Method & Detection Limit & Units \\
\hline \multicolumn{4}{|c|}{ Radionuclides } \\
\hline Gross alpha/beta & EPA 900.0 & $3-4$ & $\mathrm{pCi} / 1$ \\
\hline Am 241 & ALR 3804224 & 0.00 & $\mathrm{pCi} / 1$ \\
\hline $\mathrm{Pu} 238,239,240$ & ALR 3804223 & 0.01 & $\mathrm{pCi} / \mathrm{l}$ \\
\hline $\mathrm{U}$, total & EPA 908.1 & 0.0001 & $\mathrm{mg} / \mathrm{l}$ \\
\hline \multicolumn{4}{|c|}{ Target Metals } \\
\hline Aluminum & EPA 200.7 & 0.05 & $\mathrm{mg} / \mathrm{l}$ \\
\hline Antimony & EPA 204.7 & 0.005 & $\mathrm{mg} / \mathrm{l}$ \\
\hline Arsenic & EPA 206.2 & 0.005 & $\mathrm{mg} / \mathrm{l}$ \\
\hline Barium & EPA 200.7 & 0.05 & $\mathrm{mg} / \mathrm{l}$ \\
\hline Beryllium & EPA 200.7 & 0.005 & $\mathrm{mg} / \mathrm{l}$ \\
\hline Cadmium & EPA 213.2 & 0.0005 & $\mathrm{mg} / \mathrm{l}$ \\
\hline Chromium & EPA 200.7 & 0.005 & $\mathrm{mg} / \mathrm{l}$ \\
\hline Cobalt & EPA 200.7 & 0.005 & $\mathrm{mg} / \mathrm{l}$ \\
\hline Copper & EPA 200.7 & 0.005 & $\mathrm{mg} / \mathrm{l}$ \\
\hline Iron & EPA 200.7 & 0.01 & $\mathrm{mg} / \mathrm{l}$ \\
\hline Lead & EPA 239.2 & 0.005 & $\mathrm{mg} / 1$ \\
\hline Manganese & EPA 200.7 & 0.005 & $\mathrm{mg} / \mathrm{l}$ \\
\hline Mercury & EPA 245.1 & 0.0001 & $\mathrm{mg} / \mathrm{l}$ \\
\hline Molybdenum & EPA 200.7 & 0.01 & $\mathrm{mg} / 1$ \\
\hline Nickel & EPA 200.7 & 0.01 & $\mathrm{mg} / \mathrm{l}$ \\
\hline Selenium & EPA 270.2 & 0.005 & $\mathrm{mg} / \mathrm{l}$ \\
\hline Silver & EPA 272.2 & 0.0002 & $\mathrm{mg} / 1$ \\
\hline Thallium & EPA 200.7 & 0.1 & $\mathrm{mg} / \mathrm{l}$ \\
\hline Vanadium & EPA 200.7 & 0.005 & $\mathrm{mg} / 1$ \\
\hline Zinc & EPA 200.7 & 0.005 & $\mathrm{mg} / 1$ \\
\hline
\end{tabular}


Potassium Ferrate Treatment

Document Number:

Section:

RF/ER-94-0028.UN

of RFETS Groundwater

Page:

1.0 , Rev. 0

4 of 10

Analytical results for uranium were reported as milligrams per liter (mg/l) even though the CWQCC discharge limits are in picoCuries per liter $(\mathrm{pCi} / \mathrm{l})$. To convert from $\mathrm{mg} / \mathrm{l}$ to $\mathrm{pCi} / 1$ the conversion factor is:

$$
\mathrm{pCi} / 1=0.03(\mathrm{mg} / \mathrm{l} \mathrm{U}, \text { total })
$$

Design of the test matrix and the analysis of the resulting data was done using a computer program called ECHIP (ECHIP, Inc. 724 Yorklyn Road, Hockessin, DE 19707-8703). This statistical based program was used for several reasons. First, the examination and interpretation of the large number of measured responses, 19 elements, 3 of which are radionuclides, required a computer program to optimize the process conditions to obtain the maximum removal of all the COCs. Second, the low concentration of the contaminants of concern created significant error associated with the analysis and it was desired to minimize the impact of this when the data was evaluated. Third, in Phase I there were four primary variables; $\mathrm{pH}$, ferrate, alum and polymer concentrations. It was necessary to examine and determine the individual and interactive effects on each of the COCs.

\subsection{SITE DESCRIPTION}

\subsubsection{Site Name And Description}

RFETS, a 6550 acre industrial reservation is located in northern Jefferson County, Colorado. The RFETS is situated on a recent Alluvium which overlays the Arapahoe sandstone formation, the two major geological stratigraphic units. The Alluvium consists of weathered claystone (Kacl) and the Arapahoe formation (Kass), being the bedrock in the area, consists of weathered and unweathered sandstone. Based on a hydrogeological survey the Alluvium is more permeable to groundwater than the Arapahoe unit $(3,4)$. 
Potassium Ferrate Treatment of RFETS Groundwater
Document Number:

Section:

Page:
RF/ER-94-0028.UN

1.0 , Rev. 0

5 of 10

Monitoring welis within the RFETS reservation are all drilled through the Alluvian and penetrated the Arapahoe formation 10 to 20 feet. The contaminated groundwater used in this study were drawn from these monitoring wells.

\subsubsection{History Of Operations}

From the mid-1950s to the present, RFETS has been a government-owned [Department of Energy (DOE)] contractor-operated facility which manufactured weapon components primarily from plutonium, uranium, beryllium and stainless steels. RFETS also reprocessed certain plutonium residues for the recovery of weapons grade plutonium. Metals reprocessing, using a variety of chemicals and solvents, generated wastes which were discharged to holding facilities. During the 1970s five Solar Evaporation Ponds (SEPs) were constructed (i.e. 207A, 207B North, 207 Center, 207 South, also 207 c). These ponds received and stored liquid wastes from various buildings on the RFETS.

The operation of the RFETS caused some inadvertent contamination of the groundwater on the site through a path yet to be determined.

\subsection{GROUND WATER DESCRIPTION}

Water for this study, which had been collected prior to the start of the program, came from four monitoring wells on the RFETS. The water had been archived in one gallon polyethylene bottles which were enclosed in plastic bags. In order to have an adequate sample volume for the entire three phases of the study, multiple gallon samples from each well were selected and mixed in a 30 gallon polyethylene tank. The samples were selected to produce a lage enough composite 
Potassium Ferrate Treatment of RFETS Groundwater
Document Number:

Section:

Page:

RF/ER-94-0028.UN

1.0 , Rev. 0

6 of 10

sample that would have concentrations of the COCs as close as possible to those set forth in the work plan. The approximate volumes from each well are shown in Table 1.2-1.

Table 1.2-1 Approximate Volume of Ground Water from various Monitoring Wells

\begin{tabular}{|c|c|}
\hline Monitoring Well & Approximate Volume Used \\
\hline Number & Gallons \\
\hline 3086 & 4.000 \\
\hline 09091 & 7.000 \\
\hline B206789 & 2.000 \\
\hline 7287 & 6.500 \\
\hline
\end{tabular}

The composite sample was analyzed during each phase of the study to make sure there were no changes in the concentration of the COCs due to such factors as organic growth in the storage container. Analysis of the samples, prior to treatment, are presented in Table Number 1.2-2 with the average concentration and statistical data.

\subsection{TREATMENT TECHNOLOGY DESCRIPTION}

Removal of metallic or other contaminants from water by normal water treatment techniques requires that the contaminants form a solid phase of sufficient particle size so that they settle out of the water. To accomplish this in water treatment systems, reagents are added to the water and/or the $\mathrm{pH}$ is adjusted to precipitate the contaminants. Various treatment chemicals can also be added to assist the agglomeration process to achieve the desired removal results. Additional treatment chemicals can be added to increase the solids concentration of the solution which is sometimes necessary to sweep the suspended solids from solution. In water treatment process that depend upon sedimentation, it is usually necessary to have some minimum solid content for it to be effective. In some processes, filtration can be used in place of settling for water 
Potassium Ferrate Treatment of RFETS Groundwater
Document Number:

Section:

Page:
RF/ER-94-0028.UN

1.0 , Rev. 0

7 of 10

Table 1.2-2 Analysis of Untreated Water at Beginning of Each Phase of the Study

\begin{tabular}{|c|c|c|c|c|c|c|}
\hline Element & Units & 1st Phase & 2nd Phase & 3rd Phase & Average & S.D. \\
\hline Silver & $\mathrm{mg} / \mathrm{l}$ & 0.029 & 0.028 & 0.030 & 0.029 & 0.001 \\
\hline Aluminum & $\mathrm{mg} / \mathrm{l}$ & 18. & 20. & 20. & 19.33 & 1.155 \\
\hline Barium & $\mathrm{mg} / \mathrm{l}$ & 0.23 & 0.23 & 0.28 & 0.247 & 0.029 \\
\hline Beryllium & $\mathrm{mg} / \mathrm{l}$ & $<0.005$ & $<0.005$ & $<0.005$ & $<0.005$ & $* *$ \\
\hline Cadmium & $\mathrm{mg} / \mathrm{l}$ & $<0.005$ & $<0.005$ & $<0.005$ & $<0.005$ & ** \\
\hline Cobalt & $\mathrm{mg} / \mathrm{l}$ & 0.007 & 0.006 & $<0.04$ & 0.0065 & 0.0007 \\
\hline Chromium & $\mathrm{mg} / \mathrm{l}$ & 0.020 & 0.025 & 0.026 & 0.0237 & 0.0032 \\
\hline Copper & $\mathrm{mg} / 1$ & 0.029 & 0.023 & 0.030 & 0.0273 & 0.0038 \\
\hline Iron & $\mathrm{mg} / \mathrm{l}$ & 19. & 19. & 22. & 20.0 & 1.73 \\
\hline Manganese & $\mathrm{mg} / \mathrm{l}$ & 0.24 & 0.24 & 0.29 & 0.257 & 0.0289 \\
\hline Molybdenum & $\mathrm{mg} / \mathrm{l}$ & $<0.01$ & $<0.01$ & 0.01 & $<0.01$ & $* *$ \\
\hline Nickel & $\mathrm{mg} / \mathrm{l}$ & 0.02 & $<0.05$ & $<0.05$ & $<0.05$ & $* *$ \\
\hline Antimony & $\mathrm{mg} / \mathrm{l}$ & $<0.05$ & $<0.05$ & $<0.05$ & $<0.05$ & $* *$ \\
\hline Selenium & $\mathrm{mg} / \mathrm{l}$ & 0.044 & 0.040 & 0.021 & 0.042 & 0.0028 \\
\hline Thallium & $\mathrm{mg} / \mathrm{l}$ & $<0.1$ & $<0.5$ & $<0.5$ & $<0.5$ & $* *$ \\
\hline Vanadium & $\mathrm{mg} / 1$ & 0.042 & 0.043 & 0.045 & 0.0433 & 0.0015 \\
\hline Zinc & $\mathrm{mg} / \mathrm{l}$ & 0.086 & 0.081 & 0.093 & 0.0867 & 0.0060 \\
\hline Arsenic & $\mathrm{mg} / \mathrm{l}$ & $\theta .016$ & 0.010 & 0.010 & 0.010 & 0.0000 \\
\hline Mercury & $\mathrm{mg} / \mathrm{l}$ & $<0.0001$ & $<0.0001$ & $<0.0001$ & $<0.0001$ & $* *$ \\
\hline Lead & $\mathrm{mg} / 1$ & 0.012 & 0.013 & 0.012 & 0.0123 & 0.0006 \\
\hline \multicolumn{7}{|l|}{ Radionuclides } \\
\hline Am 241 & $\mathrm{pCi} / \mathrm{l}$ & 0.86 & 1.1 & 0.81 & 0.92 & 0.155 \\
\hline $\mathrm{Pu} \mathrm{239/240}$ & $\mathrm{pCi} / 1$ & 7.5 & 6.7 & 9.1 & 7.8 & 1.22 \\
\hline Uranium & $\mathrm{mg} / \mathrm{l}$ & 0.044 & 0.036 & 0.040 & 0.040 & 0.004 \\
\hline
\end{tabular}

** insufficient data to calculate SD ( standard deviation)

Q.0XX these data not used in the calculation of the SD 
polishing. However, filtration is an expensive unit operation and was not investigated as part of this study.

Because of its' unique chemistry potassium ferrate has been studied for its use in water treatment by many investigators $(5,6,7)$. The iron in potassium ferrate is in the plus 6 valence state. Historically, iron based chemicals used in water treatment have been in the plus two or plus three valence state. It appears, that this difference in valence state is the reason that ferrate produces different results than normal iron treatment chemicals used in water treatment. It appears that ferrate is effective in coagulating the fine hydroxide/oxides precipitated in basic waters, especially radionuclides. Several reasons for this enhanced removal have been suggested. First, the ferrate slowly decomposes in basic solutions, allowing greater interaction with the suspended solids. This phenomena is different when compared to the almost immediate formation of iron (III) hydroxide when iron (III) sulfate is added to basic solution. Second, the decomposition of the potassium ferrate produces positively charged iron oxide/hydroxide that seem to be attracted to the other solids which are negatively charged in basic water. This interaction is more effective than with other iron water treatment chemicals because those chemicals do not yield significant amounts of positively charged products when added to basic solutions. Third, there is the potential for the formation of insoluble heavy metal ferrate compounds that are also removed from solution by settling. Whatever the actual mechanism, it is believed the use of potassium ferrate, in addition with other common water treatment chemicals, it may be possible to clean the RFETS groundwater to lower concentrations than conventional water treatment methods. Implementation of this simple treatment process might meet the CWQCC water discharge limits for the COCs. 
Potassium Ferrate Treatment of RFETS Groundwater
Document Number:

Section:

Page:
RF/ER-94-0028.UN

1.0, Rev. 0

9 of 10

The water treatment process that was studied is similar to a conventional water treatment process, except for two additional steps. The two additional steps are the introduction and degradation of the potassium ferrate chemical. The general process steps and the desired effects are as follow:

1. Adjust $\mathrm{pH}$ : This initial step is needed to produce insoluble metal hydroxides (solids) which will be removed from the water in the subsequent steps. As the $\mathrm{pH}$ of the contaminated solution rises, the COCs become more insoluble.

2. Add potassium ferrate: This step requires time to allow ferrate to proceed through several decomposition steps which coagulate the metal hydroxide solids, forming larger particles. Decomposition of ferrate enhances the agglomeration of the suspended solids which promotes more efficient solids removal during the settling step.

3. Reduce the remaining ferrate: Ferrate decomposes at a slow rate in solutions with a pH greater than 10 . Therefore, it is necessary to eliminate the excess with a chemical reducing agent. This is necessary because any ferrate remaining in the solution prevents the removal of some of the COCs. In this study, the reductant used was sodium thiosulfate. The reaction product in this case will be potassium sulfate, an unregulated water impurity.

4. Add alum: Alum (aluminum sulfate) when added to the wastewater forms aluminum hydroxide floc which is very voluminous. This voluminous floc, formed by the addition of a small amount of alum, disperses throughout the solution, increasing the possibility that all of the suspended particles will be bridged with the aluminum hydroxide, thereby creating larger particles. 
Potassium Ferrate Treatment of RFETS Groundwater
Document Number:

Section:

Page:
RF/ER-94-0028.UN

1.0, Rev. 0 10 of 10

5. Add an organic polymer: Since aluminum hydroxide does not settle well because it is light, due to the waters of hydration, an organic polymer is added to make the flocs heavier so settling occurs faster.

During the entire laboratory test the $\mathrm{pH}$ was monitored and adjusted to the desired value with either potassium hydroxide or sulfuric acid. In plant operations, $\mathrm{pH}$ adjustment will not be a problem since only one control point will be monitored, that is the effluents. The addition of caustic will be only at the beginning of the process based upon the effluent $\mathrm{pH}$.

\subsection{PREVIOUS STUDIES OF FERRATE TREATMENT AT RFETS}

One previous study of potassium ferrate treatment of wastewater has been conducted on the RFETS site (8). In this study, surrogates of radionuclide contaminants were added to water to simulate the wastewater that would be produced when the plutonium processing plant would be in operation. Treatment of this wastewater with TRU/Clear ${ }^{\mathrm{TM}}$ ( potassium ferrate based treatment product) decreased the gross alpha radioactivity from $3.0 \times 10^{6}$ to $6000 \mathrm{pCi} / 1$ or a reduction of 99.8 percent. The results were below the desired water radioactivity goal of 12,500 $\mathrm{pCi} /$ l. In addition, the weight of waste-solids produced was six to seven times lower than that produced using the reagent iron (III) sulfate. This previous study, using TRU/Clear ${ }^{\mathrm{TM}}$ as an additive demonstrated that the plant would meet the established discharge limits and do so with a significant reduction of the amount of radioactive sludge produced. 
Potassium Ferrate Treatment of RFETS Groundwater
Document Number:

Section:

Page
RF/ER-94-0028.UN

2.0, Rev. 0

1 of 9

\subsection{CONCLUSIONS AND RECOMMENDATIONS}

Potassium ferrate treatment of RFETS' contaminated groundwater was conducted over several months in the fall of 1994 using a mutiphased program. In this program there were four variables to be examined for their effects upon $19 \mathrm{COCs}$ in the contaminated groundwater. Therefore, experimental design techniques were used to obtain enough information to reach definitive and unambiguous conclusions. Because of the way the experiments were designed it was possible to mathematically analyze the data generated to produce response surfaces that could be used as a model to predict results under different treatment conditions. The Phase I screening tests produced data that enabled the model to predict results of Phase II testing and was used to establish the test design in this phase of the work. Phase III was a demonstration of the technology at the optimum treatment conditions. A software package called ECHIP, which is based upon a large body of literature, was used to aid in the experimental design, statistically analyze the results and develop the mathematical models.

\subsection{CONCLUSIONS}

The first and major conclusion is that potassium ferrate treatment will reduce the concentrations of the COCs to very low levels. Table 2.1-1 contains the Phase III treated water analysis (average of four tests), the analytical detection limits and the CWQCC discharge limits. Table 2.1-1 shows that 11 of the COCs, including the radionuclides, were reduced to concentration which meet or exceeds the CWQCC discharge limits and there is a $99 \%$ assurance that these results can always be achieved. The analytical detection limit was above the CWQCC discharge limits for seven of the COCs. Though the concentration of these COCs were below the analytical detection limits in the treated water, it is uncertain if they meet the discharge limits 
Potassium Ferrate Treatment

Document Number:

RF/ER-94-0028.UN

of RFETS Groundwater

Section:

2.0, Rev. 0

Page

2 of 9

Table 2.1-1 Results of Potassium Ferrate Water Treatment and Comparison to the CWQCC Discharge Limits and the Analytical Detection Limits

\begin{tabular}{|c|c|c|c|c|}
\hline Element & $\begin{array}{c}\text { Chemical Analysis } \\
\text { of Treated Water } \\
\text { from Phase III } \\
\text { Tests }\end{array}$ & $\begin{array}{l}\text { Analytical } \\
\text { Detection } \\
\text { Limits }\end{array}$ & $\begin{array}{c}\text { CWQCC } \\
\text { Discharge Limits }\end{array}$ & $\begin{array}{c}\text { Treated Water } \\
\text { Meets the } \\
\text { CWQCC } \\
\text { Limits }\end{array}$ \\
\hline Radionuclides & $\mathrm{pCi} / \mathrm{l}$ & $\mathrm{pCi} / 1$ & $\mathrm{pCi} / 1$ & \\
\hline Americium 241 & 0.00 & 0.00 & 0.05 & Yes \\
\hline Plutonium 239/240 & 0.0325 & 0.00 & 0.05 & Yes \\
\hline Uranium, total & 0.053 & 0.003 & $5-10$ & Yes \\
\hline \multirow[t]{2}{*}{ Other COCs } & & ICP Method & & \\
\hline & $\mathrm{mg} / \mathrm{l}$ & $\mathrm{mg} / \mathrm{l}$ & $\mathrm{mg} / \mathrm{l}$ & \\
\hline Silver & $<0.005$ & 0.005 & 0.00059 & $?$ \\
\hline Aluminum & $<0.1$ & 0.1 & 0.087 & $?$ \\
\hline Barium & $<0.05$ & 0.05 & 0.024 & $?$ \\
\hline Beryllium & $<0.005$ & 0.005 & 0.004 & $?$ \\
\hline Cadmium & $<0.005$ & 0.005 & 0.0015 & $?$ \\
\hline Cobalt & $<0.01$ & 0.01 & 0.05 & Yes \\
\hline Chromium & $<0.005$ & 0.005 & 0.05 & Yes \\
\hline Copper & $<0.005$ & 0.005 & No limit available & - \\
\hline Iron & 0.02 & 0.005 & 0.3 & Yes \\
\hline Manganese & $<0.005$ & 0.005 & 0.56 & Yes \\
\hline Molybdenum & $<0.01$ & 0.01 & No limit available & - \\
\hline Nickel & $<0.05$ & 0.05 & 0.125 & Yes \\
\hline Thallium & $<0.5$ & 0.5 & No limit available & - \\
\hline Vanadium & $<0.005$ & 0.005 & 0.1 & Yes \\
\hline \multirow[t]{2}{*}{ Zinc } & $<0.005$ & 0.005 & 0.35 & Yes \\
\hline & & GFAA Method & & \\
\hline Arsenic & $<0.005$ & 0.005 & No limit available & - \\
\hline Antimony & $<0.05$ & 0.05 & 0.024 & $?$ \\
\hline Mercury & $<0.0001$ & 0.0001 & 0.00001 & $?$ \\
\hline Lead & $<0.005$ & 0.005 & 0.028 & Yes \\
\hline Selenium & 0.0562 & 0.005 & 0.005 & No \\
\hline
\end{tabular}


Potassium Ferrate Treatment of RFETS Groundwater
Document Number:

Section:

Page
RF/ER-94-0028.UN

2.0, Rev. 0

3 of 9

because these discharge limits are below the detection limits. However, the results of Phase III tests suggest that these elements meet the discharge limits based upon statistical analysis of the other elements. Selenium is the only element, which for certain, failed to meet the discharge limits using this technology.

The overall conclusion is that water treatment with potassium ferrate is a very effective technology, especially for the removal of the radionuclides. In fact, the statistical analysis of the Phase III results show that there is a $99 \%$ probability that the CWQCC discharge limits for the radionuclides will be met when this technology is applied to the RFETS groundwater. The statistical analysis of the other Phase III results indicate, that those element that have met the CWQCC discharge limits in this phase of work, have a $95 \%$ or better probability of meeting the CWQCC discharge limits if this technology is used at RFETS. This high level of confidence in the results from this study shows that the process is a very positive method for the removal of many inorganic elements from contaminated waters.

An equally important conclusion is that the technology is tolerant of minor process deviations. For example, predicted optimum treatment condition from preliminary analytical results of Phase II treated water was at a $\mathrm{pH}$ of 10.35 and addition of $10.5 \mathrm{mg} / \mathrm{l} 45 \%$ potassium ferrate. These conditions were used to conduct Phase III tests, even though these conditions were not the optimum when the final Phase II results were evaluated, but still the Phase III test results were exceptional. Also, at the conclusion of the tests in Phase III the measured $\mathrm{pH}$ of the treated water was 9.8 , but still produced better results than were expected from the preliminary data. The optimum conditions from the analysis of the final and corrected results of the Phase II were $\mathrm{pH}$ 10.6 and $19.05 \mathrm{mg} / \mathrm{l}$ of $45 \%$ potassium ferrate. As can be seen, even though there were major differences between Phase III test conditions and the predicted optimum, the results were exceptional, demonstrating the process is tolerant of process variations. This is very important 
Potassium Ferrate Treatment of RFETS Groundwater
Document Number:

Section:

Page
RF/ER-94-0028.UN

2.0, Rev. 0

when it comes to designing and operating a full scale plant in that excessive instrumentation will not be required and minor upsets can be tolerated.

Table 2.1-2 displays the analytical results of the contaminated groundwater (average of three samples) and the treated water from Phase III (average of four tests). From these data the percent removal was calculated by:

Percent removal $=$ Concentration of Groundwater-Concentration of Treated Water $X 100$ Concentration of Groundwater

Where there were definite values for both solutions the percent removals are high (for example, radionuclides removal were in excess of $95 \%$ ). For the elements where there is not a definite concentration in the treated water the recoveries are a function of the starting concentration. Therefore, not much importance should be given to their magnitude. However, based upon the results of the radionuclides it seems that all the COCs removal should exceed $90 \%$.

The results of the Phase III test were all within the $95 \%$ confidence limit range of the values predicted from the Phase II response model. In fact all of the COCs concentration in the Phase III treated water were below the exact value predicted. These data indicate that the results of Phase III are better than predicted. This is possibly due to the under estimation of interaction effects in Phase II because the tests were all conducted at conditions quite different than the optimum. It can be concluded that the model conservatively predicted the response of the COCs in the potassium ferrate water treatment process.

Additionally, it has been concluded that elements respond differently to ferrate treatment. For example, americium's removal was caused almost exclusively by ferrate as shown by the data in 


\begin{tabular}{llr}
\hline Potassium Ferrate Treatment & Document Number: & RF/ER-94-0028.UN \\
of RFETS Groundwater & Section: & 2.0, Rev. 0 \\
& Page & 5 of 9 \\
\hline \hline
\end{tabular}

Table 2.1-2 Initial Groundwater and Phase III Treated Water Chemical Analysis and

Percent Removal

\begin{tabular}{|l|c|c|c|}
\hline \multicolumn{1}{|c|}{ Elements } & $\begin{array}{c}\text { Initial } \\
\text { Groundwater }\end{array}$ & $\begin{array}{c}\text { Phase III } \\
\text { Treated Water }\end{array}$ & $\begin{array}{c}\text { Percent } \\
\text { Removal }\end{array}$ \\
\hline Radionuclides & $\mathrm{pCi} / 1$ & $\mathrm{pCi} / 1$ & \\
\hline Americium 241 & 0.92 & 0.00 & 100.0 \\
\hline Plutonium 230/240 & 7.8 & 0.0325 & 99.6 \\
\hline Uranium, total & 1.33 & 0.053 & 96 \\
\hline & & & \\
\hline Other COCs & & & \\
\hline & $\mathrm{mg} / \mathrm{mg} / 1$ & \\
\hline Silver & 0.029 & $<0.005$ & $>82.8$ \\
\hline Aluminum & 19.33 & $<0.1$ & $>99.5$ \\
\hline Barium & 0.247 & $<0.05$ & $>79.8$ \\
\hline Beryllium & $<0.005$ & $<0.005$ & \\
\hline Cadmium & $<0.005$ & $<0.005$ & \\
\hline Cobalt & 0.0065 & $<0.01$ & $>53.8$ \\
\hline Chromium & 0.0237 & $<0.005$ & $>78.9$ \\
\hline Copper & 0.0273 & $<0.005$ & $>81.7$ \\
\hline Iron & 20.0 & 0.02 & 99.9 \\
\hline Manganese & 0.257 & $<0.005$ & $>98.1$ \\
\hline Molybdenum & $<0.01$ & $<0.01$ & \\
\hline Nickel & $<0.05$ & $<0.05$ & \\
\hline Thallium & $<0.5$ & $<0.5$ & \\
\hline Vanadium & 0.0433 & $<0.005$ & $>88.4$ \\
\hline Zinc & 0.0867 & $<0.005$ & $>94.2$ \\
\hline & & & \\
\hline Arsenic & 0.010 & $<0.005$ & $>50.0$ \\
\hline Mercury & $<0.0001$ & $<0.0001$ & \\
\hline Lead & 0.0123 & $<0.005$ & $>59.3$ \\
\hline Selenium & 0.042 & 0.0562 & None \\
\hline
\end{tabular}


Potassium Ferrate Treatment of RFETS Groundwater
Document Number:

Section:

Page
RF/ER-94-0028.UN

2.0 , Rev. 0 6 of 9

Table 2.1-3. While uranium's removal was caused primarily by increasing $\mathrm{pH}$ with little effect seen by ferrate addition. Uranium's response data is given in Table 2.1-4. Finally, some COCs showed a mixed response where both $\mathrm{pH}$ and ferrate addition effect the removal. Barium does demonstrate mixed response as shown by the data in Table 2.1-5 and is the simplest of the systems. Most of the other COCs show a more complex response to $\mathrm{pH}$ and ferrate addition as can be seen in the two dimensional response graphs in the Appendices D, E and F.

Table 2.1-3 Effect of $\mathrm{pH}$ and Ferrate Addition Upon the Response of Americium

\begin{tabular}{|c|c|c|c|}
\hline Treatment $\mathbf{p H}$ & 9.5 & 10 & 11.5 \\
\hline & \multicolumn{3}{|c|}{$\begin{array}{c}\text { Americium Concentration in Treated Water } \\
(\mathbf{p C i} / \mathbf{)})\end{array}$} \\
\hline Ferrate Addition (mg/l) & & & 0.045 \\
\hline 1 & 0.090 & 0.080 & 0.029 \\
\hline 5 & 0.037 & 0.042 & 0.018 \\
\hline 40 & 0.016 & 0.023 & \\
\hline
\end{tabular}

Table 2.1-4 Effect of $\mathrm{pH}$ and Ferrate Addition Upon the Response of Uranium

\begin{tabular}{|c|c|c|c|}
\hline Treatment pH & 9.5 & 10.0 & 11.5 \\
\hline & \multicolumn{3}{|c|}{ Uranium Concentration in Treated Water } \\
& & & \\
& & & \\
\hline Ferrate Addition $(\mathrm{mg} / \mathrm{l})$ & & 0.0158 & 0.0050 \\
\hline 1 & 0.0215 & 0.0147 & 0.0032 \\
\hline 5 & 0.0205 & 0.0134 & 0.0019 \\
\hline 40 & 0.0192 & 0
\end{tabular}

It was concluded from Phase I work that the increasing amounts of alum and polymer added did not improve the removal of the COCs. However, a minimum amount was required to flocculate the suspended solids in the groundwater. Table 2.1-6 show this effect by comparing one test at 


\begin{tabular}{llr}
\hline $\begin{array}{l}\text { Potassium Ferrate Treatment } \\
\text { of RFETS Groundwater }\end{array}$ & Document Number: & RF/ER-94-0028.UN \\
& Section: & 2.0, Rev. 0 \\
& Page & 7 of 9 \\
\hline
\end{tabular}

the lowest addition of these two reagents and another test at the highest, both having the same $\mathrm{pH}$ and ferrate addition.

Table 2.1-5 Effect of $\mathrm{pH}$ and Ferrate Addition Upon the Response of Barium

\begin{tabular}{|c|c|c|c|}
\hline Treatment pH & 9.5 & 10.0 & 11.5 \\
\hline & \multicolumn{3}{|c|}{ Barium Concentration in Treated Water (mg/l) } \\
\hline Ferrate Addition (mg/) & & & \\
\hline 1 & 0.027 & 0.005 & 0.000 \\
\hline 5 & 0.020 & 0.001 & 0.000 \\
\hline 40 & 0.012 & 0.000 & 0.000 \\
\hline
\end{tabular}

One further conclusion can be made from this study. That is that between 96 to 99 percent of the solids recovered from the treatment tests were generated by contaminants from the untreated water. The balance of one to four percent of the dried solids were a result of the reagents added.

From the preliminary engineering data obtained in Phase III of this study it can be concluded that the equipment required for implementation of a full scale plant will be of modest size requiring minimal design, instrumentation and procurement. There will be no need to design new or special equipment. This treatability study of RFETS groundwater has demonstrated that potassium ferrate water treatment technology produced water for discharge of excellent quality.

\subsection{RECOMMENDATIONS}

The process chemistry indicates that treated water can be produced meeting the CWQCC discharge limits. However, for several of the COCs it cannot be said for sure that their concentrations in the treated water were below the CWQCC discharge limits because the 
Potassium Ferrate Treatment

of RFETS Groundwater
Document Number:

Section:

Page
RF/ER-94-0028.UN

2.0, Rev. 0

8 of 9

analytical method detection limits were not low enough. It is recommended that new or different analytical methods be investigated and some experiments, such as those in Phase III, be repeated to establish definitively that the concentrations of those COCs in the treated water were below the CWQCC discharge limits.

Table 2.1-6 Effect of Alum and Polymer Change on the Response of some of the COCs at the same pH and Ferrate Addition

\begin{tabular}{|c|c|c|c|}
\hline & & Phase I Test 2 & Phase I Test 3 \\
\hline & & (Ave test $2 A$ and $2 B$ ) & (Ave Test $3 A$ and $3 B)$ \\
\hline & Variables & $\begin{array}{c}\mathrm{pH} 11.5 \\
15.7, \mathrm{mg} / \mathrm{l} \text { ferrate }\end{array}$ & $\begin{array}{c}\mathrm{pH} 11.5 \\
15.7, \mathrm{mg} / \mathrm{l} \text { ferrate }\end{array}$ \\
\hline & Alum, mg/l & 10 & 0.5 \\
\hline & Polymer, mg/l & 50 & 5 \\
\hline Elements & & $\mathrm{pCi} / \mathrm{l}$ & $\mathrm{pCi} / \mathrm{l}$ \\
\hline Americium 241 & & -0.035 & -0.020 \\
\hline Plutonium 239/240 & & 0.205 & 0.185 \\
\hline & & $\mathrm{mg} / \mathrm{l}$ & $\mathrm{mg} / \mathrm{l}$ \\
\hline Uranium & & 0.0022 & 0.0038 \\
\hline Iron & & 0.77 & 0.79 \\
\hline Selenium & & 0.0535 & 0.0525 \\
\hline Silver & & 0.005 & 0.0025 \\
\hline
\end{tabular}

Selenium does not respond to the ferrate treatment process because it exists as the selenate anion which does not form an insoluble solid. However, this anion can be reduced to selenium metal and be removed by the ferrate process. It is recommended that a laboratory program be undertaken to examine this potential procedure and integrate it into the overall process allowing a single plant to treat the groundwater. 
Potassium Ferrate Treatment of RFETS Groundwater
Document Number:

Section:

Page
RF/ER-94-0028.UN

2.0, Rev. 0

9 of 9

As was discussed in this report thiosulfate is a complexing agent for silver and may prevent its' complete removal. There are many reductants that can be used to decompose the ferrate rather than thiosulfate. Therefore, if silver does not meet the CWQCC discharge limits it is recommended that a laboratory program be undertaken to find a reductant and determine if it conflicts with the removal of the other COCs.

Once these brief laboratory studies are completed and the results meet the treatment goals it is recommended that a limited engineering study be undertaken. This engineering study will develop cost estimates for the design, construction and operation of water treatment plant or plants utilizing the ferrate technology demonstrated in this laboratory study.

Upon the completion of the engineering study it is recommended that a pilot water treatment plant be built and operated to treat contaminated groundwater. This pilot plant will initially be used to decontaminate the RFETS groundwater and provide full size scale up of operating protocols, maintenance requirements and overall costs. It would also be possible to use this pilot plant to investigate ferrate treatment of other liquid waste streams on the RFETS. 


\subsection{TREATABILITY STUDY APPROACH}

\subsection{TEST OBJECTIVES AND RATIONALE}

It has been claimed by some investigators that using ferrate in conjunction with a conventional treatment process will improve the removal of inorganic metals and radionuclides from wastewater. At the same time, ferrate treatment seems to produce less solid waste to be disposed. Water treatment plants are relatively easy to design, build and operate and the operational costs are relatively low when compared to other treatment methods. For these reasons ferrate treatment appeared to be an appropriate technology to examine in order to remediate the RFETS groundwater problem. As with all technologies, a preliminary feasibility study of the process was needed to determine if the goals of the desired cleanup standards could be met. The overall goal of this study was to determine if ferrate technology could remove the COCs from groundwater at RFETS to levels that would allow the treated water to be discharged into surface waters. More specifically, the goal was to meet the CWQCC discharge limits given in Table 1.0-1 with emphasis on the radionuclides.

To determine the lowest concentrations of the COCs utilizing potassium ferrate treatment a multiphase program was used. At the suggestion of a representative of the Colorado Department of Public Health and Environment (CDPHE), the statistically based experimental design computer software ECHIP was utilized. This software was used to setup and evaluate the results of the first two phases of this study. Use of this program enabled the investigators to clearly elucidate the effect of changes of the variables upon the concentration of the COCs in the treated water to meet the objective of each phase of the study. The specific objectives of the three phases are as follows: 
Potassium Ferrate Treatment

of RFETS Groundwater
Document Number:

Section:

Page:
RF/ER-94.0028.UN

3.0, Rev. 0

Phase I objectives: To determine the relative effect of the following variables on COCs concentration in potassium ferrate treated water:

a) potassium ferrate concentration,

b) $\mathrm{pH}$ of the water during treatment,

c) the need for and the effects of alum addition and

d) the need for and the effects of organic polymer addition.

Phase Il objectives: To use the information obtained in Phase I and establish process conditions that:

a) minimize reagent consumption and

b) maintain acceptable removal of the COCs from the treated water.

Phase III objectives: To use the information gathered in the previous two phases of testing to:

a) confirm that the concentrations of the COCs, predicted

from the Phase II calculated response surfaces, can be duplicated by test at optimum process conditions and

b) gather preliminary engineering data.

\section{2 EXPERIMENTAL DESIGN}

Design of the experiments for this study was controlled by a computer program, ECHIP, that is based on a large body of literature on statistical experiment design. Discussion in detail of the program is not appropriate for this report, but some discussion is needed to understand the reasoning for these particular experimental designs. 
Potassium Ferrate Treatment of RFETS Groundwater
Document Number:

Section:

Page:
RF/ER-94.0028.UN

3.0, Rev. 0

In the first phase of the study it was desired to study the effect of four variables on the removal of the COCs from the RFETS ground water. To gather sufficient data to mathematically analyze the data and determine any interaction would require over 50 tests if an interactive model were used. This seemed excessive in view of the fact there was no information to guide the selection of the range of the variables to be examined. Therefore, a linear screening test design was used where the number of tests required to obtain sufficient data was at a minimum of fourteen tests. This design estimates only the first order effects of the variables plus the constant in a linear equation. There is some danger in using this design in that interactive effects may be significant and not found. The equation used in the analysis of the data by the program was:

$$
y=a_{0}+a_{1} x_{1}+a_{2} x_{2}+a_{3} x_{3}+a_{4} x_{4}
$$

In this equation $y$ is the measured response, the analytical concentration of the COCs in the treated water. There are five calculated constants $\left(a_{0}, a_{1}, a_{2}, a_{3}\right.$ and $\left.a_{4}\right)$. The test variables are: $x_{1}$ - the equilibrium $\mathrm{pH}$ at the end of the test, $\mathrm{x}_{2}$ - the amount of $45 \%$ potassium ferrate added in $\mathrm{mg} / \mathrm{l}, \quad \mathrm{x}_{3}$ - the amount of alum used in the test in $\mathrm{mg} / \mathrm{l}$ and $\mathrm{x}_{4}$ - the amount of polymer used in the test in $\mathrm{mg} / \mathrm{l}$. Utilizing all the test results, the computer calculated the constants and compared the calculated equation with the actual values to determine the degree of fit. The computer program also has the ability to create two and three dimensional plots of the each of the responses measured. The test matrix of the variables used for Phase I is given in Table 3.2-1. Tests were run in the order presented in Table 3.2-1 to eliminate any systematic errors that might occur during testing. These systematic errors are variations that occur during testing, such as changes in temperature, changes in the test solution concentration or any other differences in test techniques that differ from test to test but were inadvertent and not controlled that might effect the outcome of a single test. 
Potassium Ferrate Treatment of RFETS Groundwater
Document Number:

Section:

Page:
RF/ER-94.0028.UN

3.0, Rev. 0

4 of 11

When any of the variables showed little or no response they can be eliminated from further consideration. Phase I data showed that within the range tested, alum and polymer had little or no effect upon the measured responses. Therefore, only two variables needed to be considered in

Table 3.2-1 Test matrix used for the First Phase of this Study

\begin{tabular}{|c|c|c|c|c|}
\hline Test Number & $\mathbf{p H}$ & Ferrate (mg/l) & Alum (mg/l) & Polymer (mg/L) \\
\hline 11 & 10.0 & 47.15 & 30 & 2.75 \\
\hline 3 & 11.5 & 15.7 & 50 & 5 \\
\hline 8 & 8.5 & 15.7 & 50 & 5 \\
\hline 4 & 8.0 & 78.6 & 10 & 0.5 \\
\hline 2 & 11.5 & 15.7 & 10 & 0.5 \\
\hline 5 & 11.5 & 78.6 & 10 & 5 \\
\hline 7 & 11.5 & 78.6 & 50 & 0.5 \\
\hline 6 & 8.5 & 15.7 & 50 & 0.5 \\
\hline 3 & 11.5 & 15.7 & 50 & 5 \\
\hline 10 & 8.5 & 15.7 & 10 & 0.5 \\
\hline 2 & 11.5 & 15.7 & 10 & 0.5 \\
\hline 1 & 8.5 & 78.6 & 50 & 5 \\
\hline 9 & 11.5 & 78.6 & 50 & 5 \\
\hline 1 & 8.5 & 78.6 & 50 & 5 \\
\hline
\end{tabular}

Phase II of this study. As a result, limited number of tests produced sufficient data to satisfy any of the three interactive models available in the ECHIP program. The selection of which model to be used to present the results was based upon the best fit of the data. The second phase of this study used a test design to estimate interaction effects and provide sufficient data to satisfy any of the three interactive models provided in the ECHIP software. Interaction effects are important to measure, in that it might be possible to use more of a cost effective reagent and less of an expensive reagent still achieveing the same results. In other words, an economic optimum can be 


\begin{tabular}{llr}
\hline $\begin{array}{l}\text { Potassium Ferrate Treatment } \\
\text { of RFETS Groundwater }\end{array}$ & Document Number: & RF/ER-94.0028.UN \\
& Section: & 3.0 , Rev. 0 \\
& Page: & 5 of 11 \\
\hline \hline
\end{tabular}

found. The only variables investigated during Phase II were ferrate addition and $\mathrm{pH}$. The amount of alum and polymer used in all of the second phase tests were held constant and set at $20 \mathrm{mg} / 1$ and $10 \mathrm{mg} / \mathrm{l}$, respectively. The test matrix of the variables for Phase II is given in Table 3.2-2. To eliminate systematic testing errors the tests were run in the order are given in Table 3.2-2.

Table 3.2-2 Phase II Test Matrix

\begin{tabular}{|c|c|c|c|}
\hline Test Number & $\mathbf{p H}$ & $\log (\mathbf{m g} / \mathbf{l}$ ferrate) & $\mathbf{m g} / \mathbf{l}$ ferrate added \\
\hline 3 & 7.8 & 2.2 & 158.5 \\
\hline 4 & 8.81 & 1.57 & 37.2 \\
\hline 3 & 7.8 & 2.2 & 158.5 \\
\hline 12 & 9.65 & 2.2 & 158.5 \\
\hline 11 & 9.63 & 1.09 & 12.3 \\
\hline 9 & 11.5 & 0.00 & 1.0 \\
\hline 1 & 11.5 & 2.2 & 158.5 \\
\hline 2 & 11.5 & 1.1 & 12.6 \\
\hline 8 & 9.65 & 2.2 & 158.5 \\
\hline 1 & 11.5 & 2.2 & 158.5 \\
\hline 10 & 10.45 & 0.6 & 4.0 \\
\hline 1 & 11.5 & 2.2 & 158.5 \\
\hline 2 & 11.5 & 1.1 & 12.6 \\
\hline 2 & 11.5 & 1.1 & 12.6 \\
\hline
\end{tabular}

Phase III consisted of running several tests at optimum conditions determined in Phase II to: 1) confirm the predicted results at the optimum treatment reagent additions and 2) gather some preliminary engineering data. Since these confirmation tests were all done at the same treatment condition, a designed test series for Phase III was not necessary. 
Potassium Ferrate Treatment of RFETS Groundwater
Document Number:

Section:

Page:
RF/ER-94.0028.UN

3.0, Rev. 0

6 of 11

\subsection{EXPERIMENTAL EQUIPMENT, MATERIALS AND PROCEDURES}

\subsubsection{Experimental Equipment}

In addition to the usual standard laboratory glassware and plastic bottles, a Phipps and Bird stirring unit with two liter $B-K^{2}{ }^{2} \mathrm{M}$ beakers were used. This stirrer is a standard unit for conducting water treatment experiments. It allows control of the energy input into the reactor to aid in scale-up. The pH meter used was an Orion 230.

\subsubsection{Experimental Materials}

With two exceptions, all chemicals were analytical grade or better. The organic polymer used was a product of Cytec (a division of American Cyanamid Co.) called Magnifloc 985N, a nonionic polyacrylamide. Potassium ferrate used was $45 \%$ pure with the balance of the product being a mixture of potassium chloride and potassium hydroxide with a minor amount of magnesium salts. This product was produced by Analytical Development Co., Colorado Springs, Colorado.

The test reagents and their concentrations as used are:

$\mathrm{KOH}$ (potassium hydroxide)

$\mathrm{Na}_{2} \mathrm{~S}_{2} \mathrm{O}_{3}$ (sodium thiosulfate)

$\mathrm{K}_{2} \mathrm{FeO}_{4}$ (potassium ferrate)

Alum (aluminum sulfate, $\mathrm{Al}_{2} \mathrm{SO}_{4}$ )

Polymer (Cytec 984 N, made fresh daily)
$2 \mathrm{~N}$

$5 \%$ solution

dry powder (45\%)

$40 \mathrm{~g} / \mathrm{l}$ solution

$2 \mathrm{~g} / \mathrm{l}$ solution

\subsubsection{Experimental Procedures}


Potassium Ferrate Treatment of RFETS Groundwater
Document Number:

Section:

Page:
RF/ER-94.0028.UN

3.0, Rev. 0

7 of 11

Groundwater from several monitoring wells was blended in a 30 gallon tank in the laboratory several days in advance of testing. See Tables 1.2-1 and 1.2-2 for the source and composition of the water samples used in these tests. The laboratory was at a constant temperature so the water sample had thermally equilibrated. The tank was covered with a plastic membrane to minimize evaporation, then covered with the hard tank cover.

To ensure that any given aliquot used in a test would be representative of the bulk of the blended groundwater, it was necessary to mix the bulk sample. This was accomplished using a large stirring rod and agitated by hand until all the solids were uniformly suspended. Two liter samples were taken for each test by dipping a plastic beaker into the tank. The dip samples were measured in a $1000 \mathrm{ml}$ graduated cylinder and transferred to the test apparatus. The effectiveness of this mixing and sampling procedure can be seen by the agreement of the analytical results of the three aliquots taken in each phase of this study, several weeks apart, Table 1.2-2.

Usually, four tests were run at a time since the Phipps and Bird was a four position stirrer. The beakers, B-Ker ${ }^{2} \mathrm{M}$, were filled with two liters of the ground water to be treated. The B-Ker ${ }^{2} \mathrm{TM}$ polycarbanate beakers used were 4.5 inches by 4.5 inches square and approximately eight inches deep. The stirrer blade used was three inches by one inch by one quarter inch and its speed is controlled to within $2 \%$ of the test rpm.

The test solutions were stirred at $300 \mathrm{rpm}$. The $\mathrm{pH}$ was measured and adjusted to the desired test condition, using potassium hydroxide in all cases. During the $\mathrm{pH}$ adjustment, the electrode was immersed in the water for constant measurement as the solution was being stirred. 
Potassium Ferrate Treatment of RFETS Groundwater
Document Number:

Section:

Page:
RF/ER-94.0028.UN

3.0 , Rev. 0

8 of 11

When the $\mathrm{pH}$ had been adjusted to the appropriate level, the entire amount of the dry potassium ferrate was added to the reactor. The dry ferrate was weighed on an electronic balance located in the testing laboratory and had an accuracy of $0.0001 \mathrm{gram}$. This solution was stirred for a set time in Phase I, 15 minutes. During Phase II the time of mixing was varied depending on the amount of ferrate added.

The basic solutions of potassium ferrate were relatively stable, therefore a small amount of sodium thiosulfate, a reducing agent, was added during the mixing stage to cause the ferrate to decompose. In Phase I the amount of sodium thiosulfate added was based on the following chemical equation:

$$
17 \mathrm{H}_{2} \mathrm{O}+3 \mathrm{Na}_{2} \mathrm{~S}_{2} \mathrm{O}_{3}+8 \mathrm{~K}_{2} \mathrm{FeO}_{4} \rightarrow 8 \mathrm{Fe}(\mathrm{OH})_{3}+6 \mathrm{~K}_{2} \mathrm{SO}_{4}+4 \mathrm{KOH}+6 \mathrm{NaOH}
$$

This equation gave the stoichiometric relationship of:

mg sodium thiosulfate $=3.34$ ( $\mathrm{mg}$ potassium ferrate)

for pure potassium ferrate. Therefore, since $45 \%$ potassium ferrate was used in this study the amount of thiosulfate required to reduce all of the ferrate added would be $1.5 \mathrm{mg}$ of thiosulfate for every mg of potassium ferrate added to the reactor. The equation may not accurately represent the actual products of the reaction. This was of no consequence since the thiosulfate $/$ ferrate ratio was not affected by assuming other products of reaction. For example, if the iron product is assumed to be either $\mathrm{FeO}(\mathrm{OH})$ or $\mathrm{Fe}_{2} \mathrm{O}_{3}$, the relationship between thiosulfate and ferrate is the same.

It was believed that most of the ferrate would be consumed in the water treatment process and that only a small amount of the ferrate added would have to be reduced by the thiosulfate. Therefore, in Phase I only ten percent of the stoichiometric requirement was added. This proved to be insufficient in several test as could be seen by the presence of the purple color after completion of the test. Therefore, in Phase II the amount of sodium thiosulfate used was that 
Potassium Ferrate Treatment of RFETS Groundwater
Document Number:

Section:

Page:
RF/ER-94.0028.UN

3.0, Rev. 0

required to eliminate the purple color of the ferrate. The actual amount used was recorded and became a variable to be examined with the other test results.

In Phase I the thiosulfate solution was added quickly while mixing was continued for 15 minutes at $300 \mathrm{rpm}$. During the tests in Phase II, if any color remained after the completion of the initial mixing time more thiosulfate was added and mixed for 15 minutes. This sequence was repeated until the color had completely disappeared. Once the reaction of thiosulfate with the ferrate was complete, the $\mathrm{pH}$ was adjusted to the desired test condition.

After the appropriate $\mathrm{pH}$ was established, the mixing speed was slowed to about $60 \mathrm{rpm}$ $(+/-5 \%)$. Alum was prepared as a dilute solution with a concentration of 40 grams per liter. The required amount of alum was then added to the reactor. The aluminum hydroxide floc formed instantly and the $\mathrm{pH}$ shifted. The $\mathrm{pH}$ was adjusted again while mixing continued.

The prescribed amount of organic polymer as a dilute solution of $2.0 \mathrm{~g} / \mathrm{l}$ was added to the reactor. Stirring was continued for 15 minutes at the slow speed of $30 \mathrm{rpm}$. The polymer solution was made up well in advance of its use to insure the polymer was completely dissolved.

After this final mixing period, the stirring was stopped. The covered beaker was set aside and allowed to settle overnight. An large aliquot of the treated water was taken the next day for chemical and radionuclide analysis.

\subsection{SAMPLING AND ANALYSIS}

Sampling of groundwater from the monitoring well was conducted by a subcontractor to the 
Potassium Ferrate Treatment of RFETS Groundwater
Document Number:

Section:

Page:
RF/ER-94.0028.UN

3.0, Rev. 0

10 of 11

Environmental Restoration Program Division (ERPD) of EG\&G, using operating procedure for groundwater sampling (OPS-GW-06, March 1992). Approximately 10 gallons of water were collected from each well in one gallon plastic bottles over a five day period. The samples were stored for some time prior to the star of this study. Some of these groundwater samples were used in this study with no pretreatment, to prepare a bulk composite sample. An aliquot of this bulk sample was submitted for analyses at the beginning of each phase of this treatability study.

Samples from the treated water were collected the day following completion of each test. The liquid above the settled solids was decanted into clean plastic bottles, sealed and sent for analysis. Accu-Labs Research Inc. of Golden, Colorado analyzed the test samples for metals, radionuclides and several other parameters such as TSS, $\mathrm{pH}$ and hardness. The EPA approved analytical methods are shown in Table 1.0-2.

\subsubsection{Waste Stream}

Waste from this study was about 70 liters of treated water plus the sludge produced during the treatment. Approximately 80 grams of dry solids were generated and contained most of the contaminants and radionuclides from the 70 liters of water used in these tests.

\subsubsection{Experimental Treatment Process}

Techniques used during the experimental phases of this study were done to simulate the process described in Section 1.3.1. Since standard test techniques were utilized, the results can be used to estimate full scale water treatment plant costs. However, this study was directed toward the process chemistry rather than to optimize the mechanical parameters. Additional test work will be required to minimize the equipment costs of a full scale plant. 


\subsection{DATA MANAGEMENT}

All pertinent information collected from this study was recorded by EG\&G personnel in bound notebooks. Accu-Labs Research, Inc. reported the analytical results in a typed report (Appendix A, B, and C) and archived the data. These data were entered into a computer for use with the ECHIP software for evaluation and analysis by ACTA Resources, Inc. personnel. Much of the information generated with this program is presented in Appendices D, E and F.

\subsection{DEVIATION FROM THE WORK PLAN}

Deviations from the work plan were minimal. The main reason for being able to conform to the work plan closely was that the work plan allowed the second and third phases of the study to be developed after the completion and analysis of the results from the preceding work. The data analysis of one phase of work generated a definite direction for the subsequent treatability tests.

There were two minor deviations. First, the work plan specified that the water would not be stored more than six weeks. The storage time was exceeded due to the time required for analytical determinations, which prolonged the study. However, the replicate chemical analysis of the bulk water samples at each phase of the study indicate that this deviation is not significant, (Table 1.2-2). Second, several of the analytical method detection limits specified in the work plan were not met. The elements affected were aluminum, barium, molybdenum, nickel and silver. This was significant for three elements because the analytical detection limits were above the CWQCC discharge limits. These three elements were aluminum, cadmium and silver. 


\subsection{RESULTS AND DISCUSSION}

A detailed discussion of each phase of this study follows. The conclusions reached in each phase of work are presented at the end of the discussion of each of the phases. The overall conclusion and recommendations from this study are in Section 2.0. Results of each phase of the study were used to determine experimental procedures and test conditions in the subsequent phase. A large amount of information was generated by the computer program, which is displayed in the Appendices $D, E$ and $F$ rather than in the body of the report.

\subsection{PHASE I RESULTS AND DISCUSSION}

Fourteen tests were performed in Phase I following the procedures outlined in Section 3.3.3. This phase of the study was designed to examine the magnitude of the effects of four variables on the removal of $19 \mathrm{COCs}$ in the RFETS groundwater. To interpret and understand the results of Phase I work the ECHIP computer software was used to analyze the data. The matrix of the test variables (Table 3.2-1) and the analytical results of the treated water were input into the program. The $\mathrm{pH}$ values of the supernatant liquid (treated water) as measured and reported by Accu-Labs were used rather than the values measured at the time of testing. It was believed, because of the time between completion of the tests and mixing while handling the samples, that the measurements made by Accu-Labs were the true $\mathrm{pH}$ values (Appendix A, B and C).

Analytical data were entered into the ECHIP program as shown in Table 4.1-1. Of the $19 \mathrm{COCs}$, only those listed in the table had three or more values above the analytical detection limits. To define a response surface, in the linear model used to analyze the results, at least three measured responses from analytical results were needed. When using the feed solution (shown as test 17) 
Potassium Ferrate Treatment of RFETS Groundwater
Document Number:

Section:

Page:
RF/ER-94-0028.UN

4.0, Rev. 0

2 of 40

as one point, the omitted elements still had fewer than three data points. As a consequence of this, only the elements listed in Table 4.1-1 were examined in Phase I. Selenium was analyzed by Accu-Labs by inductive coupled plasma (ICP) and graphite furnace-AA (GFAA) methods. In all cases in this report the GFAA results were used in the analysis of the data. Values of the analytical results reported below the analytical detection limits were entered into Table 4.1-1 as zeros for those COCs analyzed. The radionuclide values were entered even when negative, that is less than zero. This may overestimate the effects, but Phase I was a screening series of tests, so the conclusions will not be affected. The radiochemical determinations for americium (Am) 241

Table 4.1-I Analytical Results for Phase I Ferrate Treatment Tests

\begin{tabular}{||c|c|c|c|c|c|c|c|c|c|c||}
\hline & $\mathrm{Am}$ & $\mathrm{Pu}$ & $\mathrm{U}$ & $\mathrm{Al}$ & $\mathrm{Ba}$ & $\mathrm{Cr}$ & $\mathrm{Fe}$ & $\mathrm{Se}$ & $\mathrm{Ag}$ & $\mathrm{V}$ \\
\hline Test & $\mathrm{pCi} / 1$ & $\mathrm{pCi} / 1$ & $\mathrm{mg} / \mathrm{l}$ & $\mathrm{mg} / \mathrm{l}$ & $\mathrm{mg} / 1$ & $\mathrm{mg} / \mathrm{l}$ & $\mathrm{mg} / \mathrm{l}$ & $\mathrm{mg} / \mathrm{l}$ & $\mathrm{mg} / \mathrm{l}$ & $\mathrm{mg} / \mathrm{l}$ \\
\hline 1 & -0.03 & 0.18 & 0.038 & 0.7 & 0.06 & 0.000 & 0.03 & 0.051 & 0.000 & 0.000 \\
\hline 1 & -0.06 & 0.17 & 0.037 & 0.7 & 0.06 & 0.000 & 0.03 & 0.047 & 0.000 & 0.000 \\
\hline 4 & 0.01 & 0.21 & 0.039 & 0.2 & 0.08 & 0.000 & 0.04 & 0.047 & 0.005 & 0.000 \\
\hline 6 & -0.03 & 0.16 & 0.036 & 0.7 & 0.07 & 0.000 & 0.02 & 0.052 & 0.000 & 0.000 \\
\hline 8 & -0.02 & -0.02 & 0.037 & 0.2 & 0.09 & 0.000 & 0.02 & 0.049 & 0.000 & 0.000 \\
\hline 10 & 0.02 & 0.02 & 0.036 & 0.2 & 0.08 & 0.000 & 0.02 & 0.056 & 0.000 & 0.000 \\
\hline 11 & 0.00 & 0.00 & .0035 & 0.3 & 0.00 & 0.000 & 0.13 & 0.055 & 0.007 & 0.000 \\
\hline 17 & 0.86 & 7.50 & 0.044 & 18. & 0.23 & 0.020 & 19.00 & 0.044 & 0.029 & 0.042 \\
\hline 2 & -0.06 & 0.17 & .0024 & 0.0 & 0.00 & 0.000 & 0.78 & 0.055 & 0.005 & 0.000 \\
\hline 2 & -0.01 & 0.24 & .0020 & 0.0 & 0.00 & 0.000 & 0.76 & 0.052 & 0.005 & 0.000 \\
\hline 3 & 0.01 & 0.14 & .0042 & 2.2 & 0.00 & 0.000 & 0.68 & 0.053 & 0.000 & 0.006 \\
\hline 3 & -0.05 & 0.23 & .0035 & 1.7 & 0.00 & 0.000 & 0.90 & 0.052 & 0.005 & 0.005 \\
\hline 5 & -0.05 & 0.12 & .0025 & 0.2 & 0.00 & 0.000 & 2.30 & 0.054 & 0.000 & 0.000 \\
\hline 7 & 0.05 & 0.12 & .0028 & 2.2 & 0.00 & 0.005 & 2.70 & 0.052 & 0.009 & 0.005 \\
\hline 9 & 0.09 & 0.19 & .0034 & 2.0 & 0.00 & 0.006 & 2.30 & 0.050 & 0.006 & 0.000 \\
\hline \hline
\end{tabular}


Potassium Ferrate Treatment of RFETS Groundwater

Document Number:

Section:

RF/ER-94-0028.UN

4.0, Rev. 0

Page: 3 of 40

and plutonium ( $\mathrm{Pu}$ ) 239/240 were reported in picoCuries per liter (pCi/l, total). Uranium (U) and all other elements' analytical results are reported in milligrams per liter $(\mathrm{mg} / \mathrm{l})$.

The ECHIP program, utilizing the information in Tables 3.2-1 and 4.1-1 analyzed the results. The program creates numerous sets of output data (Appendix D). The program calculated the coefficients of the linear equation and estimated the fit of the data to the model.

The test matrix designed by ECHIP required duplicates of Tests 1,2 and 3 be done to estimate the testing error and the standard deviation (SD). Therefore, these duplicate treatment tests and chemical analyses were run separately as individual tests. The calculated SD from duplicate tests is shown in Tables 4.1-2 and 4.1-3, called Replicate SD. Also shown is the difference between the calculated values of the model and the actual test values, called Residual SD. If these two SD values are close there is a fit of the calculated model to the data. If not, a "Lack of Fit" (LOF) message is displayed, which occurred for six of the ten elements where there was sufficient data in this phase of the study.

Figure 4.1-1 is the first output from the ECHIP program showing the effect of individual variables upon the elements listed. The number of stars, in the row to the left of the variable name, indicates the relative effect of that variable. The more stars, the greater the effect a change in that variable has upon the element's concentration in the treated water. In Figure 4.1-1 there are no stars in the polymer and alum rows indicating, that over the range of the amount of reagents used in this phase of the study, there was little or no effect upon the element's concentration in the treated water caused by these two reagents. By examining the numerical values of the coefficients of alum and polymer in Table 4.1-2 and 4.1-3 for these two variables, it can be seen that they are very small, $<0.002$. Therefore, the effects are insignificant and can be eliminated as a variable in subsequent phases. The number of stars indicated that ferrate had a 


\begin{tabular}{llr}
\hline Potassium Ferrate Treatment & Document Number: & RF/ER-94-0028.UN \\
of RFETS Groundwater & Section: & 4.0, Rev. 0 \\
& Page: & 4 of 40 \\
\hline \hline
\end{tabular}

major impact upon eight of the ten constituents. Again, from the number of stars, $\mathrm{pH}$ and ferrate are both significant for the removal of barium while $\mathrm{pH}$ is the only important variable affecting uranium removal.

Figure 4.1-1 Summary of Results of Phase I Tests Using ECHIP Program

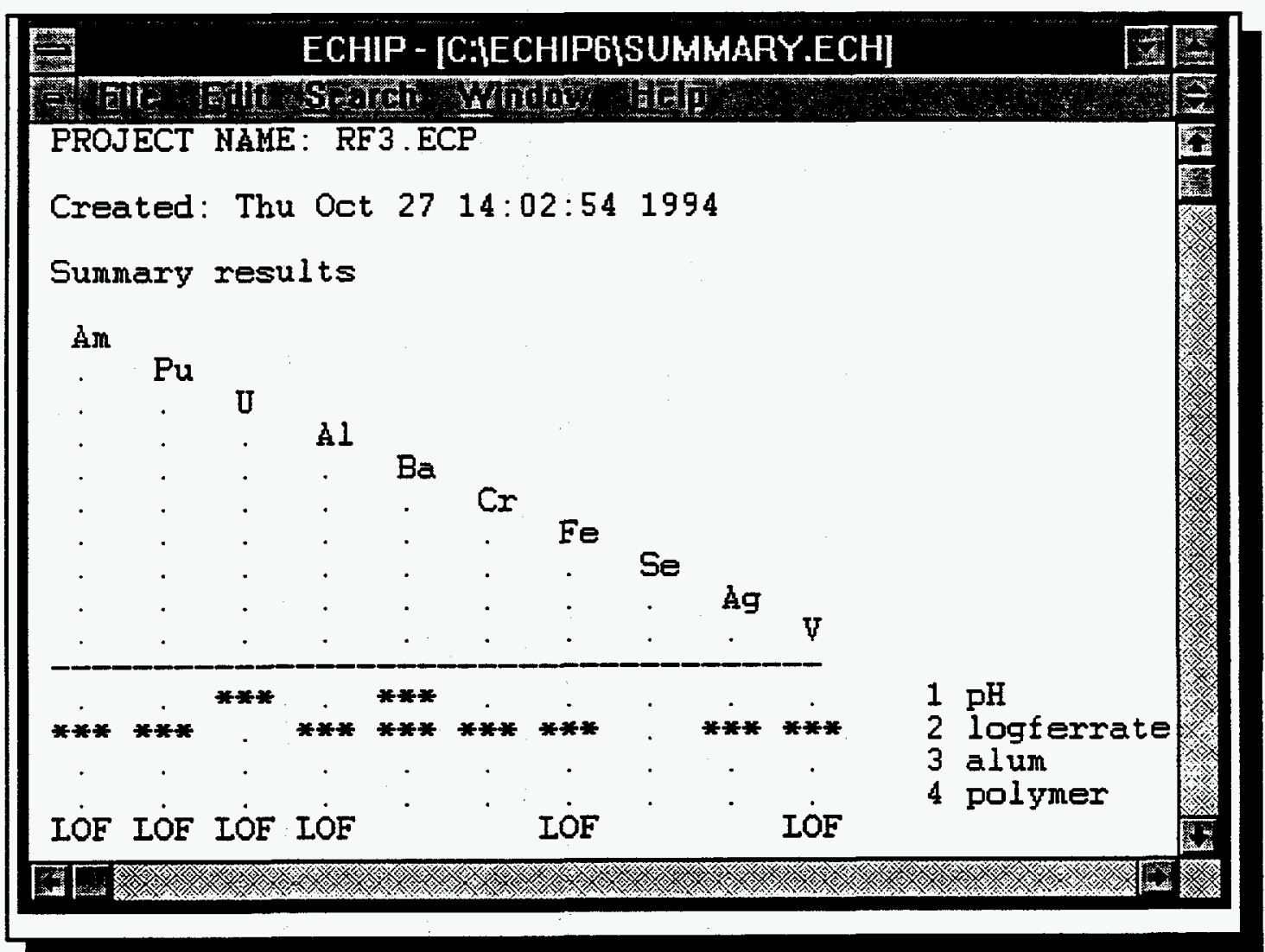

To discuss Tables 4.1-2 and 4.1-3, which shows the coefficients of response, the equation used for this analysis must be recalled; it is:

$$
y=a_{o}+a_{1} x_{1}+a_{2} x_{2}+a_{3} x_{3}+a_{4} x_{4}
$$


Coefficients $a_{0}$ through $a_{4}$ are shown in Tables 4.1-2 and 4.1-3 for each of the variables: $x_{1}=$ $\mathrm{pH}, \mathrm{x}_{2}=\log$ ferrate, $\mathrm{x}_{3}=$ alum and $\mathrm{x}_{4}=$ polymer, in units of $\mathrm{mg} / \mathrm{l}$. The value of $\mathrm{y}$ is the concentration of the COCs in solution. A sign was assigned to the coefficients; as the concentration of the reagent (variable) increases the sign of the coefficient is positive $(+)$ if the concentration of the particular element increases or negative $(-)$ if it decreases. Other than the

\section{Table 4.1-2 Coefficients for Response of Americium}

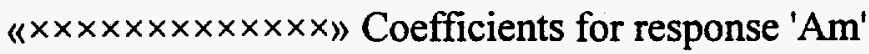

Centered continuous variables

COEFFICIENTS SD $\quad \mathrm{P}$ CONDITION TERM

0.332844

0 CONSTANT

$\begin{array}{lllll}-0.00477232 & 0.0165708 & 0.7792- & 0.943 & 1 \mathrm{pH}\end{array}$

$\begin{array}{lllll}-0.177047 & 0.0250332 & 0.0000 & 0.847 & 2 \text { logferrate }\end{array}$

$0.0007932090 .00147026 \quad 0.6013-0.841 \quad 3$ alum

$\begin{array}{lllll}-0.00197069 & 0.0130205 & 0.8827 & 0.866 & 4 \text { polymer }\end{array}$

$\mathrm{N}$ trials $\quad=15$

$\mathrm{N}$ terms $\quad=5$

Residual SD $=0.096570$, Lack-Of-Fit $\mathrm{P}=0.0373 *$

Residual DF $=10$

Residual SD used for tests

Replicate SD $=0.034157$

Replicate DF $=3$

$\mathrm{R}$ Squared $\quad=0.872, \mathrm{P}=0.0002 * * *$

Adj R Squared $=0.821$ 
Potassium Ferrate Treatment of RFETS Groundwater
Document Number:

Section:

Page:
RF/ER-94-0028.UN

4.0, Rev. 0

6 of 40

constant term $\left(a_{0}\right)$ in the case of Am 241, the largest coefficient $\left(a_{2}\right)$ was for logferrate and minus. This means that the addition of ferrate will cause a decrease in the concentration of americium. The coefficients for the other reagents are two to three orders of magnitude smaller.

Figure 4.1-2 Response Surface of Americium

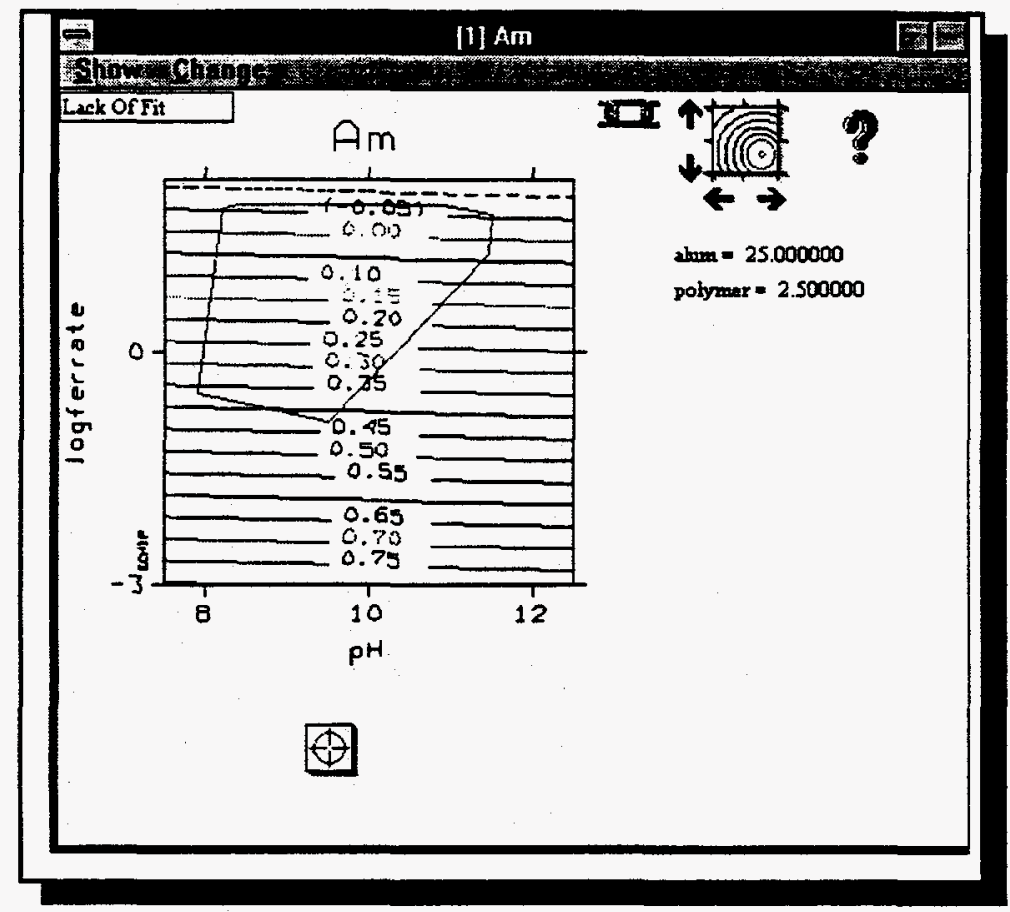

Therefore, these reagents will have little or no effect on the concentration of americium in the treated water. Figure 4.1-2 displays the system in graphical form which shows a reduction of the americium concentration as more ferrate was added, but as $\mathrm{pH}$ increases little or no effect was observed.

From published information on the aqueous chemistry of americium, it would be expected that as the $\mathrm{pH}$ rises, americium would form a hydroxide and as a solid phase should have been removed 
Potassium Ferrate Treatment of RFETS Groundwater
Document Number:

Section:

Page:
RF/ER-94-0028.UN

4.0, Rev. 0 7 of 40

more effectively. This anticipated result was not observed and raised the question as to the applicability of the test procedures or whether the addition of ferrate in basic solutions caused increased americium solubility. Examination of the other elements' responses shows this same discrepancy, especially iron (Appendix D). The only exceptions to this observation were barium and uranium. In Table 4.1-3 the coefficients for uranium's response to the variables

Table 4.1-3 Coefficients for Response of Uranium

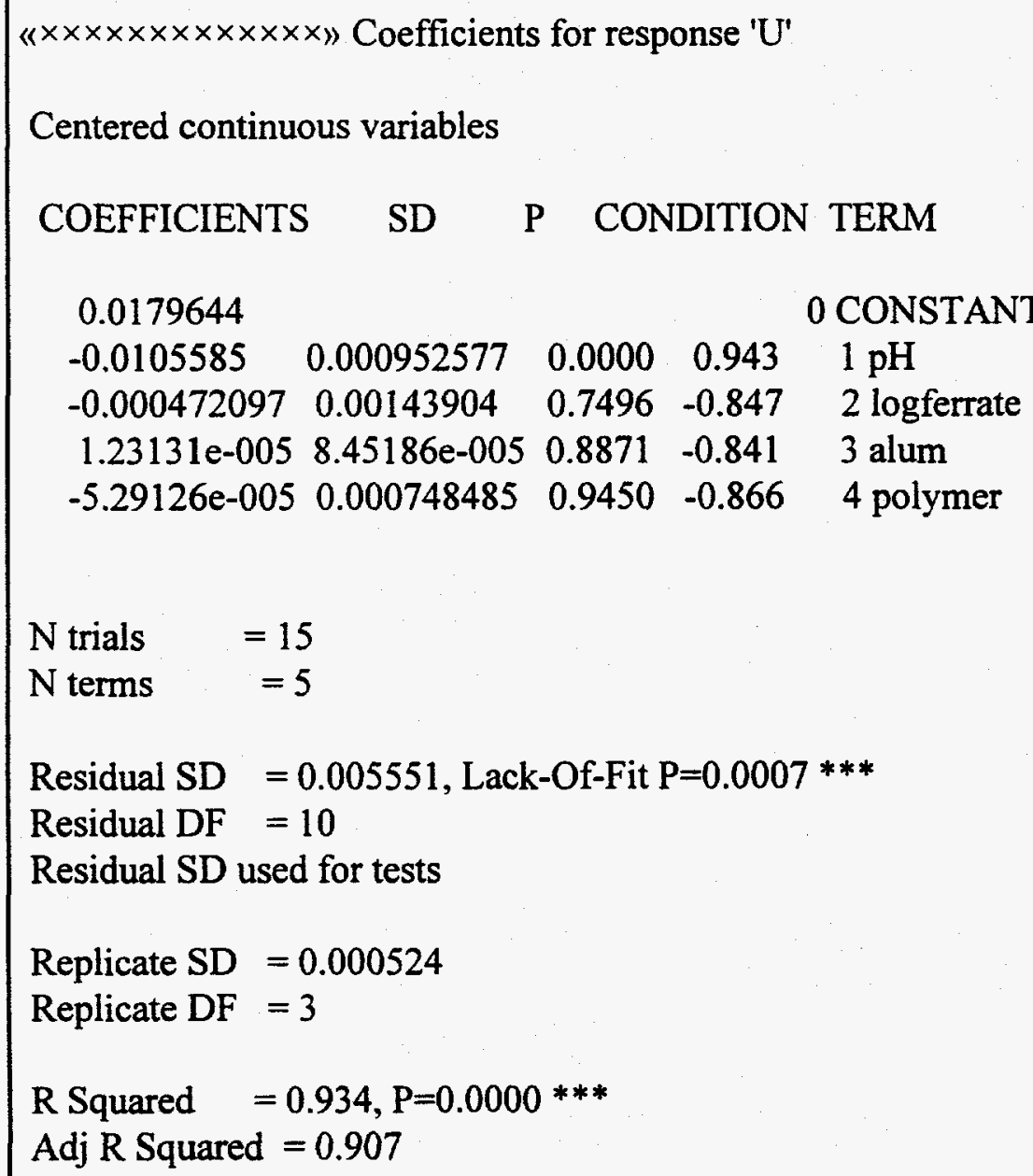


Potassium Ferrate Treatment of RFETS Groundwater
Document Number:

Section:

Page:
RF/ER-94-0028.UN

4.0 , Rev. 0

8 of 40

shows that the coefficient for $\mathrm{pH}$ is three orders of magnitude larger than any of the others; therefore, it is the only variable that had any measurable effect upon the removal of uranium. This effect of $\mathrm{pH}$ was what would be expected from aqueous chemistry of uranium.

In reviewing all the response data in Appendix $\mathrm{D}$, it is seen that $\mathrm{Al}, \mathrm{Cr}$ and $\mathrm{Fe}$, which also precipitate as the $\mathrm{pH}$ of the solution rises, should have been removed more effectively at higher $\mathrm{pH}$ but were not. Since these results were completely unexpected other factors were examined to explain this phenomenon. Observations made during testing indicated that the ferrate ion was not completely reduced at the end of the tests. This was obvious, since the purple color of the ferrate ion was still present in the solution. The next day, when the solution was decanted for analysis, those tests which had the purple color were then cloudy and yellow. This seemed to indicate that some iron compounds had not settled out of the solution. The chemical analysis of the treated water confirmed this assumption. From these results it was concluded that the incomplete reduction of ferrate accounted for the lack of effect of increasing $\mathrm{pH}$ upon the removal of the COCs in the treated water.

Other observations made are: 1) the response of barium was closer to what was expected in that there was a response to both ferrate and $\mathrm{pH}$ and 2) selenium was not effected by this technology. In order to obtain more significant information from this phase of the study a modified test matrix was used to analyze the results. This modified matrix used data for only those tests where no color was seen at the end of the test (Test Nos.1,1,4,6,8,10 and 11) and the analytical data of the sample of the bulk solution, labeled as Test No. 17, in an analytical results matrix (Appendix E). Summary of the responses from the calculations using the modified matrix of both the test variables and analytical results are given in Figure 4.1-3 The results fit the data better than the full test matrix in that only plutonium and selenium have the LOF message. 
Potassium Ferrate Treatment of RFETS Groundwater

Document Number:

Section:

RF/ER-94-0028.UN

Page:

4.0 , Rev. 0

9 of 40

Analysis of the modified Phase I test results over the limited $\mathrm{pH}$ range ( $\mathrm{pH} 7.4$ to 9.7), showed combined response to both $\mathrm{pH}$ and ferrate by most of the COCs concentration in the treated water. These were the expected responses.

Figure 4.1-3 Summary of the Responses from the Modified Phase I Test Program

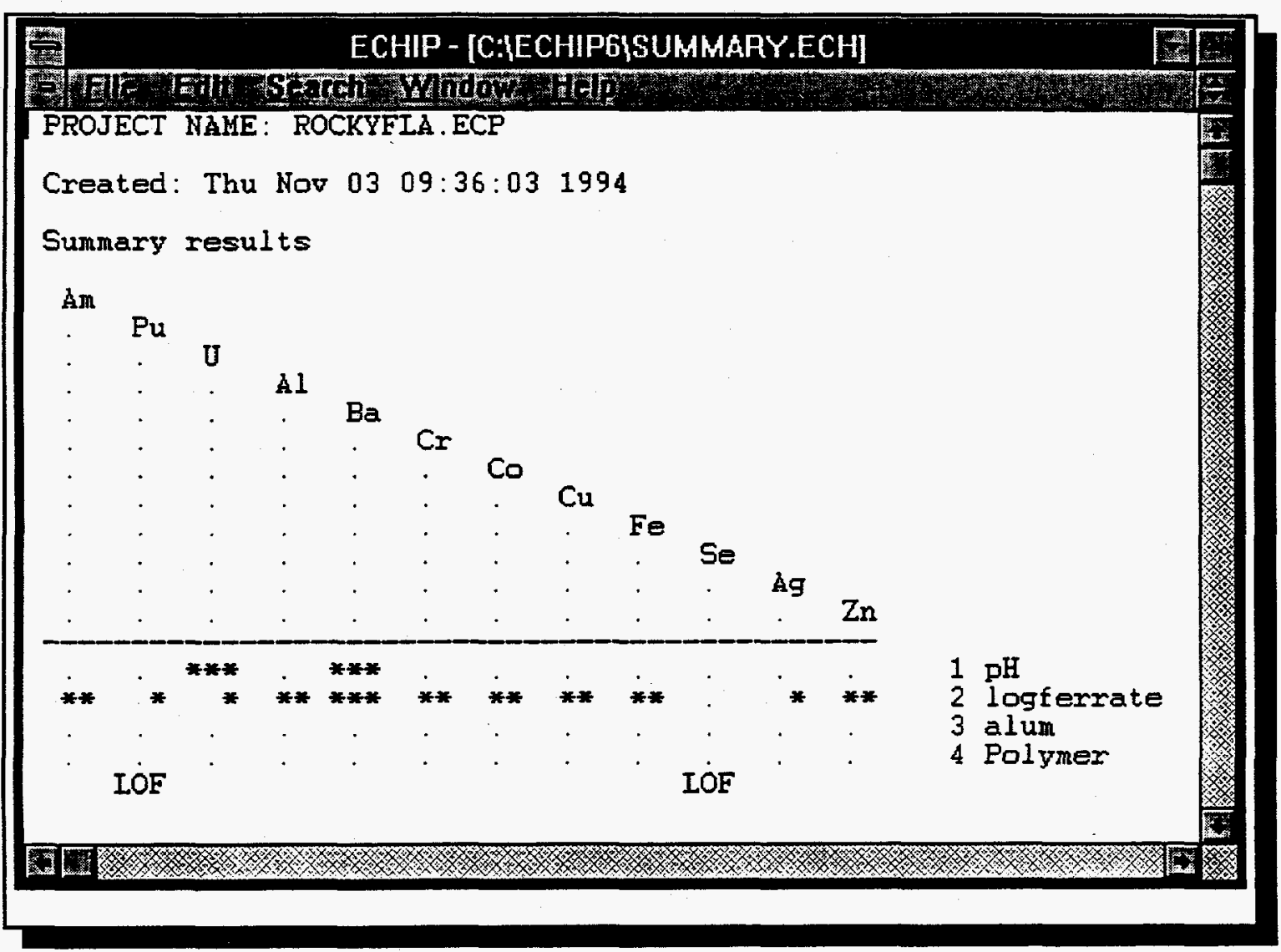

\subsubsection{Conclusions from Phase I Tests}

The following conclusions result from analysis of Phase I data:

1) Ferrate does lower the concentration of several of the COCs from the RFETS 


\begin{tabular}{llr}
\hline Potassium Ferrate Treatment & Document Number: & RF/ER-94-0028.UN \\
of RFETS Groundwater & Section: & 4.0, Rev. 0 \\
& Page: & 10 of 40 \\
\hline
\end{tabular}

contaminated groundwater, at least $\mathrm{Am}, \mathrm{Pu}, \mathrm{Al}, \mathrm{Fe}$ and possibly $\mathrm{Cr}$, at $\mathrm{pH}$ at less than 9.7;

2) Removal of contaminants is more effective if all of the ferrate is eliminated by chemical reduction during treatment;

3) Chemical reduction of ferrate is more difficult at $\mathrm{pH}$ values greater than 9.7 , requiring longer mixing times in the reactor;

4) Several elements show mixed response, where both $\mathrm{pH}$ and ferrate concentration effect the final concentration after treatment. These include $\mathrm{Ba}$, $\mathrm{Ag}$ and $\mathrm{U}$ with $\mathrm{U}$ having negative response to ferrate addition and silver showing an increase in concentration as the $\mathrm{pH}$ rises and

5) Changing the concentration of both alum and polymer has a very slight affect upon the removal of any of the contaminants of concern; however, the observations suggest that a minimum amount is required.

\subsection{PHASE II RESULTS AND DISCUSSION}

According to the work plan, the design of the Phase II tests was to be based upon the results of Phase I and lead to the overall objective of the study. Results and conclusions of Phase I pointed out that: 1) the range of $\mathrm{pH}$ investigated must be expanded, 2) more time for the degradation of the ferrate must be allowed and 3) before the tests were completed all of the ferrate must be eliminated by chemical reduction, that is all of the purple color must be gone. Since the COCs had different responses to the treatment, an optimum treatment condition was 
Potassium Ferrate Treatment of RFETS Groundwater
Document Number: Section:

Page:
RF/ER-94.0028.UN

4.0 , Rev. 0

sought that would maximize the removal of all the COCs with a single treatment and still produce treated water meeting the CWQCC discharge limits (Table 1.0-1). For example, the radionuclides of americium and plutonium were eliminated by the addition of ferrate and uranium was removed by increasing the $\mathrm{pH}$.

Secondary treatment was not considered as part of the process to be investigated in this study.

Phase I results showed that the COCs removal was not improved with the addition of more than $10.0 \mathrm{mg} / \mathrm{l}$ alum or $0.50 \mathrm{mg} / 1$ polymer. As a result, these two reagents were not considered variables in Phase II and their additions were constant in all the tests.

Phase I results also indicated that there was interaction between ferrate addition and $\mathrm{pH}$ upon the removal of several COCs. In Phase II ferrate addition and $\mathrm{pH}$ were tested over a broader range to determine, if in fact, a common point did exist in the system to remove most, if not all, of the COCs in the groundwater. The dosing of ferrate studied in the Phase II tests ranged from 0 to approximately $160 \mathrm{mg} / \mathrm{l}$. The $\mathrm{pH}$ range examined was from the value of the groundwater as received up to 11.5 .

To find a common point where all the COCs were removed to acceptable limits, Phase II examined the COCs' responses as a function of ferrate and $\mathrm{pH}$ and the interactions of these two variables. The results of Phase II tests had to be evaluated with a model that was capable of estimating interactions. Even though there were only two variables, a large number of tests were required to gather sufficient data to estimate the interaction terms in any model chosen. In addition, replicate tests were needed to estimate the statistical variations from test to test. 
Potassium Ferrate Treatment of RFETS Groundwater
Document Number:

Section:

Page:
RF/ER-94.0028.UN

4.0, Rev. 0

12 of 40

Using the ECHIP software, it was determined that 18 was the minimum number of tests needed to satisfy the interaction estimating models. Five replicate tests were recommended by the program. To save time and analytical costs it was decided that only three replicate tests would be needed. Several Phase I tests could be used in the calculations as replicate tests. The Phase II study then consisted of 15 additional tests which satisfied the criteria of any of the models available in the ECHIP software. Table 4.2-1 shows the matrix of the variables to be used for Phase II testing generated by ECHIP.

As was the case in Phase I, the tests were conducted in the order presented in the test matrix to eliminate any systematic errors that might be introduced by the experimenter. Alum and polymer were constant at $10 \mathrm{mg} / 1$ and $5.0 \mathrm{mg} / 1$ respectively in each test in the second phase of this study. Thiosulfate was added in several stages of addition and mixing (15 minutes) to completely eliminate all of the purple color of the ferrate ion. Other than these changes the tests were done as described in Section 3.3.3.

The treated water was decanted the day after completing the test into plastic bottles, sealed, labeled and sent to Accu-Labs for analysis of both the inorganic and radionuclide contaminants. Appendix B contains three analytical reports of the treated water from Accu-Labs. These reports consist of the inorganic analysis report dated 10/04/94, a preliminary radionuclide report dated 10/04/94 and the final and corrected radionuclide report dated 10/25/94.

Upon receiving the analytical results, the data was input into the Response Table of the ECHIP program for analysis. As before, the $\mathrm{pH}$ values reported by Accu-Labs were used for the data analysis. 
Potassium Ferrate Treatment of RFETS Groundwater
Document Number:

Section:

Page:
RF/ER-94.0028.UN

4.0, Rev. 0

13 of 40

In order to obtain sufficient data to satisfy the interactive models of the ECHIP software seven Phase I tests were used with the Phase II matrix (Table 4.2-1) to produce the modified Phase II test matrix (Table 4.2-2) prior to computer analysis. Different amounts of alum and polymer were used in these Phase I tests but because these two variables had little or no effect upon the removal of the COCs they were acceptable for use in this computer analysis of Phase II results. Chemical analysis of the feed solution ( Test 17 ) from both Phase I and II were also included in the matrix. This modified test matrix was used to the analyze the performance of ferrate treatment technology to eliminate COCs from RFETS groundwater.

Table 4.2-1 Phase II Test Matrix

\begin{tabular}{|c|c|c|r|l|}
\hline $\begin{array}{c}\text { Trial } \\
\text { Number }\end{array}$ & $\mathbf{p H}$ & log Ferrate & Ferrate, mg/ & Comments \\
\hline 3 & 7.80 & 2.200 & 158.5 & As received \\
\hline 4 & 8.81 & 1.576 & 37.7 & \\
\hline 12 & 9.65 & 2.2 & 158.5 & \\
\hline 11 & 9.63 & 1.069 & 11.7 & \\
\hline 9 & 11.5 & 0.000 & 1.0 & \\
\hline 1 & 11.50 & 2.200 & 158.5 & \\
\hline 2 & 11.50 & 1.100 & 12.6 & \\
\hline 8 & 9.65 & 2.200 & 158.5 & \\
\hline 1 & 11.50 & 2.200 & 158.5 & \\
\hline 10 & 10.45 & 0.602 & 4.0 & \\
\hline 2 & 11.50 & 1.100 & 12.6 & \\
\hline 13 & 10.00 & 1.100 & 12.6 & \\
\hline 14 & 11.5 & -3.000 & 0.0 & 0 mg/l Ferrate \\
\hline 16 & 10.00 & 2.200 & 158.5 & \\
\hline 17 & 8.0 & -3.000 & 0.0 & Feed Sol'n \\
\hline
\end{tabular}


Potassium Ferrate Treatment of RFETS Groundwater
Document Number:

Section:

Page:
RF/ER-94.0028.UN

4.0, Rev. 0

14 of 40

Table 4.2-2 Modified Phase II Test Matrix

\begin{tabular}{|c|c|c|c|}
\hline Trial Number & pH & $\log (m g / l$ ferrate $)$ & Comments \\
\hline 1 & 11.4 & 2.200 & Phase II Test 1 \\
\hline 1 & 11.4 & 2.200 & Phase II Test 1 \\
\hline 2 & 11.8 & 1.100 & Phase II Test 2 \\
\hline 2 & 11.8 & 1.100 & Phase II Test 2 \\
\hline 3 & 8.5 & 2.200 & Phase II Test 3 \\
\hline 4 & 8.6 & 1.576 & Phase II Test 4 \\
\hline 8 & 9.4 & 2.200 & Phase II Test 0 , on analytical report \\
\hline 9 & 11.6 & 0.000 & Phase II Test 9 \\
\hline 11 & 9.6 & 1.069 & Phase II Test 11 \\
\hline 12 & 9.8 & 2.200 & Phase II Test 12 \\
\hline 13 & 10.2 & 1.100 & Phase II Test 13 \\
\hline 12 & 10.0 & 2.200 & Phase II Test 16 \\
\hline 17 & 8.0 & -3.000 & Phase II Feed Solution, untreated \\
\hline 18 & 8.2 & 1.895 & Phase I Test 1 \\
\hline 18 & 8.3 & 1.895 & Phase I Test 1 \\
\hline 19 & 8.4 & 1.196 & Phase I Test 6 \\
\hline 19 & 8.3 & 1.196 & Phase I Test 10 \\
\hline 20 & 9.7 & 1.673 & Phase I Test 11 \\
\hline 10 & 10.1 & 0.602 & Phase II Test 10 \\
\hline 14 & 11.9 & -3.000 & Phase II Test 14 \\
\hline 17 & 7.4 & -3.000 & Phase I Feed Solution \\
\hline 19 & 8.2 & 1.196 & Phase I Test 8 \\
\hline 18 & 8.2 & 1.895 & Phase I Test 4 \\
\hline
\end{tabular}


Potassium Ferrate Treatment of RFETS Groundwater
Document Number:

Section:

Page:
RF/ER-94.0028.UN

4.0, Rev. 0

15 of 40

Table 4.2-3 Corrected Analytical Results for the Modified Phase II Ferrate Treatment Tests

\begin{tabular}{|c|c|c|c|c|c|c|c|c|c|c|c|c|}
\hline \multirow[t]{2}{*}{ Test } & Am & $\mathbf{P u}$ & $\mathbf{U}$ & Al & $\mathbf{B a}$ & $\mathrm{Cr}$ & Co & $\mathbf{C u}$ & $\mathbf{F e}$ & Se & $\mathbf{A g}$ & $\mathbf{Z n}$ \\
\hline & $\mathrm{pCi} /$ & $\mathrm{pCi} /$ & \multicolumn{10}{|c|}{$\mathrm{mg} / \mathrm{l}$} \\
\hline 8 & 0.03 & 0.26 & 0.020 & 0.2 & 0.0 & 0.008 & 0.0 & 0.0 & 0.05 & 0.058 & 0.008 & 0.0 \\
\hline 1 & 0.01 & 0.12 & 0.0011 & 0.5 & 0.0 & 0.009 & 0.0 & 0.0 & 0.08 & 0.055 & 0.010 & 0.0 \\
\hline 1 & 0.03 & 0.12 & 0.0012 & 0.4 & 0.0 & 0.006 & 0.0 & 0.0 & 0.13 & 0.056 & 0.007 & 0.0 \\
\hline 2 & 0.02 & 0.17 & 0.0039 & 0.1 & 0.0 & 0.000 & 0.0 & 0.0 & 0.19 & 0.056 & 0.005 & 0.0 \\
\hline 2 & 0.01 & 0.14 & 0.0015 & 0.0 & 0.0 & 0.000 & 0.0 & 0.0 & 0.26 & 0.059 & 0.007 & 0.006 \\
\hline 3 & 0.04 & 1.1 & 0.034 & 0.0 & 0.07 & 0.011 & 0.0 & 0.0 & 0.0 & 0.049 & 0.009 & 0.0 \\
\hline 4 & 0.02 & 0.36 & 0.030 & 0.0 & 0.08 & 0.008 & 0.0 & 0.0 & 0.0 & 0.059 & 0.011 & 0.0 \\
\hline 9 & 0.04 & 0.10 & 0.0018 & 0.0 & 0.0 & 0.000 & 0.0 & 0.0 & 0.07 & 0.054 & 0.000 & 0.0 \\
\hline 10 & 0.03 & 0.13 & 0.0069 & 0.0 & 0.0 & 0.000 & 0.0 & 0.0 & 0.02 & 0.065 & 0.000 & 0.0 \\
\hline 11 & 0.00 & 0.19 & 0.027 & 0.0 & 0.0 & 0.000 & 0.0 & 0.006 & 0.02 & 0.061 & 0.005 & 0.0 \\
\hline 12 & 0.02 & 0.20 & 0.025 & 0.0 & 0.0 & 0.000 & 0.0 & 0.0 & 0.02 & 0.059 & 0.007 & 0.0 \\
\hline 13 & 0.08 & 1.8 & 0.022 & 0.0 & 0.0 & 0.000 & 0.0 & 0.0 & 0.02 & 0.059 & 0.008 & 0.0 \\
\hline 12 & 0.03 & 0.12 & 0.0077 & 0.0 & 0.0 & 0.000 & 0.0 & 0.0 & 0.05 & 0.056 & 0.009 & 0.0 \\
\hline 17 & 1.10 & 6.70 & 0.036 & 20.0 & 0.23 & 0.025 & 0.006 & 0.023 & 19.00 & 0.040 & 0.028 & 0.081 \\
\hline 14 & 0.00 & 0.00 & 0.001 & 0.0 & 0.0 & 0.000 & 0.008 & 0.0 & 0.02 & 0.056 & 0.000 & 0.0 \\
\hline 18 & -0.03 & 0.18 & .038 & 0.7 & 0.06 & 0.000 & 0.00 & 0.00 & 0.03 & 0.051 & 0.000 & 0.0 \\
\hline 18 & -0.06 & .17 & .037 & 0.7 & 0.06 & 0.00 & 0.03 & 0.02 & 0.03 & 0.047 & 0.000 & 0.0 \\
\hline 19 & -0.03 & 0.16 & .036 & 0.7 & 0.07 & 0.00 & 0.00 & 0.00 & 0.02 & 0.052 & 0.000 & 0.0 \\
\hline 19 & 0.02 & 0.02 & 0.036 & 0.2 & 0.08 & 0.00 & 0.00 & 0.00 & 0.02 & 0.056 & 0.000 & 0.0 \\
\hline 20 & 0.00 & 0.00 & 0.0035 & 0.3 & 0.00 & 0.00 & 0.00 & 0.00 & 0.13 & 0.055 & 0.000 & 0.0 \\
\hline 17 & 0.86 & 7.5 & 0.044 & 18 & 0.25 & 0.20 & 0.007 & 0.029 & 19 & 0.044 & 0.029 & 0.086 \\
\hline 19 & -0.02 & -0.02 & 0.037 & 0.2 & 0.09 & 0.00 & 0.00 & 0.00 & 0.02 & 0.049 & 0.000 & 0.0 \\
\hline 18 & 0.01 & 0.21 & 0.039 & 0.2 & 0.08 & 0.00 & 0.00 & 0.00 & 0.04 & 0.047 & 0.005 & 0.00 \\
\hline
\end{tabular}


Potassium Ferrate Treatment of RFETS Groundwater
Document Number:

Section:

Page:
RF/ER-94.0028.UN

4.0, Rev. 0

16 of 40

The analytical response table used for the analysis of the second phase work is displayed in Table 4.2-3. As in Phase I only those elements that had a sufficiently large number of responses above the analytical detection limits were input into the program. Analytical results reported below the detection limits were entered into this table as zeros. The radionuclide data were entered into the table as reported, even when that value was negative. Using zero values may over estimate the response but because of the large number of tests used the impact on the results and conclusions is not significant. This statement can be substantiated by the fact that the residual standard deviation for these tests is large when compared to the analytical detection limits. For example, the analytical detection limit is $0.05 \mathrm{mg} / \mathrm{l}$ for aluminum and the residual standard deviation calculated is 0.437 . This means that whatever the true concentration of the metal element is in the treated water below the detection limit, the value would not effect the results of the computer analysis of the data.

Three mathematical models were tried to analyze the data. Of the three, the partial cubic model fit the best and will be used for the discussion of Phase II results. The partial cubic model is expressed by the following equation:

$$
y=a_{0}+a_{1} x_{1}+a_{2} x_{2}+a_{12} x_{1} x_{2}+a_{11} x_{1}^{2}+a_{22} x_{2}^{2}+a_{112} x_{1}^{2} x_{2}+a_{122} x_{1} x
$$

In this equation $y$ is the concentration of the COCs in solution and $x_{1}$ is the $\mathrm{pH}$ and $\mathrm{x}_{2}$ is the $\log$ of the concentration of potassium ferrate in $\mathrm{mg} / \mathrm{l}$ and the $\mathrm{a}_{\mathrm{i}}$ are coefficients calculated by the ECHIP software.

\subsubsection{Determining the Test Conditions to be Used in Phase III Tests}

To maintain the schedule of this study the preliminary radionuclide analytical results were used to 
Potassium Ferrate Treatment of RFETS Groundwater
Document Number:

Section:

Page:
RF/ER-94.0028.UN

4.0, Rev. 0

17 of 40

estimate the optimum treatment conditions to be used in Phase III. This required that a set of treatment conditions be found that would reduce the concentrations of all the COCs in solution to acceptable concentrations of the COCs. Again the ECHIP, program was used to accomplish this goal. The program allows for responses of all of the elements to be combined to calculate a combined response surface so that the optimum conditions can be determined. A graph of the response surface is produced that displayed a region that maximizes the removal of all the COCs. Within this region there was a optimum set of treatment conditions.

To combine the responses of the individual elements their response's were weighted, as part of the calculations, based upon the CWQCC discharge criteria. This weighting factor was simply one divided by the allowable discharge concentration normalized so the total would be one. Therefore, the optimum value in the combined response contour plot would have a value of one if all of the discharge limits were met exactly for each element. If the value of the combined response was very small then there would be some assurance that all the elements had met the discharge limits. Figure 4.2.1-1 shows the contour plot of the combined responses using the uncorrected radionuclide analysis. The optimum conditions selected from this figure are $\mathrm{pH}$ 10.35 and logferrate 1.02. This point was picked to minimize the consumption of reagents and still yield acceptable responses of all elements. At this point the calculated combined response is 0.58 . It is not possible to say that all the contaminants met their individual limits but, on the average, the elements are below the CWQCC discharge limits. Since an average is not good enough, each individual limit must be met, the optimum condition was checked on each individual plot to get a predicted concentration at these conditions. The results are shown in Table 4.2.1-1. In Table 4.2.1-1 there are 13 elements for which the predicted results are below the CWQCC discharge limits. Four of the elements have CWQCC discharge limits that are below the analytical detection limits; therefore, it is not known if their discharge limits were met. 


\begin{tabular}{llr}
\hline $\begin{array}{l}\text { Potassium Ferrate Treatment } \\
\text { of RFETS Groundwater }\end{array}$ & Document Number: & RF/ER-94.0028.UN \\
& Section: & 4.0, Rev. 0 \\
& Page: & 18 of 40 \\
\hline \hline
\end{tabular}

Figure 4.2.1-1 Combined Response Surface Using Uncorrected Radionuclide Data

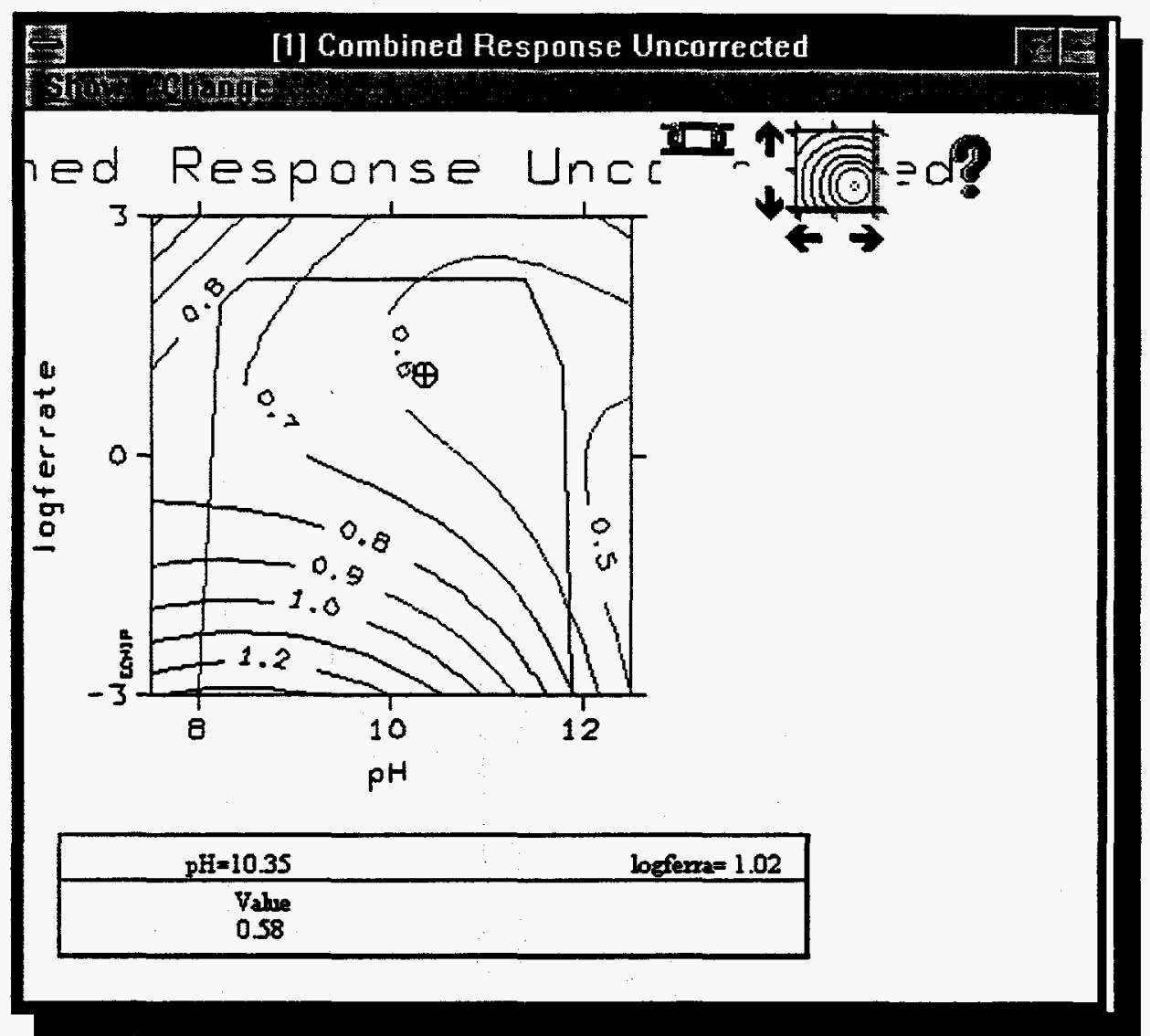

Notice that the $95 \%$ confidence limit range is rather broad. This means that the predicted value has a $95 \%$ probability that it falls within this range and not at the predicted value. Therefore, Phase III tests were required to determine if the predicted values could be achieved at the optimum treatment conditions. The predicted values indicate that ferrate water treatment technology, when applied to the RFETS groundwater, will produce treated water meeting most of the CWQCC discharge limits with the exceptions of selenium and possibly silver. 
Potassium Ferrate Treatment of RFETS Groundwater
Document Number:

Section:

Page:
RF/ER-94.0028.UN

4.0, Rev. 0

19 of 40

Table 4.2.1-1 Predicted Contaminant Concentrations at the Optimum Condition Using Uncorrected Radionuclide Data

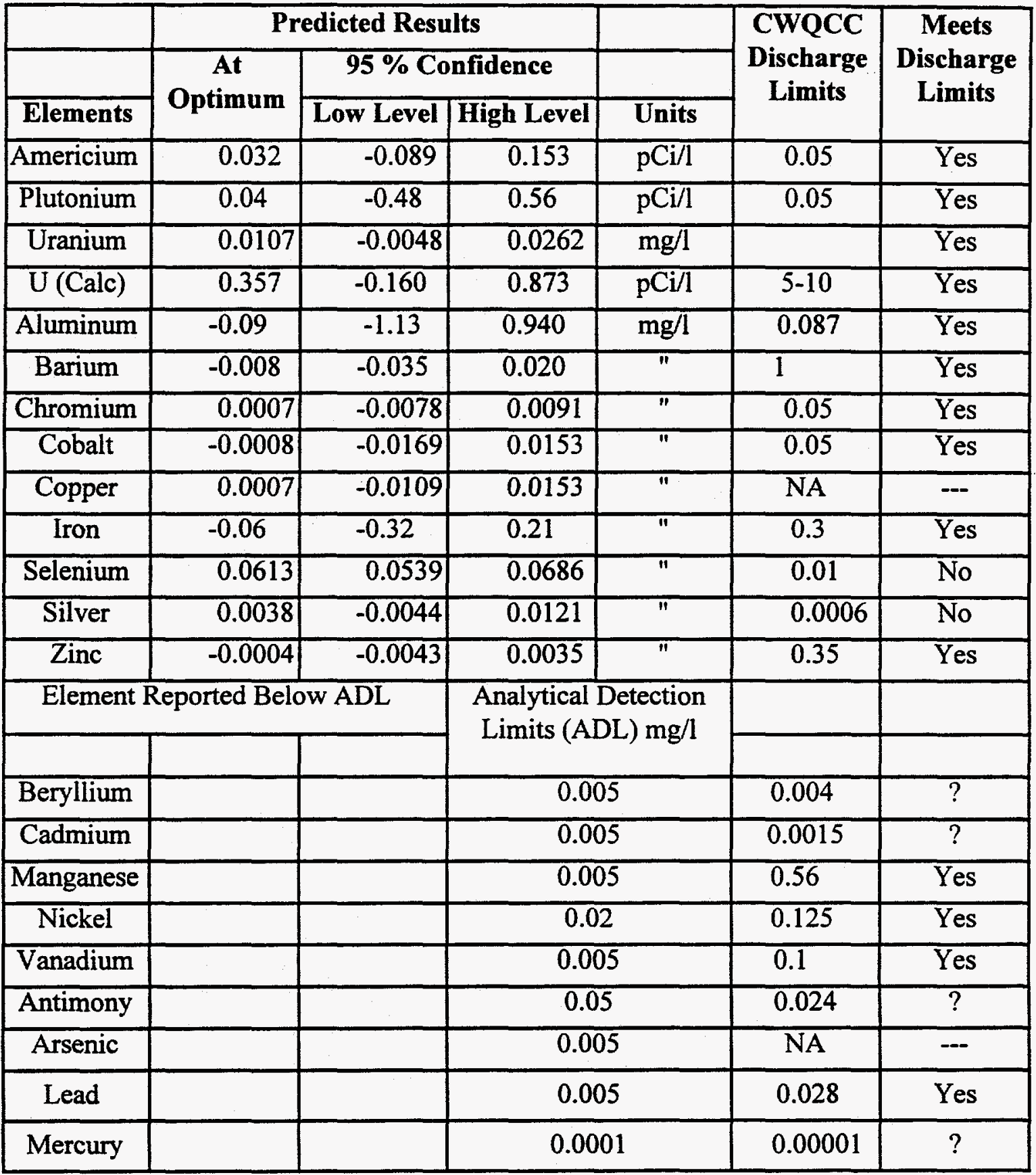

NA CWQCC discharge limit not available 
Potassium Ferrate Treatment of RFETS Groundwater
Document Number:

Section:

Page:
RF/ER-94.0028.UN

4.0, Rev. 0

20 of 40

Similar calculations were done with the corrected data. These results and other details of the computer analysis using the corrected analytical data are discussed in some detail, rather than discussing the results with the uncorrected data.

\subsubsection{Discussion of Phase II Results With Corrected Radionuclide Data}

The ECHIP program generates substantial amounts of information which is not germane to the study but may be of interest to those who want to examine such factors as the robust nature of the

Figure 4.2.2-1 Summary of Results of Phase II Tests Using ECHIP Program

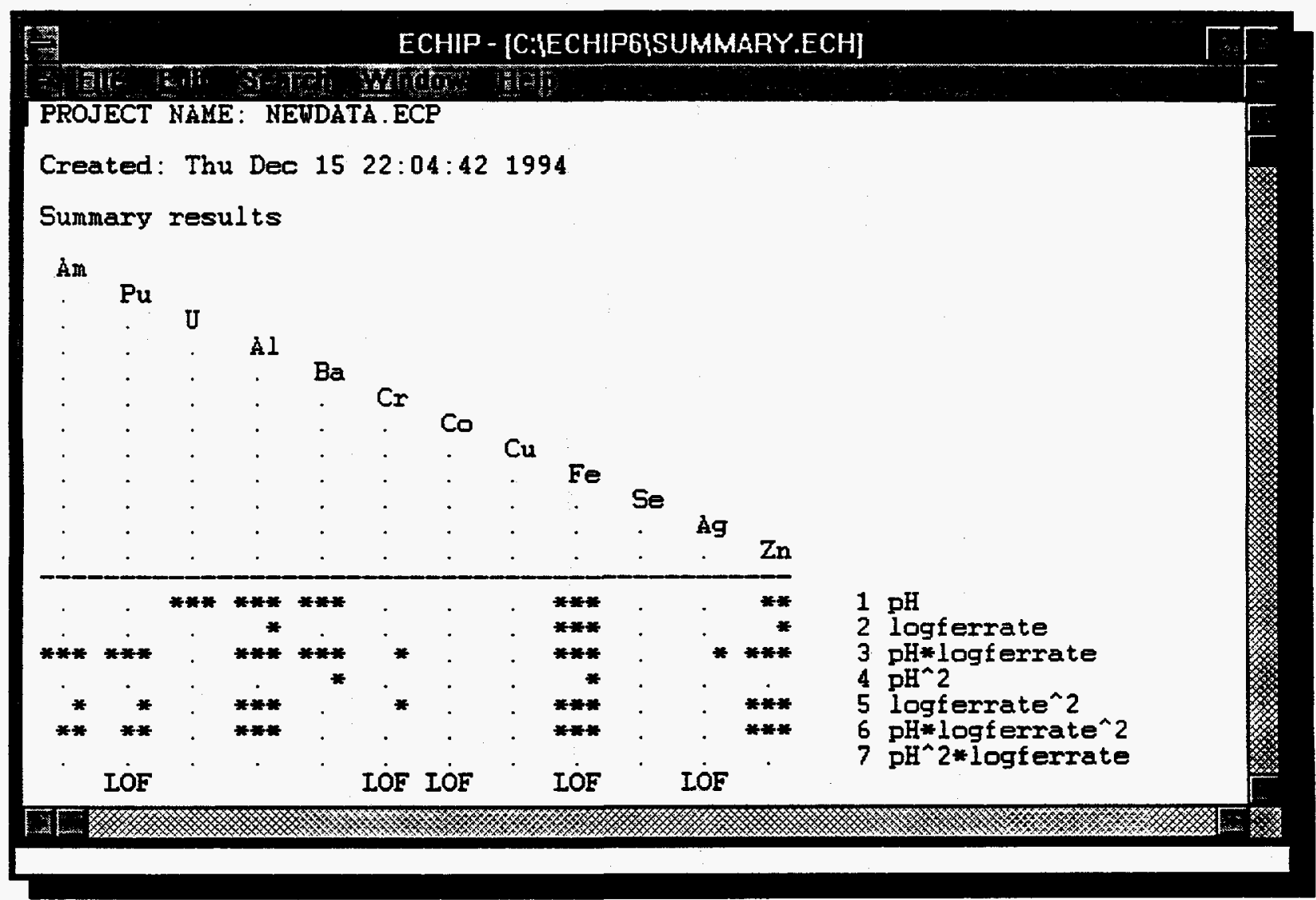


Potassium Ferrate Treatment of RFETS Groundwater
Document Number: Section: Page:
RF/ER-94.0028.UN

4.0, Rev. 0

21 of 40

results or other statistical information; therefore, the complete output for the partial cubic model is presented in Appendix F. Figure 4.2.2-1 is the first of the computer outputs showing the effects of the variables, $\mathrm{pH}$ and ferrate, upon the elements. In this table the number of stars under each element and in the row of a particular factor indicate the relative effect. This figure does not give the absolute magnitude or sign of the effect. Figure 4.2.2-1 shows a lack of fit, using this model, for only five of the contaminants $\mathrm{Pu}, \mathrm{Cr}, \mathrm{Co} \mathrm{Fe}$, and $\mathrm{Ag}$. Lack of Fit message is displayed when there was a significant difference between the residual SD and the replicate SD. Many of the analytical results were at or below the analytical detection limits and the replicate SD is a small number, so this lack of fit for at least $\mathrm{Cr}, \mathrm{Co}$ and $\mathrm{Ag}$ was not serious. There was no explanation for the lack of fit for iron, but it could be attributed to the addition of iron to the experiment, causing a different response and thus requiring a different model to analyze the results. Also, the lack of fit for silver (Ag) was probably caused by its interaction with thiosulfate, a known complexing agent for silver.

To determine the magnitude and sign of the coefficients of the variables, the "Pareto Graphs" are very useful. Several of these are presented here to point out the effect of the test variables upon the removal of the COCs. Interaction of ferrate with $\mathrm{pH}$ creates a more effective response for an element's removal than either by itself. In Figure 4.2.2-2 the Pareto Graph is presented for americium. Notice that the effects are in descending order of the absolute effects. The effects are scaled to the units of the response, in this case $\mathrm{pCi} / 1$. The line represents the $95 \%$ confidence limit and was very broad. This is due to experimental error, both testing and analytical, and it is not possible to separate the two in this study. The " * " in the line is for a positive coefficient and the " $\mathrm{o}$ " is for a negative response. Those factors with " $\mathrm{x}$ " only, no line, has a small effect so it can be eliminated from consideration. 


\begin{tabular}{llr}
\hline $\begin{array}{l}\text { Potassium Ferrate Treatment } \\
\text { of RFETS Groundwater }\end{array}$ & Document Number: & RF/ER-94.0028.UN \\
& Section: & 4.0, Rev. 0 \\
& Page: & 22 of 40 \\
\hline \hline
\end{tabular}

Figure 4.2.2-2 Pareto Effects Graph of Americium

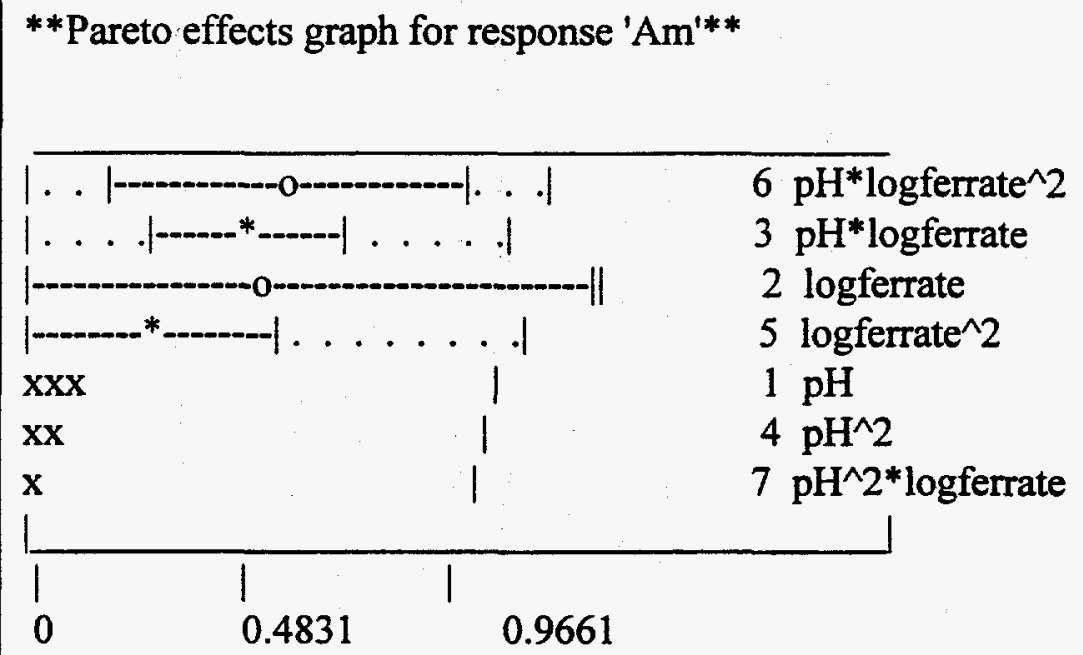

For americium, it is obvious that ferrate addition is needed to reduce its' concentration in solution because the effect of logferrate and $\mathrm{pH}^{*} \log$ ferrate ${ }^{\wedge} 2$ are negative. As these two values increase, the concentration of americium decreases. Notice that $\mathrm{pH}$ and $\mathrm{pH}^{\wedge} 2$ have little or no effect upon americium, which confirms what was observed in Phase I.

Figure 4.2.2-3 presents the two dimensional graph of the response surface for americium. This figure shows the response surface calculated from the equation generated by the computer analysis of the test data. The contours in this figure are approximately one standard deviation apart. The series of lines that cross the contours is essentially the experimental region.

Review of the information in Appendix $\mathrm{F}$ shows that the responses are similar for groups of elements. Uranium and barium have similar response surfaces and are more dependent upon $\mathrm{pH}$ than are the other elements. Americium and plutonium have similar removal responses, which 


\begin{tabular}{llr}
\hline $\begin{array}{l}\text { Potassium Ferrate Treatment } \\
\text { of RFETS Groundwater }\end{array}$ & Document Number: & RF/ER-94.0028.UN \\
& Section: & 4.0, Rev. 0 \\
& Page: & 23 of 40 \\
\hline
\end{tabular}

Figure 4.2.2-3 Response Surface of Americium

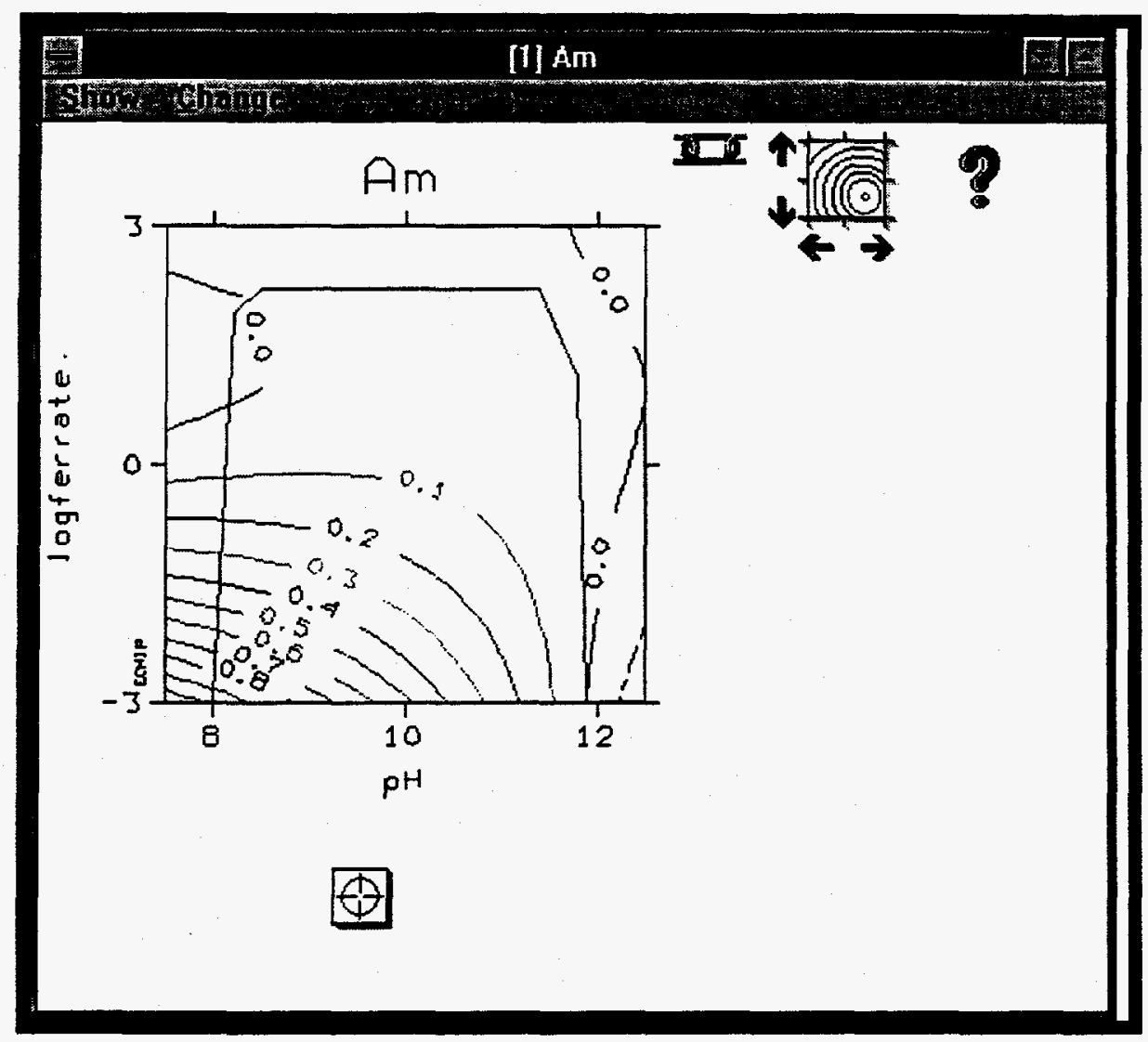

are dependent on ferrate in combination with $\mathrm{pH}$. $\mathrm{Cr}, \mathrm{Co}, \mathrm{Cu}$ and $\mathrm{Ag}$ are similar having a rather complex response. Selenium shows a response very different from any of the other contaminants in that there is no decrease in its' concentration in the test region. In fact a maximum occurs in the center of the field of investigation. It is possible that this is due to the fact that there are more data points in this region. $\mathrm{Fe}, \mathrm{Al}$ and $\mathrm{Zn}$ are similar in their response to the interaction of ferrate and $\mathrm{pH}$. 


\begin{tabular}{llr}
\hline Potassium Ferrate Treatment & Document Number: & RF/ER-94.0028.UN \\
of RFETS Groundwater & Section: & 4.0, Rev. 0 \\
& Page: & 24 of 40 \\
\hline \hline
\end{tabular}

The Pareto Graph for uranium is shown in Figure 4.2.2-4. It can be seen that $\mathrm{pH}$ was the only major factor that removed it from solution. All of the other factors were of no importance. Barium is similar but with some interaction of the two variables $\mathrm{pH}$ and ferrate.

Figure 4.2.2-4 Pareto Effects Graph of Uranium

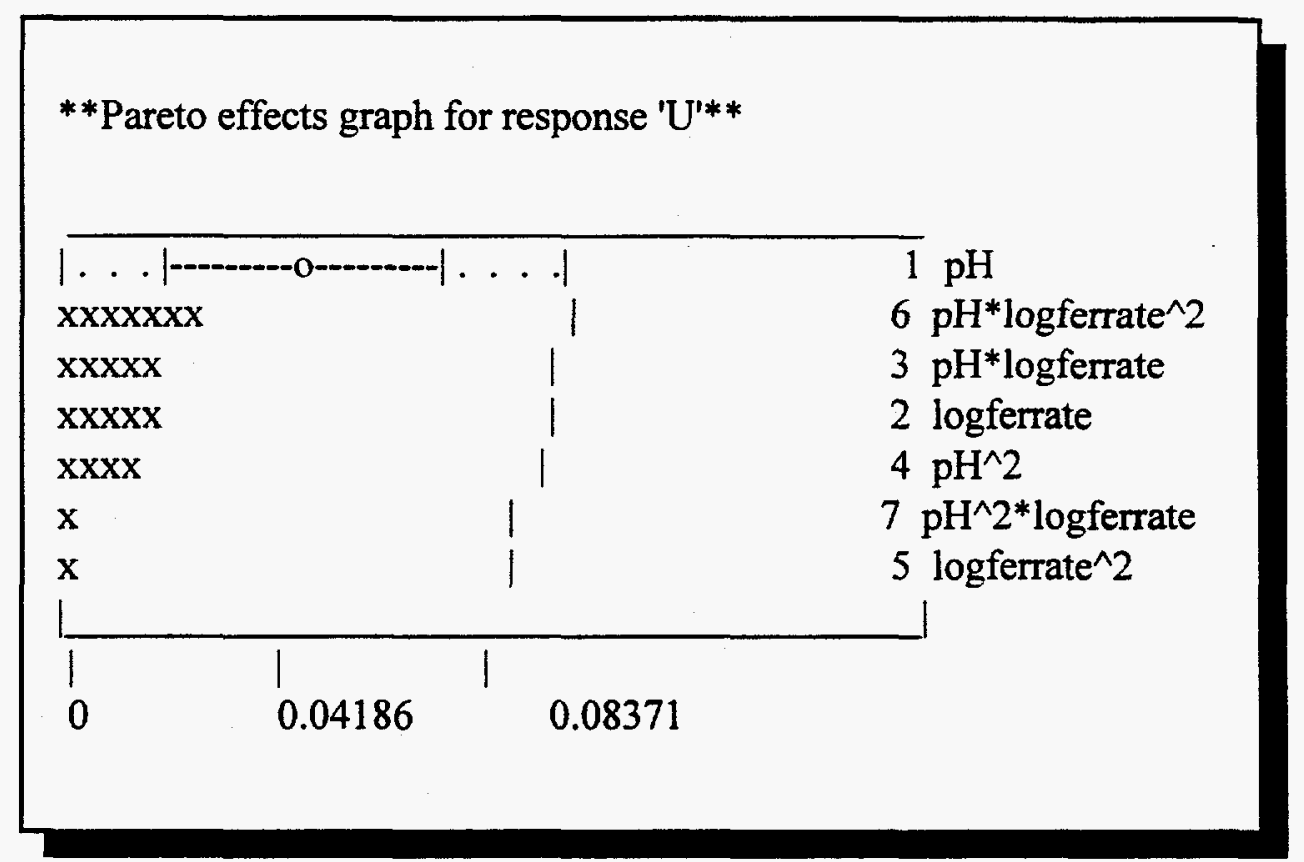

The Pareto Graph of $\mathrm{Al}$ shows the strong effect of ferrate upon its' removal from solution, but with more interaction of the variables. Figure 4.2.2-5 shows that $\mathrm{pH}^{*} \log$ ferrate has a strong positive effect, that is the concentration of $\mathrm{Al}$ in solution will increase as the product of these two variables increases. However, the second term logferrate has a strong negative effect, therefore, it is obvious which variable to manipulate to increase the removal of $\mathrm{Al}$ from the treated water. From the Pareto Graph its difficult to picture what actually occurs. It is much easier to interpret this system using the two dimensional graph, Figure 4.2.2-6. 
Figure 4.2.2-5 Pareto Effects Graph of Aluminum

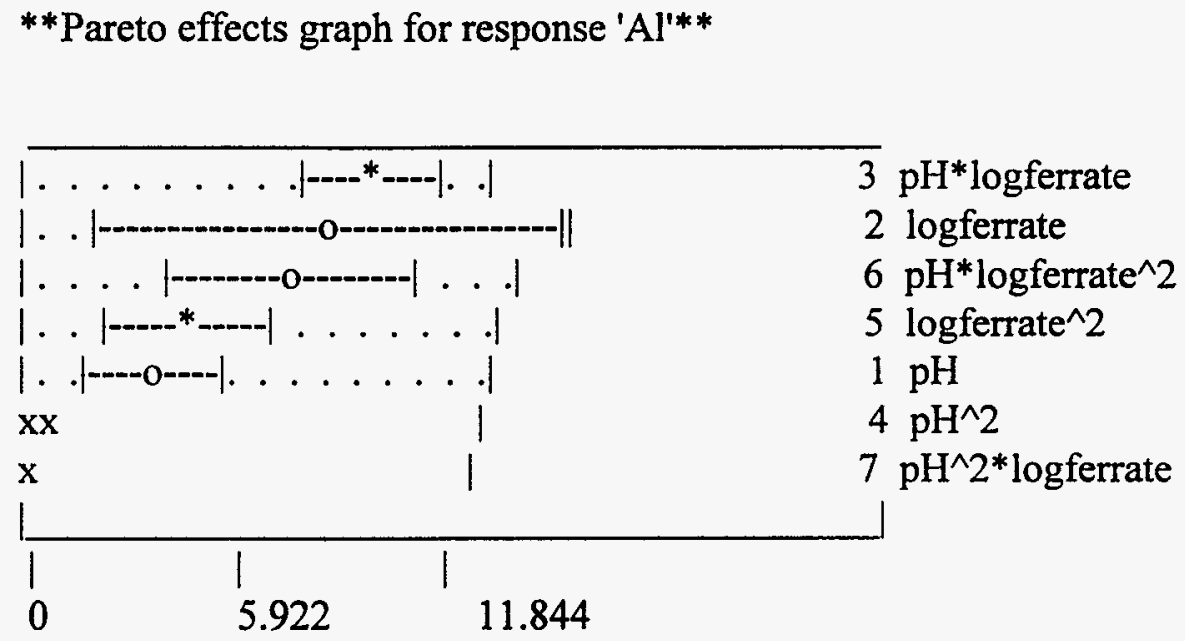

Results of the computer analysis of Phase II data show that all the COCs except selenium are removed by the ferrate treatment process. By inspection of the response surfaces in Appendix $F$ it appeared that concentrations below the CWQCC discharge limits were achieved in a common region of all the elements, except for selenium and possibly silver.

The final step of the analysis of Phase II results was to determine the optimum treatment conditions using the corrected radionuclide data. Again the objective of this optimum search was to determine if there is a single set of treatment conditions that would produce treated water in which all of the COCs are below the CWQCC discharge limits. This was done by combining the responses using the same weighting factor used when the uncorrected data was optimized. Figure 4.2.2-7 shows the combined response graph and the optimum point picked by searching the region where the combined response was less than 0.06 . The optimum conditions selected from this figure are $\mathrm{pH} 10.2$ and logferrate 1.36 ( $22.9 \mathrm{mg} / \mathrm{l} 45 \%$ potassium ferrate ). This point 


\begin{tabular}{llr}
\hline Potassium Ferrate Treatment & Document Number: & RF/ER-94-0028.UN \\
of RFETS Groundwater & Section: & 4.0, Rev. 0 \\
& Page: & 26 of 40 \\
\hline
\end{tabular}

Figure 4.2.2-6 Aluminum Response to Ferrate Treatment

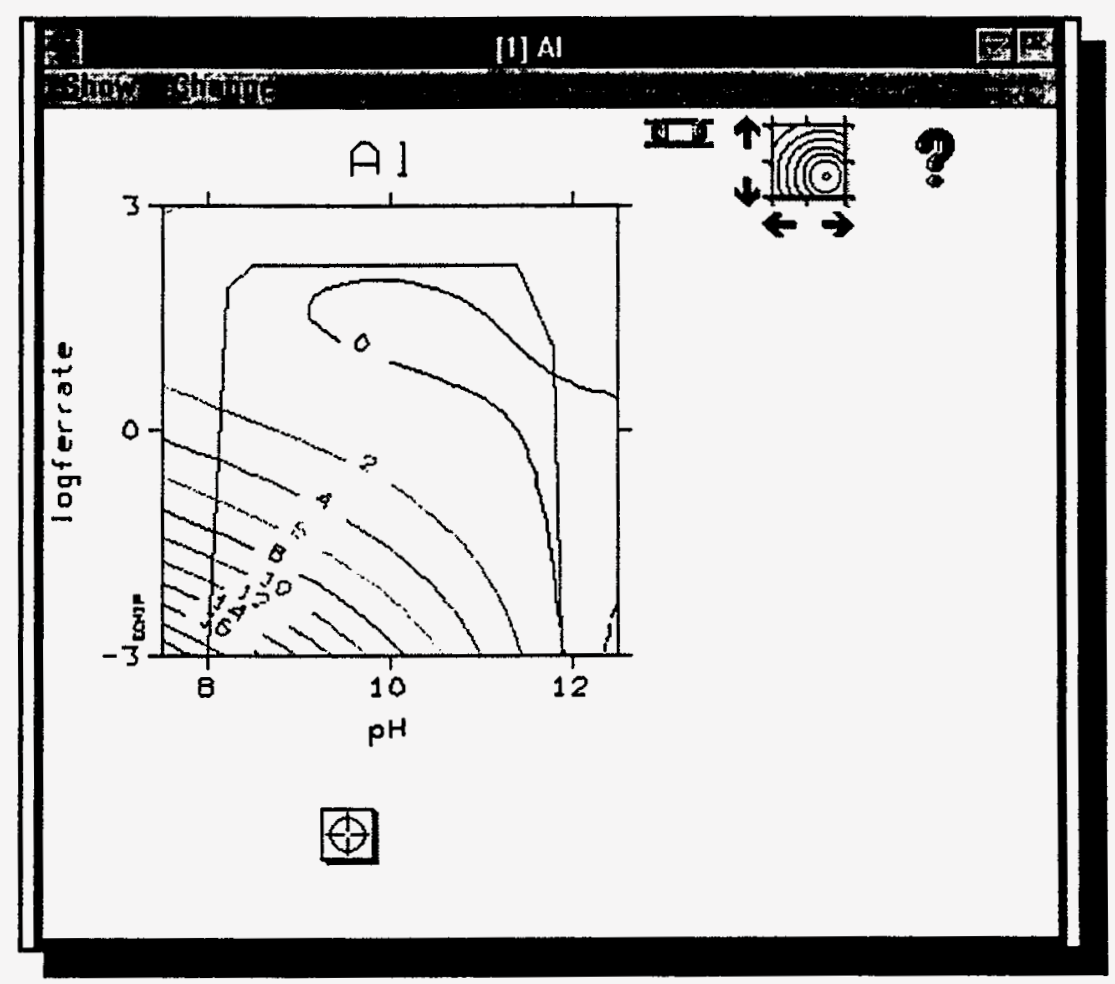

was picked to minimize reagent consumption of reagents and still yield acceptable responses of the majority of the elements. At this point the calculated combined response is 0.54 . It is not possible to say that all the contaminants met their individual limits. Therefore, as before, the optimum condition was checked for each of the element on their response plots to determine the concentration of the COCs that can be expected from treatment with these conditions. The results are shown in Table 4.2.2-1.

In Table 4.2.2-1 there are 13 elements where the predicted results are below the CWQCC discharge limits. Four additional the elements have CWQCC discharge parameters below the 


\begin{tabular}{llr}
\hline Potassium Ferrate Treatment & Document Number: & RF/ER-94-0028.UN \\
of RFETS Groundwater & Section: & 4.0, Rev. 0 \\
& Page: & 27 of 40 \\
\hline
\end{tabular}

Figure 4.2.2-7 Combined Response Surface of Corrected Phase II Responses

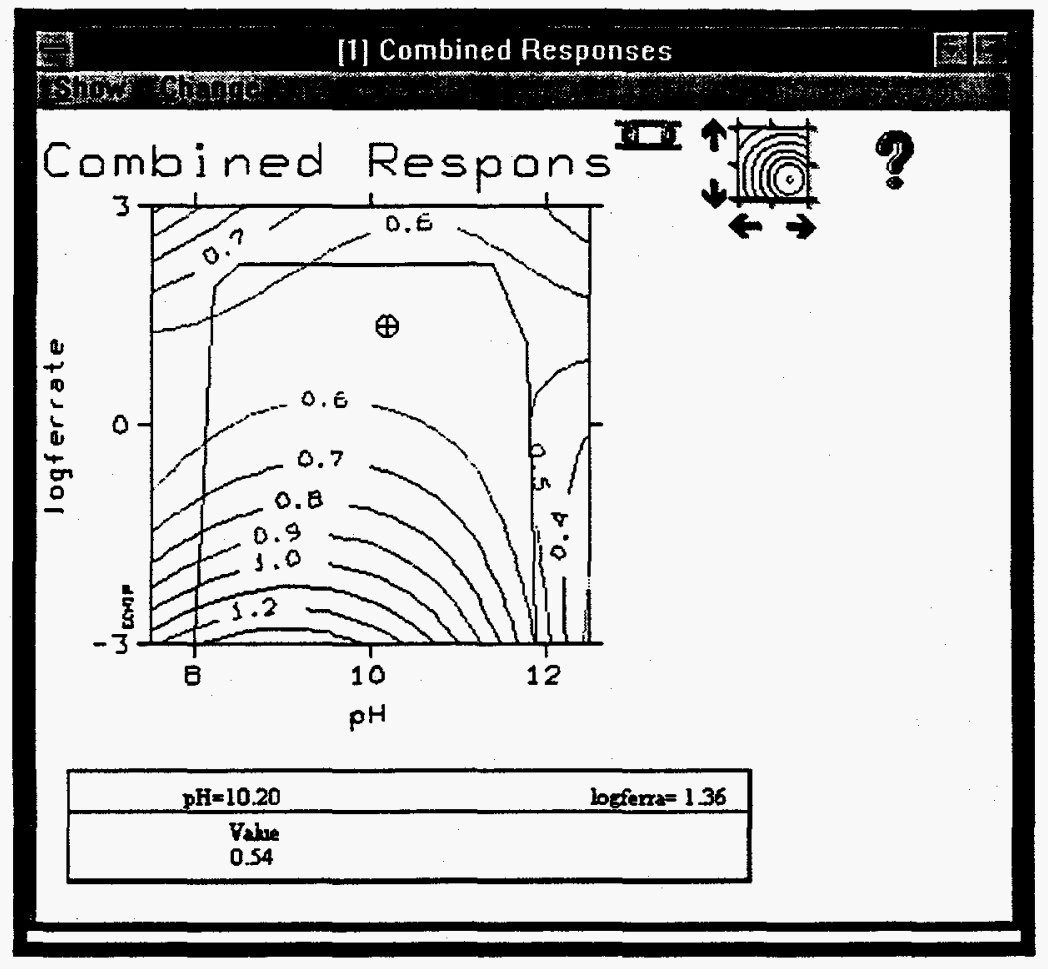

analytical detection limits; therefore, it is not known if the discharge limits were met. The predicted concentrations of plutonium, selenium and silver water are above the CWQCC discharge limits. However, the $95 \%$ confidence range is rather broad, meaning that the elements predicted value has a $95 \%$ probability that it falls within a range meeting CWQCC discharge limits. Therefore, test are required to confirm these predicted values. The results do show, however, that ferrate water treatment technology when applied to the RFETS groundwater will produce treated water meeting most of the CWQCC discharge limits. 
Potassium Ferrate Treatment of RFETS Groundwater
Document Number:

Section:

Page:
RF/ER-94-0028.UN

4.0, Rev. 0

28 of 40

Table 4.2.2-1 Predicted Contaminant Concentration at the Optimum Treatment Conditions

\begin{tabular}{|c|c|c|c|c|c|c|}
\hline & \multicolumn{3}{|c|}{ Predicted Results } & & \multirow{3}{*}{$\begin{array}{c}\text { CWQCC } \\
\text { Discharge } \\
\text { Limits }\end{array}$} & \multirow{3}{*}{$\begin{array}{c}\text { Meets } \\
\text { Discharge } \\
\text { Limits }\end{array}$} \\
\hline & \multirow{2}{*}{$\begin{array}{c}\text { At } \\
\text { Optimum }\end{array}$} & \multicolumn{2}{|c|}{$95 \%$ Confidence } & & & \\
\hline Elements & & Low Level & High Level & Units & & \\
\hline Americium & 0.027 & -0.090 & 0.143 & $\mathrm{pCi} / 1$ & 0.05 & Yes \\
\hline Plutonium & 0.36 & -0.69 & 1.41 & $\mathrm{pCi} / 1$ & 0.05 & No \\
\hline Uranium & 0.0118 & -0.0028 & 1.41 & $\mathrm{mg} / \mathrm{l}$ & & Yes \\
\hline $\mathrm{U}($ Calc $)$ & 0.393 & -0.0924 & 46.95 & $\mathrm{pCi} / 1$ & $5-10$ & Yes \\
\hline Aluminum & -0.14 & -1.14 & 0.86 & $\mathrm{mg} / \mathrm{l}$ & 0.087 & Yes \\
\hline Barium & -0.005 & -0.033 & 0.023 & $"$ & 1 & Yes \\
\hline Chromium & 0.0001 & -0.033 & 0.0092 & $"$ & 0.05 & Yes \\
\hline Cobalt & -0.0015 & -0.0171 & 0.014 & 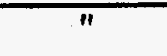 & 0.05 & $\overline{Y e s}$ \\
\hline Copper & -0.0001 & -0.0114 & 0.0111 & $\bar{~}$ & NA & -- \\
\hline Iron & -0.12 & -0.37 & 0.14 & $"$ & 0.3 & Yes \\
\hline Selenium & 0.0605 & 0.0534 & 0.0676 & $"$ & 0.01 & No \\
\hline Silver & 0.0048 & -0.0031 & 0.0127 & " & 0.0006 & No \\
\hline Zinc & -0.0007 & -0.0044 & 0.0031 & $"$ & 0.35 & Yes \\
\hline \multicolumn{3}{|c|}{ Element Reported Below ADL } & \multicolumn{2}{|c|}{$\begin{array}{l}\text { Analytical Detection } \\
\text { Limits (ADL) mg/l }\end{array}$} & & \\
\hline Beryllium & & & \multicolumn{2}{|c|}{0.005} & 0.004 & $?$ \\
\hline Cadmium & & & \multicolumn{2}{|c|}{0.005} & 0.002 & $?$ \\
\hline Manganese & & & \multicolumn{2}{|c|}{0.005} & 0.56 & Yes \\
\hline Nickel & & & \multicolumn{2}{|c|}{0.02} & 0.125 & Yes \\
\hline Vanadium & & & \multicolumn{2}{|c|}{0.005} & 0.1 & Yes \\
\hline Antimony & & & \multicolumn{2}{|c|}{0.05} & 0.024 & $?$ \\
\hline Arsenic & & & \multicolumn{2}{|c|}{0.005} & $\overline{\mathrm{NA}}$ & $\overline{---}$ \\
\hline Lead & & & \multicolumn{2}{|c|}{0.005} & 0.028 & Yes \\
\hline Mercury & & & \multicolumn{2}{|c|}{0.0001} & 0.00001 & $?$ \\
\hline
\end{tabular}




\begin{tabular}{llr}
\hline Potassium Ferrate Treatment & Document Number: & RF/ER-94-0028.UN \\
of RFETS Groundwater & Section: & 4.0, Rev. 0 \\
& Page: & 29 of 40 \\
\hline \hline
\end{tabular}

The element selenium did not respond to this process since it exists as an anion in these solutions. Selenium as an anion cannot form an insoluble solid phase under these conditions; therefore, it cannot be expected to be removed by this water treatment method because the technique depends upon the formation of a solid phase containing the contaminant of concern. Selenium can be changed, by a simple pretreatment step, into a form that can be removed by the treatment process tested in this study.

Silver, the other element that was not removed satisfactorily, can be eliminated by a minor modification to the process. In this test program, thiosulfate was used to reduce excess ferrate and it was the thiosulfate which caused the silver to remain in solution. Silver forms a strong soluble complex of thiosulfate which would prevent the precipitation of a solid silver compound. This problem can be overcome by using a reductant that does not complex any of the COCs. Sulfurous acid, $\mathrm{SO}_{2}$ dissolved in water, would be a suitable alternative.

Phase III tests were performed at slightly different conditions than the optimum picked from the corrected combined response surface. The predicted concentrations at the treatment conditions used were determined from the response surface with the corrected results and tabulated in Table 4.2.2-2. It can be seen by comparing the data in Table 4.2.2-1 and 4.2.2-2 that Phase III tests were not conducted at the optimum conditions in that every predicted COCs concentration at the Phase III test conditions are higher than those predicted at the optimum conditions. 
Potassium Ferrate Treatment of RFETS Groundwater
Document Number:

Section:

Page:
RF/ER-94-0028.UN

4.0, Rev. 0

30 of 40

Table 4.2.2-2 Predicted Results at Phase III Treatment Conditions Using the Corrected Data

Response Surface Model

\begin{tabular}{|c|c|c|c|c|c|c|}
\hline & \multicolumn{3}{|c|}{ Predicted Results } & & \multirow{3}{*}{$\begin{array}{c}\text { CWQCC } \\
\text { Discharge } \\
\text { Limits }\end{array}$} & \multirow{3}{*}{$\begin{array}{c}\text { Meets } \\
\text { Discharge } \\
\text { Limits }\end{array}$} \\
\hline & \multirow{2}{*}{$\begin{array}{c}\text { At } \\
\text { Optimum }\end{array}$} & \multicolumn{2}{|c|}{$95 \%$ Confidence } & & & \\
\hline Elements & & Low Level & High Level & Units & & \\
\hline Americium & 0.029 & -0.092 & 0.15 & $\mathrm{pCi} / 1$ & 0.05 & Yes \\
\hline Plutonium & 0.47 & -0.62 & 1.56 & $\mathrm{pCi} / 1$ & 0.05 & No \\
\hline Uranium & 0.0164 & 0.0013 & 0.0315 & $\mathrm{mg} / 1$ & & Yes \\
\hline $\mathrm{U}(\mathrm{Calc})$ & 0.546 & 0.0433 & 1.049 & $\mathrm{pCi} / \mathrm{l}$ & $5-10$ & Yes \\
\hline Aluminum & -0.01 & -1.08 & 1.03 & $\mathrm{mg} / \mathrm{l}$ & 0.087 & Yes \\
\hline Barium & 0.006 & -0.023 & 0.035 & $"$ & 1 & Yes \\
\hline Chromium & 0.0004 & -0.008 & 0.0089 & " & 0.05 & Yes \\
\hline Cobalt & -0.007 & -0.0169 & 0.0155 & $"$ & 0.05 & Yes \\
\hline Copper & 0.0009 & -0.0108 & 0.0126 & $"$ & $\mathrm{NA}$ & $-\cdots$ \\
\hline Iron & -0.13 & -0.039 & 0.13 & $"$ & 0.3 & Yes \\
\hline Selenium & 0.0609 & 0.0536 & 0.0683 & $"$ & 0.01 & No \\
\hline Silver & 0.0043 & -0.0036 & 0.0122 & $"$ & 0.0006 & No \\
\hline Zinc & -0.0005 & -0.0044 & 0.0034 & $"$ & 0.35 & Yes \\
\hline \multicolumn{3}{|c|}{ Element Reported Below ADL } & \multicolumn{2}{|c|}{$\begin{array}{l}\text { Analytical Detection } \\
\text { Limits (ADL) mg/l }\end{array}$} & & \\
\hline Beryllium & & & 0.0 & & 0.004 & $?$ \\
\hline Cadmium & & & 0.0 & & 0.002 & $?$ \\
\hline Manganese & & & 0.0 & & 0.56 & Yes \\
\hline Nickel & & & 0.0 & & 0.125 & Yes \\
\hline Vanadium & & & 0.0 & & 0.1 & Yes \\
\hline Antimony & & & 0.0 & & 0.024 & $?$ \\
\hline Arsenic & & & 0.0 & & $\mathrm{NA}$ & -- \\
\hline$\overline{\text { Lead }}$ & & & 0.0 & & 0.028 & Yes \\
\hline Mercury & & & 0.00 & & 0.00001 & $?$ \\
\hline
\end{tabular}


Potassium Ferrate Treatment of RFETS Groundwater
Document Number:

Section:

Page:
RF/ER-94-0028.UN

4.0, Rev. 0

31 of 40

\subsubsection{Conclusions from Phase II Tests}

A major conclusion from Phase II was that ferrate effectively removed or aided in the removal of the COCs from the RFETS groundwater except selenium. The ferrate treatment process produces treated water that meets or very closely approaches the CWQCC discharge limits. The technology is simple and easy to apply in conventional water treatment plants. Other conclusions from this phase of the work are:

1) There is a single combination of $\mathrm{pH}$ and ferrate addition that can be used to eliminate the COCs from the RFETS groundwater and meet all but three of the CWQCC discharge limits.

2) Ferrate alone removes some elements from solution such as americium and plutonium.

3) High $\mathrm{pH}$ alone was effective in removing uranium from the groundwater.

4) Many elements respond to both $\mathrm{pH}$ and ferrate and/or their interaction, such as chromium, cobalt, copper and others. 
Potassium Ferrate Treatment of RFETS Groundwater
Document Number:

Section:

Page:
RF/ER-94-0028.UN

4.0, Rev. 0

32 of 40

\subsection{PHASE III RESULTS AND DISCUSSION}

Results of Phase II were very encouraging. The ECHIP mathematically calculated response surfaces, from the Phase II modified test matrix, predicted that for 12 of the 19 COCs their concentrations in water treated with potassium ferrate will be below the CWQCC discharge limits. For four of the elements the analytical detection limits were greater than the CWQCC discharge limits, so it is not certain if ferrate treatment reduced their concentrations enough to meet the discharge requirements. Plutonium, selenium and silver failed to meet the discharge limits as predicted by the combined surface model. The possible reasons for the lack of response of these element were discussed in Section 4.2 of this report.

Phase III was conducted to confirm that ferrate treated water would be as clean as predicted in Phase II (Table 4.2.2-2). Some preliminary engineering data were also obtained in this phase of the study. The Phase II combined response surface (Combined Response Contour plot Figure 4.2.2-7) shows a rather large area where the combined response (removal of the COCs) is less than 0.6 and a much smaller area where the combined response is less than 0.5 . Treatment at points in the $<0.5$ zone would yield the best overall removal of the COCs. However, raising the $\mathrm{pH}$ to over 12 so as to be in the $<0.5$ response zone and then neutralizing the treated water back to $\mathrm{pH} \mathrm{7,} \mathrm{for} \mathrm{discharge,} \mathrm{would} \mathrm{greatly} \mathrm{increase} \mathrm{the} \mathrm{dissolved} \mathrm{solids} \mathrm{in} \mathrm{the} \mathrm{treated} \mathrm{water} \mathrm{and}$ consume large amounts of reagents. Rather than select the technical optimum (combined response $<0.5$ ) a more practical economic optimum was selected. The practical optimum will produce water with acceptable COCs concentrations and minimize the amount of reagents required, lowering the overall treatment costs. The zone $<0.6$ to $>0.5$ was examined to find a point that would minimize reagents and still yield acceptable results. The optimum point picked using the uncorrected analytical results was at a $\mathrm{pH}$ of 10.35 with potassium ferrate addition of $10.5 \mathrm{mg} / \mathrm{l}$ ( $\log$ ferrate 1.02 ). The Phase III test plan was to simply perform several tests at the 


\begin{tabular}{llr}
\hline Potassium Ferrate Treatment & Document Number: & RF/ER-94-0028.UN \\
of RFETS Groundwater & Section: & 4.0, Rev. 0 \\
& Page: & 33 of 40 \\
\hline
\end{tabular}

optimum treatment conditions. In this phase four tests were performed in order to statistically analyze the results and detect any significant differences in the tests results.

The Phase III test conditions were:
1) $\mathrm{pH} 10.35$
2) $10.5 \mathrm{mg} / \mathrm{l} 45 \%$ potassium ferrate (log ferrate 1.02 )
3) $20 \mathrm{mg} / \mathrm{l} \mathrm{alum}$
4) $5 \mathrm{mg} / \mathrm{l}$ polymer

These tests were run as described in Section 3.3.3, except thiosulfate was added in two steps, allowing 15 minutes of mixing after each addition. As in the previous tests, an aliquot of the treated water was decanted from the settled solids into clean plastic bottles, sealed and submitted to Accu-Labs for chemical analysis.

\subsubsection{Preliminary Engineering Data}

In addition, several measurements were made to gather preliminary engineering data. The settling rate of the solids was measured as well as the volume of the settled solids. These two measurements were made using an Imhoff settling cone. After decanting the majority of the treated water from the beakers, into analytical sample containers, there was not enough slurry to conduct a settling test on individual test runs. Therefore, slurries from two tests were combined and then the settling rate and the settled solids volume determined. These measurements were done twice. Settling rate was measured, after the slurry was poured into the cone, by timing the drop of the solid/clear water interface and reporting the results in inches per minute. The Imhoff cone is calibrated at the bottom, in milliliters, so the volume of settled solids was read directly from this scale. The volume was measured at timed intervals until the volume of solids became 
Potassium Ferrate Treatment of RFETS Groundwater
Document Number:

Section:

Page:
RF/ER-94-0028.UN

4.0, Rev. 0 34 of 40

constant. The settled solids from the two tests were combined and then filtered to make an assessment of their filterability. It was not possible to conduct a filtration test because of the small volume of the settled solids available. Finally, the solids from all eight liters of groundwater treated in Phase III were dried, weighed and submitted to Accu-Lab for chemical analysis. Table 4.3-1 presents the analytical results (Appendix C) of the treated water from the four test and the combined dried solid from the four tests.

The preliminary engineering data gathered during Phase III were:

1) The settling rate of the flocculated solids was 2.5 inches per minute (average of two tests).

2) The solution above the settled solids was cloudy, but it cleared at an approximate rate of 0.05 inches per minute.

3) Solids compacted completely in 8 to 10 minutes to $17.25 \mathrm{ml}$ per liter of treated solution or 2.31 cubic feet per 1000 gallons of treated water. This settled slurry was 13 percent solids (average of two tests).

4) The settled solids filtered rapidly; much faster than expected of water treatment sludge. Based on experience the rate was such that excessive filter surface area will not be required in a treatment plant.

5) The weight of dry solids recovered was $1.25 \mathrm{gm} / 1$ of treated water or 10.45 pounds per 1000 gallons of treated water. 


\begin{tabular}{llr}
\hline Potassium Ferrate Treatment & Document Number: & RF/ER-94-0028.UN \\
of RFETS Groundwater & Section: & 4.0, Rev. 0 \\
& Page: & 35 of 40 \\
\hline
\end{tabular}

A one liter sample of treated water produced $1.25 \mathrm{gm}$ of solids. Only $0.0355 \mathrm{gm}$ of reagents were added per liter of treated water. Assuming all of the reagents added to the water in the tests were recovered in the solids, then $96.8 \%$ of that weight was formed by clarification and precipitation of the contaminants in the groundwater. Potassium ferrate and alum both form metal hydroxides in the system which are lighter than the reagents. Therefore, solids formed from the reagents would weigh less. For example, alum $\left(\mathrm{Al}_{2}\left(\mathrm{SO}_{4}\right)_{3}\right)$ will form $\mathrm{Al}(\mathrm{OH})_{3}$ which weighs only $22.8 \%$ of the alum. If the weight loss of both these reagents is considered, it can then be said that $99.0 \%$ of the weight of the recovered solids are from the ground water.

Using the laboratory test procedures and this preliminary engineering information, a generalized flowsheet and material balance can be generated. A condensed flowsheet is presented in Figure 4.3.1-1. The potassium hydroxide $(\mathrm{KOH})$ addition was not measured, but the $\mathrm{pH}$ was monitored, so an estimate of the consumption can be made. It was estimated that about $0.65 \mathrm{lb}$ of $\mathrm{KOH}$ will be required to treat 1000 gal of groundwater. The other reagent consumption's are based upon the amounts used in the tests. The filtered solid waste was assumed to be $50 \%$ moisture for the material balance. Overall, treating $1000 \mathrm{gal}$ of RFETS contaminated groundwater with the ferrate process will produce $20.9 \mathrm{lb}$ of wet waste material.

\subsubsection{Phase III Potassium Ferrate Demonstration Results}

The analytical results of the treated water are presented in Table 4.3.2-1 along with the averages of the four tests and the analysis of the dried solids recovered from the four tests.

All of the radionuclides were removed well below the CWQCC discharge limits and well below the predicted concentrations from any of the models developed in Phase II. Iron's results were 
Potassium Ferrate Treatment of RFETS Groundwater
Document Number:

Section:

Page:
RF/ER-94-0028.UN

4.0 , Rev. 0

36 of 40

Figure 4.3.1-1 General Flowsheet for Ferrate Treatment of RFETS Contaminated Groundwater

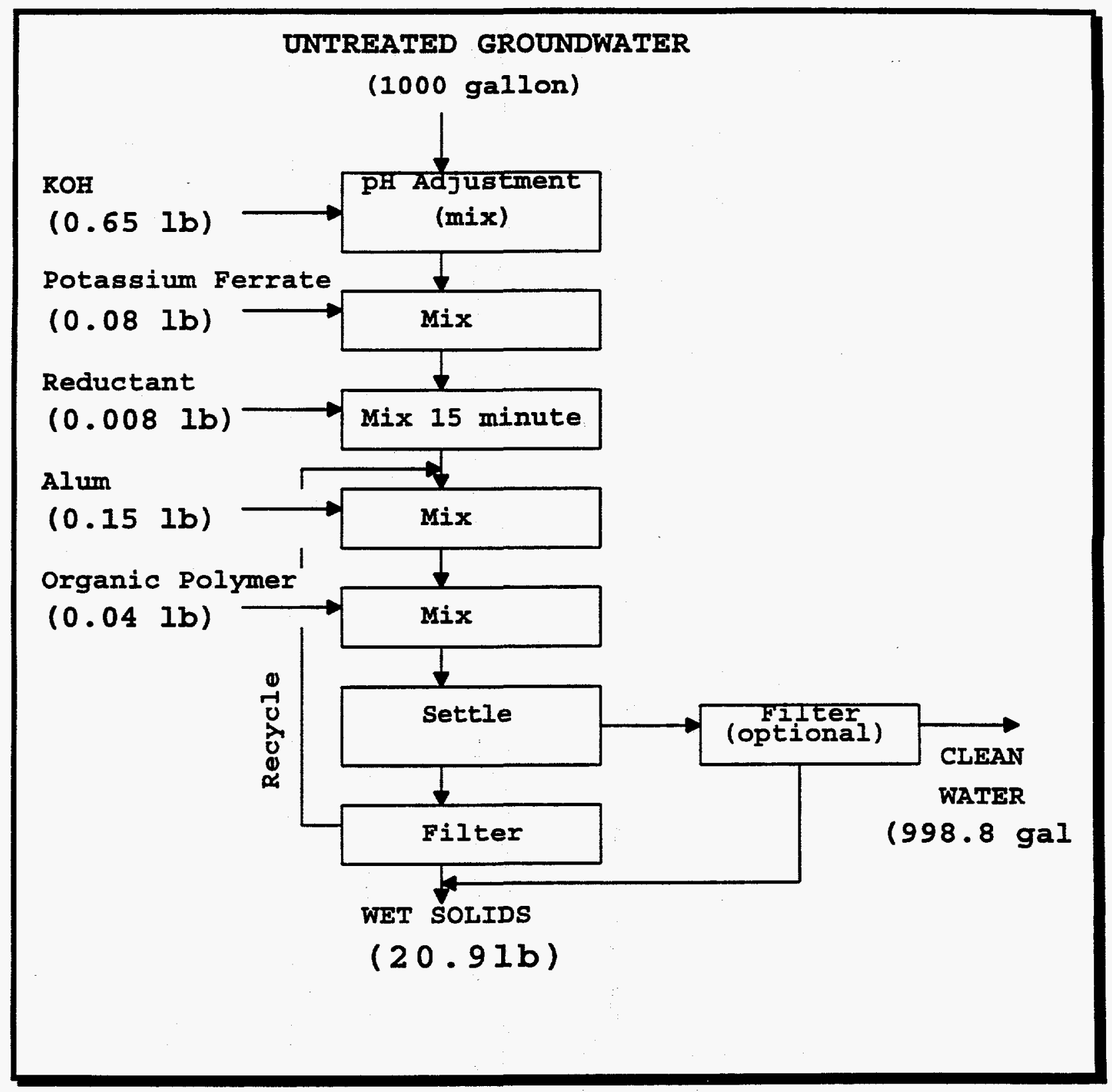


Potassium Ferrate Treatment of RFETS Groundwater
Document Number:

Section:

Page:
RF/ER-94-0028.UN

4.0 , Rev. 0

37 of 40

Table 4.3.2-1 Results of the Phase III Ferrate Treatment Tests at the Optimum Conditions

\begin{tabular}{|c|c|c|c|c|c|c|}
\hline & \multicolumn{4}{|c|}{ Treated Water Analysis } & & \multirow{2}{*}{$\begin{array}{c}\text { Dried } \\
\text { Solids } \\
\text { Analysis }\end{array}$} \\
\hline Element & Test No. 1 & Test No. 2 & Test No. 3 & Test No. 4 & Average & \\
\hline Radionuclide & $\mathrm{pCi} / \mathrm{l}$ & $\mathrm{pCi} / \mathrm{l}$ & $\mathrm{pCi} / 1$ & $\mathrm{pCi} / 1$ & $\overline{\mathrm{pCi} / \mathrm{l}}$ & $\mathrm{pCi} / \mathrm{gm}$ \\
\hline Am 241 & 0.00 & -0.02 & 0.00 & 0.00 & 0.00 & $1.7+/-0.72$ \\
\hline $\mathrm{Pu} \mathrm{239/240}$ & 0.02 & 0.04 & 0.04 & 0.03 & 0.0325 & $7.7+/-1.4$ \\
\hline Uranium & $0.0013 \mathrm{mg} / \mathrm{l}$ & $0.0016 \mathrm{mg} / \mathrm{l}$ & $0.0017 \mathrm{mg} / \mathrm{l}$ & $0.0018 \mathrm{mg} / \mathrm{l}$ & $0.0016 \mathrm{mg} / 1$ & $31 \mathrm{ug} / \mathrm{gm}$ \\
\hline \multirow[t]{2}{*}{ U-calculated } & $0.043 \mathrm{pCi} / 1$ & $0.053 \mathrm{pCi} / 1$ & $0.057 \mathrm{pCi} / 1$ & $0.060 \mathrm{pCi} / 1$ & $0.053 \mathrm{pCi} / 1$ & \\
\hline & $\mathrm{mg} / \mathrm{l}$ & $\mathrm{mg} / \mathrm{l}$ & $\mathrm{mg} / \mathrm{l}$ & $\mathrm{mg} / \mathrm{l}$ & $\mathrm{mg} / \mathrm{l}$ & $\mathrm{mg} / \mathrm{kg}$ \\
\hline Silver & $<0.005$ & $<0.005$ & $<0.005$ & $<0.005$ & $<0.005$ & 21 \\
\hline Aluminum & $<0.1$ & $<0.1$ & $<0.1$ & $<0.1$ & $<0.1$ & 15,000 \\
\hline Barium & $<0.05$ & $<0.05$ & $<0.05$ & $<0.05$ & $<0.05$ & 150 \\
\hline Beryllium & $<0.005$ & $<0.005$ & $<0.005$ & $<0.005$ & $<0.005$ & 1.0 \\
\hline Cadmium & $<0.005$ & $<0.005$ & $<0.005$ & $<0.005$ & $<0.005$ & 0.6 \\
\hline Cobalt & $<0.01$ & $<0.01$ & $<0.01$ & $<0.01$ & $<0.01$ & 6 \\
\hline Chromium & $<0.005$ & $<0.005$ & $<0.005$ & $<0.005$ & $<0.005$ & 17 \\
\hline Copper & $<0.005$ & $<0.005$ & $<0.005$ & $<0.005$ & $<0.005$ & 27 \\
\hline Iron & 0.02 & 0.02 & 0.02 & 0.02 & 0.02 & 15,000 \\
\hline Manganese & $<0.005$ & $<0.005$ & $<0.005$ & $<0.005$ & $<0.005$ & 200 \\
\hline Mo & $<0.01$ & $<0.01$ & $<0.01$ & $<0.01$ & $<0.01$ & 1 \\
\hline Nickel & $<0.05$ & $<0.05$ & $<0.05$ & $<0.05$ & $<0.05$ & 18 \\
\hline Antimony & $<0.05$ & $<0.05$ & $<0.05$ & $<0.05$ & $<0.05$ & $<5$ \\
\hline Selenium & 0.056 & 0.055 & 0.056 & 0.058 & 0.0562 & $<5$ \\
\hline Thallium & $<0.5$ & $<0.5$ & $<0.5$ & $<0.5$ & $<0.5$ & $<50$ \\
\hline Vanadium & $<0.005$ & $<0.005$ & $<0.005$ & $<0.005$ & $<0.005$ & 25 \\
\hline Zinc & $<0.005$ & $<0.005$ & $<0.005$ & $<0.005$ & $<0.005$ & 60 \\
\hline Arsenic & $<0.005$ & $<0.005$ & $<0.005$ & $<0.005$ & $<0.005$ & 7.2 \\
\hline Mercury & $<0.0001$ & $<0.0001$ & $<0.0001$ & $<0.0001$ & $<0.0001$ & $<0.1$ \\
\hline Lead & $<0.005$ & $<0.005$ & $<0.005$ & $<0.005$ & $<0.005$ & 11 \\
\hline
\end{tabular}

* Uranium $\mathrm{pCi} / \mathrm{l}$ calculated using the relationship $1 \mathrm{pCi} / \mathrm{l}=0.03 \mathrm{mg} / \mathrm{l}$ 


\begin{tabular}{llr}
\hline $\begin{array}{l}\text { Potassium Ferrate Treatment } \\
\text { of RFETS Groundwater }\end{array}$ & Document Number: & RF/ER-94-0028.UN \\
& Section: & 4.0, Rev. 0 \\
& Page: & 38 of 40 \\
\hline \hline
\end{tabular}

greater than predicted. All of the other element's the results were so low they were all below the analytical detection limits.

It appears from this data that all of the COCs concentration in treated water from this process will be below CWQCC discharge limits with the exception of selenium and possibly silver. For both of these elements a simple pretreatment of the water with a reductant, such as zinc, will ensure that they too will meet the CWQCC discharge limits.

\subsubsection{Discussion of the Statistical Implications of Phase III Results}

In the previous phases of this study the ECHIP software did the statistical analysis of the results. In this phase some discussion of the statistics are also necessary because there are some implications upon the conclusions from this work.

Calculations of the standard deviation of four elements where there is sufficient data show that the overall treatment error is very small. This includes both treatment testing error and analytical error. In fact, the results indicate that the overall error is much lower than the reported analytical error. If three times the standard deviation is added to the average results the total is below the CWQCC discharge limits. Interpreting this data indicates that at these treatment conditions there is a $99 \%$ assurance that the treated water will meet the discharge limits. The treated water concentrations and three times the SD of the four COCs are presented below:

$3 \times$ SD

$\begin{array}{lll}\mathrm{Am} & 0.00 \mathrm{pCi} / \mathrm{l} & +/-0.005 \mathrm{pCi} / 1 \\ \mathrm{Pu} & 0.0325 \mathrm{pCi} / 1 & +/-0.029 \mathrm{pCi} / 1 \\ \mathrm{U} & 0.053 \mathrm{pCi} / 1 & +/-0.022 \mathrm{pCi} / 1 \\ \mathrm{Fe} & 0.02 \mathrm{mg} / 1 & +/-0.005 \mathrm{mg} / 1\end{array}$




\begin{tabular}{llr}
\hline Potassium Ferrate Treatment & Document Number: & RF/ER-94-0028.UN \\
of RFETS Groundwater & Section: & 4.0, Rev. 0 \\
& Page: & 39 of 40 \\
\hline \hline
\end{tabular}

This means that the treatment process will always meet the discharge limits for these elements and it can be assumed that the same accuracy applies to all the other elements that meet the discharge limits but are below the analytical detection limits in the Phase III results.

With the exception of selenium it seems reasonable that all of the COCs will be below the CWQCC discharge limits. This is based upon the fact that the actual Phase III results for the three radionuclides are at least one order of magnitude lower than the predicted concentrations using the ECHIP software. It is estimated that this same effect was experienced by the other COCs and their concentrations should have been well below CWQCC discharge limits. The reason that the results from Phase III are so much better than predicted from previous work is not clear; however one could postulate that the interaction effects at or near the optimum treatment condition are much more important than could be determined by testing over such a broad range of the test variables. This is especially true for uranium were it appeared that only $\mathrm{pH}$ effected its' removal. Results from these tests are much better than Phase II results would predict based upon $\mathrm{pH}$ removal only.

\subsubsection{Conclusion from Phase III Tests}

The results from the four tests were spectacular in that the removal of the COCs was much better than predicted for all of the elements, even silver. Also, the agreement of the analytical results (Table 4.3.2-1) between the four tests was excellent indicating the process is not very sensitive to minor variations and should be a relatively easy process to operate and control.

It also can be concluded from this phase of the work that the combined surface model developed in Phase II does predict the results of treatment conditions, but errors on the conservative side. In fact for the radionuclides the actual results are one order of magnitude less than predicted. 
Potassium Ferrate Treatment of RFETS Groundwater
Document Number:

Section:

Page:
RF/ER-94-0028.UN

4.0 , Rev. 0

40 of 40

Iron, the only other element where the data was above the analytical detection limit was within the $95 \%$ confidence limits of the predicted results. It must be remembered that iron has a lack of fit to the mathematical model used to generate the combined response surface. If the difference between the predicted concentration and the actual is true, in that the actual is one order of magnitude lower, then even silver would meet the CWQCC discharge limits. 
Potassium Ferrate Treatment of RFETS Groundwater
Document Number:

Section:

Page:
RF/ER-94-0028.UN

5.0 , Rev. 0

1 of 5

\subsection{QUALITY ASSURANCE/QUALITY CONTROL (QA/QC)}

Throughout this study many of the steps were subjected to QA/QC controls, some formal and others as a result of the testing procedures. In this section the QA/QC procedures will be enumerated and discussed.

\subsection{GROUNDWATER SAMPLING}

The groundwater was taken from the monitoring walls within the RFETS over several days. Sampling was done in accordance to the EG\&G operating procedure for groundwater sampling, OPS-GW-06, March 1992 by an EG\&G subcontractor.

\subsection{CHEMICAL ANALYSIS}

All of the chemical analysis were performed by Accu-Labs Research, Inc., Golden, Colorado. The EPA approved methods are listed in Table 1.0-2 along with the detection limits for these methods. Accu-Labs is a certified environmental analytical laboratory following all the required QAVQC protocols.

\subsection{COMPUTER MODELING}

A software program called ECHIP was used in this study to evaluate the results of the experiments. These results were the analytical determinations of the COCs in the treated water from the experiments. The other input to the program were the experimental variables used in 


\begin{tabular}{llr}
\hline $\begin{array}{l}\text { Potassium Ferrate Treatment } \\
\text { of RFETS Groundwater }\end{array}$ & Document Number: & RF/ER-94-0028.UN \\
& Section: & 5.0, Rev. 0 \\
& Page: & 2 of 5 \\
\hline
\end{tabular}

each test. Therefore, the boundaries of the model used were conditions established by the investigators which were well defined and no extraneous factors could have been introduced.

The spacing (grid) of the test variables was set at the limits of the range of the variable examined with one center point. The variables in the first phase of testing were $\mathrm{pH}$, amount of ferrate, alum and organic polymer added to the reactor. In the second phase of the study there were only two variables, $\mathrm{pH}$ and ferrate addition. Measurement of the variable was done by instrumentation ( $\mathrm{pH}$ meter) and weight or volume of dissolved reagents. All of these measurements were with in $+/-0.10 \%$.

The hardware needs for this program are those required for Windows ${ }^{\mathrm{TM}}$. These requirements are:

80386 (or higher) processor

$4 \mathrm{Mb}$ of RAM ( $640 \mathrm{~K}$ conventional +3456 extended)

$10.5 \mathrm{Mb}$ free hard disk space

VGA video graphics.

The software ECHIP is based upon a large body of literature of experimental design and statistics. This program is licensed to users by ECHIP Inc. and is copyrighted. For use in this study, the program was not modified in any way from the published version 6.0 .

The input information was only that generated in the laboratory or by the analytical laboratory. No assumptions were made in its application.

The output from the program are presented in Appendices D, E and F of this report and are clearly labeled. 
Potassium Ferrate Treatment of RFETS Groundwater
Document Number:

Section:

Page:
RF/ER-94-0028.UN

5.0 , Rev. 0 3 of 5

Verification that the program was installed and operating correctly was done by solving several sample problems provided with the software. Since the models and other features within the software are not unique there was no other verification made.

\subsection{INSTRUMENTATION}

An Orion $230 \mathrm{pH}$ meter was used to monitor the tests. This meter was calibrated each day and the standardization checked with a $\mathrm{pH} 10$ buffer each time a measurement was made. If the $\mathrm{pH}$ meter reading was $0.05 \mathrm{pH}$ units from 10 the meter was calibrated using the two point method, a common laboratory technique. The only other instrumentation used was the stirrer speed control. This was not calibrated or checked for accuracy. It was believed that since the unit used the electrical power frequency to calibrate itself no further calibrations were needed.

\subsection{LABORATORY TECHNIQUES}

Several procedures were followed when conducting this study to determine how well the program was performing and how consistent the results were from one phase of the program to the next since they were conducted several weeks apart.

First, an aliquot of the bulk groundwater sample was taken at the beginning of each phase of the study to determine if: 1) the mixing and sampling techniques of this bulk sample were adequate and 2) to insure that there was no change in the concentration of the COCs over the period of study (about three months) due to the growth of organisms or other factors. Table 1.2-2 shows the analysis of the bulk groundwater samples taken during each phase of the program. These data show that the mixing and sampling techniques used were consistent throughout the tests. 


\begin{tabular}{lcr}
\hline $\begin{array}{l}\text { Potassium Ferrate Treatment } \\
\text { of RFETS Groundwater }\end{array}$ & Document Number: & RF/ER-94-0028.UN \\
& Section: & 5.0, Rev. 0 \\
& Page: & 4 of 5 \\
\hline \hline
\end{tabular}

There were no changes in the concentration of the COCs over the several months when this study was conducted.

To assess the accuracy and precision of the analytical results and determine if the test methods used in this study were acceptable, a material balance was performed. In the last phase of the study the recovered solids and treated water were analyzed. Using these two analyses and the average analysis of the bulk solution it was possible to calculate a material balance for each of the COCs, shown in Table 5.5-1. These calculations show that the analytical data and experimental techniques were acceptable; especially, when considering the low concentrations of the contaminants where large deviations of analytical results are expected.

The material balance calculations in Table 5.5-1 were based upon the four two liter tests performed in Phase III. From these four tests 10.0 grams of dried solids and eight of liters of treated water were produced. The analysis of these products (Appendix $\mathrm{C}$ ) and the average analysis of the bulk sample (Table 1.2-2) were used for the calculations. When the analytical results were below the detection limits, zeros were used in the calculation. The column labeled "Material Balance" is the recovered mg of the elements divided by the initial mg times 100 . A value of $100 \%$ would confirm accountability for the total weight of each COCs constituent in the Phase III tests. The table displays material balances for each COCs between $72 \%$ and $231 \%$ with an average accountability of $108 \%$ for the total COCs group. The only poor material balance was for americium which was $231 \%$. When this value is removed, the average accountability is $100.4 \%$, which is exceptional. Removal of the americium balance is justified by statistics because it is beyond three standard deviations $(1 \mathrm{SD}=18.3 \%)$ of the average. 
Potassium Ferrate Treatment of RFETS Groundwater
Document Number:

Section:

Page:
RF/ER-94-0028.UN

5.0, Rev. 0

5 of 5

Table 5.5-1 Material Balance Calculations

\begin{tabular}{|c|c|c|c|c|c|c|c|c|}
\hline \multirow[t]{3}{*}{ Element } & \multicolumn{2}{|c|}{ Groundwater } & \multicolumn{2}{|c|}{ Treated Water } & \multicolumn{2}{|c|}{ Dried Solids } & \multirow{3}{*}{\begin{tabular}{|c|}
$\begin{array}{c}\text { Element } \\
\text { Recover }\end{array}$ \\
$\ldots$ \\
$\mathbf{m g}$ \\
\end{tabular}} & \multirow{3}{*}{\begin{tabular}{|c}
$\begin{array}{c}\text { Material } \\
\text { Balance }\end{array}$ \\
$\%$ \\
\end{tabular}} \\
\hline & \multicolumn{2}{|c|}{8 liters } & \multicolumn{2}{|c|}{8 liters } & \multicolumn{2}{|c|}{10.0 grams } & & \\
\hline & mg/l & mg & $\mathrm{mg} / \mathbf{l}$ & mg & $\mathrm{mg} / \mathrm{Kg}$ & mg & & \\
\hline Silver & 0.029 & 0.232 & $<0.005$ & 0.000 & 21 & 0.21 & 0.21 & 90.5 \\
\hline $\mathrm{Al}$ & 19.33 & 154.64 & $<0.1$ & 0.000 & 15,000 & 150 & 150 & 97.0 \\
\hline Barium & 0.247 & 1.967 & $<0.05$ & 0.000 & 150 & 1.5 & 1.5 & 76.3 \\
\hline $\mathrm{Be}$ & $<0.005$ & 0.000 & $<0.005$ & 0.000 & 1.0 & 0.01 & 0.01 & NA \\
\hline $\mathrm{Cd}$ & $<0.005$ & 0.000 & $<0.005$ & 0.000 & 0.6 & 0.006 & 0.006 & NA \\
\hline Cobalt & 0.0065 & 0.052 & $<0.01$ & 0.000 & 6 & 0.06 & 0.06 & 115.4 \\
\hline $\mathrm{Cr}$ & 0.0237 & 0.1896 & $<0.005$ & 0.000 & 17 & 0.17 & 0.17 & 89.7 \\
\hline Copper & 0.0273 & 0.2184 & $<0.005$ & 0.000 & 27 & 0.27 & 0.27 & 127.5 \\
\hline Iron & 20.0 & 160 & 0.02 & 0.16 & 15,000 & 150 & 150.16 & 93.8 \\
\hline $\mathrm{Mn}$ & 0.257 & 2.056 & $<0.005$ & 0.000 & 200 & 2.00 & 2.00 & 97.3 \\
\hline Mo & $<0.01$ & 0.000 & $<0.01$ & 0.000 & 1 & 0.01 & 0.01 & NA \\
\hline Nickel & $<0.05$ & 0.000 & $<0.01$ & 0.000 & 18 & 0.18 & 0.18 & $\mathrm{NA}$ \\
\hline $\mathrm{Sb}$ & $<0.05$ & 0.000 & $<0.05$ & 0.000 & $<5$ & 0.000 & 0.000 & $\mathrm{NA}$ \\
\hline $\mathrm{Se}$ & 0.042 & 0.336 & 0.0562 & 0.4496 & $<5$ & 0.000 & 0.4496 & 133.8 \\
\hline Th & $<0.5$ & 0.000 & $<0.1$ & 0.000 & $<50$ & 0.000 & 0.000 & NA \\
\hline $\mathrm{V}$ & 0.0433 & 0.3464 & $<0.005$ & 0.000 & 25 & 0.25 & 0.25 & 72.2 \\
\hline Zinc & 0.0867 & 0.6936 & $<0.005$ & 0.000 & 60 & 0.6 & 0.6 & 86.5 \\
\hline Arsenic & 0.010 & 0.080 & $<0.005$ & 0.000 & 7.2 & 0.072 & 0.072 & 90.0 \\
\hline Mercury & $<0.0001$ & 0.000 & $<0.0001$ & 0.000 & $<0.1$ & 0.000 & 0.000 & $\mathrm{NA}$ \\
\hline Lead & 0.0123 & 0.0984 & $<0.005$ & 0.000 & 11 & 0.11 & 0.11 & 111.8 \\
\hline \multicolumn{3}{|c|}{ Radionuclides } & & & & & & \\
\hline \multirow[t]{2}{*}{ Uranium } & 0.04 & 0.32 & 0.0016 & 0.013 & 31 & 0.31 & 0.323 & 100.9 \\
\hline & $\mathrm{pCi} / 1$ & $\mathrm{pCi}$ & $\mathrm{pCi} / \mathrm{l}$ & $\mathrm{pCi}$ & $\mathrm{pCi} / \mathrm{gm}$ & $\mathrm{pCi}$ & pCi tot. & \\
\hline Am & 0.92 & 7.36 & 0.00 & 0.00 & 1.7 & 17 & 17.0 & 231.0 \\
\hline $\mathrm{Pu}$ & 7.80 & 62.4 & 0.0325 & 0.26 & 7.7 & 77 & 77.26 & 123.8 \\
\hline
\end{tabular}




\begin{tabular}{llr}
\hline $\begin{array}{l}\text { Potassium Ferrate Treatment } \\
\text { of RFETS Groundwater }\end{array}$ & Document Number: & RF/ER-94-0028.UN \\
& Section: & References, Rev. 0 \\
& Page: & 1 of 1 \\
\hline
\end{tabular}

\section{REFERENCES}

1) $\mathrm{CDH} / \mathrm{WQCC}$, Colorado Water Quality Standards 3.1.0 (5 CCR 1002-6) 1/15/74; amended 10/17/1991 (ARAR).

2) Work Plan for Potassium Ferrate Treatment of RFP Ground Water, Rocky Flats Plant, Environmental Restoration Program, July 1994, RFP/ERM-94-00010.

3) U. S. DOE 1991, "1990 Annual RCRA Grounwater Monitoring Report for Regulated Units at Rocky Flats Plant, Golden, Colorado," March 1991.

4) U. S. DOE, 1991, "1991 Annual RCRA Groundwater Monitoring Report for Regulated Units at Rocky Flats Plant, Golden, Colorado," March 1992.

5) Stoupine, D.Y., Ozernol, M. I., "Application of Commercially Available Sodium Ferrate for Treatment of Especially Hazardous Industrial Waste Waters," Environmental Conference, Moscow, September 1994.

6) Waite, T. D. "Feasibility of Wastewater Treatment with Ferrate," Journal of the Environmental Engineering Division, ASCE, vol. 105, NEE6, pp 1023-1034, 1979.

7) Potts, M. E., Churchwell, D. R., "Removal of Radionulides in Wastewaters Utilizing Potassium Ferrate (VI)," Water Environment Research, vol. 66, pp 107-109, March-April, 1994.

8) "Treatability Study for the TRU/Clear ${ }^{\mathrm{TM}}$ Precipitation Process at the Rocky Flats Plant," Rev. 1, EG \& G Solicitation No. 221457BC, July, 1992. 
Potassium Ferrate Treatment of RFETS Groundwater

Document Number:

Section:
RF/ER-94-0028.UN

Appendix A, Rev. 0

Page: 1 of 13

\section{APPENDIX A}

ANALYTICAL REPORTS OF TREATED WATER FROM PHASE I TESTS 
4643 Thbit Mountoln Drive Colden, Colorado 80403-1650 (305) 277.9514

FAX (303) 277-9512

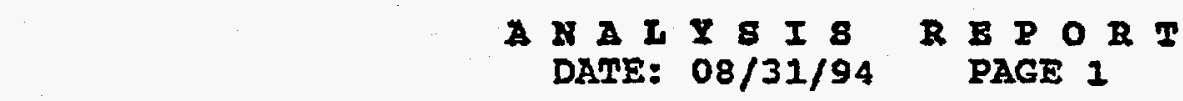

J.C. IAUL

EGEG ROCKY FIATS

ENVIRONMENTTAL TECEMYOLOGY SITE

$P$ O BOX 464 BIDG 881

GOLDEN, CO 80402-0464
Lab Job Number: 2426-56170-15

Date Samples Received: 08/22/94

Customer PO Number: ASC233268JO3

These samples to be disposed of 30 days after the date of this report.

\begin{tabular}{|c|c|c|c|c|c|c|c|}
\hline & $\begin{array}{l}\text { ALR designation - } \\
\text { sponsor Designazion - } \\
\text { Date Collected. . - }\end{array}$ & $\begin{array}{l}\text { 2626-56170-15-1 } \\
\text { FEED SOLUTION } \\
\end{array}$ & $\cdots$ & $\begin{array}{l}2426-56170-15 \\
21 \\
\ldots \quad: \ldots- \\
\end{array}$ & $\begin{array}{l}5-2 \\
\ldots \ldots \\
\end{array}$ & $\begin{array}{l}2626-56170-15 \cdot 3 \\
16 \\
\ldots \ldots \ldots \ldots\end{array}$ & $\begin{array}{l}2426-56170-95-4 \\
24 \quad- \\
\end{array}$ \\
\hline \multicolumn{8}{|c|}{ Determinations in $\mathrm{mo} / \mathrm{t}$ untesss roted } \\
\hline stiver - cotal & & 0.029 & & $\$ .005$ & & $\infty .005$ & 0.005 \\
\hline Atutrum - total & & 18 & & 0.7 & & 0.7 & $\infty .1$ \\
\hline Barium - total & & 0.23 & & 0.06 & & 0.06 & $\infty .05$ \\
\hline Beryllitu - totol & . & $\$ .005$ & & $<0.005$ & & $<0.005$ & $<0.005$ \\
\hline Calcium - total & & 130 & & 57 & & so & 1.2 \\
\hline Cectinis - total & & $<0.005$ & & $<0.005$ & & $\infty 0.005$ & $<0.005$ \\
\hline cobalt - total & & 0.007 & & $<0.005$ & & $<0.005$ & $<0.005$ \\
\hline Chromiun - totol & & a:020 & & $<0.005$ & & $<0.005$ & $<0.005$ \\
\hline Cesper - total & & 0.029 & & $<0.005$ & & $<0.005$ & $\$ 0.005$ \\
\hline Iron - totel & & 19 & & 0.03 & & 0.03 & 0.78 \\
\hline$\cdot$ & & & & & - & & \\
\hline Porassium - total & & 6.8 & & 100 & & 97 & 340 \\
\hline Lithium - total & & 0.15 & & 0.14 & & 0.15 & 0.14 \\
\hline Magnesium - total & & 30 & & 25 & & 26 & 0.12 \\
\hline Marganese - tatal & 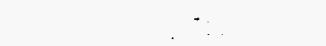 & 0.24 & & $<0.005$ & & $<0.005$ & $<0.005$ \\
\hline Holyboderum - total & & $<0.01$ & & $\$ 0.07$ & & 0.01 & $<0.01$ \\
\hline sodiun - total & & 150 & & 150 & & 150 & 140 \\
\hline Mickel - roral & $\therefore$ & 0.02 & & $<0.02$ & $\ddots$ & 0.02 & $\$ 0.02$ \\
\hline Antinomy - total & & $\infty .05$ & & $<0.05$ & & $<0.05$ & $<0.05$ \\
\hline selenium - total & & 0.06 & & 0.09 & & 0.08 & 0.08 \\
\hline That litu - totel & & $<0.7$ & & $<0.1$ & $=$ & $<0.1$ & $<0.1$ \\
\hline Vanedius - total & & 0.042 & & $<0.005$ & & $\infty .005$ & $<0.005$ \\
\hline 2ine - total & & 0.086 & & $<0.005$ & & 40.005 & $\times 0.005$ \\
\hline Alkolinity, Total & $0 s \operatorname{coc03}$ to pH 4.53 & 300 & & 160 & & ---- & 320 \\
\hline Carbonate (as cos) & & 45 & & 5 & & $\ldots$ & 160 \\
\hline Bicarborate Cas HCOS & & 360 & & 200 & & $\ldots$ & $\mathbf{5}$ \\
\hline
\end{tabular}

An Environmental Laboratory Specializing in:

Organic Chemistry - Metals Analysis - Inorganic Chemistry - Radlochemistry - 5park Source Mass Spectrometry 


\section{Accu-Labs' Research, Inc.}

\section{A I I I 1 I 8 R E POR T DATE: $08 / 31 / 94$ PAGE 2 \\ Lab Job Number 2426-56170-15}

These disposed of 30 days after the be of this report.

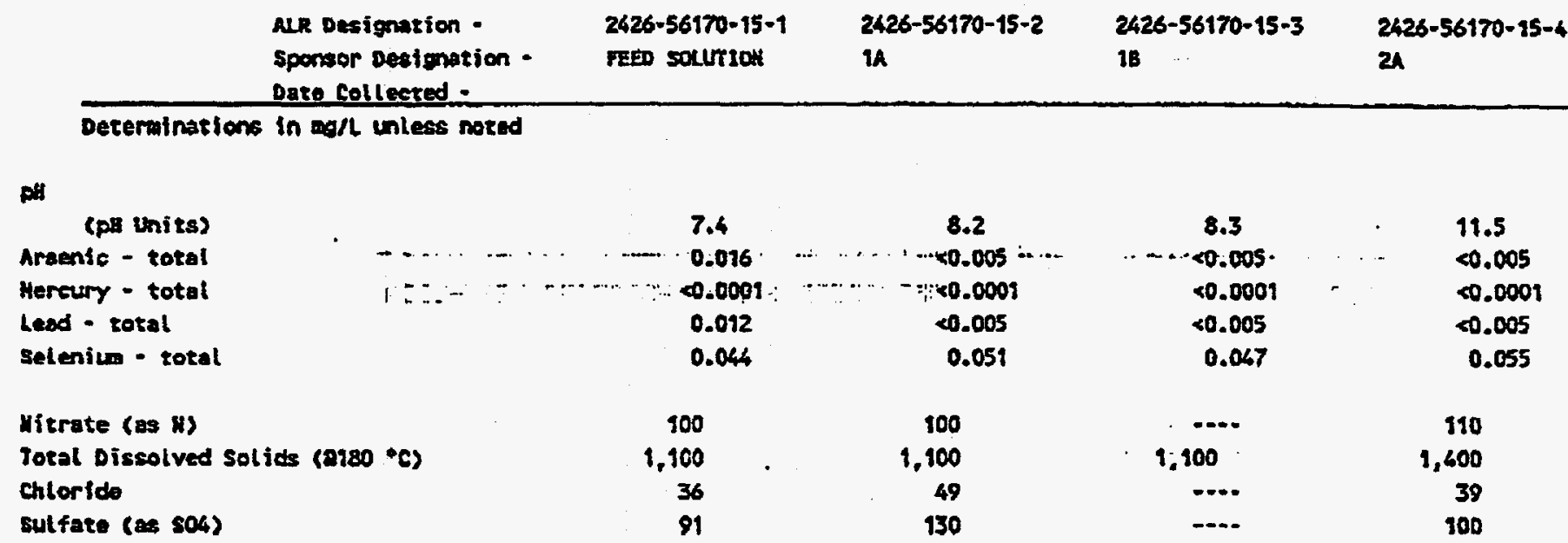




\section{Accu-Labs' Research, Inc.}

\section{A II I I I I B R B P O R T \\ DATE: 08/31/94 PAGE 3 \\ Lab Job Number 2426-56170-15}

These samples to be disposed of 30 doys after the date of this report.

\begin{tabular}{|c|c|c|c|c|c|c|}
\hline & $\begin{array}{l}\text { ALR Designation - } \\
\text { Sporsor Designation - } \\
\text { Date Collected - }\end{array}$ & $\begin{array}{l}2426-56170-15+5 \\
28\end{array}$ & $\begin{array}{l}2426-56170-15-6 \\
3 A\end{array}$ & $\begin{array}{l}2426-56170-15-7 \\
3 B\end{array}$ & & $\begin{array}{l}2426-56170-15-8 \\
4\end{array}$ \\
\hline Determinstions i & in $x \in \Omega$ unl ees noted & & $\cdot$ & & & \\
\hline silver - tocal & & 0.005 & $<0.005$ & 0.005 & & 0.005 \\
\hline Alumiran - total & & $\infty .1$ & 2.2 & 1.7 & & 0.2 \\
\hline Bariug - total & $\cdots$ & $\infty .05$ & $\$ .05 \quad \cdots$ & $\infty .05$ & & 0.08 \\
\hline Beryllfun - cotal & $-\ldots$ & $\therefore<6.005 \quad \therefore \quad \vdots$ & $: 0.005$ & $\infty .005$ & - & $\infty 0.005$ \\
\hline Coleitu - total & & 1.2 & 1.1 & 1.0 & & 85 \\
\hline Cachiun - rotal & & 40.005 & $\$ .005$ & $<0.005$ & & $<0.005$ \\
\hline Cobslt - eotal & & $\$ 0.005$ & $\infty .005$ & $\$ 0.005$ & & $<0.005$ \\
\hline Chroaiun - total & & 0.005 & $\infty 0.005$ & $\infty .005$ & & $<0.005$ \\
\hline copper - zotal & & $\infty .005$ & $\infty .005$ & $<0.005$ & & $\infty .005$ \\
\hline Iron - sotal & & 0.76 & 0.68 & 0.90 & & 0.04 \\
\hline Potassium - total & & 330 & 370 & 350 & & 66 \\
\hline Lithtum - total & & 0.14 & 0.14 & 0.14 & & 0.15 \\
\hline Masnesium - total & & 0.18 & 0.07 & 0.08 & & 27 \\
\hline Manganese = total & & $<0.005$ & 0.005 & $<0.005$ & & $<0.005$ \\
\hline molytidenes - totol & & $<0.01$ & $<0.01$ & $\infty .01$ & & $<0.01$ \\
\hline Sodium - total & & 150 & 140 & 340 & & 160 \\
\hline Niekel - total & & $\infty .02$ & $\infty .02$ & $<0.02$ & & $\infty .02$ \\
\hline Antinony - totel & & 60.05 & $\infty .05$ & $<0.05$ & &.$<0.05$ \\
\hline seteniun - rorsl & & 0.08 & 0.08 & 0.07 & & 0.06 \\
\hline Thellium - totel & & $\infty .1$ & $<0.1$ & $<0.1$ & & $<0.1$ \\
\hline Vanediun - total & & $\infty .005$ & 0.006 & 0.005 & & $<0.005$ \\
\hline Zinc - total & & $<0.005$ & $\times 0.005$ & $<0.005$ & & $<0.005$ \\
\hline Alkalinity, Total tas & is CacO3 to pH 4.5) & $\cdots$ & 300 & $\cdots$ & & $\cdots$ \\
\hline Curbanate (as cos) & & $\cdots$ & 160 & $\cdots+$ & & $\ldots$ \\
\hline Bicarbonate (as $\mathrm{kCO} 3$ ) & & $\cdots$ & $\times 5$ & $\cdots$ & & $\cdots-$ \\
\hline \multicolumn{7}{|l|}{ pH } \\
\hline (pd Unies) & & 11.5 & 13.6 & 11.3 & & 8.2 \\
\hline
\end{tabular}




\section{Accu-Labs̊ Research, Inc.}

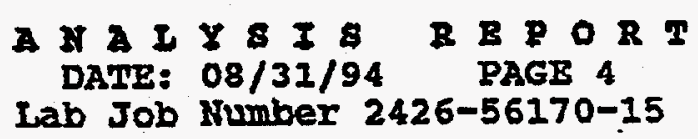

A A A I I I I B R F O T DATE: 08/31/94 PAGE 4

Lab Job Number 2426-56170-15

Theae amples to be disposed of 30 days after the date of this report.

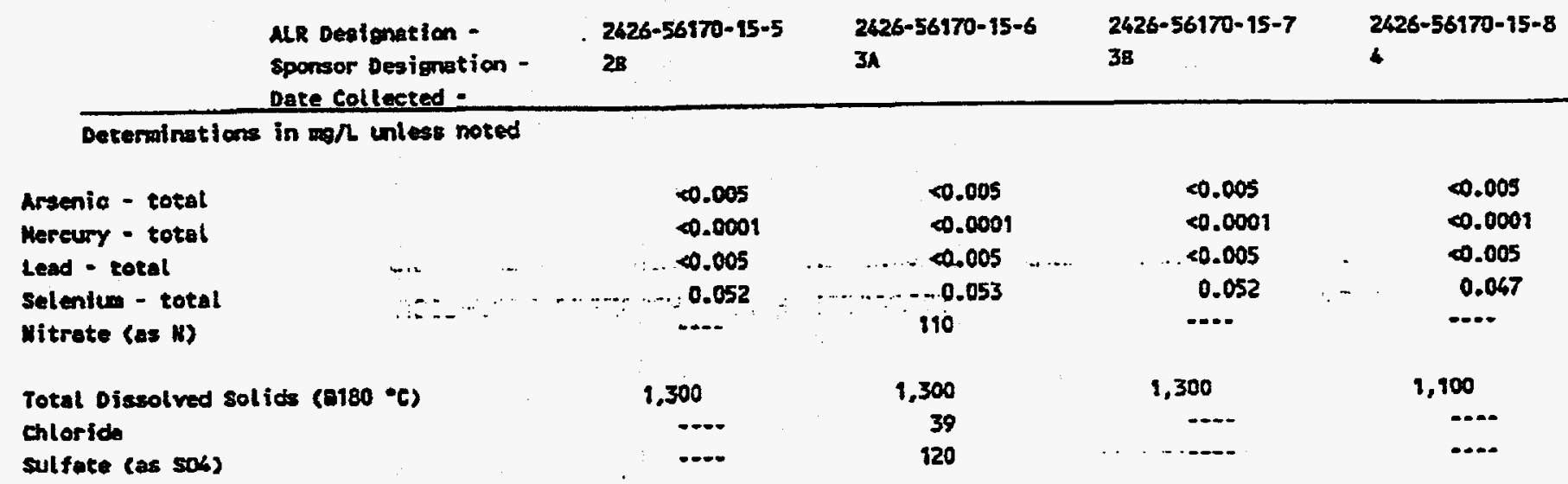




\section{Accu-Labs̊ Research, Inc.}

\section{A NAIYEIE REIORT \\ DATE: 08/31/94 PAGE 5 \\ Lab Job Number 2426-56170-15}

These samples to be disposed of 30 days after the date of this report.

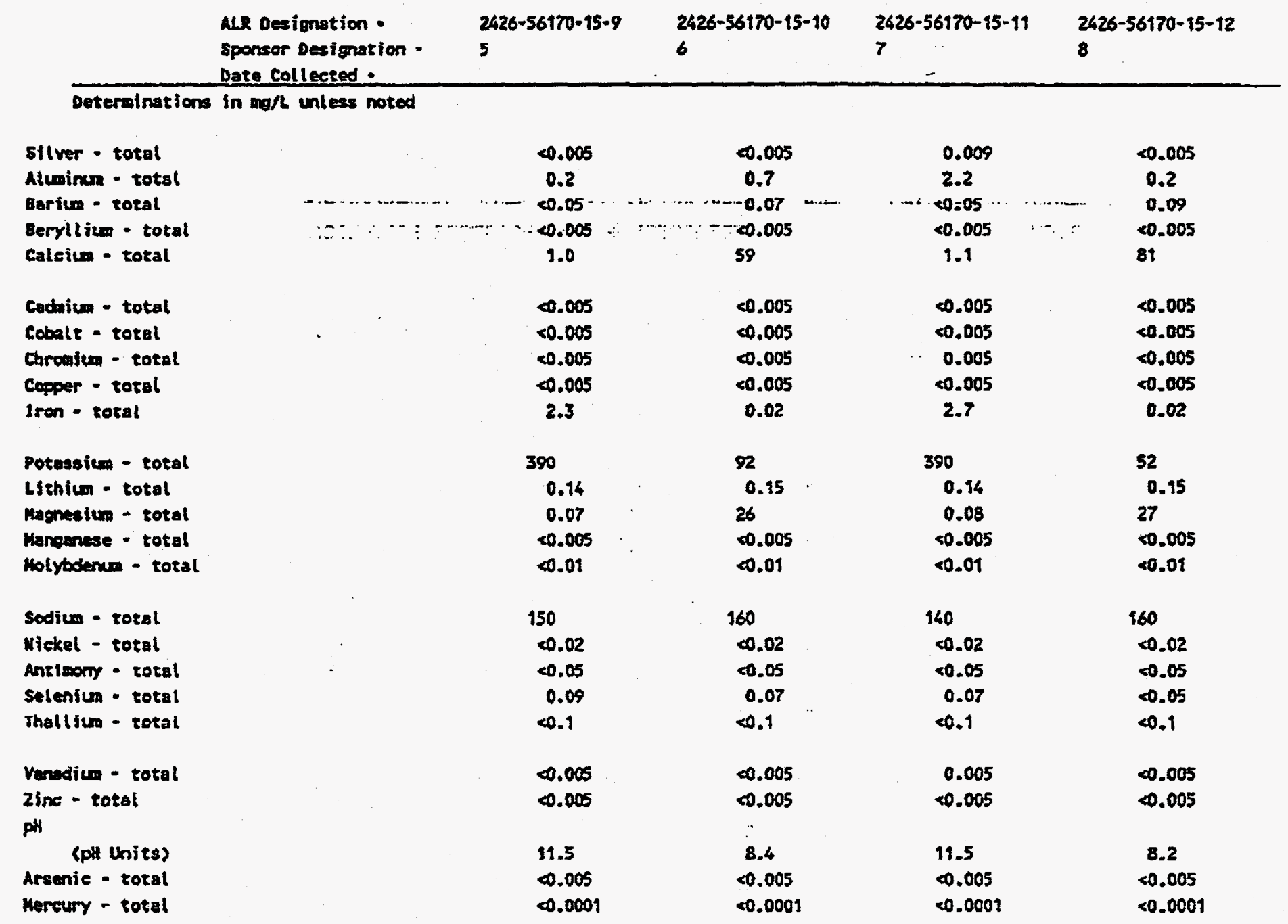


A I I I 8 I 8 R $R$ P O R T

DATE: 08/31/94 PAGE 6

Iab Job Number 2426-56170-15

These eaples to be disposed of 30 days after the date of this report.

ML Deaignation -

Sporsor Designation. Date Collected.

Determinations in ma/h unless noted
$2426-56170-15-9$

5

2426-56170-15-10

6

$2426-56170-15-11$

7
$2426-56170-15-12$

8
Lead - total

Selenitu - total

Total Dlesolved sollids (ot80 'C)

c) $\begin{gathered}0.005 \\ 0.034\end{gathered}$

0.005 in.

\section{$<0.005$}

0.052 1,100

$<0.005$
0.057

$<0.005$

0.049 8.100 


\section{A I A I I S I B R B P ORT DATE: 08/31/94 PAGE 7 \\ Lab Job Number 2426-56170-15}

These samples to be dispased of 30 days after the date of this report.

\begin{tabular}{|c|c|c|c|c|}
\hline & $\begin{array}{l}\text { AlR Deslanation - } \\
\text { Sporsor Designation - } \\
\text { Dage collected - }\end{array}$ & $\begin{array}{l}2626-56170-95-13 \\
9\end{array}$ & $\begin{array}{l}2626-56170-15-14 \\
10 .\end{array}$ & $\begin{array}{l}2426-56170-15-15 \\
11\end{array}$ \\
\hline \multicolumn{5}{|c|}{ Determinations in ma/l inless noted } \\
\hline sflver - total & & 0.006 & $\infty .005$ & 0.007 \\
\hline Altmirum - rotal & & 2.0 & 0.2 & 0.3 \\
\hline Barium - total & 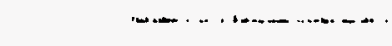 & $\cdots-\infty<0.05 \cdots \cdots$ & $\quad-\cdots-0.08 \cdots$ & $\cdots+\cdots<0.05 \cdots \cdots \cdots$ \\
\hline $\begin{array}{l}\text { Berrllium - total } \\
\text { calcium - total }\end{array}$ & $\because: \cdots !$ & $\begin{array}{c}\quad 00.005 \\
1.3\end{array}$ & $\begin{array}{c}65 \\
65.005\end{array}$ & $\begin{array}{l}<0.005 \\
6.7\end{array}$ \\
\hline Cudnirm - total & & $<0.005$ & $<0.005$ & $<0.005$ \\
\hline cobelt - totel & & $<0.005$ & $<0.005$ & $<0.005$ \\
\hline Chromium - total & & 0.006 & $<0.005$ & $\cdots \cdots 0.005$ \\
\hline copper - rotal & & $<0.005$ & $<0.005$ & $\$ 0.005$ \\
\hline Iron - tocal & & 2.3 & 0.02 & 0.13 \\
\hline Potassíum - totel & & 360 & 73 & 210 \\
\hline Lithitm - total & & 0.14 & 0.15 & 0.14 \\
\hline magnesfun - total & & 0.06 & $27 \quad \cdots$ & 11 \\
\hline Manganese - total & & $<0.005$ & $<0.005:$ & $<0.005$ \\
\hline Molyboderun - total & & $<0.01$ & $\infty 0.01$ & $\infty .01$ \\
\hline sodiun - total & & 350 & 160 & 140 \\
\hline Mtekel - total & & 40.02 & $<0.02$ & $<0.02$ \\
\hline Antfuony - total & & $<0.05$ & $\infty 0.05$ & $<0.05$ \\
\hline Selenius - tetal & & 0.07 & 0.10 & 0.11 \\
\hline Thalliuen - total & & $<0.1$ & $\infty .1$ & $<0.1$ \\
\hline Vandiun - total & & 20.005 & 40.005 & $<0.005$ \\
\hline 2inc - total & & $<0.005$ & $<0.005$ & $<0.005$ \\
\hline \multicolumn{5}{|l|}{ pat } \\
\hline (pll Units) & & 11.3 & 8.3 & 9.7 \\
\hline Arsenic - total & & $<0.005$ & $\infty 0.005$ & $<0.005$ \\
\hline Mareury - total & & $<0.0001$ & $<0.0001$ & $<0.0001$ \\
\hline
\end{tabular}




\section{A I I I 8 I 8 R E $R$ O R $T$ DATE: $08 / 31 / 94$ PAGE 8 \\ Lab Job Number 2426-56170-15}

These amplea to be disposed of 30 days after the date of this report.

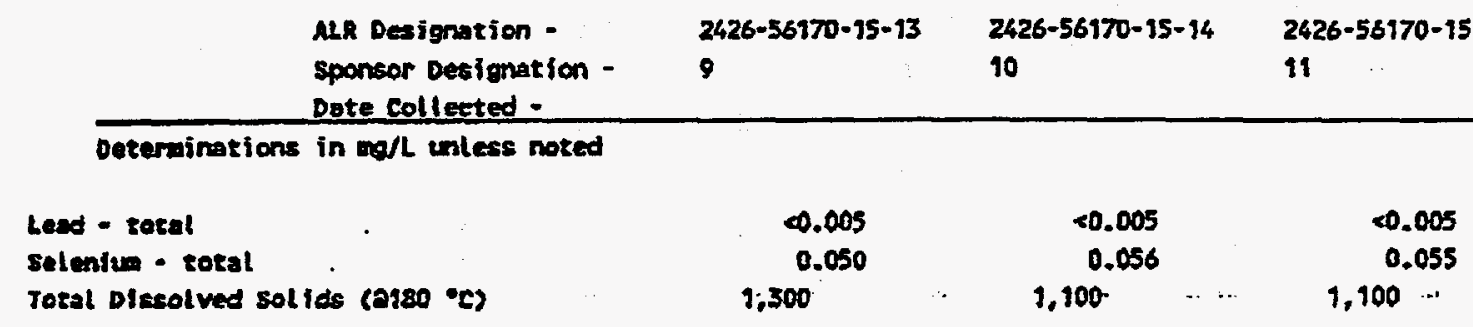

By: Ioude Alecaemunar

EY Ha Henreder

Metals Laboratory supervisor

By: Awsangtawher

susan I. Barker

Inorganic Chemistry Supervisor

EE/SJB/rti 


\section{Accu-Labs Research, Inc.}

Re: 2426-56170-5

\section{case Narrative}

Selenium was analyzed by both ICP and graphite furnace.

QA results are as follows:

Reagent Blank:

ICP

$<0.05 \mathrm{mg} / \mathrm{t}$

HGA

$<0.005 \mathrm{mg} / \mathrm{L}$

Laboratory control sample:

ICP $\quad(T V=1.0 \mathrm{mg} / \mathrm{I}) \quad 85 \%$

HGA $(\mathrm{TV}=0.80 \mathrm{mg} / \mathrm{L}) \quad 95 \%$

Bpike:

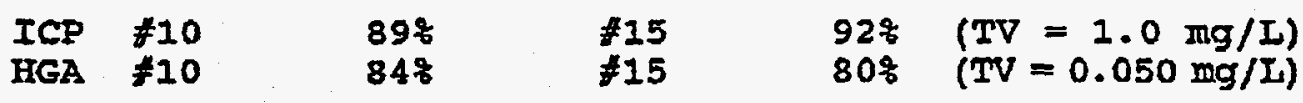

Duplicate:

ICP $\# 10.06 \mathrm{mg} / \mathrm{I}$ and

$\$ 110.07 \mathrm{mg} / \mathrm{L} \quad$ and

$0.06 \mathrm{mg} / \mathrm{L}$

0 \%

$0.07 \mathrm{mg} / \mathrm{I}$

$0 \%$

BGA $\$ 10.044 \mathrm{mg} / \mathrm{L} \quad$ and

$0.042 \mathrm{mg} / \mathrm{L}$

and

$0.052 \mathrm{mg} / \mathrm{L}$

$5 \%$

\#11 $0.052 \mathrm{mg} / \mathrm{L}$

and

D? 
Accu-Labs Research, Inc.

1663 Itble Mountain Drtve Colden, Coloredo B0403-1650 (305) 277.9514

$\operatorname{Fax}(303)$ 277.9512

Date: $09 / 02 / 94$

Page 1

\section{REPORT OF ANALYSIS}

MI Mike Rupert

EGEG Rocky Flats Inc

Rocky Flats Env Tech site

Lab Job Number: 000120

POB 464 Bldg 080

Date Samples Received: 08/22/94

Golden, CO 80402-0464

ArR Degignation:

Clsent Derignation:

Sample Location:

Location II:

Date/Time collected

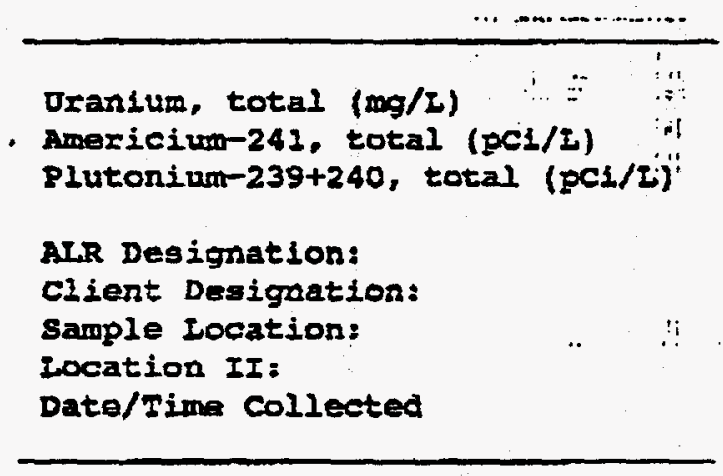

Uranium, total $(\mathrm{mg} / I) \cdots \cdots$

Americium-241, total (pc1/L)

Plutonium-239+240, total (pCl/L)

ArR Designation:

Cllent Designation:

sample Location:

Iooation II:

Date/Ifine collected

Oraniua, total (ang/t)

Americium-241, total (pici/Ij)

Plutonium-239+240, total (pCl/L)

$$
\begin{aligned}
& 0.044 \\
& 0.86+/-0.36 \\
& 7.5+/-0.93 \\
& 94-21136 \\
& 28
\end{aligned}
$$

$94-A 1234$

Igigo sorurion

94-A1135

IA

0.038
$-0.03+1-0.10$

$0.18+/-0.12$

94-A1137

$2 \pi$
0.0024

$-0.06+1-0.08$

$0.17+/=0.13$

94-AI139
$\begin{array}{ll}94-\mathrm{A} 1138 & 94 \\ 28 & 3 \mathrm{~A}\end{array}$

0.0020

$-0.01+/-0.12$

$0.24+1-0.17$

$\therefore$
0.0042

$0.01+/-0.14$

$0.14+/-0.12$

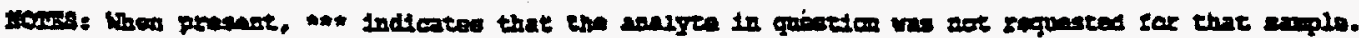

An Environmentel Laboretory Specialtring in:

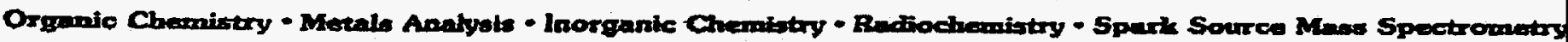




\section{Accu-Labs̊ Research, Inc.}

Dates $09 / 02 / 94$

Page 2

Bupost of anarygIs

Mr Hike Rupert

BCse Rocky Plats Ine
Lab Job thumber 000120

Date Samples Received: 08/22/94
ALR Designation: Client Designation: Sample Locatlons rocation II:

Data/Time collected
$94-\mathbf{A 1} 140$

38
94-A1141

4

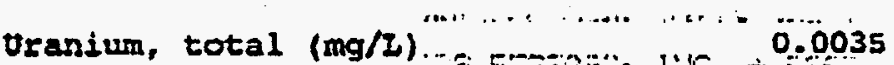

Amertelum-241, total (pcl/ti)

Plutonium-239+240, total (pcl/I)

$0.23+/-0.14$

0.039

$0.01+/-0.11$

$0.21+/-0.11$

AtR Designation:

$94-81142$

Client Deslgnation:

5

$94-\mathrm{A} 1143$

6

Sample Location:

Location II:

Date/Time Collected

Dranium, total (mg/L)

Americium-241, total (pci/L)

Plutonium-239+240, total (pCl/L)

ALR Degignations

Client Designation:

Sample Location:

Iocation II:

Date/Time collected

Uxaniura, total (mg/L)

Aruericium-241, total (pci/I)

Plutonium-239+240, total (pcl/I)

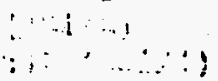

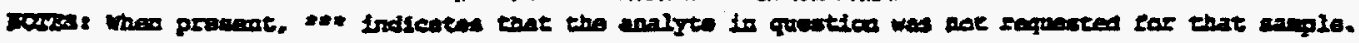

$$
\begin{aligned}
& \text { 2. }-0.05+1-0.09 \\
& \text { r } 0.12+1-0.10
\end{aligned}
$$$$
0.0025
$$

94-A1144

7
0.0028

$0.05+/-0.18$

$0.12+/-0.08$

0.037

$-0.02+/-0.02$

$-0.02+/-0.11$

\subsection{6}

$-0.03+1-0.10$

$0.16+/-0.14$

94-A1145

8

$\cdots$, 
Date: 09/02/94

Paga 3

\section{Accu-Labs Research. Inc}

Mix Mike Rupert

Beec Rocicy Flats Ine

Iab Job dumber: 000120

Date Samples Received: 08/22/94

ALR Designation:

94-\$1146

9

Client Deslgnation:

sample Loortion:

Location II:

Date/Time collected
Repore or AnTygis
94-A1147

10

Oranium, total (mg/
Americium-241, total
Plutonium-239+240,
ArR Designation:
Cliant Designation:
Sample Location:
Location II:
Date/Time Collected

Oranius, total (mg/I)

Arericlum-241, total (pCi/L)

0.0035

Plutonium-239+240, total (pCi/L)

L. $0.00+1-0.01$

$.0 .00+1-0.10$

11

Variability of the radioactive distntegration process (counting error) at the 954 confidence level 181.96 aigma and the level of aigniflcance may exceed that of the reported analytical result. scheduled sample disposal date: October 2, 1994.

\subsection{6}

$0.02+/-0.03$

$0.02+1-0.11$

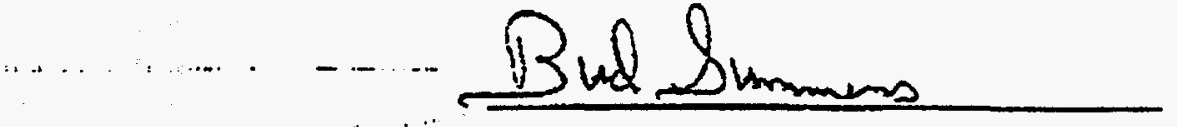

Bud sumers

Radlochemistry supervisor

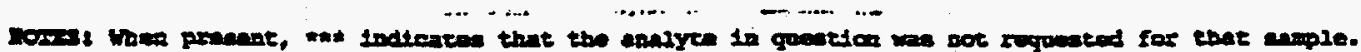




\section{Accu-Labs Research, Inc.}

4663 Table Mountain Drive Golden, Colorado 80403-1650

(303) 277.9514

FAX (303) 277.9512

\section{A N A I I $B$ I $S$ R $R$ P O R T \\ DATE: $10 / 04 / 94$ PAGE 1 .}

\section{J.C. LAUL}

EG\&G ROCKY FLATS

ENVIRONMENTAL TECHNOLOGY SITE

$P$ O BOX 464 BLDG 881

GOLDEN, CO 80402-0464
Lab Job Number: 2426-56738-16

Date Samples Received: 09/21/94

Customer Po Number: AsC233268J03

These samples to be disposed of 30 days after the date of this report.

ALR Designation -

Sponsor Designation -

Date Collected -

Determinations in $\mathrm{mg} / \mathrm{L}$ unless noted
2426-56738-16-9

FEED SOLN

$09 / 20 / 94$

\begin{tabular}{ll}
$2426-56738-16-2$ & $2426-56738-16-3$ \\
$\# 0$ & $\# 1$ \\
$09 / 15 / 94$ & $09 / 15 / 94$ \\
\hline
\end{tabular}

Potassium - total

Lithium - total

Magnesium - total

Manganese - total

Molybdenum - total

Sodiun - total

Nickel - total

Antimony - total

Selenium - total

Thallium - total

Vanadiun - total

Zinc - total

PH

(pH Units)

0.028
20
0.23
$<0.005$
98
$<0.005$
0.006
0.025
0.023
19

0.008

0.2

$<0.05$

$<0.005$

11

$<0.005$

$<0.005$

0.008

$<0.005$

0.05

6.6

0.17

29

0.24

$<0.01$

150

$<0.05$

$<0.05$

$<0.05$

$<0.5$

0.043

0.081

8.0

180

0.16

22

$<0.005$

$<0.01$

170

$<0.05$

$<0.05$

$<0.05$

$<0.5$

$<0.005$

$<0.005$

9.4
0.010

0.5

$<0.05$

$<0.005$

1.0

$<0.005$

$<0.005$

0.009

$<0.005$

0.08
390

0.15

0.09

$<0.005$

$<0.01$

160

$<0.05$

$<0.05$

$<0.05$

$<0.5$

$<0.005$

$<0.005$

11.4
$2426-56738-16-4$ \#18 $09 / 16 / 94$
0.007

0.4

$<0.05$

$<0.005$

i.1

$<0.005$

$<0.005$

0.006

$<0.005$

0.13

370

0.14

0.07

$<0.005$

$<0.01$

170

$<0.05$

$<0.05$

$<0.05$

$<0.5$

$<0.005$

$<0.005$

11.4 
Potassium Ferrate Treatment of RFETS Groundwater
Document Number: Section:

Page:
RF/ER-94-0028.UN

Appendix B, Rev. 0

1 of 18

\section{APPENDIX B}

ANALYTICAL REPORTS OF TREATED WATER FROM PHASE II TESTS 


\section{Accu-Labs̊ Research, Inc.}

\section{A $N$ A I $Y$ I 8 I 8 R $E$ P O $R$ T \\ DATE: $10 / 04 / 94$ PAGE 2 \\ Lab Job Number 2426-56738-16}

These samples to be disposed of 30 days after the date of this report.

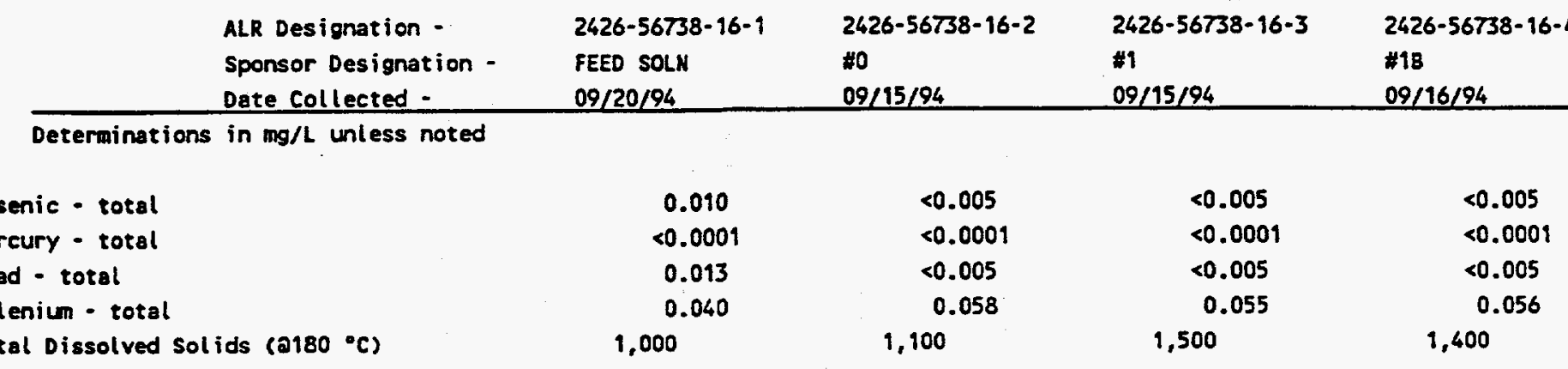




\section{Accu-Labsं Research, Inc.}

\section{A N A I Y 8 I $S$ R E P O R T \\ DATE: $10 / 04 / 94$ PAGE 3 \\ Lab Job Number 2426-56738-16}

These samples to be disposed of 30 days after the date of this report.

\begin{tabular}{lllll} 
ALR Designation - & $2426-56738-16-5$ & $2426-56738-16-6$ & $2426-56738-16-7$ & $2426-56738-16-8$ \\
Sponsor Designation - & $\$ 2$ & $\$ 28$ & $\$ 3$ & $\$ 4$ \\
Date Collected - & $09 / 15 / 94$ & $09 / 16 / 94$ & $09 / 14 / 94$ & $09 / 14 / 94$ \\
\hline
\end{tabular}

Determinations in $\mathrm{mg} / \mathrm{L}$ unless noted

\begin{tabular}{|c|c|c|c|c|}
\hline Silver - total & 0.005 & 0.007 & 0.009 & 0.011 \\
\hline Aluminum - total & 0.1 & $<0.9$ & $<0.1$ & $<0.1$ \\
\hline Barium - total & $<0.05$ & $<0.05$ & 0.07 & 0.08 \\
\hline Beryllium - total & $<0.005$ & $<0.005$ & $<0.005$ & $<0.005$ \\
\hline Calcium - total & 1.3 & 1.3 & 80 & 59 \\
\hline Cachium - total & $<0.005$ & $<0.005$ & $<0.005$ & $<0.005$ \\
\hline Cobalt - total & $<0.005$ & $<0.005$ & $<0.005$ & $<0.005$ \\
\hline Chromium - total & $<0.005$ & $<0.005$ & 0.011 & 0.008 \\
\hline Copper - total & $<0.005$ & $<0.005$ & $<0.005$ & $<0.005$ \\
\hline Iron - total & 0.19 & 0.26 & $<0.01$ & $<0.01$ \\
\hline Potassium - total & 370 & 320 & 74 & 47 \\
\hline Lithium - total & 0.14 & 0.15 & 0.15 & 0.15 \\
\hline Magnesium - total & 0.07 & 0.12 & 25 & 25 \\
\hline Manganese - total & $<0.005$ & $<0.005$ & $<0.005$ & $<0.005$ \\
\hline Molybdenum - total & $<0.01$ & $<0.01$ & $<0.09$ & $<0.01$ \\
\hline Sodium - total & 150 & 150 & 160 & 150 \\
\hline Nickel - total & $<0.05$ & $<0.05$ & $<0.05$ & $<0.05$ \\
\hline Antimony - total & $<0.05$ & $<0.05$ & $<0.05$ & $<0.05$ \\
\hline Seleniun - total & $<0.05$ & $<0.05$ & $<0.05$ & $<0.05$ \\
\hline Thallium - total & $<0.5$ & $<0.5$ & $<0.5$ & $<0.5$ \\
\hline Vanadium - total & $<0.005$ & $<0.005$ & $<0.005$ & $<0.005$ \\
\hline Zinc $\cdot$ total & $<0.005$ & 0.006 & $<0.005$ & $<0.005$ \\
\hline \\
\hline (pH Units) & 11.8 & 11.8 & 8.5 & 8.6 \\
\hline Arsenic - total & $<0.005$ & $<0.005$ & $<0.005$ & $<0.005$ \\
\hline Mercury - total & $<0.0001$ & $<0.0001$ & $<0.0001$ & $<0.0001$ \\
\hline
\end{tabular}




\title{
Accu-Labs Research, Inc.
}

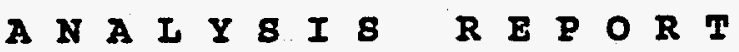 \\ DATE: $10 / 04 / 94$ \\ PAGE 4 \\ Lab Job Number 2426-56738-16
}

These samples to be disposed of 30 days after the date of this report.

\begin{tabular}{|c|c|c|c|c|}
\hline $\begin{array}{l}\text { ALR Designation - } \\
\text { Sponsor Designation - } \\
\text { Date Collected - }\end{array}$ & $\begin{array}{l}2426-56738-16-5 \\
\$ 2 \\
09 / 15 / 94 \\
\end{array}$ & $\begin{array}{l}2426-56738-16-6 \\
\$ 28 \\
09 / 16 / 94 \\
\end{array}$ & $\begin{array}{l}2426-56738-16-7 \\
\$ 3 \\
09 / 14 / 94 \\
\end{array}$ & $\begin{array}{l}2426-56738-16- \\
14 \\
09 / 14 / 94\end{array}$ \\
\hline \multicolumn{5}{|l|}{ in $\mathrm{mg} / \mathrm{L}$ unless noted } \\
\hline & $<0.005$ & $<0.005$ & $<0.005$ & $<0.005$ \\
\hline & 0.056 & 0.059 & 0.049 & 0.059 \\
\hline ids $\left(2180^{\circ} \mathrm{C}\right)$ & 1,400 & 1,300 & 1,100 & 1,000 \\
\hline
\end{tabular}

Lead - total

Selenium - total

Total Dissolved Solids $\left(2180^{\circ} \mathrm{C}\right)$
1,400
1,100
0.059

1,000 


\section{Accu-Labs Research, Inc.}

\section{A N A I $\begin{array}{llllllllll} & & \text { S I } & 8 & R & E & P & O & R & T\end{array}$ \\ DATE: $10 / 04 / 94$ PAGE 5 \\ Lab Job Number 2426-56738-16}

These samples to be disposed of 30 days after the date of this report.

\begin{tabular}{|c|c|c|c|c|c|}
\hline & $\begin{array}{l}\text { ALR Designation - } \\
\text { Sponsor Designation - } \\
\text { Date Collected - }\end{array}$ & $\begin{array}{l}2426-56738-16-9 \\
\# 9 \\
09 / 15 / 94\end{array}$ & $\begin{array}{l}2426-56738-16-10 \\
\# 10 \\
09 / 16 / 94\end{array}$ & $\begin{array}{l}2426-56738-16-11 \\
\# 11 \\
09 / 14 / 94\end{array}$ & $\begin{array}{l}2426-56738-16-12 \\
\# 12 \\
09 / 14 / 94\end{array}$ \\
\hline \multicolumn{6}{|c|}{ Determinations in $\mathrm{mg} / \mathrm{L}$ unless noted } \\
\hline silver - total & & $<0.005$ & $<0.005$ & 0.005 & 0.007 \\
\hline Aluminum - total & & $<0.1$ & $<0.1$ & $<0.1$ & $<0.9$ \\
\hline Barium - total & & $<0.05$ & $<0.05$ & $<0.05$ & $<0.05$ \\
\hline Beryllium - total & & $<0.005$ & $<0.005$ & $<0.005$ & $<0.005$ \\
\hline Calcium - total & & 1.3 & 7.9 & 16 & 14 \\
\hline Cadnium - total & & $<0.005$ & $<0.005$ & $<0.005$ & $<0.005$ \\
\hline Cobalt - total & & $<0.005$ & $<0.005$ & $<0.005$ & $<0.005$ \\
\hline Chronium - total & & $<0.005$ & $<0.005$ & $<0.005$ & $<0.005$ \\
\hline Copper - total & & $<0.005$ & $<0.005$ & 0.006 & $<0.005$ \\
\hline Iron - total & & 0.07 & 0.02 & 0.02 & 0.02 \\
\hline Potassium - total & & 340 & 160 & 100 & 150 \\
\hline Lithium - total & & 0.14 & 0.15 & 0.15 & 0.15 \\
\hline Magnesium - total & & 0.14 & 15 & 23 & 22 \\
\hline Manganese - total & & $<0.005$ & $<0.005$ & $<0.005$ & $<0.005$ \\
\hline Molytodenum - total & & $<0.01$ & $<0.01$ & $<0.01$ & $<0.01$ \\
\hline Sodium - total & & 150 & 150 & 150 & 160 \\
\hline Nickel - total & & $<0.05$ & $<0.05$ & $<0.05$ & $<0.05$ \\
\hline Antimony - total & & $<0.05$ & $<0.05$ & $<0.05$ & $<0.05$ \\
\hline Seleniun - total & & $<0.05$ & 0.06 & 0.06 & $<0.05$ \\
\hline Thallium - total & & $<0.5$ & $<0.5$ & $<0.5$ & $<0.5$ \\
\hline Vanadium - total & & $<0.005$ & $<0.005$ & $<0.005$ & $<0.005$ \\
\hline Zine - total & & $<0.005$ & $<0.005$ & $<0.005$ & $<0.005$ \\
\hline \\
\hline (pH Units) & & 11.8 & 10.1 & 9.6 & 9.8 \\
\hline Arsenic - total & & $<0.005$ & $<0.005$ & $<0.005$ & $<0.005$ \\
\hline Mercury - total & & $<0.0001$ & $<0.0001$ & $<0.0001$ & $<0.0001$ \\
\hline
\end{tabular}




\section{Accu-Labs̊ Research, linc.}

\section{A N A I Y 8 I $S$ R E P O R T \\ DATE: $10 / 04 / 94$ PAGE 6 \\ Lab Job Number 2426-56738-16}

These samples to be disposed of 30 days after the date of this report.

\begin{tabular}{|c|c|c|c|c|c|}
\hline & $\begin{array}{l}\text { ALR Designation - } \\
\text { Sponsor Designation - } \\
\text { Date Collected - }\end{array}$ & $\begin{array}{l}2426-56738-16-9 \\
\# 9 \\
09 / 15 / 94\end{array}$ & $\begin{array}{l}2426-56738-16-10 \\
\# 10 \\
09 / 16 / 94\end{array}$ & $\begin{array}{l}2426-56738-16-11 \\
\# 11 \\
09 / 14 / 94\end{array}$ & $\begin{array}{l}2426-56738-16 \\
\# 12 \\
09 / 14 / 94 \\
\end{array}$ \\
\hline \multicolumn{6}{|c|}{ Determinations in $\mathrm{mg} / \mathrm{L}$ unless noted } \\
\hline - total & & $<0.005$ & $<0.005$ & $<0.005$ & $<0.005$ \\
\hline hium - total & & 0.054 & 0.065 & 0.061 & 0.059 \\
\hline Dissolved solic & ids $\left(2180^{\circ} \mathrm{C}\right)$ & 1,300 & 1,000 & 1,000 & 1,100 \\
\hline
\end{tabular}




\section{Accu-Labs Research, Inc.}

\section{A N A I Y $S$ I $B$ R E P O R T \\ DATE: $10 / 04 / 94$ PAGE 7 \\ Lab Job Number 2426-56738-16}

These samples to be disposed of 30 days after the date of this report.

\begin{tabular}{lllll} 
ALR Designation - & $2426-56738-16-13$ & $2426-56738-16-14$ & $2426-56738-16-15$ & $2420-56738-16-16$ \\
Sponsor Designation - & $\# 13$ & $\# 14$ & $\# 15$ & $\# 16$ \\
Date Collected - & $09 / 15 / 94$ & $09 / 15 / 94$ & $09 / 16 / 94$ & $09 / 15 / 94$ \\
\hline
\end{tabular}

Determinations in $\mathrm{mg} / \mathrm{L}$ unless noted

\begin{tabular}{|c|c|c|c|c|}
\hline silver - total & 0.008 & $<0.005$ & $<0.005$ & 0.009 \\
\hline Aluminum - total & $<0.1$ & $<0.1$ & 0.6 & $<0.1$ \\
\hline Barium - total & $<0.05$ & $<0.05$ & $<0.05$ & $<0.05$ \\
\hline Beryllium - total & $<0.005$ & $<0.005$ & $<0.005$ & $<0.005$ \\
\hline Calciun - total & 11 & 1.4 & 0.5 & 9.2 \\
\hline Cadmium - total & $<0.005$ & $<0.005$ & $<0.005$ & $<0.005$ \\
\hline Cobalt - total & $<0.005$ & 0.008 & 0.005 & $<0.005$ \\
\hline Chromium - total & $<0.005$ & $<0.005$ & $<0.005$ & $<0.005$ \\
\hline Copper - total & $<0.005$ & $<0.005$ & $<0.005$ & $<0.005$ \\
\hline Iron - total & 0.02 & 0.02 & 0.15 & 0.05 \\
\hline Potassium - total & 130 & 350 & 5.8 & 180 \\
\hline Lithium - total & 0.15 & 0.14 & $<0.01$ & 0.15 \\
\hline Magnesium - total & 20 & 0.13 & $<0.05$ & 17 \\
\hline Manganese - total & $<0.005$ & $<0.005$ & $<0.005$ & $<0.005$ \\
\hline Molybdenum - total & $<0.01$ & $<0.01$ & $<0.01$ & $<0.01$ \\
\hline Sodium - total & 150 & 150 & 3.6 & 170 \\
\hline Nickel - total & $<0.05$ & $<0.05$ & $<0.05$ & $<0.05$ \\
\hline Antimony - total & $<0.05$ & $<0.05$ & $<0.05$ & $<0.05$ \\
\hline Selenium - total & $<0.05$ & $<0.05$ & $<0.05$ & $<0.05$ \\
\hline Thallium - total & $<0.05$ & $<0.05$ & $<0.05$ & $<0.05$ \\
\hline Vanadium - total & $<0.005$ & $<0.005$ & $<0.005$ & $<0.005$ \\
\hline Zinc $\cdot$ total & $<0.005$ & $<0.005$ & $<0.005$ & $<0.005$ \\
\hline \\
\hline (pH Units) & 10.2 & 11.9 & 8.6 & 10.0 \\
\hline Arsenic - total & $<0.005$ & $<0.005$ & $<0.005$ & $<0.005$ \\
\hline Mercury - total & $<0.0001$ & $<0.0001$ & $<0.0001$ & $<0.0001$ \\
\hline
\end{tabular}




\section{Accu-Labs Research, Inc.}

\section{A N A I $Y$ S I $S$ R E $P$ O $R$ T DATE: $10 / 04 / 94$ PAGE 8 \\ Lab Job Number 2426-56738-16}

These samples to be disposed of 30 days after the date of this report.

\begin{tabular}{|c|c|c|c|c|c|}
\hline & $\begin{array}{l}\text { ALR Designation - } \\
\text { Sponsor Designation - } \\
\text { Date Collected - }\end{array}$ & $\begin{array}{l}2426-56738-16-13 \\
\$ 13 \\
09 / 15 / 94 \\
\end{array}$ & $\begin{array}{l}2426-56738-16-14 \\
\$ 14 \\
09 / 15 / 94 \\
\end{array}$ & $\begin{array}{l}2426-56738-16-15 \\
\# 15 \\
09 / 16 / 94\end{array}$ & $\begin{array}{l}2426-56738-16 \\
\# 16 \\
09 / 15 / 94 \\
\end{array}$ \\
\hline \multicolumn{6}{|c|}{ Determinations in $\mathrm{mg} / \mathrm{L}$ unless noted } \\
\hline - total & & $<0.005$ & $<0.005$ & $<0.005$ & $<0.005$ \\
\hline lium - total & & 0.059 & 0.056 & $<0.005$ & 0.056 \\
\hline
\end{tabular}

By: Euda, Neraensulu

Exja Hefgenreder

Metals Laboratory Supervisor

By:

Arsangaras

susan J. Barker

Inorganic Chemistry Supervisor

$\mathrm{EH} / \mathrm{SJB} / \mathrm{r}$ th 
Date: $10 / 10 / 94$

Page 1

\section{FREIIMINARY REPORT OF ANALYSIS}

Mr Mike Rupert

EG\&G RockY Flats Inc

Rocky Flats Env Tech site

POB 464 Bldg 080

Golden, CO 80402-0464
Iab Job Number: 000240

Date Samples Received: 09/21/94

Customer PO Number: ASC $233268 \mathrm{JO}$
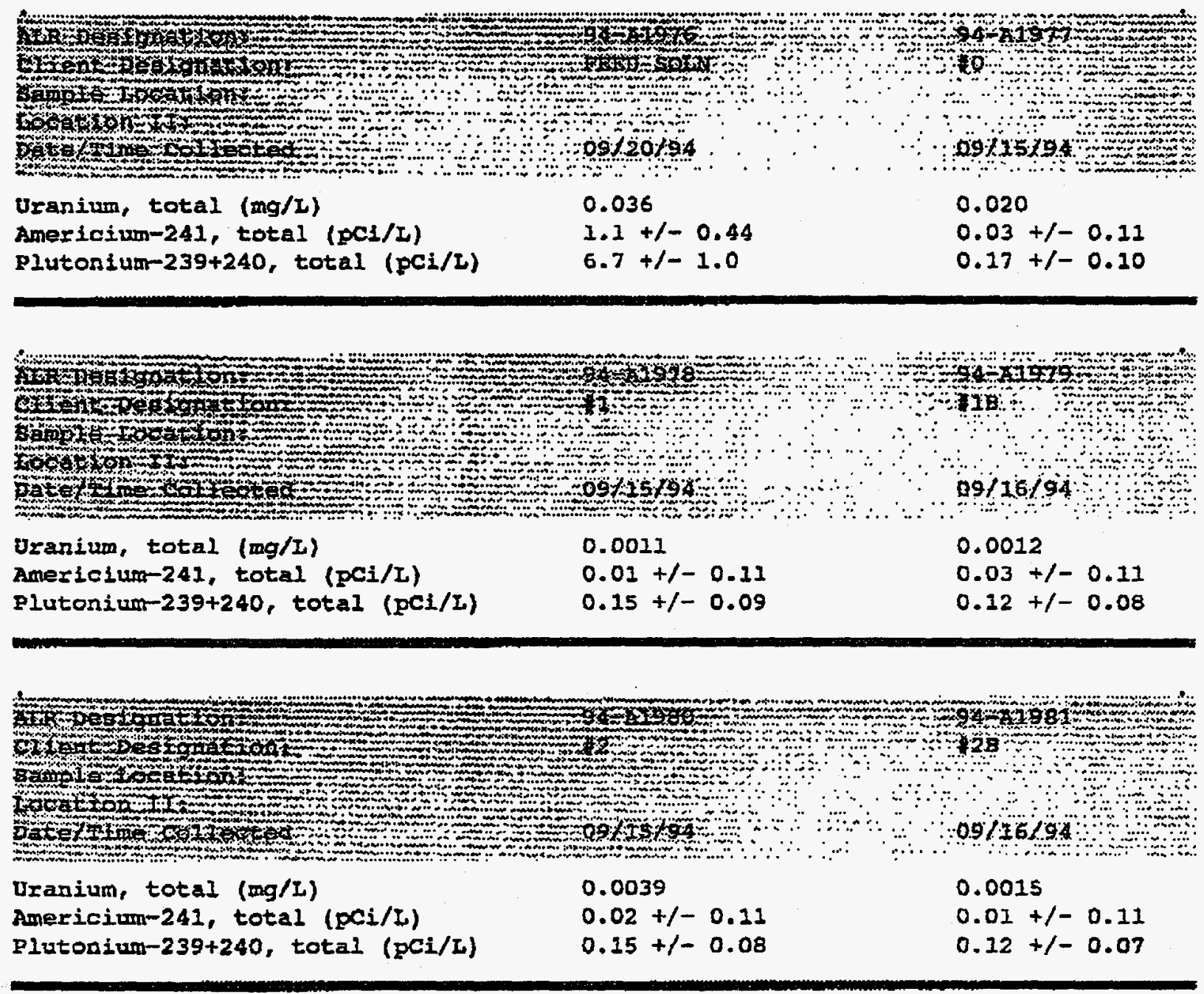

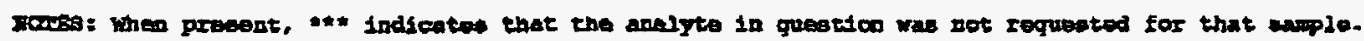


Date: $10 / 10 / 90$

Page 2

PRALIMINARY RAPORT OP AAATYSI8

Mr Mike Rupext

ECed Rocky Flats Ino
Lab Job Number: 000240

Date Samples Received: 09/21/94
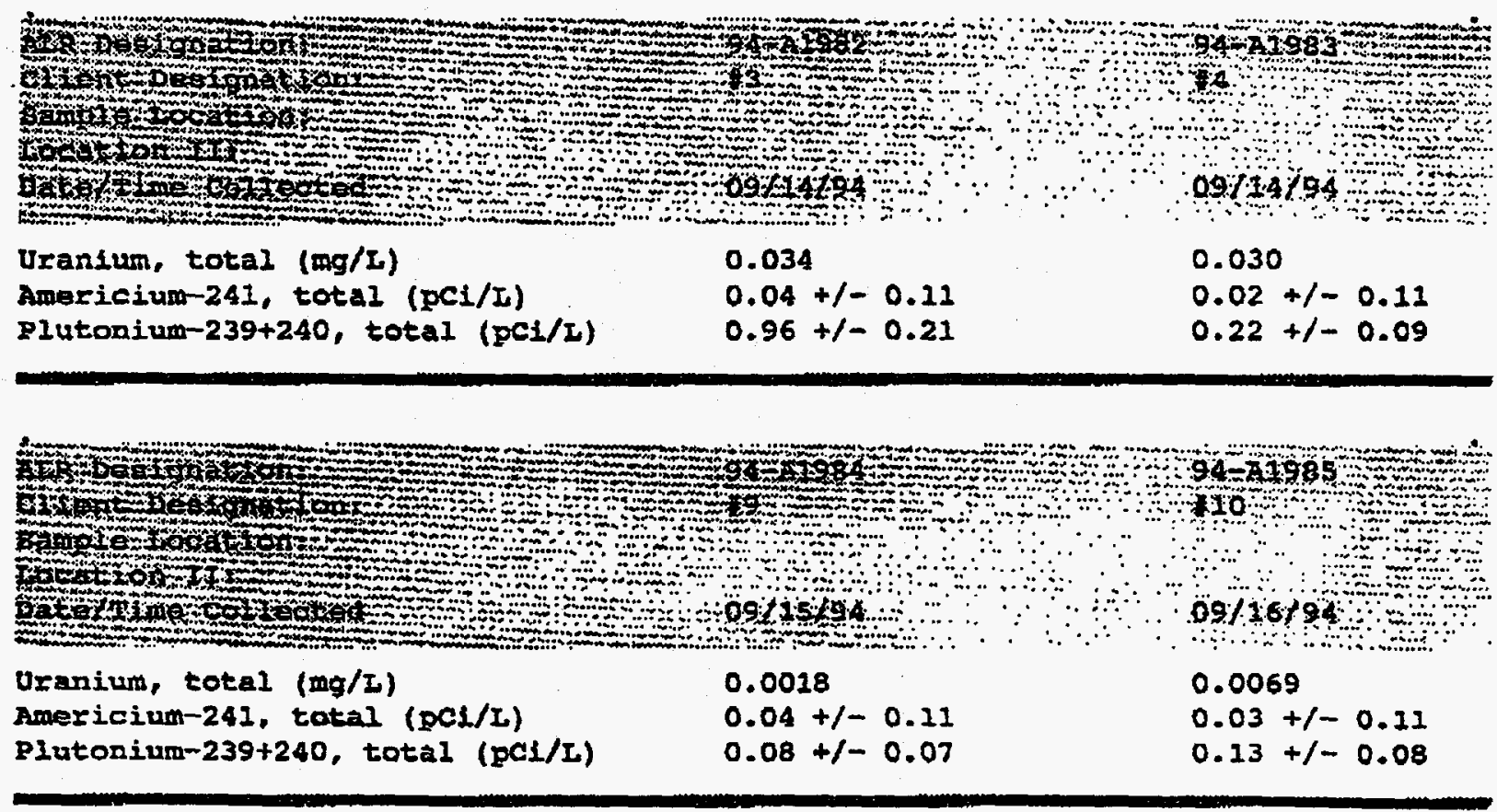

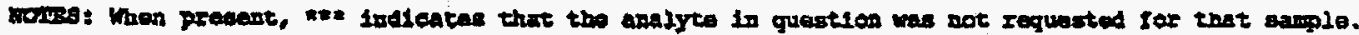




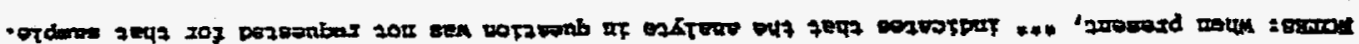

\begin{tabular}{|c|c|c|}
\hline $\begin{aligned} \tau \tau \cdot 0-1+0 \varepsilon \cdot 0 \\
\varepsilon 0 \cdot 0-1+20 \cdot 0 \\
920 \cdot 0\end{aligned}$ & $\begin{aligned} 60 \cdot 0-1+s \tau \cdot 0 \\
T 0^{\circ} \cdot 0-1+00 \cdot 0 \\
\angle 20^{\circ} 0\end{aligned}$ & 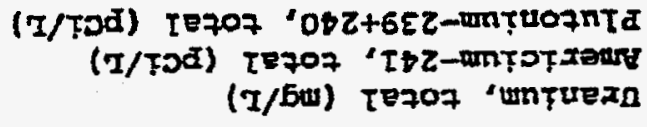 \\
\hline
\end{tabular}

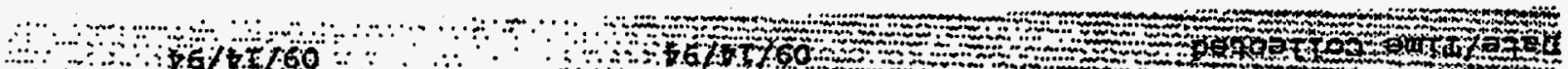

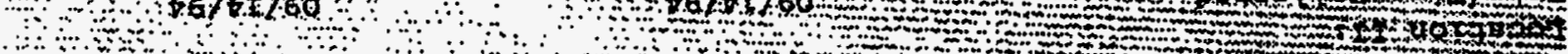
: a

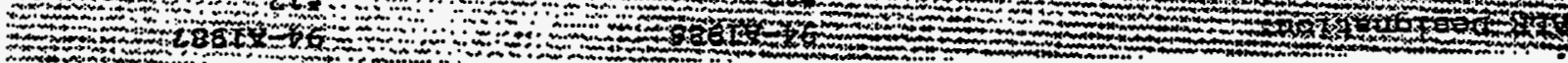

$\downarrow 6 / T 2 / 60$ :pantoosy sकtauses ozed

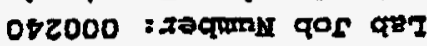

DUI 878TA Kroor 9809 7xadny อxth

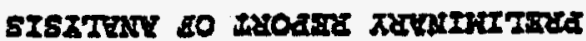

$\varepsilon$ abed

\6/OT/OT IafEd 
Date: 10/10/94

Page 4

PRELIMITRARY REPORT OF AMRAYSIS

Ur Mike Rupert EGEG Rooky Ilats Inc
Iab Job Number: 000240

Date Samples Recelved: 09/21/94

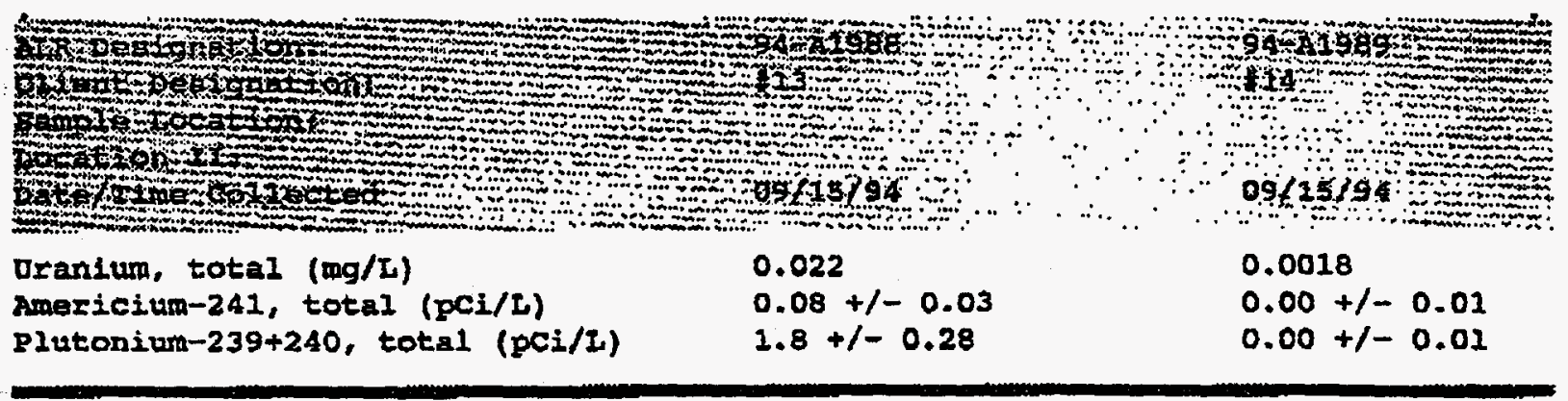

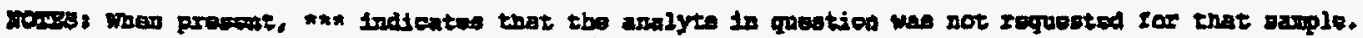


Date: $10 / 10 / 94$

Page 5

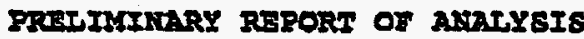

Nr Mike Rupert

ECeE Rocky Flats Inc
Iab Job Number: 000240

Date Samples Received: 09/21/94

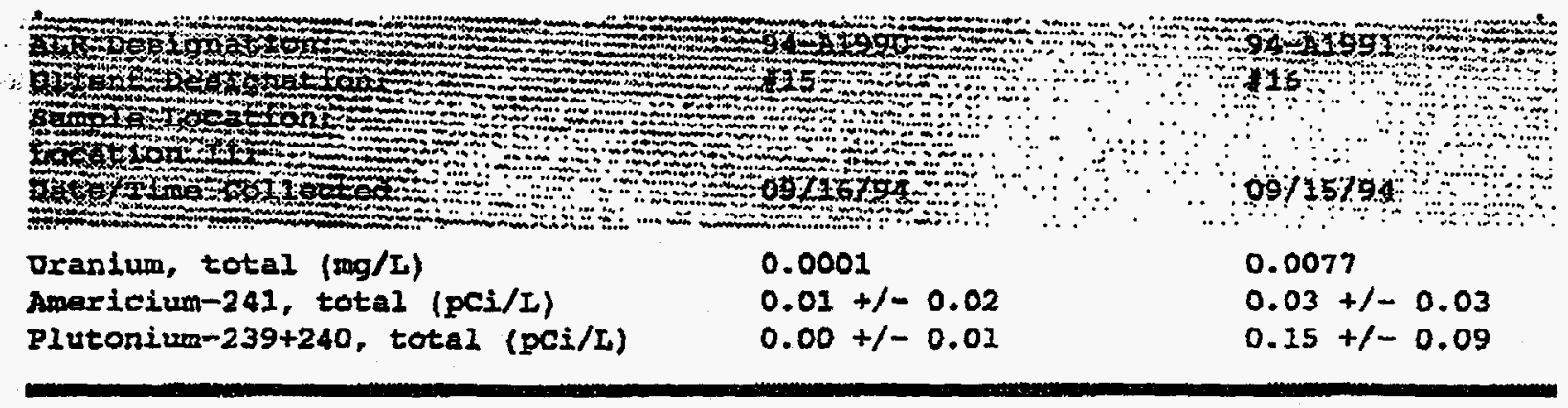


Date: $10 / 10 / 94$

Page 6

Lab Job tumber: 000240

Mr Mike Rupert

Bese Rocky Elata Ine
Date samplea Recelved: 09/21/94

Variability of the racioactive disintegration process (counting error) at the 958 confidence level is 1.96 Bigma and the level of gignificance may exceed that of the reported analytical result.

scheduled sarole disposal date: .

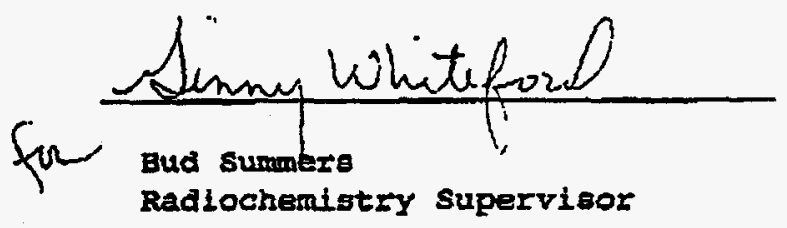

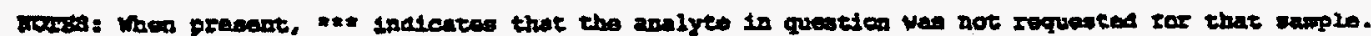




\section{Accu-Labs Research, Inc.}

1663 Table Mountain Drive Golden, Colorado 80403-1650 303) 277.9514

FAX (303) 277.9512

Date: $10 / 25 / 94$

Page 1

\section{REPORT OF ANALYSIS}

Mr Mike Rupert

EG\&G Rocky Flats Inc

Rocky Flats Env Tech Site

POB 464 Bldg 080

Golden, $\mathrm{CO}$ 80402-0464
Lab Job Number: 000240

Date Samples Received: 09/21/94

Customer PO Number: ASC 233268JO3 CORRECTED REPORT
$94-A 1978$

11

$09 / 15 / 94$

0.0011

$0.01+/-0.11$

$0.12+/-0.03$

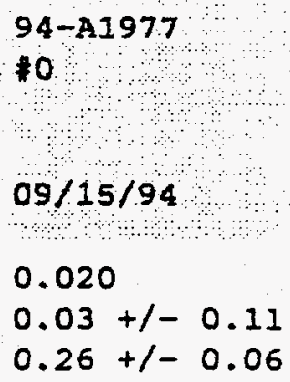

$\therefore$

ALR Designation:

client Deaignation:

sample Iocation:

Location II:

Date/Time collected

Uranium, total (mg/L)

Americium-24I, total (pCi/I)

Plutonium-239+240, total (pCi/I)

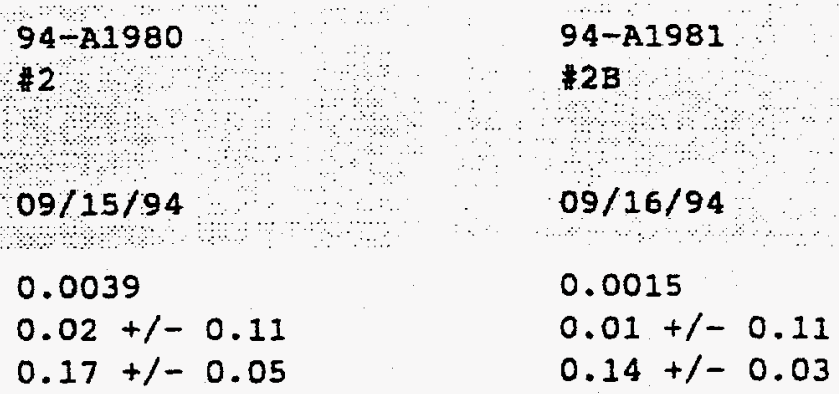

NOTES: When present, $* * *$ indicates that the analyte in question was not requested for that sample. 


\section{Accu-Labs Research, Inc.}

Date: $10 / 25 / 94$

Page 2

\section{REPORT OF ANALYSIS}

Mr Mike Rupert

EG\&G Rocky Flats Inc

ALR Designation:

Client Designation:

Sample tocation:

Location II:

Date/Time collected

Uranium, total (mg/L)

Americium-241, total (pCi/L)

Plutonium-239+240, total (PCi/L)
Lab Job Number: 000240

Date Sampleg Received: 09/21/94 CORRECTED REPORT

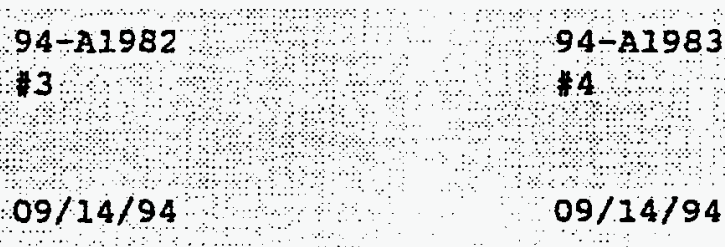

0.034

0.030

$0.04+/-0.11$

$0.02+/-0.11$

$1.1+/-0.10$
ATR Designation:

Client Deaignation:

Sample rocation:

Location II:

Date/Time Collected

Uranium, total (mg/I)

Americium-241, total (pCi/I)

Plutonium-239+240, total (pCi/L)
$94-\$ 1984$

49

$09 / 15 / 94$

0.0018

$0.04+/-0.11$

$0.10+/-0.04$
$94-A 1985$

$\$ 10$

$09 / 16 / 94$

0.0069

$0.03+/-0.11$

$0.10+/-0.03$
AIR Designation:

$94-\mathrm{A} 2986$

411

Client Designation:

Sample Location:

Location II:

Date/Time collected

Uranium, total (mg/L)

Americium-241, total (pCi/L)

Plutonium-239+240, total (pCi/I)
OS: $24 / 54$

0.027

$0.00+1-0.01$

$0.19+1-0.05$
$09 / 14 / 54$

94-A1987

$\# 12$

0.025

$0.02+1-0.03$

$0.20+1-0.05$

NOTES: When present, ** Indicates that the analyte in question was not requested for that sample. 


\section{Accu-Labs̊ Research, Inc.}

Date: $10 / 25 / 94$

Page 3

REPORT OF ANALYSIS

Mr Mike Rupert

EG\&G Rocky Flats Inc
Lab Job Number: 000240

Date Samples Received: 09/21/94 CORRECTED REPORT
ATR Designat ion:
$94-11988$

113

Client Designatson:

sample tocation:

Location II:

Date/Time Collectea

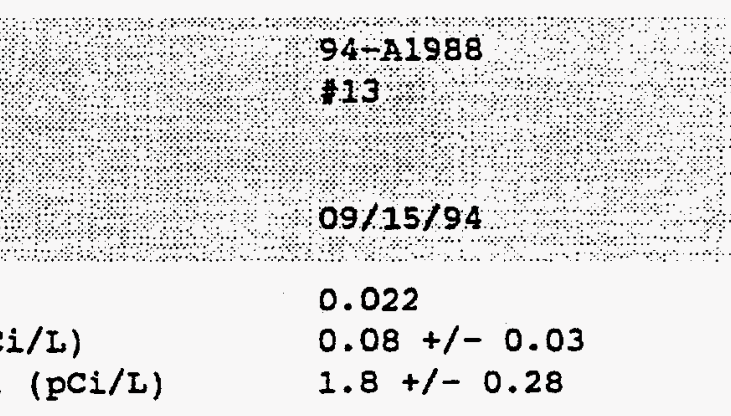

0.022

Uranium, total (mg/L)

Americium-241, total (pCi/I)

Plutonium-239+240, total (pCi/I)

$1.8+1-0.28$
$94-11990$

115

$09 / 16 / 94$

0.0001

$0.01+1-0.02$

$0.00+/-0.01$
$94-A 1989$

114

$09 / 15 / 94$

0.0018

$0.00+/-0.01$

$0.00+1-0.01$

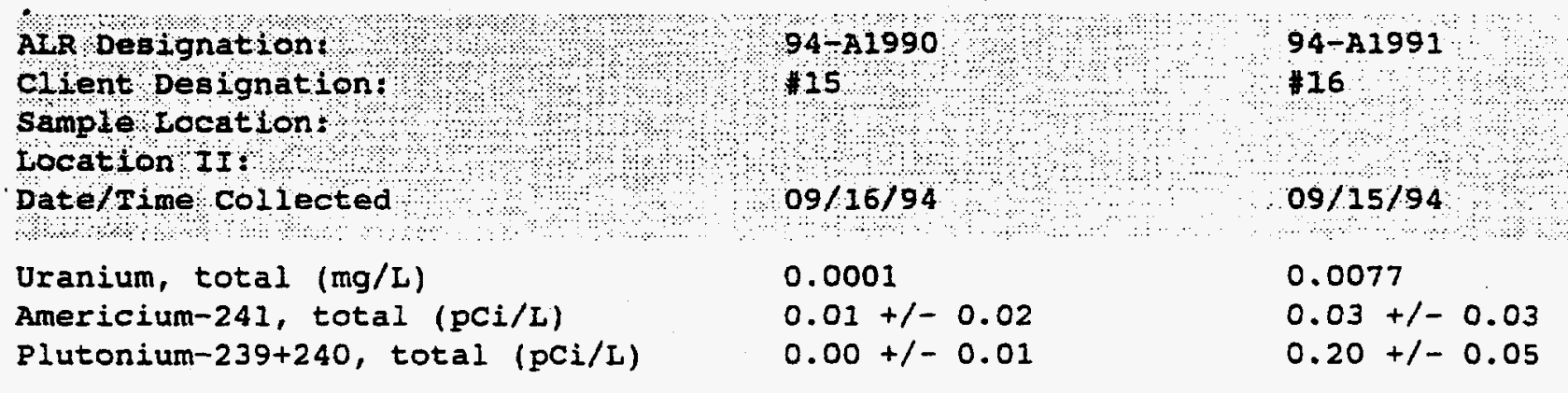

Variability of the radioactive disintegration process (counting error) at the 958 confidence level is 1.96 sigma and the level of significance may exceed that of the reported analytical result.

Scheduled sample disposal date: November 24, 1994.

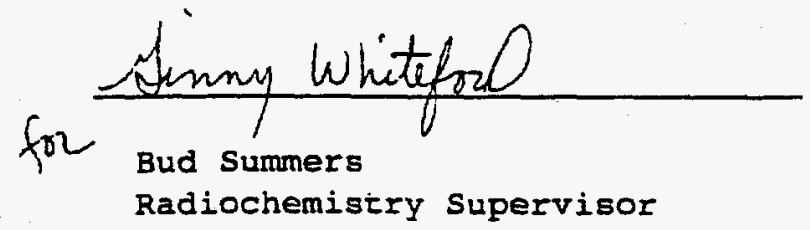

NorBs: When present, *** indicates that the analyte in question was not requested for that sample. 
Potassium Ferrate Treatment of RFETS Groundwater

Document Number:

Section:

Page:
RF/ER-94-0028.UN

Appendix C, Rev. 0

\section{APPENDIX C}

ANALYTICAL REPORTS OF THE PRODUCTS FROM PHASE III TESTS 


\section{Accu-Labs Research, Inc.}

663 Table Mountain Drive Golden, Colorado 80403-1650

303) 277.9514

FAX (303) 277.9512

COMPLETED REPORT

J.C. IAUL

EG\&G ROCKY FLATS

ENVIRONMENTAL TECHNOLOGY SITE

$P$ O BOX 464 BLDG 881

GOLDEN, CO 80402-0464

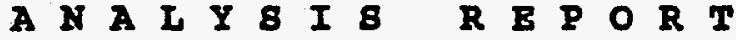

DATE: $11 / 29 / 94$ PAGE 1

These semples to be disposed of 30 days after the date of this report.

\begin{tabular}{|c|c|c|c|c|}
\hline $\begin{array}{l}\text { ALR Designation - } \\
\text { Sponsor Designation - } \\
\text { Dete Collected : }\end{array}$ & $\begin{array}{l}2426-57356-5-1 \\
\text { FEED SOLUTION } \\
10 / 20 / 94\end{array}$ & $\begin{array}{l}2426-57356-5-2 \\
\text { TEST \#1 } \\
10 / 21 / 94\end{array}$ & $\begin{array}{l}2426-57356-5-3 \\
\text { TEST } \$ 2 \\
10 / 21 / 94 \\
\end{array}$ & $\begin{array}{l}2426-57356-5- \\
\text { TEST } \$ 3 \\
10 / 26 / 94\end{array}$ \\
\hline \multicolumn{5}{|l|}{ Determinations in $\mathrm{mg} / \mathrm{L}$ unless noted } \\
\hline silver - total & 0.030 & $<0.005$ & $<0.005$ & $<0.005$ \\
\hline Aluminum - total & 20 & $<0.1$ & $<0.8$ & $<0.1$ \\
\hline Bariun - total & 0.28 & $<0.05$ & $<0.05$ & $<0.05$ \\
\hline Beryllium - total & $<0.005$ & $<0.005$ & $<0.005$ & $<0.005$ \\
\hline Calcium - total & 96 & 10 & 12 & 12 \\
\hline Cadnium - total & $<0.005$ & $<0.005$ & $<0.005$ & $<0.005$ \\
\hline Cobalt - total & $<0.01$ & $<0.01$ & $<0.01$ & $<0.01$ \\
\hline Chromium - total & 0.026 & $<0.005$ & $<0.005$ & $<0.005$ \\
\hline Copper - total & 0.030 & $<0.005$ & $<0.005$ & $\infty .005$ \\
\hline Iron - total & 22 & 0.02 & 0.02 & 0.02 \\
\hline Potassium - total & 7.4 & 150 & 140 & 140 \\
\hline Lithium - total & 0.15 & 0.14 & 0.14 & 0.14 \\
\hline Magnesium - total & 31 & 8.4 & 10 & 10 \\
\hline Manganese - total & 0.29 & $<0.005$ & $<0.005$ & $<0.005$ \\
\hline Molybolemm - total & 0.01 & $<0.01$ & $<0.01$ & $<0.01$ \\
\hline Sodium - total & 150 & 150 & 150 & 160 \\
\hline Nickel - total & $<0.05$ & $<0.05$ & $<0.05$ & $<0.05$ \\
\hline Antimony - total & $<0.05$ & $<0.05$ & $<0.05$ & 40.05 \\
\hline Selenium - total & 0.10 & 0.08 & $<0.05$ & 0.07 \\
\hline Thallium - total & $<0.5$ & $<0.5$ & $<0.5$ & $<0.5$ \\
\hline Vanadiun - total & 0.045 & $<0.005$ & $<0.005$ & $\infty .005$ \\
\hline Zinc - total & 0.093 & $<0.005$ & $<0.005$ & $<0.005$ \\
\hline Alkalinity, Total (as $\mathrm{CaCO}$ to pH 4.5 ) & 90 & $\cdots$ & 50 & $\cdots$ \\
\hline Carbonate (as co3) & $<5$ & $\cdots$ & 24 & $\cdots$ \\
\hline Bicarbonate (as HCO3) & 110 & $\ldots$ & 12 & $\cdots$ \\
\hline
\end{tabular}

An Environmental Laboratory Specializing in:

Organic Chemistry - Metals Analysis - Inorganic Chemistry - Radiochemistry - Spark Source Mass Spectrometry 


\title{
Accu-Labs Research, Inc.
}

\author{
A N A I \\ DATE: $11 / 29 / 94$ PAGE 2 \\ Lab Job Number 2426-57356-5
}

These samples to be disposed of 30 days after the date of this report.

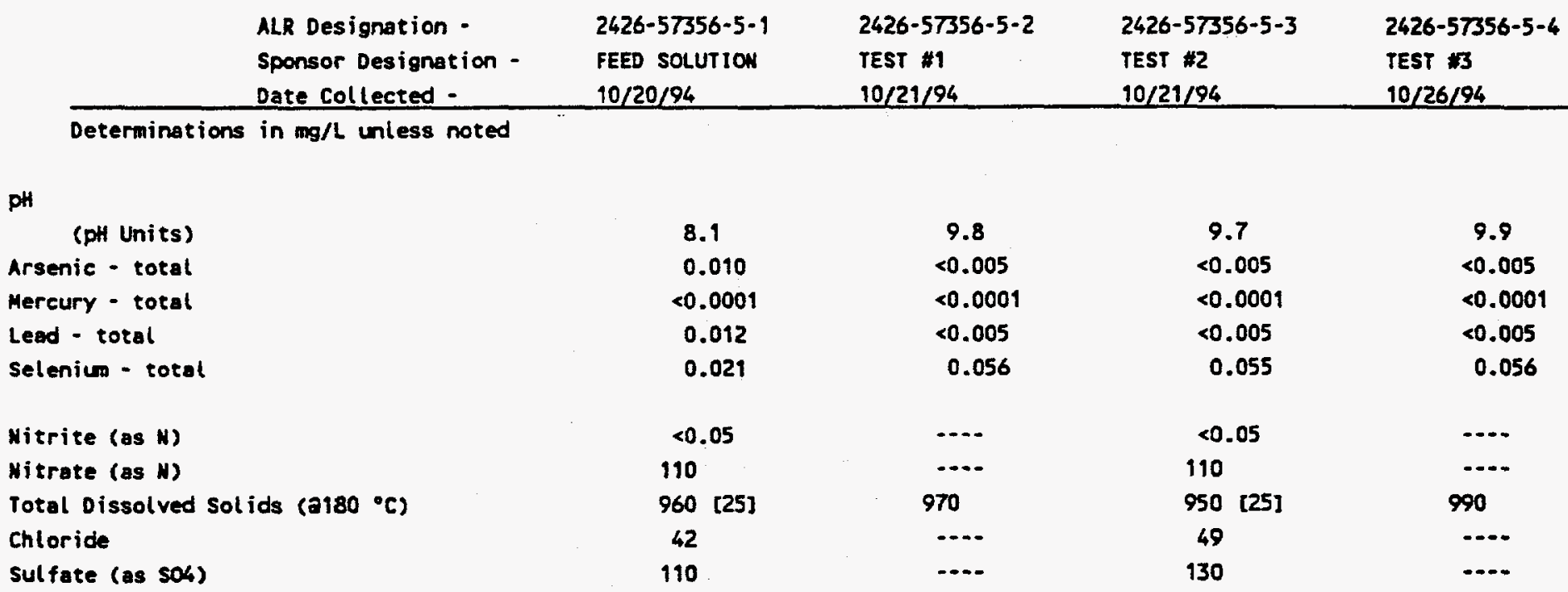




\section{Accu-Labs Research, Inc.}

\section{A N A I \\ DATE: $11 / 29 / 94$ PAGE 3 \\ Lab Job Number 2426-57356-5}

These samples to be disposed of 30 days after the date of this report.
ALR Designation -
2426-57356-5-5
Sponsor Designation - TEST
Date Collected -
$10 / 26 / 94$

Determinations in $\mathrm{mg} / \mathrm{L}$ unless noted

$\begin{array}{lc}\text { Silver - total } & <0.005 \\ \text { Aluninum - total } & <0.1 \\ \text { Barium - total } & <0.05 \\ \text { Beryllium - total } & <0.005 \\ \text { Calcium - total } & 13 \\ & \\ \text { Cactnium - total } & <0.005 \\ \text { Cobalt - total } & <0.01 \\ \text { Chromium - total } & <0.005 \\ \text { Copper - total } & <0.005 \\ \text { Iron - total } & 0.02 \\ & \\ \text { Potassium - total } & 140 \\ \text { Lithium - total } & 0.14 \\ \text { Magnesium - total } & 11 \\ \text { Manganese - total } & <0.005 \\ \text { Molyboencm - total } & <0.01 \\ \text { Sodium - total } & 160 \\ \text { Nickel - total } & <0.05 \\ \text { Antimony - total } & <0.05 \\ \text { Selenium - total } & 0.08 \\ \text { Thallium - total } & <0.5 \\ \text { Vanodium - total } & <0.005 \\ \text { Zine - total } & <0.005 \\ \text { pH } & \\ \text { Arsenic - total } & 8.8 \\ \text { Mercury - total } & <0.005 \\ & <0.0001\end{array}$




\title{
Accu-Labs Research, Inc.
}

\author{
A N A I Y 8 I $B$ R E P O R T \\ DATE: $11 / 29 / 94$ PAGE 4 \\ Lab Job Number 2426-57356-5
}

These samples to be disposed of 30 days after the date of this report.

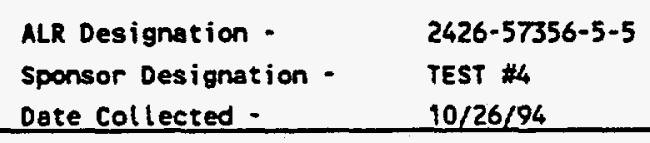

Lead - total

Seleniun - total

Total Dissolved Solids (a180 ${ }^{\circ} \mathrm{C}$ )

\author{
$<0.005$ \\ 0.058 \\ 1,000
}

Notes:

[25] -- RESULT VERIFIED BY REANALYSIS.

By: Euda Jlevomulo

Eyda Hergenryeder

Metals Labolatory supervisor

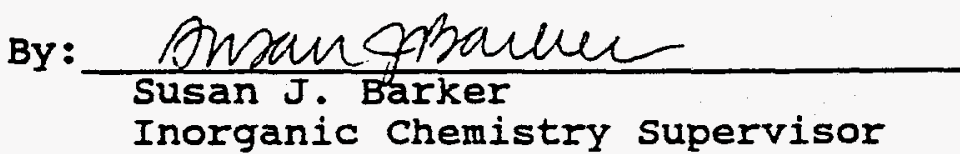

$\mathrm{EH} / \mathrm{SJB} / \mathrm{rth}$ 


\section{Accu-Labs ${ }^{\circledR}$ Research, Inc.}

663 Table Mountain Drive Golden. Colorado 80403.1650

03) 277.9514

FAX (303) 277.9512

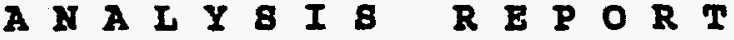
DATE: $11 / 21 / 94$ PAGE 1

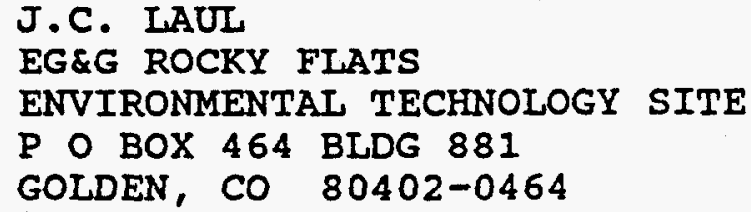

These samples to be disposed of 30 days after the date of this report.
Lab Job Number: 2426-57355-1

Date Samples Received: 10/26/94

Customer PO Number: ASC233268J03

.

$\begin{array}{ll}\text { ALR Designation - } & 2426-57355-1-1 \\ \text { Sponsor Designation - } & \text { TRU/CLEAR SOLID } \\ \text { Comments - } & \text { (PHASE 3) }\end{array}$

Date collected.

Determinations in $\mathrm{mg} / \mathrm{kg}$ unless noted

\begin{tabular}{|c|c|}
\hline Silver - total & 21 \\
\hline Aluminum - total & 15,000 \\
\hline Barium - total & 150 \\
\hline Beryllium - total & 1.0 \\
\hline Calcium - total & 55,000 \\
\hline Cadniun - total & 0.6 \\
\hline Cobalt - total & 6 \\
\hline Chromium - total & 17 \\
\hline Copper - total & - 27 \\
\hline Iron - total & 15,000 \\
\hline Potassium - total & 3,500 \\
\hline Lithium - total & 19 \\
\hline Magnesium - total & 14,000 \\
\hline Manganese - total & 200 \\
\hline Molyboiemm - total & 1 \\
\hline Sodium - total & 580 \\
\hline Nickel - total & 18 \\
\hline Ant imony - total & $<5$ \\
\hline Selenium - total & $<5$ \\
\hline Thallium - total & $<50$ \\
\hline Vanadiun - total & 25 \\
\hline Zinc - total & 60 \\
\hline Arsenic - total & 7.2 \\
\hline Mercury - total & $<0.1$ \\
\hline Leed - total & 11 \\
\hline
\end{tabular}

An Environmental Laboratory Specializing in:

Organic Chemistry - Metals Analysis - Inorganic Chemistry - Radiochemistry - Spark Source Mass Spectrometry 


\section{Accu-Labs Research, Inc.}

\section{A $N$ A I $Y$ Y I I 8 R E P O R T DATE: $11 / 21 / 94$ PAGE 2 \\ Lab Job Number 2426-57355-1}

These samples to be disposed of 30 days after the date of this report.

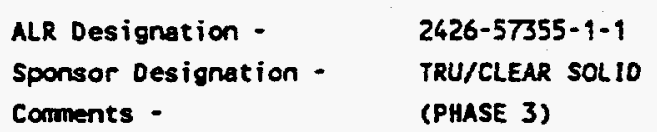

Determinetions in $\mathrm{mg} / \mathrm{kg}$ unless noted

Selenium - totol

Notes:

[ 9] -- HIGHER D.L. DUE TO SAMPLE MATRIX INTERFERENCE

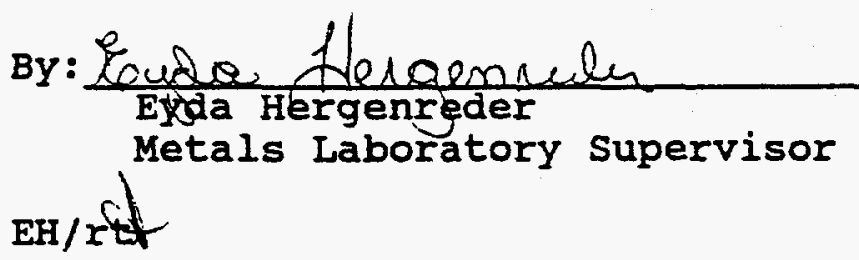




\section{Accu-Labs Research, Inc.}

663 Table Mountain Drive Golden. Colorado 80403-1650 303) 277.9514 FAX (303) 277.9512

Date: $12 / 12 / 94$

Page 1

\section{REPORT OF ANALYSIS}

Mr Mike Rupert

EG\&G Rocky Flats Inc

Rocky Flats Env Tech Site

POB 464 Bldg 080

Golden, CO 80402-0464

ALR Degignation:

Client Degignation:

Sample Location:

Location II:

Datelinime collected
Lab Job Number: 000383

Date Samples Received: $10 / 26 / 94$

Customer PO Number: ASC233268JO3
Uranium, total (mg/L)

Americium-241, total (pci/L)

Plutonium-239+240, total ( $\mathrm{pCi} / \mathrm{L}$ )
0.040
$0.81+1-0.20$
$9.1+1-0.83$

$94-A 2873$

$94-A 2874$

$+1$

$10 \% 21 / 94$
ALR Designation:

Client Designation:

Sample location:

Location: II:

Date/Time collected
$94-A 2875$

$\$ 2$

$10 / 21 \% 94$
94-A2876

* 3

$10 / 26 / 94$
Uranium, total (mg/L)

Anericium-241, total (pCi/L)

Plutonium-239+240, total ( $\mathrm{pCi} / \mathrm{L}$ )
0.0016
$-0.02+/-0.05$
$0.04+1-0.05$

0.0013

$0.00+1-0.01$

$0.02+1-0.04$ 


\section{Accu-Labs Research, Inc.}

Date: $12 / 12 / 94$

Page 2

REPORT OF ANALYSIS

Mr Mike Rupert

EGsG Rocky Flats Inc
Lab Job Number: 000383

Date Samples Received: 10/26/94

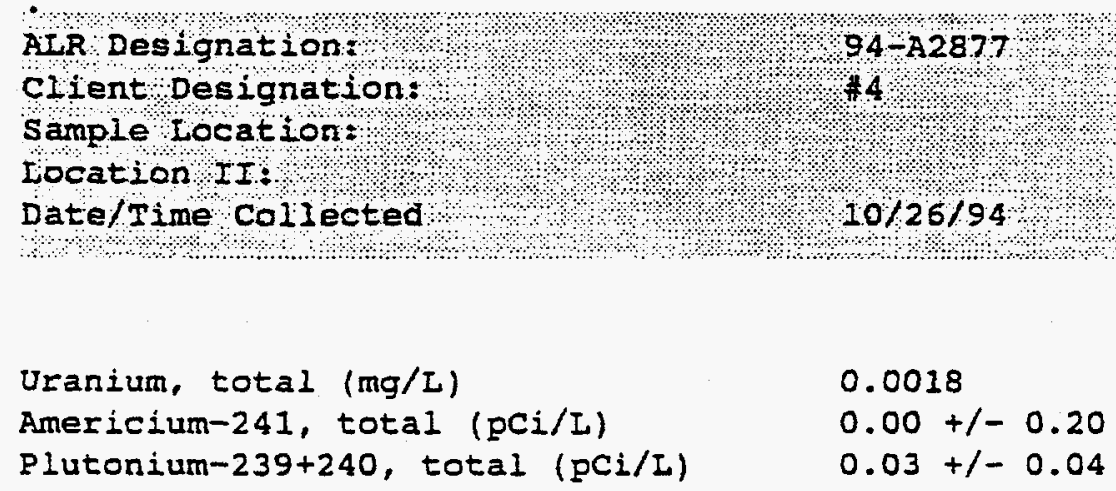

Variability of the radioactive disintegration process (counting error) at the 95\% confidence level is 1.96 sigma and the level of significance may exceed that of the reported analytical result.

Scheduled sample disposal date: January 11, 1995.

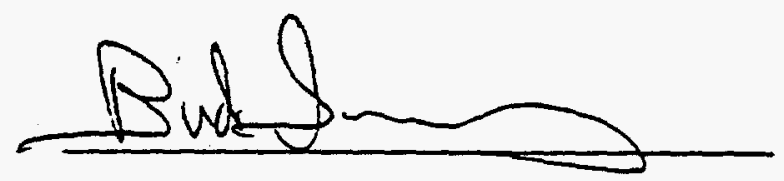

Bud Summers

Radiochemistry Supervisor 
Potassium Ferrate Treatment of RFETS Groundwater

\section{APPENDIX D}

Document Number: Section:

Page:
RF/ER-94-0028.UN

Appendix D, Rev. 0 1 of 30

ECHIP OUTPUT OF PHASE I TESTS 
OJECT NAME: RE3.ECP

eated: Thu Oct 27 14:02:54 1994

mary results

m

Pu

- U

- Al

- . $\mathrm{Ba}$

- . $\quad . \quad \mathrm{Cr}$

. $. \quad . \quad . \mathrm{Ee}$

. $. \quad . \quad . \quad . \quad \mathrm{Se}$

. $. \quad . \quad . \quad . \quad . \quad . \quad A g$

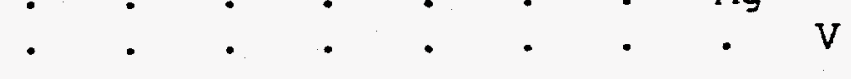

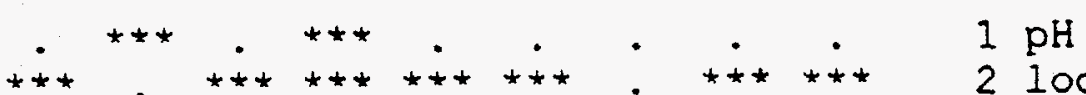

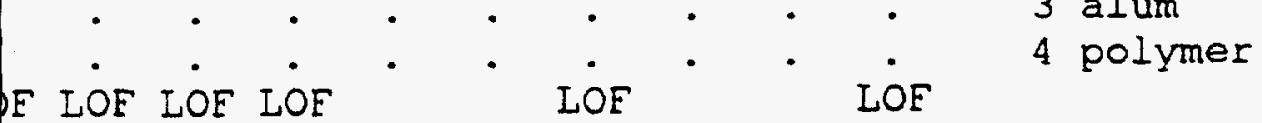


PROJECT NAME: RF3.ECP

Created: Thu Oct 27 14:02:47 1994

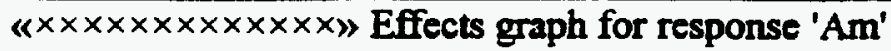

\section{LACK-OF-FTI}

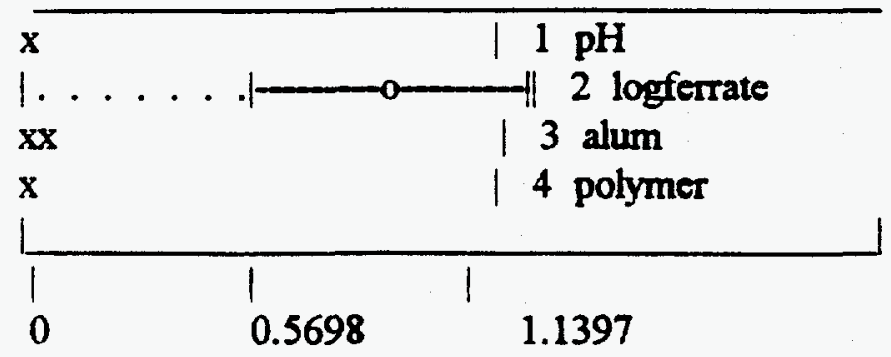

**Pareto effects graph for response 'Am'***

LACK-OF-FIT

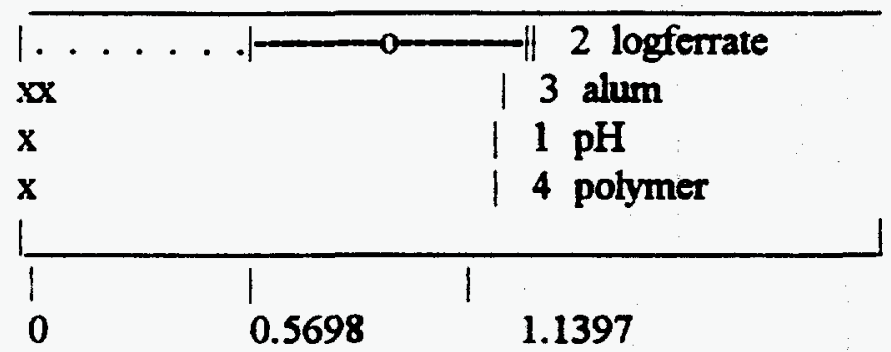

« $x \times x \times x \times x \times x \times x \times x »$ Effects graph for response 'Pu'

\section{LACK-OF-FIT}

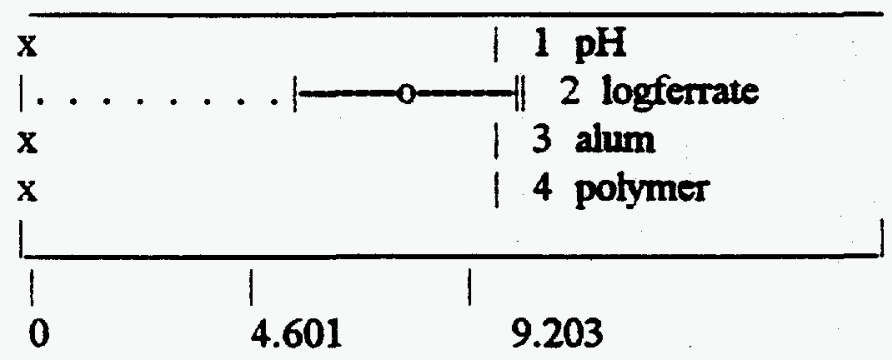


**Pareto effects graph for response 'Pu'**

\section{LACK-OF-FIT}

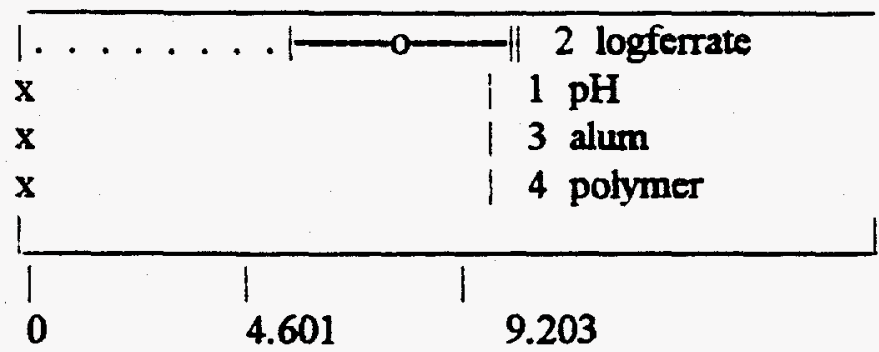

$« \times \times \times \times \times \times \times \times \times \times \times \times \times)$ Effects graph for response $U$

\section{LACK-OF-FIT}

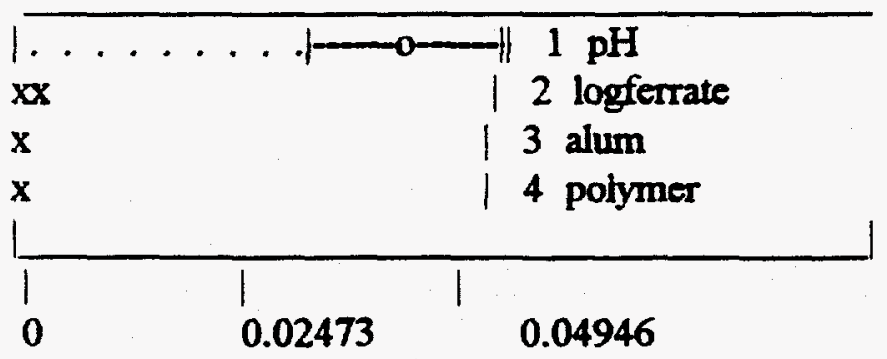

**Pareto effects graph for response $U^{* * *}$

LACK-OF-FIT

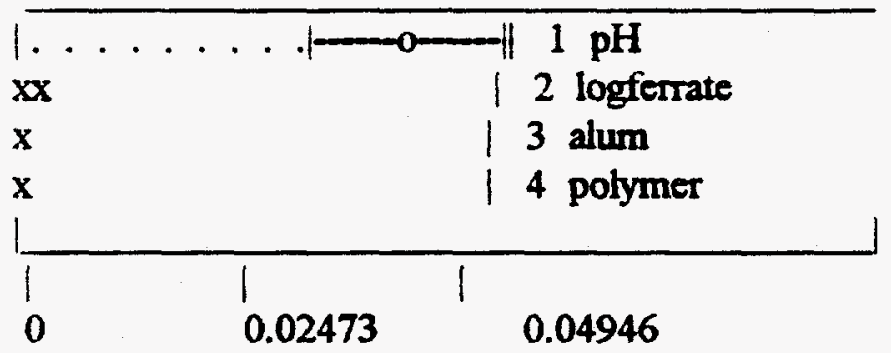


« $\times \times \times \times \times \times \times \times \times \times \times \times \times \gg$ Effects graph for response ' $\mathrm{Al}$ '

LACK-OF-FIT

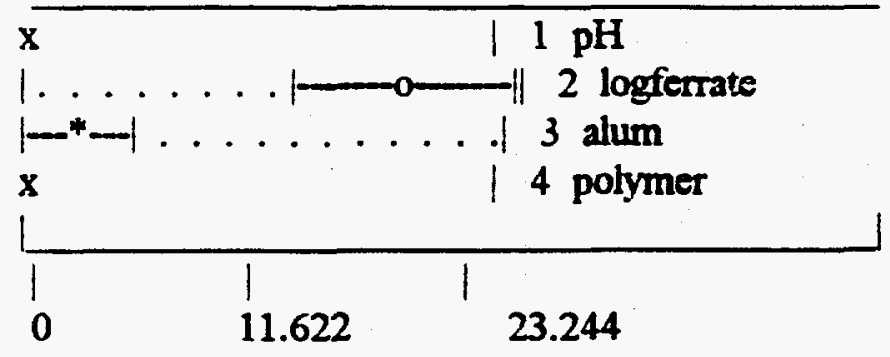

**Pareto effects graph for response 'Al'**

LACK-OF-FIT

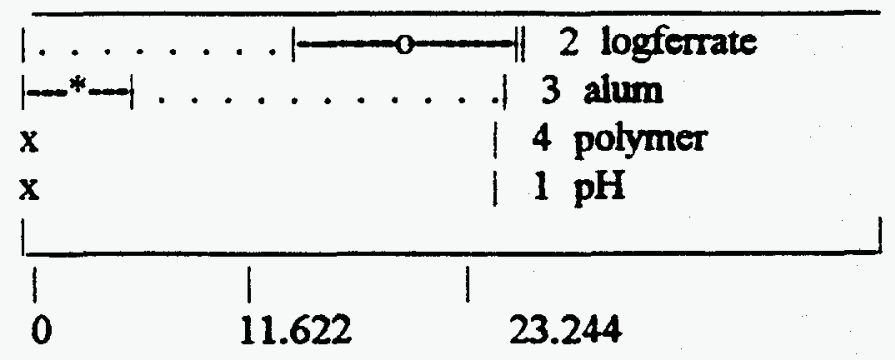

« $x \times x \times x \times x \times x \times x \times x\rangle$ Effects graph for response 'Ba'

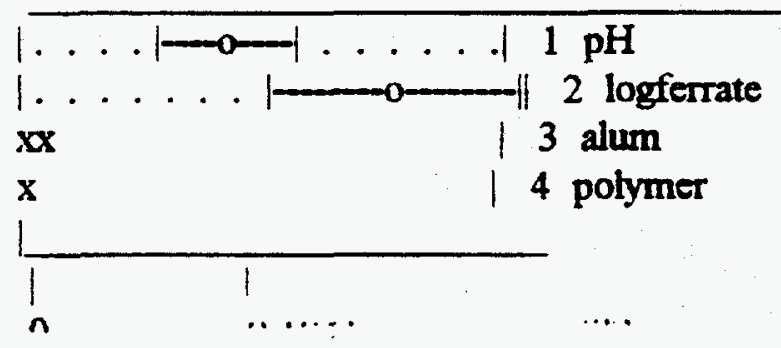


raph tor response ' $\mathrm{Ba}^{\prime * * *}$

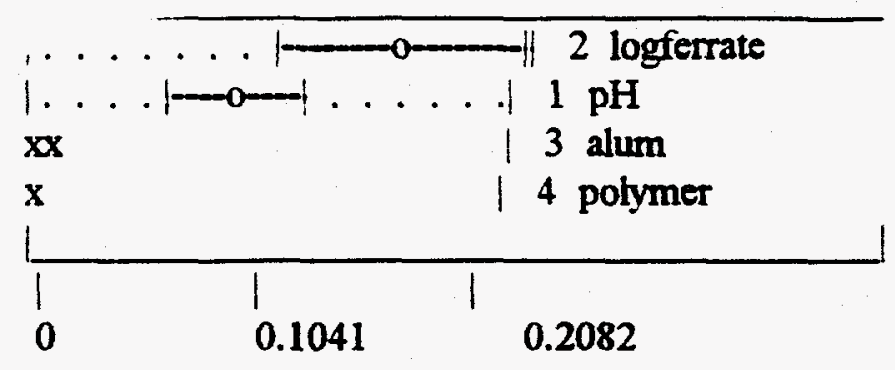

« $x \times x \times x \times x \times x \times x \times x\rangle$ Effects graph for response ' $\mathrm{Cr}$

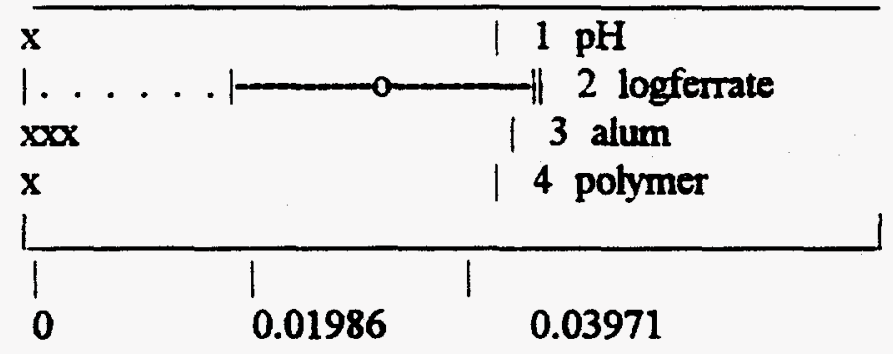

**Pareto effects graph for response 'Cr'***

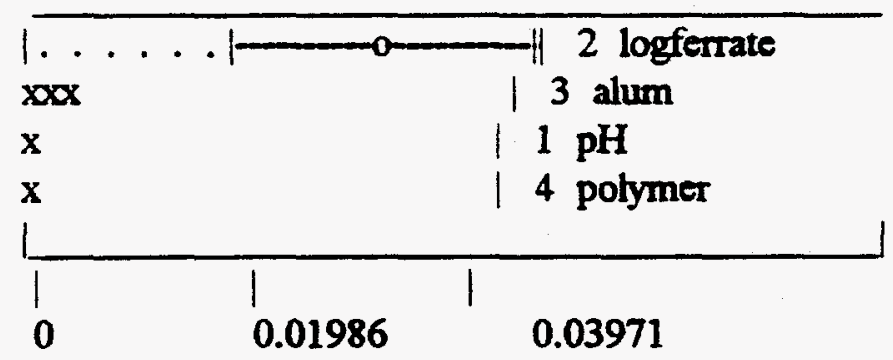


ix $\times x \times x \times x \times x \times x \times x »$ Effects graph for response Fe'

LACK-OF-FIT

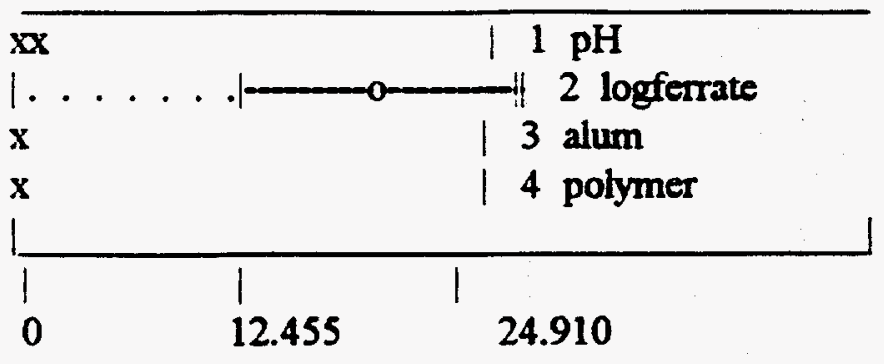

**Pareto effects graph for response $\mathrm{Fe}^{* * *}$

LACK-OF-FIT

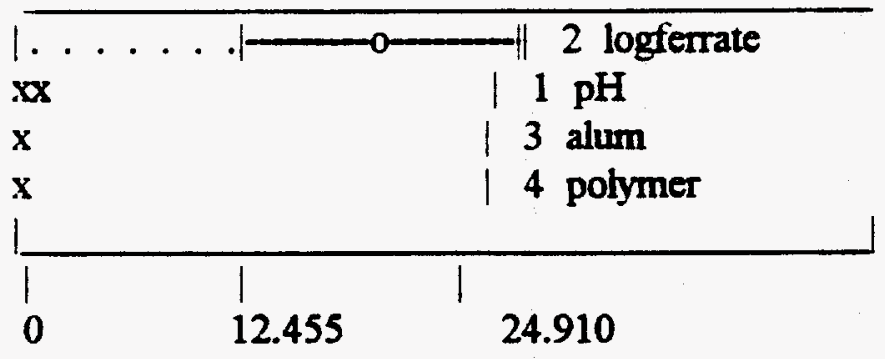

ix $\times x \times x \times x \times x \times x \times \rrbracket$ Effects graph for response 'Se'

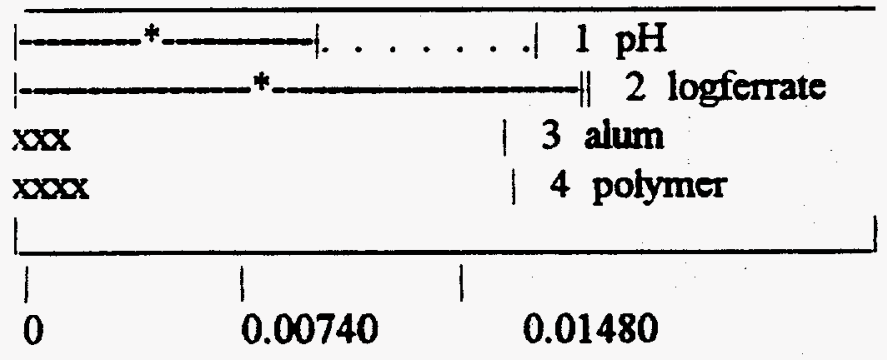


**Pareto effects graph for response ' $\mathrm{Se}^{* * *}$

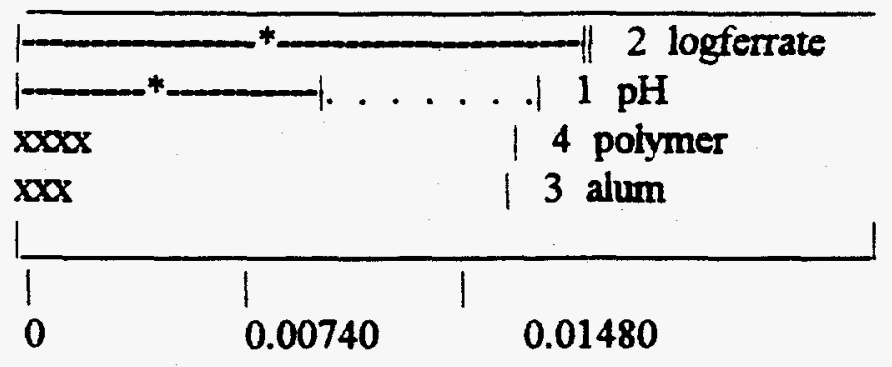

« $x \times x \times x \times x \times x \times x \times x\rangle$ Effects graph for response 'Ag'

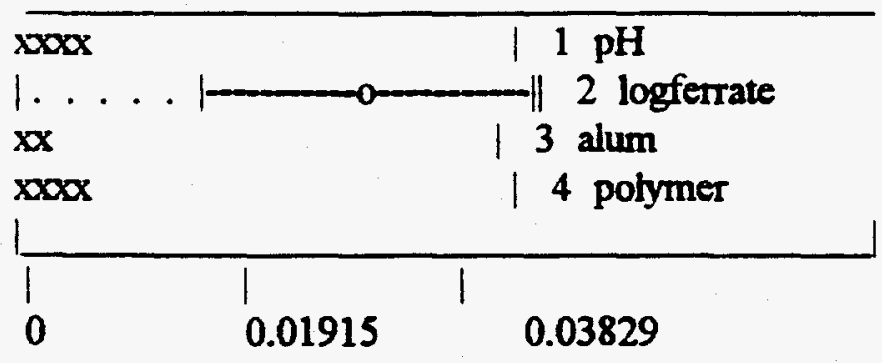

**Pareto effects graph for response 'Ag'***

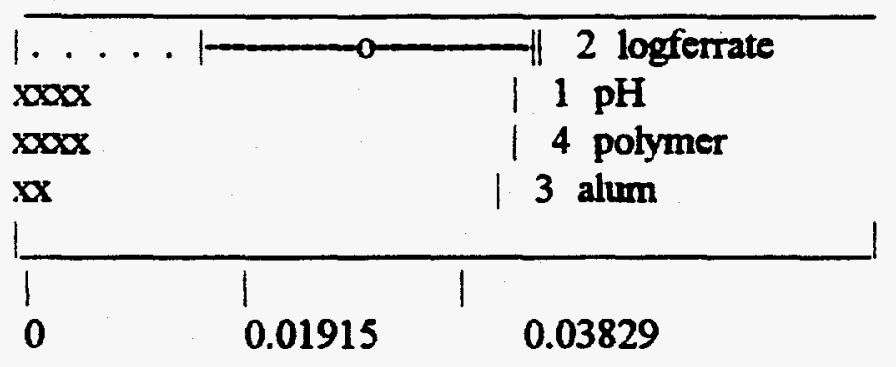


« $\times \times \times \times \times \times \times x \times x \times \times \times$ Effects graph for response ' $V$ '

\section{LACK-OF-FIT}

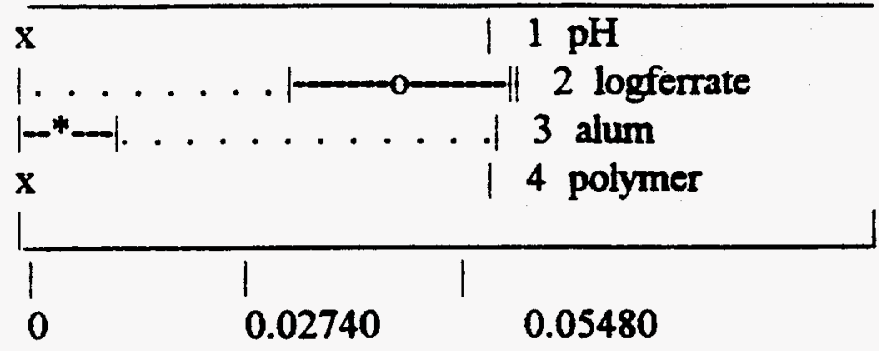

**Pareto effects graph for response $V$ !**

\section{LACK-OF-FIT}

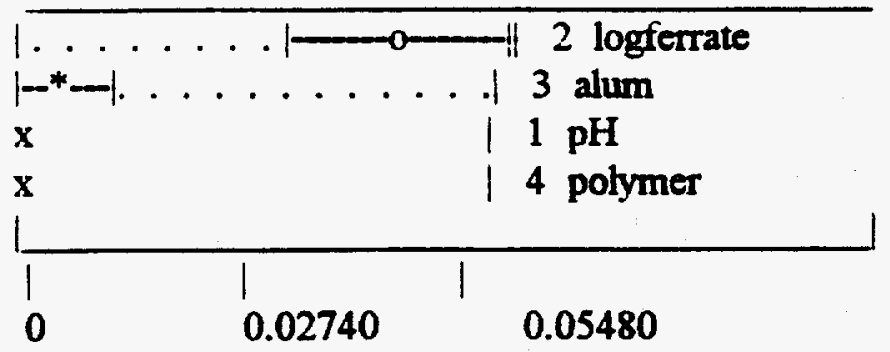


PROJECT NAME: RF3.ECP

Created: Thu Oct 27 14:02:43 1994

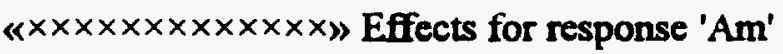

\section{LACK-OF-FIT}

EFFECTS RESLTN SIG TERM

$$
\begin{array}{ccc}
0.3328 & & 0 \text { CONSTANT } \\
-0.0186 & 0.1626 & 1 \text { pH } \\
-0.8666 & * * * & 2 \text { logferrate } \\
0.0397 & 0.2035 & 3 \text { alum } \\
-0.0099 & 0.1549 & 4 \text { polymer }
\end{array}
$$

$$
\begin{array}{ll}
\text { Residual SD } & =0.096570 \\
\text { Replicate SD } & =0.034157 \\
N \text { terms } & =5 \\
N \text { unique trials } & =12 \\
N \text { replicates }=3 \\
N \text { total trials }=15
\end{array}
$$

« $x \times x \times x \times \times x \times x \times x \times x \times \rrbracket$ Effects for response 'Pu'

\section{LACK-OF-FIT}

\section{EFFECTS RESLTN SIG TERM}

$$
\begin{array}{ccc}
3.068 & & 0 \text { CONSTANT } \\
-0.211 & 1.146 & 1 \mathrm{pH} \\
-7.429 & * * * & 2 \text { logferrate } \\
0.188 & 1.252 & 3 \text { alum } \\
0.100 & 1.043 & 4 \text { polymer }
\end{array}
$$

Residual SD $=\mathbf{0 . 6 2 7 4 2 0}$

Replicate SD $=0.046726$ 
$\mathrm{N}$ terms $\quad=5$

$\mathrm{N}$ unique trials $=12$

$\mathrm{N}$ replicates $=3$

$\mathrm{N}$ total trials $=15$

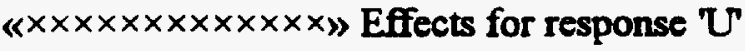

\title{
LACK-OF-FIT
}

EFFECTS RESLTN SIG TERM
0.01796
0 CONSTANT
$-0.04118$
*** $1 \mathrm{pH}$
$-0.002310 .01801 \quad 2$ logferrate
$0.000620 .01003 \quad 3$ alum
$-0.000260 .00860 \quad 4$ polymer

\author{
Residual SD $=0.005551$ \\ Replicate SD $=0.000524$ \\ $\mathrm{N}$ terms $\quad=5$ \\ $\mathrm{N}$ unique trials $=12$ \\ $\mathrm{N}$ replicates $=3$ \\ $\mathrm{N}$ total trials $=15$
}

« $\times \times \times \times \times \times \times \times \times \times \times \times \times \times \gg$ Effects for response 'Al'

\section{LACK-OF-FIT}

EFFECTS RESLTN SIG TERM

$\begin{array}{crl}7.999 & & 0 \text { CONSTANT } \\ 0.092 & 2.483 & 1 \mathrm{pH} \\ -18.712 & * * * & 2 \text { logferrate } \\ 1.891 & 4.610 & \text { 3 alum } \\ 0.392 & 2.800 & 4 \text { polymer }\end{array}$

Residual SD $=1.602920$

Replicate SD $=\mathbf{0 . 2 0 4 1 2 4}$ 

$\mathrm{N}$ terms$$
=5
$$
$N$ unique triais $=12$
$\mathrm{N}$ replicates $=3$
$\mathrm{N}$ total trials $=15$

« $x \times x \times x \times x \times x \times x \times x\rangle$ Effects for response 'Ba'

\section{EFFECTS RESLTN SIG TERM}

$\begin{array}{rrr}0.0960 & & 0 \text { CONSTANT } \\ -0.0925 & * * * & 1 \text { pH } \\ -0.1633 & * * * & 2 \text { logferrate } \\ -0.0081 & 0.0351 & 3 \text { alum } \\ 0.0019 & 0.0258 & 4 \text { potymer }\end{array}$

Residual SD $=0.015913$

Replicate SD $=0.000000$

$\mathrm{N}$ terms $\quad=5$

$\mathrm{N}$ unique trials $=12$

$\mathrm{N}$ replicates $=3$

$\mathrm{N}$ total trials $=15$

$\ll \times x \times \times \times \times \times \times \times x \times x \times »$ Effects for response ' $\mathrm{Cr}$ '

EFFECTS RESLTN SIG TERM
0.01214
0 CONSTANT
$0.000490 .00613 \quad 1 \mathrm{pH}$
$-0.02901$
*** 2 logferrate
$0.002460 .00889 \quad 3$ alum
$-0.000360 .00604 \quad 4$ polymer

Residual SD $=0.003786$

Replicate SD $=0.000000$

$\mathrm{N}$ terms $\quad=5$

$\mathrm{N}$ unique trials $=12$ 
$N$ replicates $=3$

$\mathrm{N}$ total trials $=15$

«xx $x \times x \times x \times x \times x \times x\rangle$ Effects for response 'Fe'

\section{LACK-OF-FIT}

EFFECTS RESLTN SIG TERM
8.266
0 CONSTANT
0.976
4.140
$1 \mathrm{pH}$
$-18.909$
*** 2 logferrate
$\begin{array}{lll}0.456 & 4.056 \quad 3 \text { alum }\end{array}$
$0.342 \quad 3.530 \quad 4$ polymer

Residual SD $=2.122410$

Replicate SD $=\mathbf{0 . 0 9 0 1 8 5}$

$\mathrm{N}$ terms $\quad=5$

$\mathrm{N}$ unique trials $=12$

$\mathrm{N}$ replicates $=3$

$\mathrm{N}$ total trials $=15$

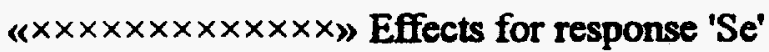

EFFECTS RESLTN SIG TERM
0.04948
0 CONSTANT
0.003360 .00781
$1 \mathrm{pH}$
0.006360 .01480
2 logferrate
$-0.000990 .00605$
3 alum
$-0.001430 .00592$
4 polymer

Residual SD $=0.002985$

Replicate SD $=0.002082$

$\mathrm{N}$ terms $\quad=5$

$\mathrm{N}$ unique trials $=12$

$\mathrm{N}$ replicates $=3$ 
$\mathrm{N}$ total trials $=15$

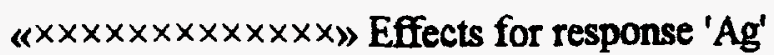

EFFECTS RESLTN SIG TERM
0.01334
0 CONSTANT
0.003080 .00910
$1 \mathrm{pH}$
$-0.02690$
*** 2 logferrate
$0.001890 .00873 \quad 3$ alum
$-0.003020 .00907 \quad 4$ polymer

Residual SD $=0.004031$

Replicate SD $=0.002041$

$\mathrm{N}$ terms $\quad=5$

$\mathrm{N}$ unique trials $=12$

$N$ replicates $=3$

$\mathrm{N}$ total trials $=15$

« $x \times x \times x \times x \times x \times x \times x »$ Effects for response ' $\mathrm{V}$ '

\section{LACK-OF-FIT}

EFFECTS RESLTN SIG TERM
0.01853
$\begin{array}{lll}0.001130 .00633 & 1 \mathrm{pH} \\ -0.04495 \quad * * * & 2 \text { logferrate }\end{array}$
0 CONSTANT
$0.003650 .00956 \quad 3$ alum
$0.000690 .00592 \quad 4$ polymer

Residual SD $=0.003485$

Replicate SD $=0.000408$

$\mathrm{N}$ terms $=5$

$\mathrm{N}$ unique trials $=12$

$N$ replicates $=3$

$N$ total trials $=15$ 
PROJECT NAME: RF3.ECP

Created: Thu Oct 27 14:02:37 1994

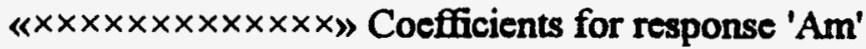

Centered continuous variables

$\begin{array}{llll}\text { COEFFICIENTS SD } & P & \text { CONDITION TERM }\end{array}$

0.332844

$-0.00477232$

$-0.177047$

0 CONSTANT

$0.01657080 .7792-0.943 \quad 1 \mathrm{pH}$

$\begin{array}{llll}0.0250332 & 0.0000 & 0.847 & 2 \text { logferrate }\end{array}$

$\begin{array}{llll}0.000793209 & 0.00147026 & 0.6013-0.841 & 3 \text { alum }\end{array}$

$\begin{array}{llll}-0.00197069 & 0.0130205 & 0.8827-0.866 & 4 \text { polymer }\end{array}$

$\mathrm{N}$ trials $\quad=15$

$\mathrm{N}$ terms $\quad=5$

Residual SD $=0.096570$, Lack-Of-Fit $\mathrm{P}=0.0373$ *

Residual DF $=10$

Residual SD used for tests

Replicate SD $=0.034157$

Replicate DF $=3$

$\mathrm{R}$ Squared $\quad=0.872, \mathrm{P}=0.0002 * * *$

Adj R Squared $=0.821$

Maximum Cook-Weisberg $L D$ influence $($ scaled $0-1)=1.000$

Maximum studentized residual $=7.858 \quad \mathrm{P}=0.0042^{* *}$

- This term may be eliminated

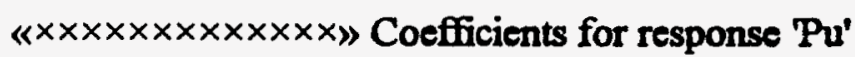

Centered continuous variables

COEFFICIENTS SD $P$ CONDITION TERM

3.06778

0 CONSTANT

$\begin{array}{lllll}-0.0540345 & 0.107661 & 0.6266-0.943 \quad 1 \mathrm{pH}\end{array}$

$\begin{array}{lllll}-1.51764 & 0.1626420 .0000 & 0.847 & 2 \text { logferrate }\end{array}$

$\begin{array}{lllll}0.003753 & 0.00955237 & 0.7026-0.841 \quad 3 \text { alum }\end{array}$ 


\section{$0.0200388 \quad 0.08459450 .8175-0.866 \quad 4$ polymer}

$\mathrm{N}$ trials $\quad=15$

$\mathrm{N}$ terms $\quad=5$

Residual SD $=0.627420$, Lack-Of-Fit $\mathrm{P}=0.0004 * * *$

Residual DF $=10$

Residual SD used for tests

Replicate SD $=0.046726$

Replicate DF $=3$

$\mathrm{R}$ Squared $\quad=0.923, \mathrm{P}=0.0000 * * *$

Adj R Squared $=0.892$

Maximum Cook-Weisberg $L D$ influence (scaled 0-1) $=1.000$

Maximum studentized residual $=9.825 \quad \mathrm{P}=0.0000 * * *$

- This torm may be eliminated

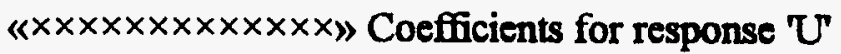

Centered continuous variables

COEFFICIENTS SD $\quad P$ CONDITION TERM

\begin{tabular}{ccccc}
0.0179644 & \multicolumn{4}{c}{0 CONST ANT } \\
-0.0105585 & 0.0009525770 .0000 & 0.943 & $1 \mathrm{pH}$ \\
-0.000472097 & 0.00143904 & $0.7496-$ & 0.847 & 2 logferrate \\
$1.23131 \mathrm{e}-005$ & $8.45186 e-005$ & $0.8871-$ & 0.841 & 3 alum \\
$-5.29126 \mathrm{e}-0.05$ & 0.000748485 & $0.9450-$ & 0.866 & 4 polymer
\end{tabular}

$\mathrm{N}$ trials $\quad=15$

$\mathrm{N}$ terms $\quad=5$

Residual SD $=0.005551$, Lack-Of-Fit $\mathrm{P}=0.0007 * * *$

Residual DF $=10$

Residual SD used for tests

Replicate SD $=0.000524$

Replicate DF $=3$

$R$ Squared $\quad=0.934, P=0.0000 * * *$

Adj R Squared $=0.907$

Maximum Cook-Weisberg LD influence (scaled 0-1) $=1.000$ 
Maximum studentized residual $=9.843 \mathrm{P}=0.0000 * * *$

- This term may be eliminated

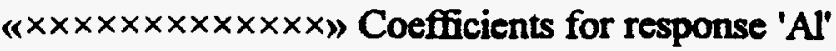

Centered continuous variables

COEFFICIENTS SD $\quad \mathrm{P}$ CONDITION TERM

7.99939

0.0237025

$\begin{array}{llll}-3.8227 & 0.4155150 .0000 & 0.847 & 2 \text { logferrate }\end{array}$

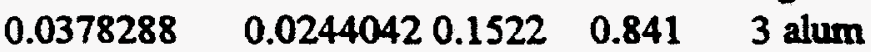

$0.0784541 \quad 0.2161210 .7242-0.866 \quad 4$ polymer

$\mathrm{N}$ trials $\quad=15$

$\mathrm{N}$ terms $\quad=5$

Residual SD $=1.602920$, Lack-Of-Fit $\mathrm{P}=0.0018^{* *}$

Residual DF $=10$

Residual SD used for tests

Replicate SD $=0.204124$

Replicate DF $=3$

$R$ Squared $\quad=0.910, P=0.0000 * * *$

Adj $R$ Squared $=0.874$

Maximum Cook-Weisberg $L D$ influence (scaled 0-1) $=1.000$

Maximum studentized residual $=9.171 \quad \mathrm{P}=0.0001 * * *$

- This term may be eliminated

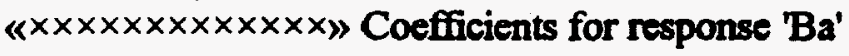

Centered continuous variables

COEFFICIENTS SD $P$ CONDITION TERM

0.0960052

$-0.0237139$

$-0.033352$

0 CONSTANT

$-0.000161626$

$-0.000161626$

$0.004125020 .0000 \quad 0.847 \quad 2$ logferrate

0.000370484

$0.0002422730 .5198-0.841$

3 alum

$0.002145540 .8664-0.866$ 4 polymer 
$N$ trials $\quad=15$

$\mathrm{N}$ terms $\quad=5$

Residual SD $=0.015913$

Residual DF $=10$

Residual SD used for tests

Replicate SD $=0.000000$

Replicate DF $=3$

R Squared $\quad=0.960, \mathrm{P}=0.0000 * * *$

Adj R Squared $=0.944$

Maximum Cook-Weisberg LD influence $($ scaled $0-1)=1.000$

- This term may be eliminated

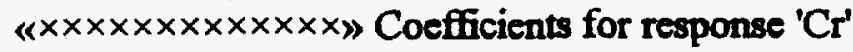

Centered continuous variables

COEFFICIENTS SD $P$ CONDIIION TERM

\begin{tabular}{cccc}
0.0121402 & \multicolumn{3}{c}{ 0 CONSTANT } \\
0.000125132 & $0.0006496360 .8511-$ & 0.943 & $1 \mathrm{pH}$ \\
-0.00592617 & 0.0009813940 .0001 & 0.847 & 2 logferrate \\
$4.92949 \mathrm{e}-005$ & $5.76398 \mathrm{e}-0050.4124-$ & 0.841 & 3 alum \\
$-7.12924 \mathrm{e}-005$ & $0.000510450 .8917-$ & 0.866 & 4 polymer
\end{tabular}

$\mathrm{N}$ trials $\quad=15$

$\mathrm{N}$ terms $\quad=5$

Residual SD $=0.003786$

Residual DF $=10$

Residual SD used for tests

Replicate SD $=0.000000$

Replicate DF $=3$

$\mathrm{R}$ Squared $\quad=0.820, \mathrm{P}=0.0010 * * *$

Adj R Squared $=0.748$

Maximum Cook-Weisberg LD influence $($ scaled 0-1) $=1.000$

Maximum studentized residual $=8.151 \mathrm{P}=0.0021$ **

- This term may be eliminated 


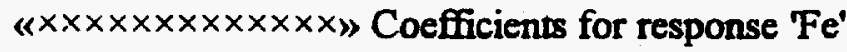

Centered continuous variables

$\begin{array}{llll}\text { COEFFICIENTS } & \text { SD } & P & \text { CONDITION TERM }\end{array}$

\begin{tabular}{|c|c|c|c|}
\hline 8.26555 & \multicolumn{3}{|c|}{0 CONSTANT } \\
\hline 0.25 & $0.3641920 .5077-$ & 0.943 & $1 \mathrm{pH}$ \\
\hline & 0.0000 & 0.847 & \\
\hline $\begin{array}{l}.00912676 \\
.0683267\end{array}$ & $\begin{array}{l}0.0323134 \\
0.7834 \\
0.2861630 .8161\end{array}$ & $\begin{array}{c}0.841 \\
0.866\end{array}$ & 4 polymer \\
\hline
\end{tabular}

$\mathrm{N}$ trials $\quad=15$

$\mathrm{N}$ terms $\quad=5$

Residual SD $=2.122410$, Lack-Of-Fit $\mathrm{P}=0.0001 * * *$

Residual DF $=10$

Residual SD used for tests

Replicate SD $=0.090185$

Replicate DF $=3$

$\mathrm{R}$ Squared $\quad=0.860, \mathrm{P}=0.0003 * * *$

Adj R Squared $=0.804$

Maximum Cook-Weisberg LD influence (scaled 0-1) $=1.000$

Maximum studentized residual $=9.409 \quad \mathrm{P}=0.0000 * * *$

- This term may be eliminated

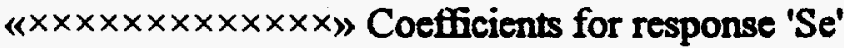

Centered continuous variables

$\begin{array}{llll}\text { COEFFICIENTS } & \text { SD } & \mathbf{P} & \text { CONDITION TERM }\end{array}$

\begin{tabular}{|c|c|c|c|}
\hline & \multicolumn{3}{|c|}{0 CONSTANT } \\
\hline $.00 \mathrm{x}$ & 0.0005122430 .1234 & 0.943 & $1 \mathrm{pH}$ \\
\hline & 0.0007738360 .1243 & 0.847 & 2. \\
\hline & $54494 \mathrm{e}-0050.6731$ & 0.841 & \\
\hline & .0004024930 .4925 & 0.866 & \\
\hline
\end{tabular}

$\mathrm{N}$ trials $\quad=15$

$\mathrm{N}$ terms $\quad=5$ 
Residual SD $=0.002985$

Residual DF $=10$

Residual SD used for tests

Replicate SD $=0.002082$

Replicate DF $=3$

$\mathrm{R}$ Squared $\quad=0.439, \mathrm{P}=0.1772$

Adj R Squared $=0.215$

Maximum Cook-Weisberg LD influence $($ scaled 0-1) $=1.000$

- This term may be eliminated

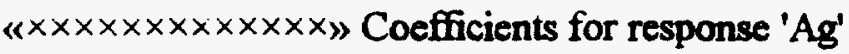

Centered continuous variables

COEFFICIENTS SD $P$ CONDITION TERM

\begin{tabular}{ccccc}
0.0133403 & \multicolumn{4}{c}{0 CONST ANT } \\
0.000790988 & 0.000691696 & $0.2794-$ & 0.943 & $1 \mathrm{pH}$ \\
-0.00549468 & 0.00104493 & 0.0004 & 0.847 & 2 logferrate \\
$3.78901 e-005$ & $6.13715 e-005$ & $0.5508-$ & 0.841 & 3 alum \\
-0.000603806 & 0.000543498 & $0.2926-$ & 0.866 & 4 polymer
\end{tabular}

$\mathrm{N}$ trials $\quad=15$

$\mathrm{N}$ terms $\quad=5$

Residual SD $=0.004031$

Residual DF $=10$

Residual SD used for tests

Replicate SD $=0.002041$

Replicate DF $=3$

$\mathrm{R}$ Squared $\quad=0.793, \mathrm{P}=0.0019 * *$

Adj R Squared $=0.710$

Maximum Cook-Weisberg $L D$ influence (scaled 0-1) $=1.000$

Maximum studentized residual $=6.703 \mathrm{P}=0.0308$ *

- This term may be eliminated

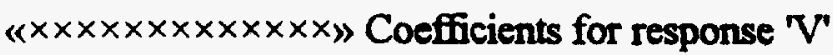


Centered continuous variables

\begin{tabular}{cccccc} 
COEFFICIENTS & SD & $P$ & CONDITION TERM \\
& \multicolumn{4}{c}{0 CONST ANT } \\
0.0185256 & \multicolumn{4}{c}{ CONS } \\
0.000289925 & 0.000598041 & $0.6383-$ & 0.943 & 1 pH \\
-0.00918185 & 0.000903451 & 0.0000 & 0.847 & 2 logferrate \\
$7.29692 \mathrm{e}-005$ & $5.3062 \mathrm{e}-005$ & 0.1991 & 0.841 & 3 alum \\
0.000137551 & 0.000469909 & 0.7757 & 0.866 & 4 polymer
\end{tabular}

$N$ trials $\quad=15$

$\mathrm{N}$ terms $\quad=5$

Residual SD $=0.003485$, Lack-Of-Fit $\mathrm{P}=0.0014 * *$

Residual DF $=10$

Residual SD used for tests

Replicate SD $=0.000408$

Replicate DF $=3$

$\mathrm{R}$ Squared $\quad=0.925, \mathrm{P}=0.0000 * * *$

Adj R Squared $=0.895$

Maximum Cook-Weisberg LD influence (scaled 0-1) $=1.000$

Maximum studentized residual $=7.424 \quad \mathrm{P}=0.0098 *$

- This term may be eliminated 
PROJECT NAME: RF3.ECP

Created: Thu Oct 27 14:02:52 1994

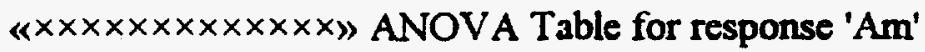

LACK-OF-FIT

Mean Squares DF P

$0.000773493 \quad 10.7792 \mathrm{pH}$

$0.466476 \quad 10.0000$ logferrate

$0.00271437 \quad 10.6013$ alum

0.00021363310 .8827 polymer

$0.0093257610 \quad$ ERROR

0.001166673 REPLICATE ERROR

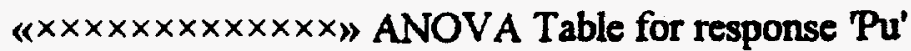

LACK-OF-FIT

Mean Squares DF P

$\begin{array}{ccc}0.0991608 & 1 & 0.6266 \mathrm{pH} \\ 34.276 & 10.0000 \text { logferrate } \\ 0.0607647 & 10.7026 \text { alum } \\ 0.022089 & 1 & 0.8175 \text { polymer } \\ 0.393655 & 10 & \text { ERROR }\end{array}$

0.002183333 REPLICATE ERROR

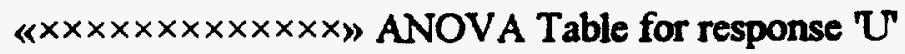

LACK-OF-FIT

Mean Squares DF P

$0.00378621 \quad 10.0000 \mathrm{pH}$

3.31676e-006 10.7496 logferrate

$6.54074 \mathrm{e}-00710.8871$ alum

$1.5401 \mathrm{e}-007 \quad 10.9450$ polymer 
3.08176e-005 $10 \quad$ ERROR

\subsection{9e-007 3 REPLICATE ERROR}

« $x \times x \times x \times x \times x \times x \times x \times x 》$ ANOVA Table for response 'Al'

\section{LACK-OF-FIT}

Mean Squares DF $\mathbf{P}$

$$
\begin{array}{ccc}
0.0190804 & 1 & 0.9330 \mathrm{pH} \\
217.466 & 1 & 0.0000 \text { logferrate } \\
6.17359 & 10.1522 \text { alum } \\
0.338581 & 10.7242 \text { polymer } \\
2.56935 & 10 & \text { ERROR }
\end{array}
$$

$0.04166673 \quad$ REPLICATE ERROR

« $x \times x \times x \times x \times x x \times x \times x\rangle$ ANOVA Table for response ' $\mathrm{Ba}$ '

Mean Squares DF P

$0.0190987 \quad 10.0000 \mathrm{pH}$

$0.0165537 \quad 10.0000$ logferrate

$0.000112698 \quad 10.5198$ alum

7.5504e-006 10.8664 polymer

$0.00025322310 \quad$ ERROR

$\begin{array}{lll}0 & 3 & \text { REPLICATE ERROR }\end{array}$

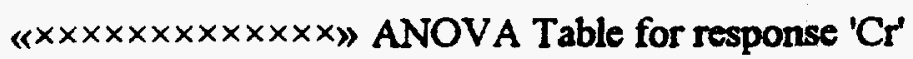

Mean Squares DF P
$5.31786 \mathrm{e}-007 \quad 10.8511 \mathrm{pH}$ 0.00052263610 .0001 logferrate
$1.04833 \mathrm{e}-00510.4124$ alum
$2.79588 \mathrm{e}-007 \quad 10.8917$ polymer
$1.4333 \mathrm{e}-00510 \quad$ ERROR

$\begin{array}{lll}0 & 3 & \text { REPLICATE ERROR }\end{array}$ 


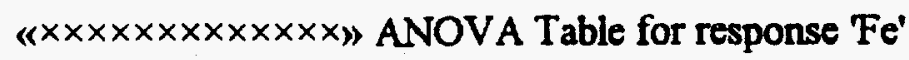

\section{LACK-OF-FTT}

Mean Squares DF P

$\begin{array}{ccc}2.12569 & 10.5077 \mathrm{pH} \\ 222.065 & 10.0000 \text { logfemate } \\ 0.359358 & 10.7834 \text { alum } \\ 0.25681 & 10.8161 \text { polymer } \\ 4.50463 & 10 \quad \text { ERROR }\end{array}$

$0.00813333 \quad 3 \quad$ REPLICATE ERROR

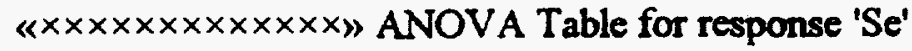

Mean Squares DF P

\begin{tabular}{|c|c|}
\hline $84 e-005$ & \\
\hline & 10.1243 logferrate \\
\hline 6 & 10.6731 alum \\
\hline $2 e-006$ & $10.4925 \mathrm{pc}$ \\
\hline
\end{tabular}

4.33333e-006 3 REPLICATE ERROR

« $x \times x \times x \times x \times x \times x \times x \times »$ ANOVA Table for response 'Ag'

Mean Squares DF P

$$
\begin{array}{ll}
2.1249 \mathrm{e}-005 & 10.2794 \mathrm{pH} \\
0.000449299 & 10.0004 \text { logferrate } \\
6.19362 \mathrm{e}-006 & 10.5508 \text { alum } \\
2.00552 \mathrm{e}-005 & 10.2926 \text { polymer } \\
1.6249 \mathrm{e}-005 & 10 \quad \text { ERROR }
\end{array}
$$

\subsection{7e-006 3 REPLICATE ERROR}

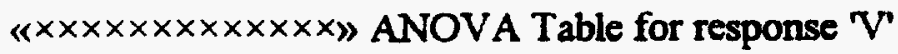


LACK-OF-FIT

Mean Squares DF P

$2.85475 \mathrm{e}-006 \quad 10.6383 \mathrm{pH}$

0.0012546210 .0000 logferrate

2.29706e-005 10.1991 alum

$1.04078 \mathrm{e}-006 \quad 10.7757$ polymer

$1.21468 \mathrm{e}-00510$

ERROR

1.66667e-007 3 REPLICATE ERROR 


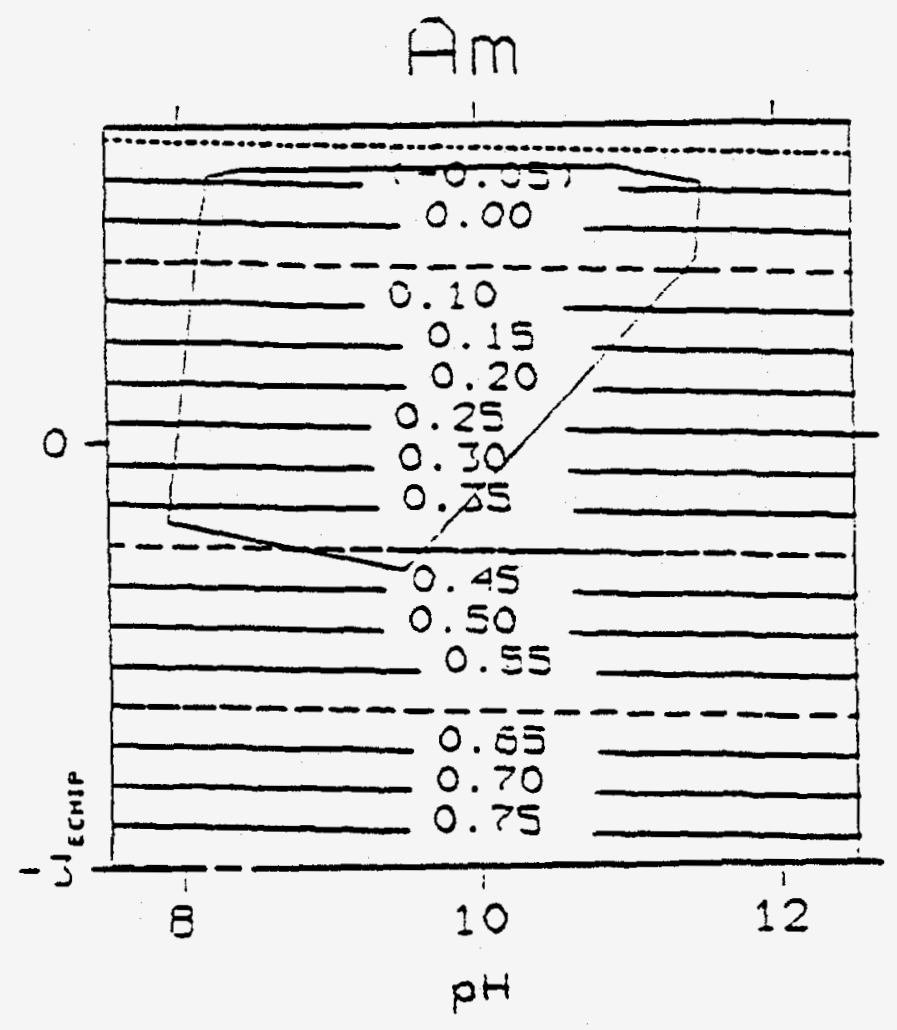

Lack of Eit

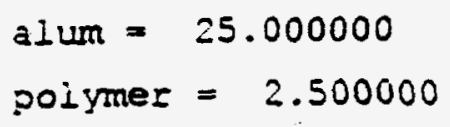

poiymez $=2.500000$

Lack of Eit

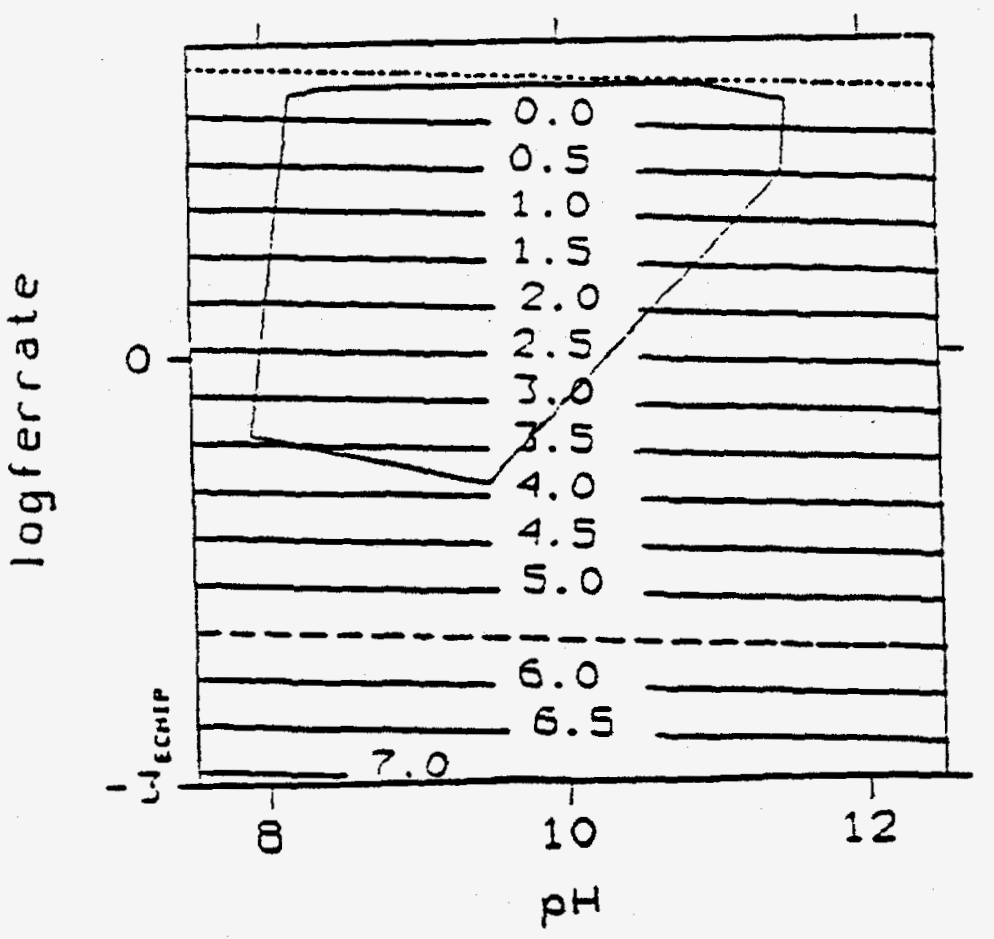

alum $=25.000000$
polymer $=2.500000$ 


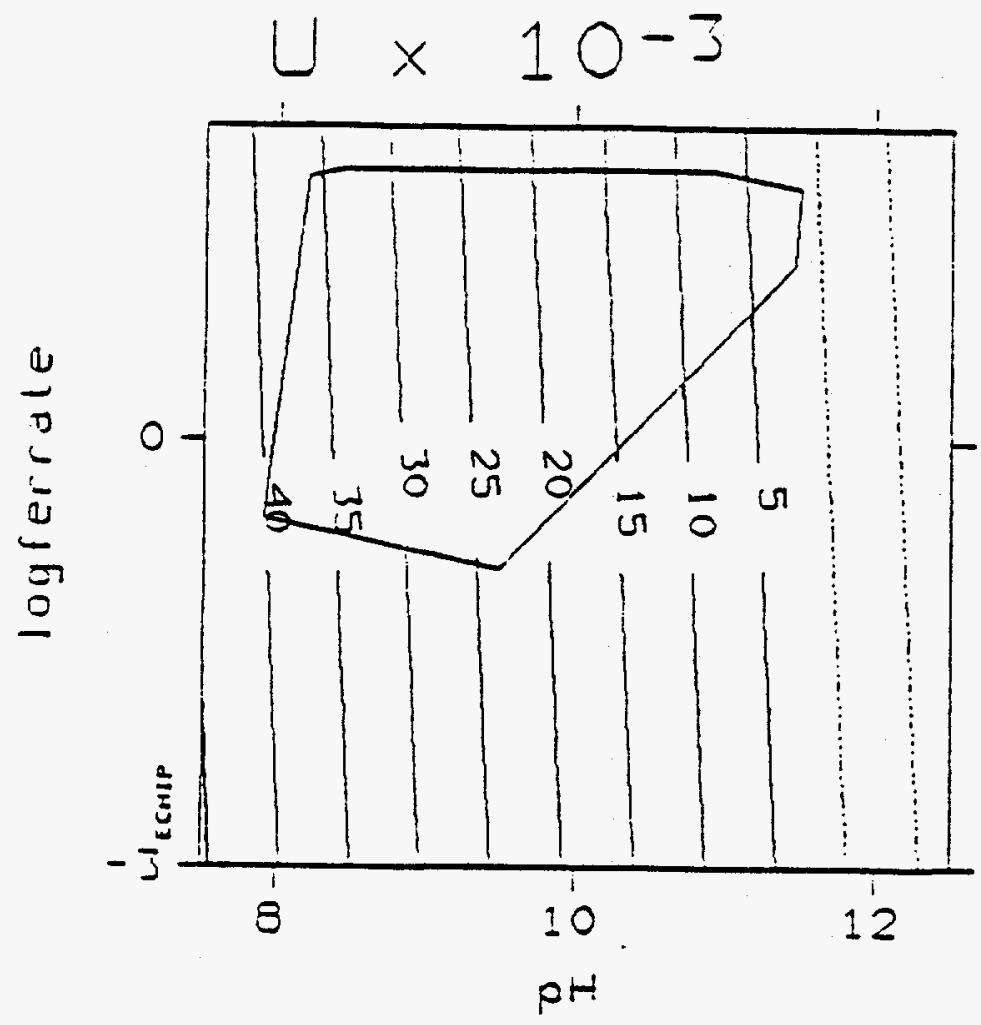

Lack of Eic

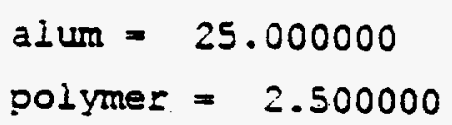

polymez $=2.500000$

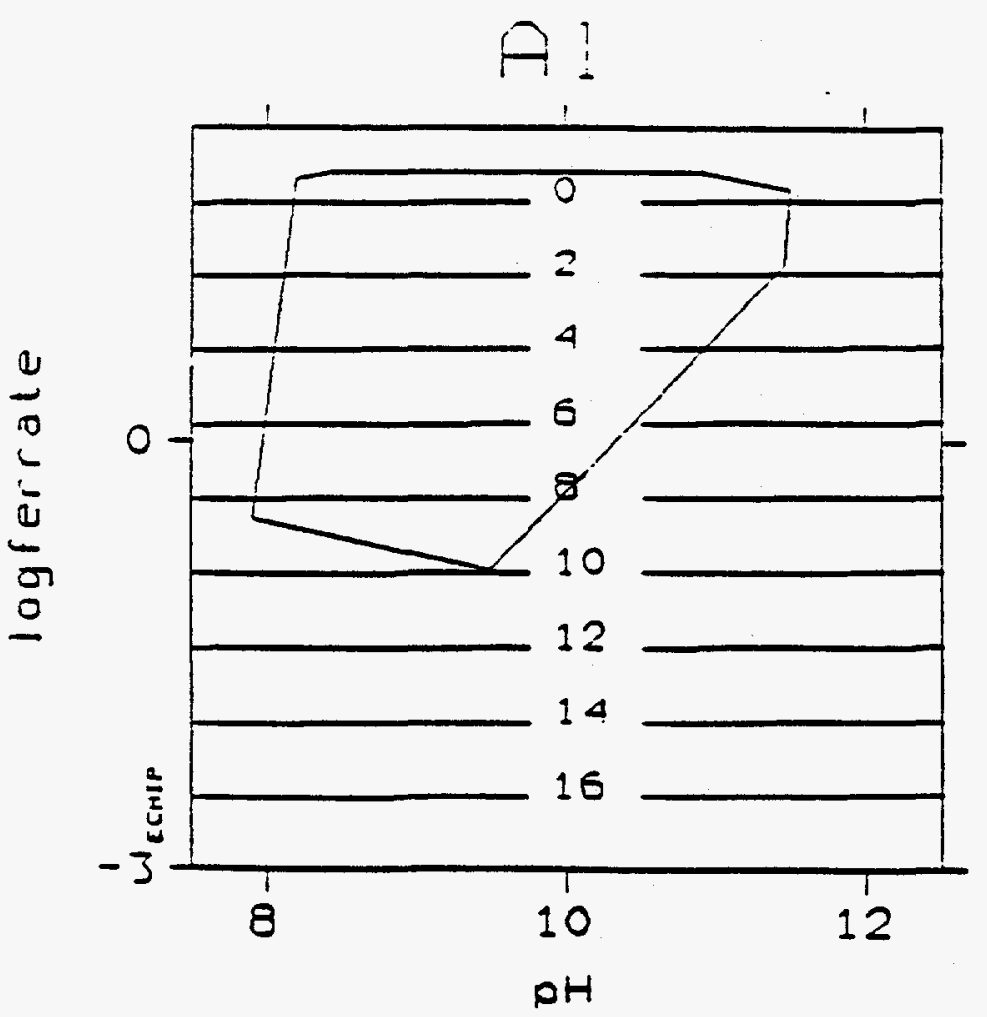

Lack OE EIT

alum $=25.000000$

polymer $=2.500000$ 
a

$\frac{\overline{1}}{0}$
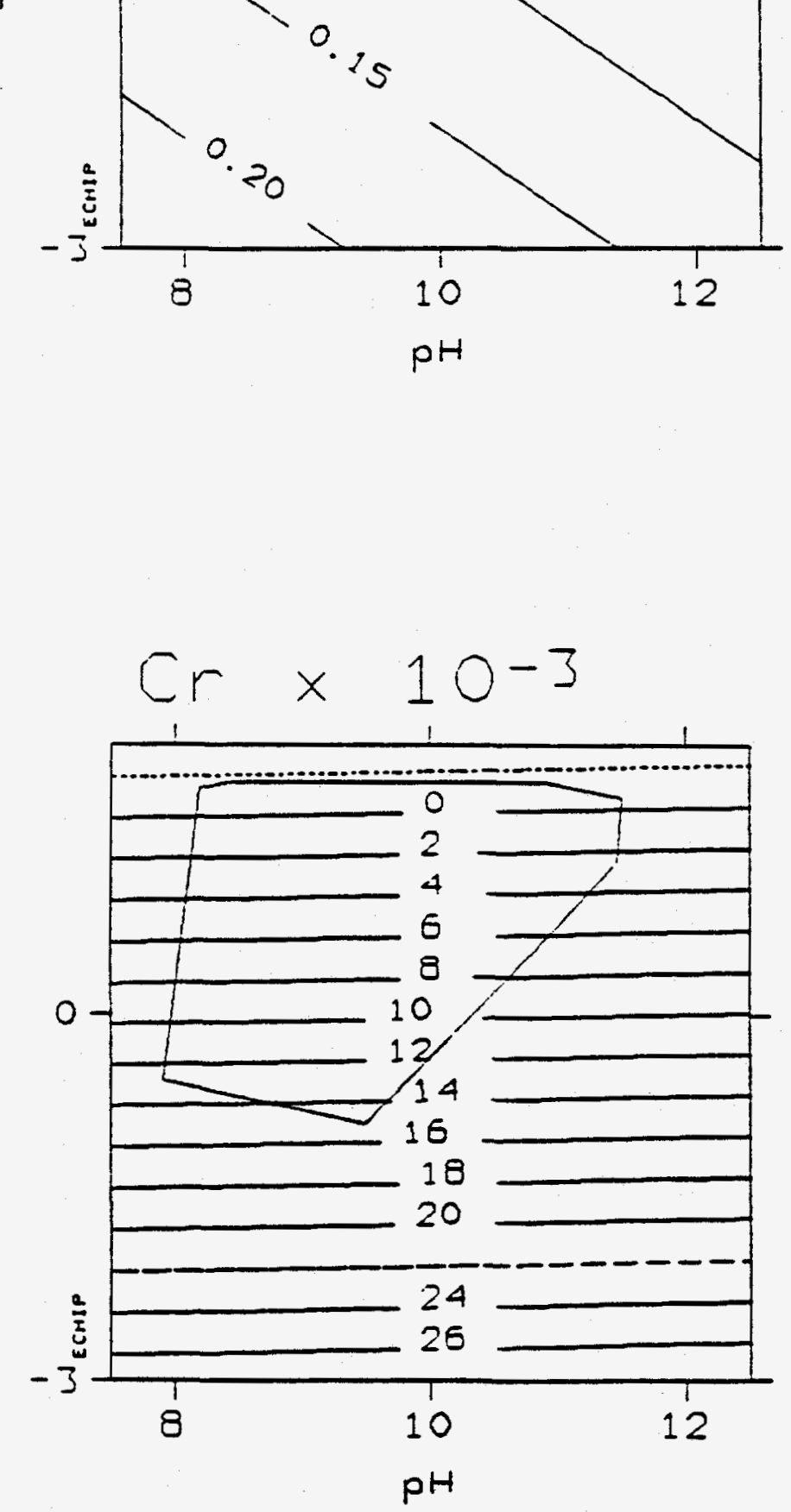

polymer $=2.500000$ 


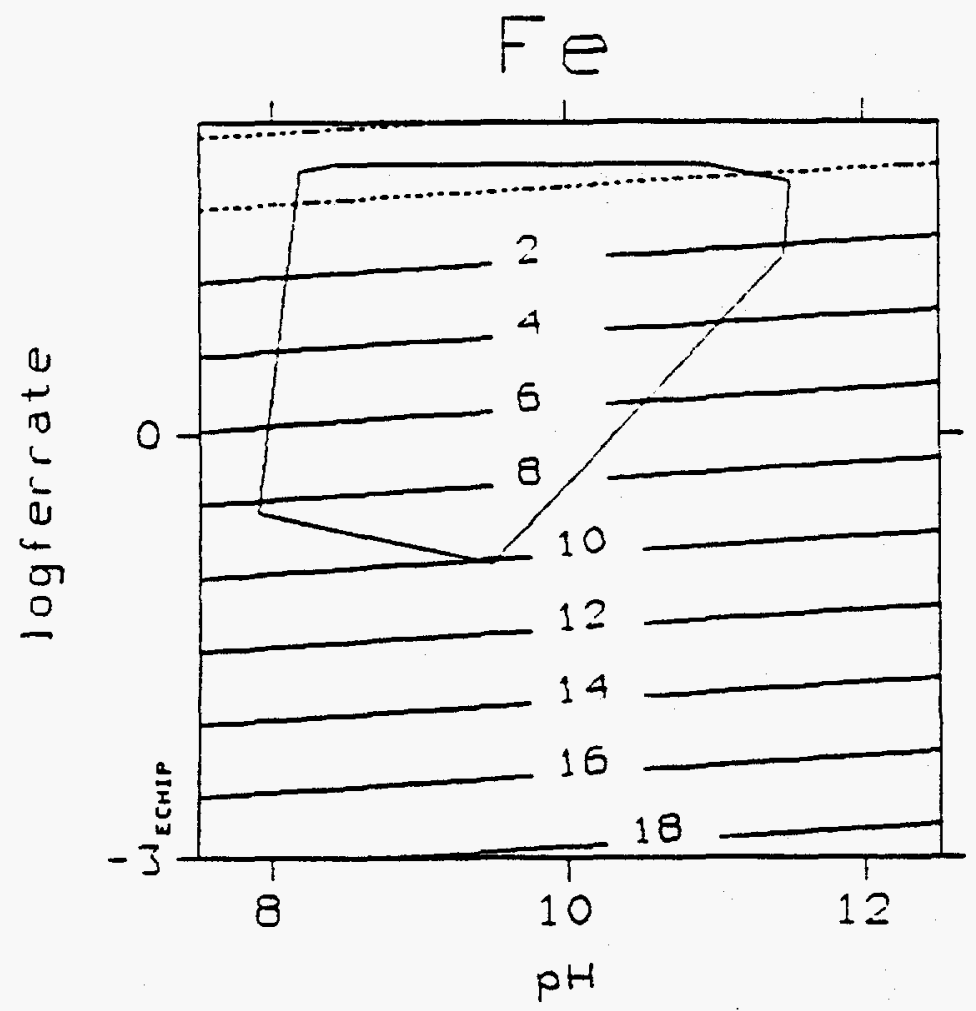

Lack of Eit

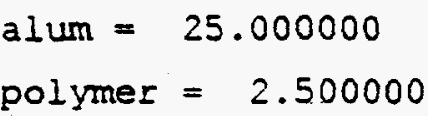

polymer $=2.500000$

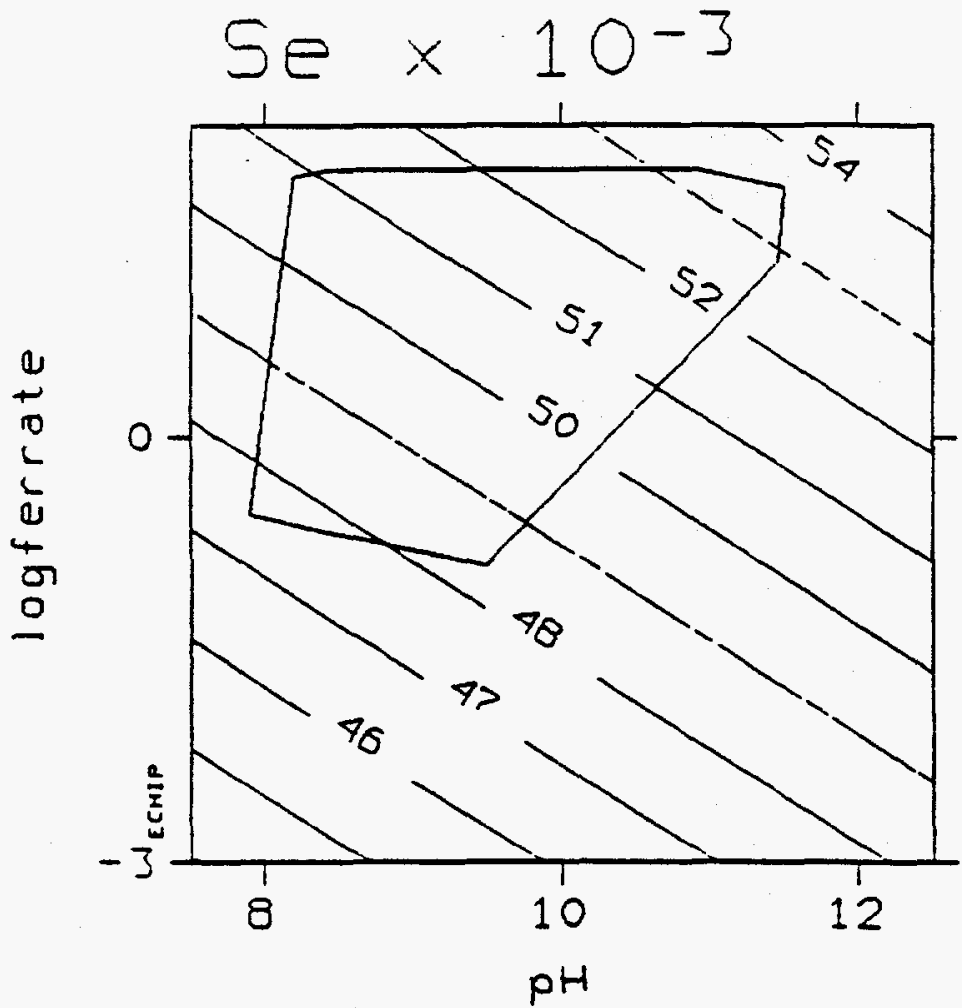

alum $=25.000000$

polymer $=2.500000$ 


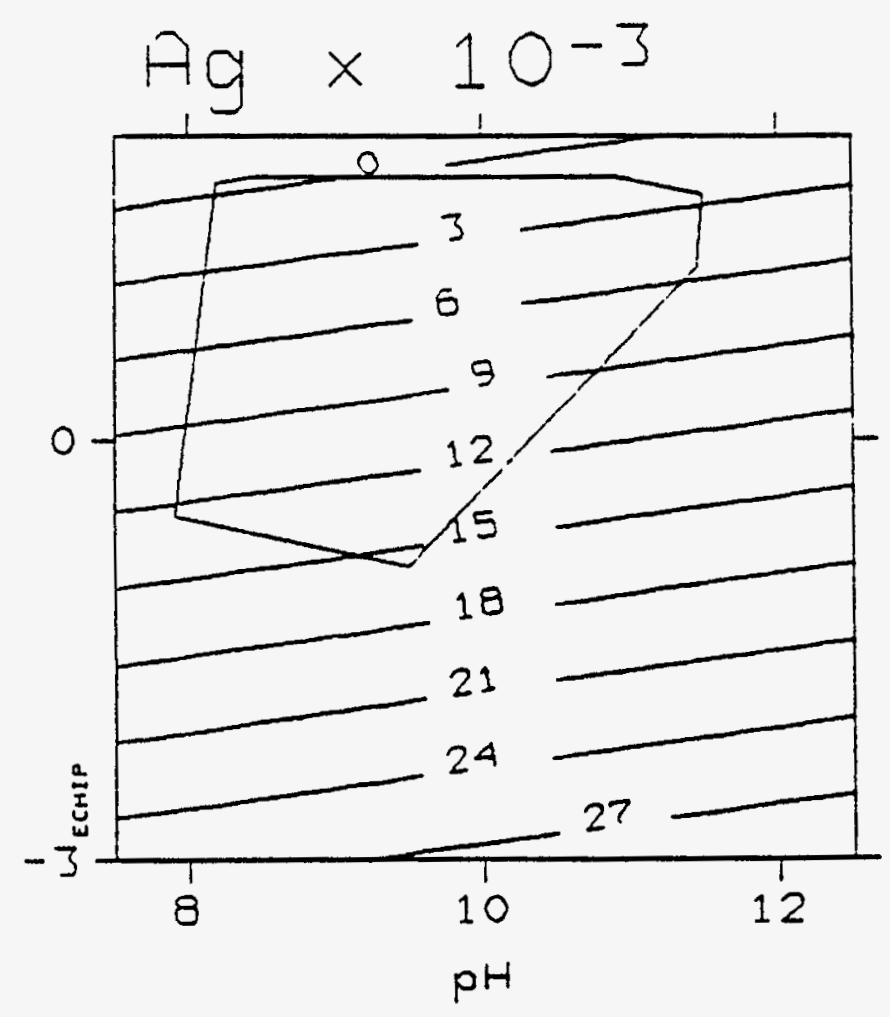

alum $=25.000000$
polymer $=2.500000$

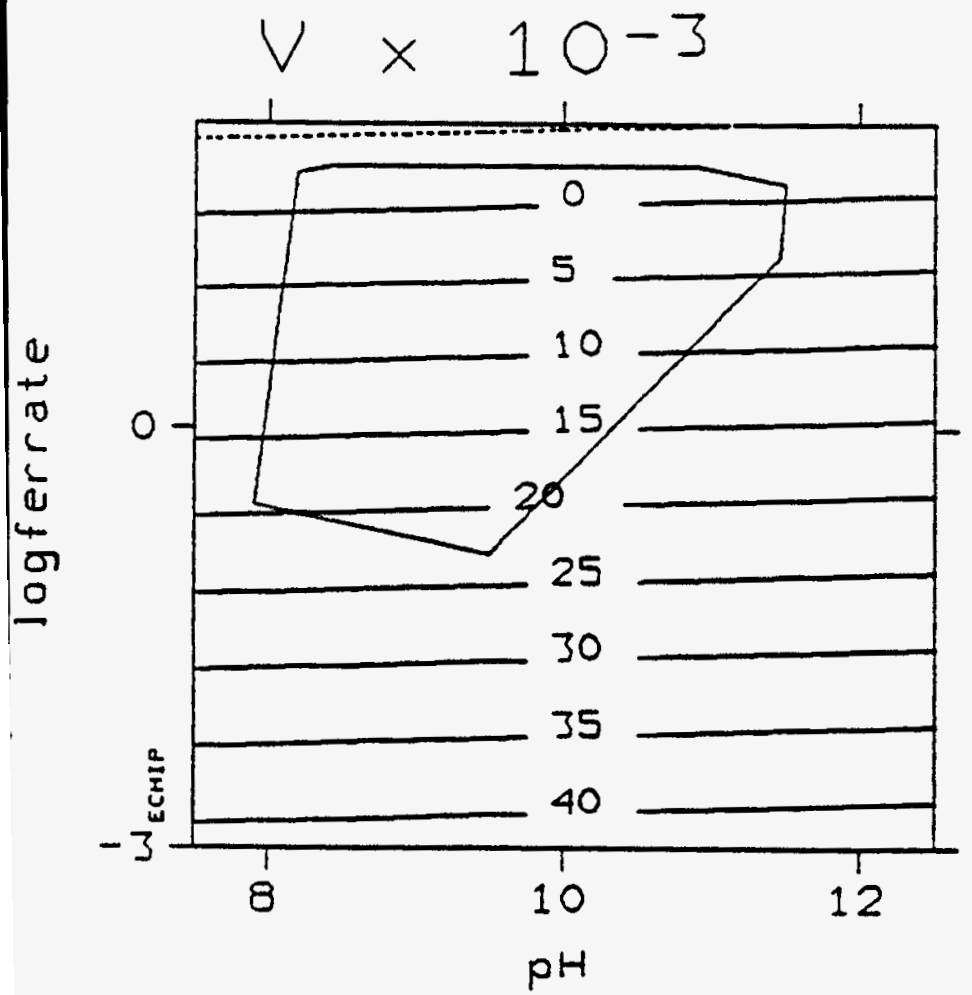

alum $=25.000000$
polymer $=2.500000$ 
Potassium Ferrate Treatment of RFETS Groundwater

Document Number: Section:

Page:
RF/ER-94-0028.UN

Appendix E, Rev. 0

1 of 38

\section{APPENDIX E}

ECHIP OUTPUT OF PHASE I MODIFIED TEST PLAN 
OJECT NAME: ROCKYFLA.ECP

eated: Thu Nov 03 09:36:03 1994

mmary results

m

Pu

. U

- Al

. $\quad . \quad B a$

. $. \quad . \mathrm{Cr}$

$\cdot \cdot \cdot \cdot \cdot \mathrm{Co}$

$\cdot \cdot \cdot \cdot \cdot \cdot \mathrm{Cu}$

. $. \quad . \quad . \quad . \quad . \quad \mathrm{Ee}$

$\cdot \cdot \cdot \cdot \cdot \cdot \cdot \cdot \mathrm{Se}$

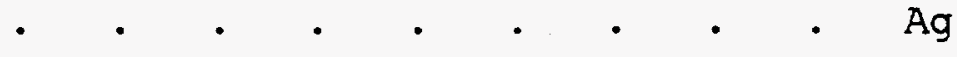

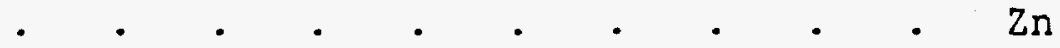

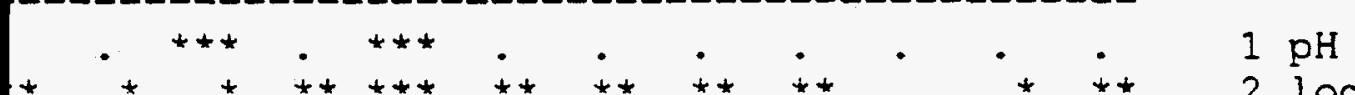

$+*+*++*+*+*+* * * \cdot *+*+2$ logferrate

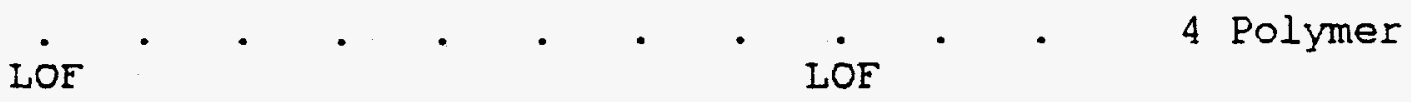


PROJECT NAME: ROCKYFLA.ECP

Created: Thu Nov 03 09:35:54 1994

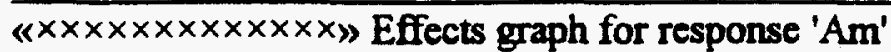

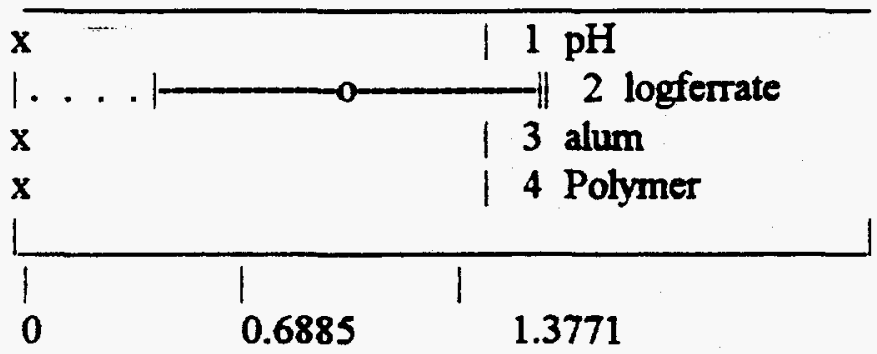

**Pareto effects graph for response 'Am'**

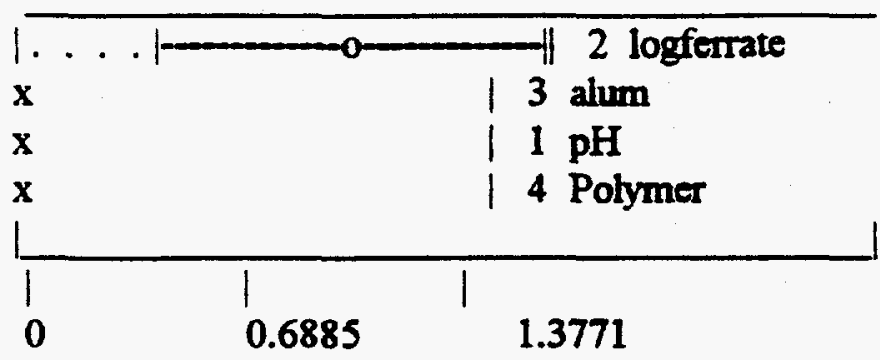

« $x \times x \times x \times x \times x \times x x \times x »$ Effects graph for response 'Pu'

\section{LACK-OF-FIT}

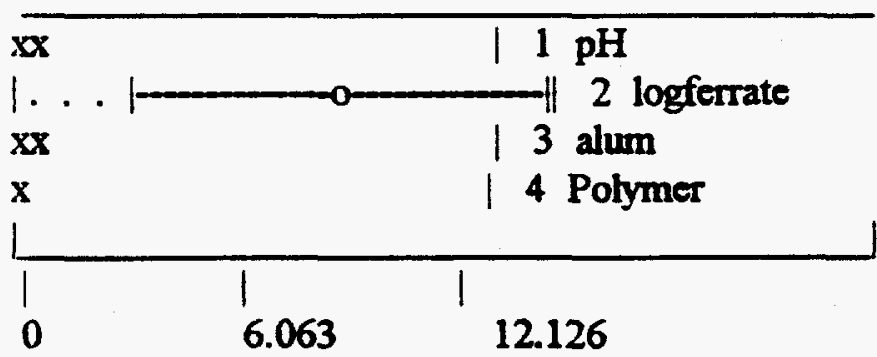


**Pareto effects graph for response Pu***

LACK-OF-FIT

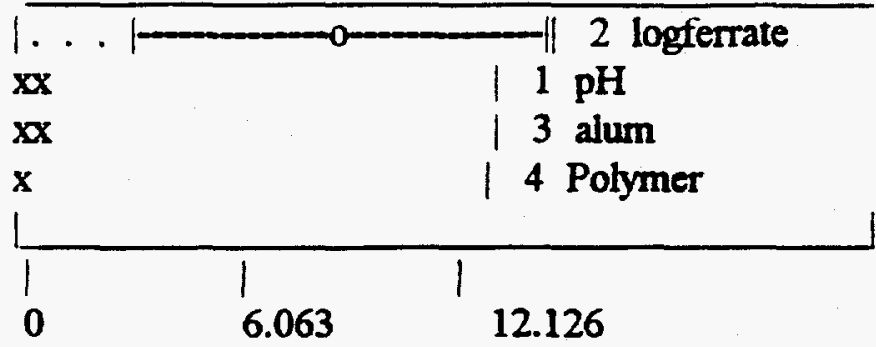

«x $\times x \times x \times x \times x \times x \times x\rangle$ Effects graph for response $U$

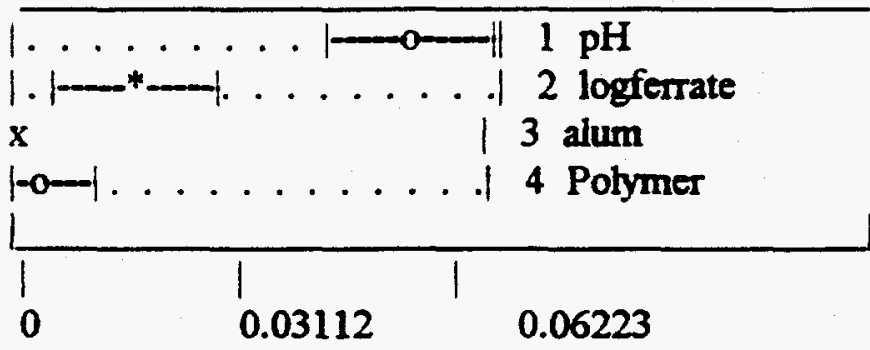

**Pareto effects graph for response U**

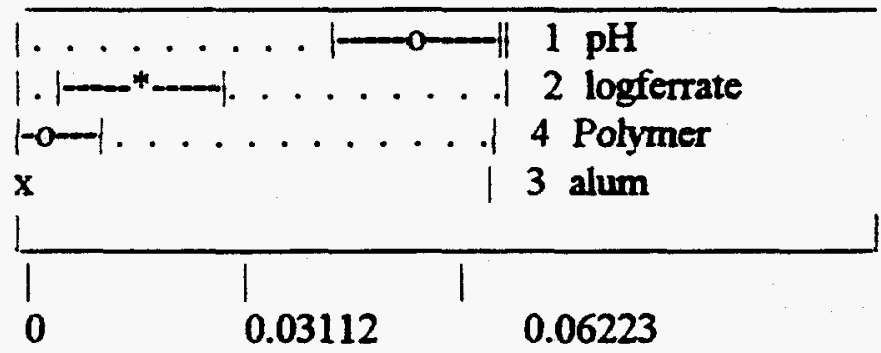


« $x \times x \times x \times x \times x \times x \times x »$ Effects graph for response 'Al'

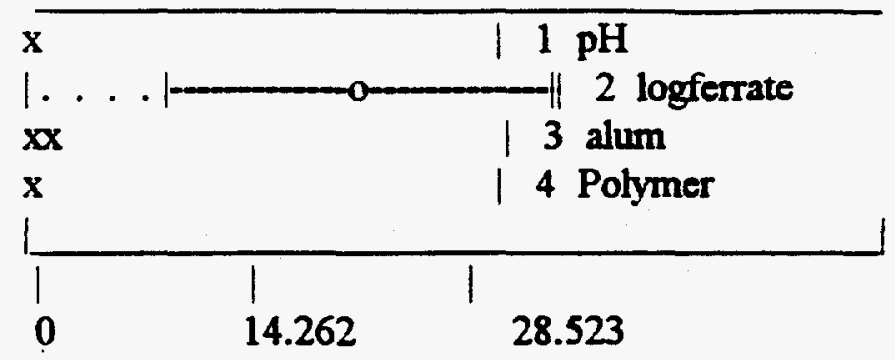

**Pareto effects graph for response 'Al***

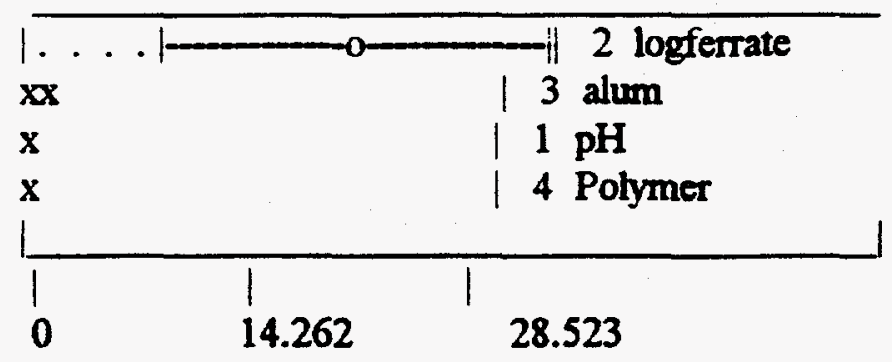

«x $x \times x \times x \times x \times x \times x \times$ Effects graph for response 'Ba'

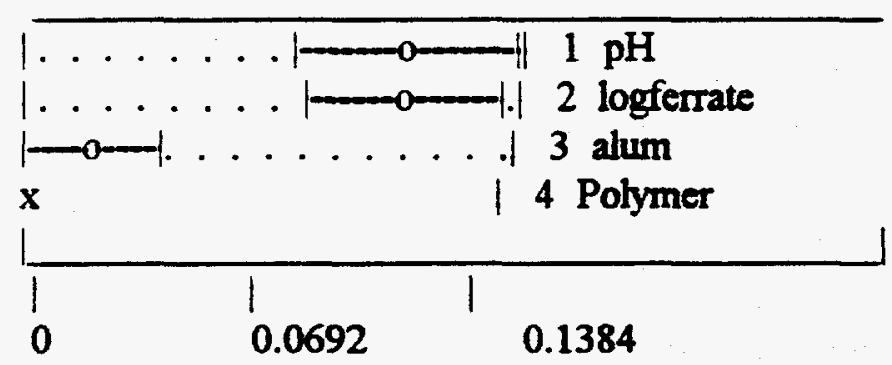


**Pareto effects graph for response $\mathrm{Ba} a^{\prime * *}$

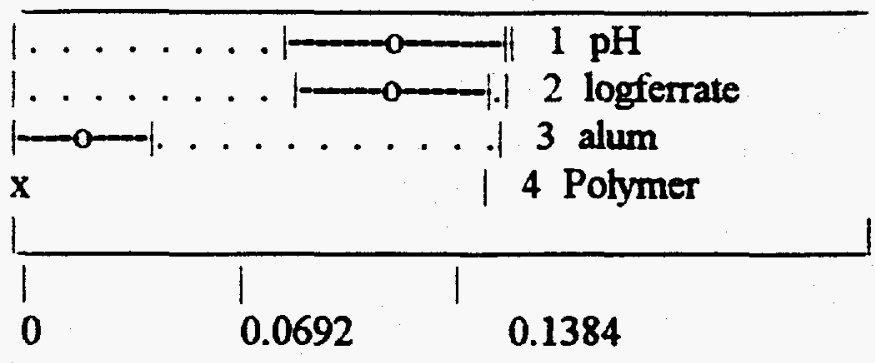

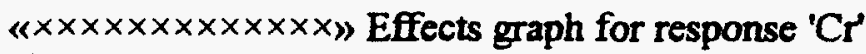

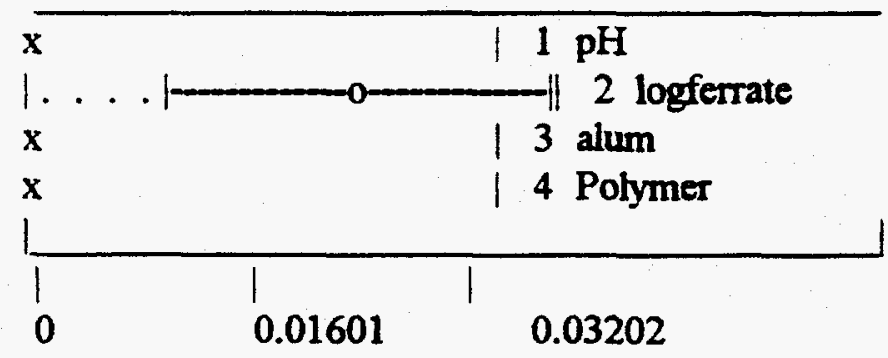

**Pareto effects graph for response ' $\mathrm{Cr}^{\prime * *}$

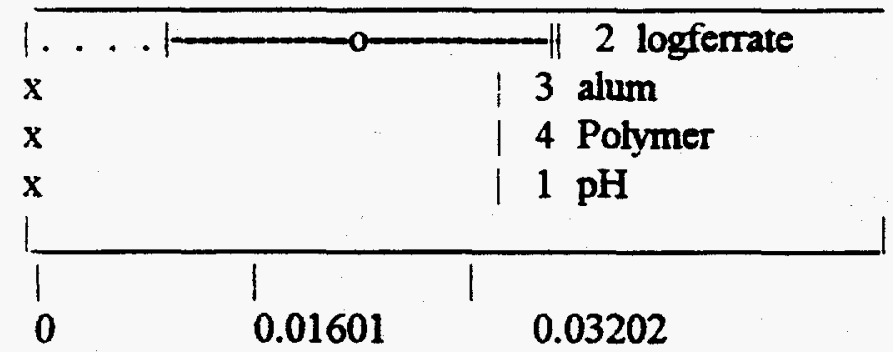

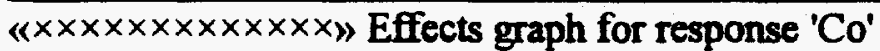

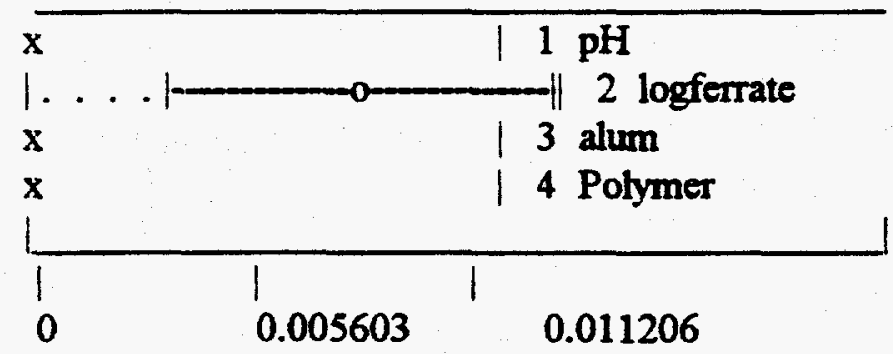


**Pareto effects graph for response ' $\mathrm{Co}{ }^{1 * *}$

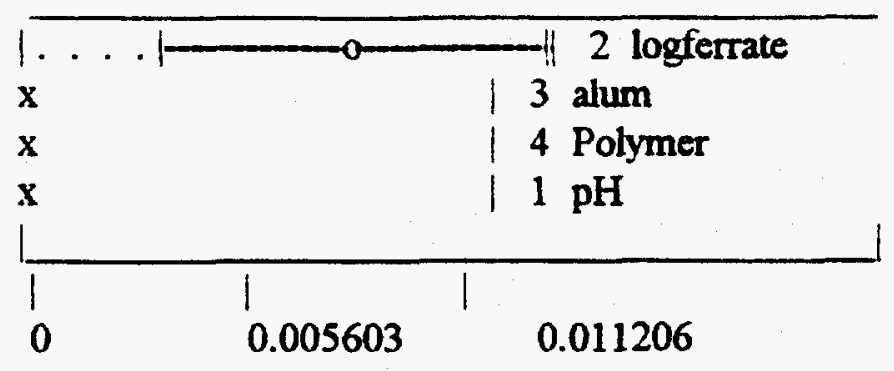

« $x \times x \times x \times x \times x \times x \times x \times x 》$ Effects graph for response 'Cu'

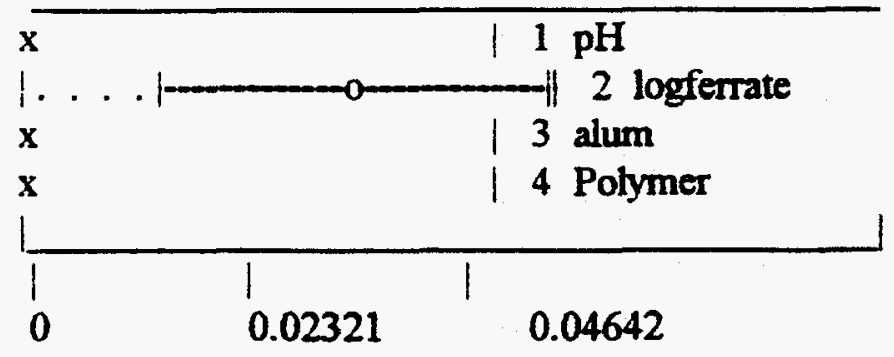

**Pareto effects graph for response ' $\mathrm{Cu}^{* * *}$

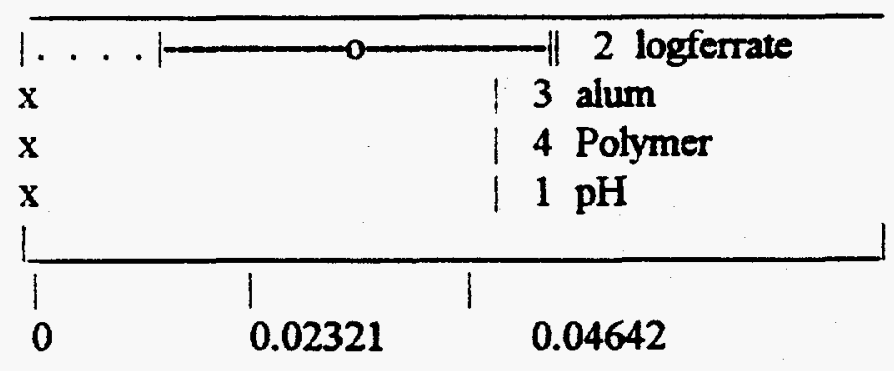

« $x \times x \times x \times x \times x \times x \times x \times x 》$ Effects graph for response $\mathrm{Fe}^{\prime}$

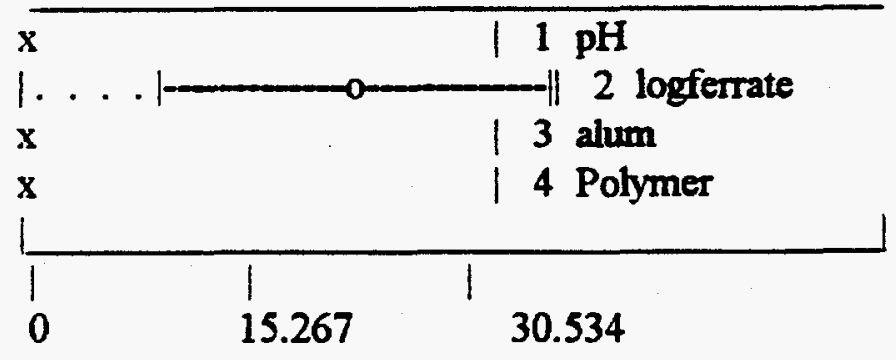


**Pareto effects graph for response $\mathrm{Fe} e^{\text {****}}$

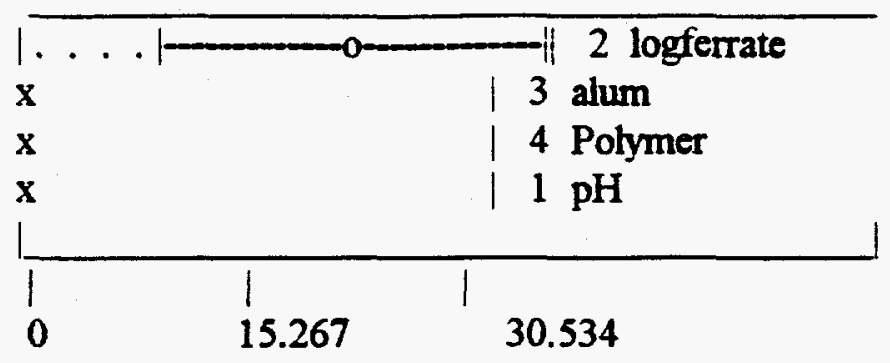

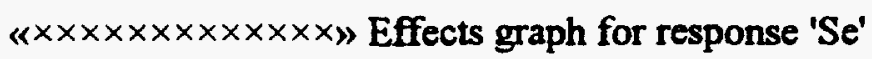

LACK-OF-FIT

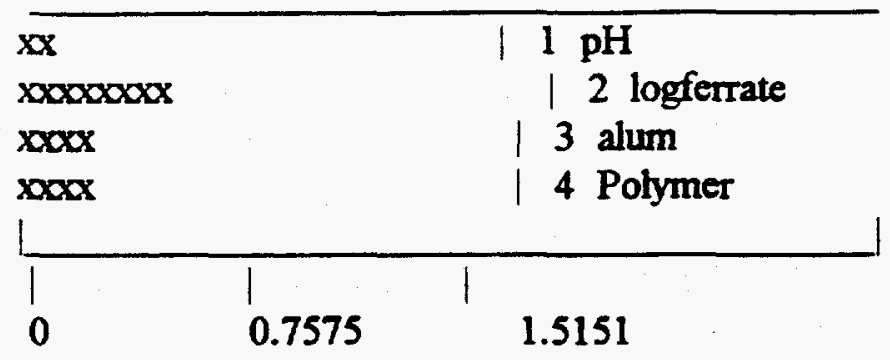

**Pareto effects graph for response 'Se***

LACK-OF-FIT

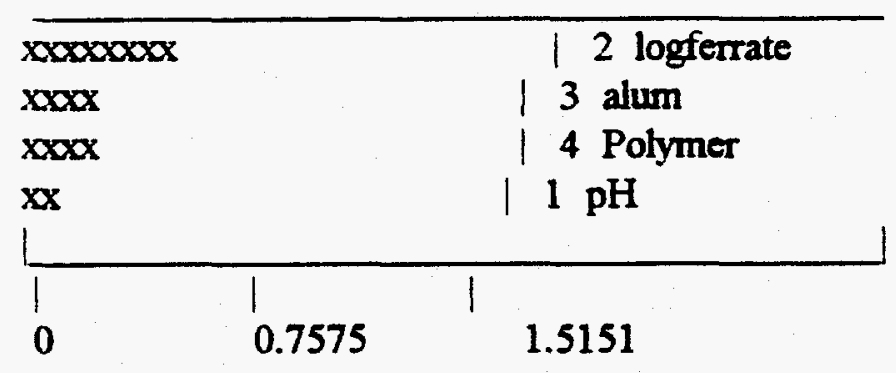


« $x \times x \times x \times x \times x \times x \times x \times »$ Effects graph for response ' $\mathrm{Ag}$ '

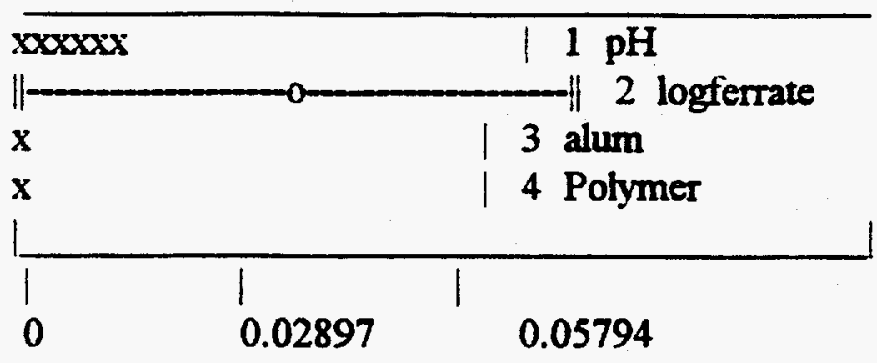

**Pareto effects graph for response ' $\mathrm{Ag}^{\prime * *}$

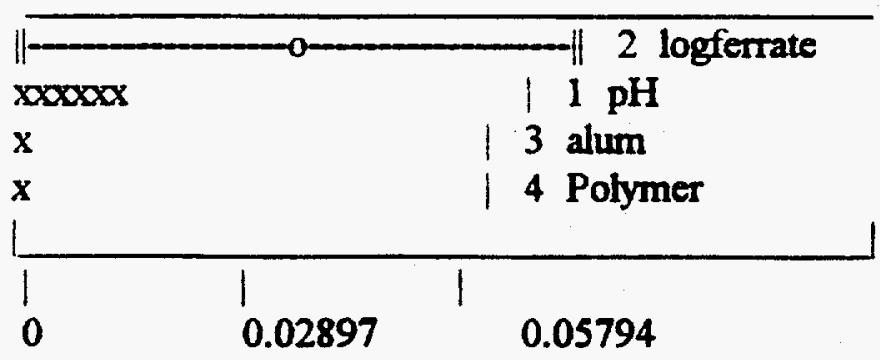

«x $\times x \times x \times x \times x \times x \times »$ Effects graph for response ' $\mathrm{Zn}$ '

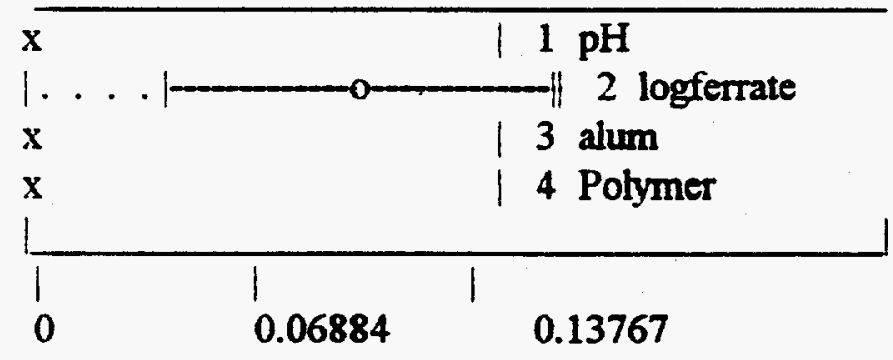

**Pareto effects graph for response ' $\mathrm{Zn}$ "**

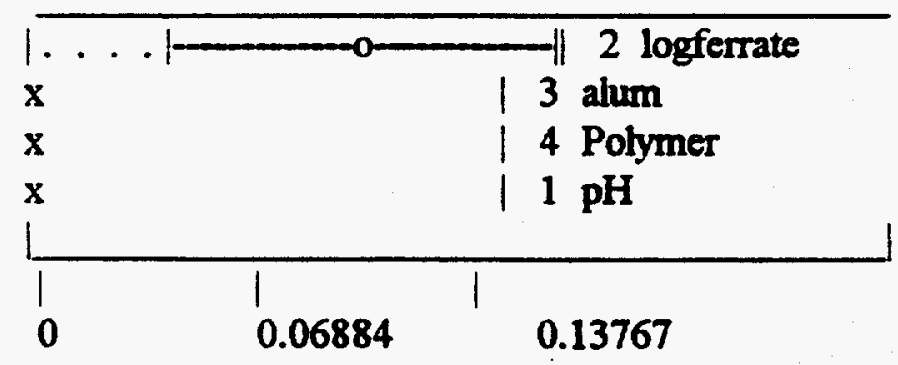


PKUJECI NAME: KUCKKYLA.ECH

Created: Thu Nov 03 09:35:49 1994

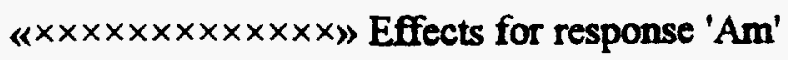

EFFECTS RESLTN SIG TERM
0.0025
0 CONSTANT
$\begin{array}{lll}0.0070 & 0.5022 \quad 1 \mathrm{pH}\end{array}$
$-0.8970 \quad * * 2$ logferrate
$\begin{array}{lll}-0.0182 & 0.3385 \quad 3 \text { alum }\end{array}$
$\begin{array}{ccc}-0.0001 & 0.2859 \quad 4 \text { Pohymer }\end{array}$

$$
\begin{array}{ll}
\text { Residual SD } & =0.091206 \\
\text { Replicate SD } & =0.021213 \\
& =5 \\
N \text { terms } & =5 \\
N \text { unique trials } & =7 \\
N \text { replicates } & =1 \\
N \text { total trials } & =8
\end{array}
$$

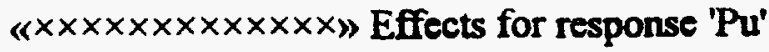

\section{LACK-OF-FIT}

EFFECTS RESLTN SIG TERM
0.116
O CONSTANT
$\begin{array}{lll}-0.417 & 4.939 \quad 1 \mathrm{pH}\end{array}$
$-7.742 * 2$ logferrate
$0.381 \quad 3.307 \quad 3$ alum
$0.1382 .748 \quad 4$ Polymer

Residual SD $=0.832848$

Replicate SD $=0.007071$

$\mathrm{N}$ terms $\quad=5$ 
$\mathrm{N}$ unique trials $=7$

$\mathrm{N}$ replicates $=1$

$\mathrm{N}$ total trials $=8$

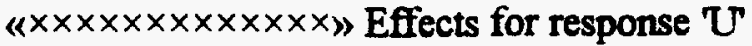

EFFECTS RESLTN SIG TERM

$\begin{array}{lcc}0.01970 & & 0 \text { CONSTANT } \\ -0.05295 \quad * * * & 1 \mathrm{pH} \\ 0.01408 \quad * & 2 \text { logferrate } \\ 0.001150 .00716 & 3 \text { alum } \\ -0.003050 .00841 & 4 \text { Polymer }\end{array}$

Residual SD $=0.001709$

Replicate SD $=0.000707$

$N$ terms $\quad=5$

$\mathrm{N}$ unique trials $=7$

$N$ replicates $=1$

$\mathrm{N}$ total trials $=8$

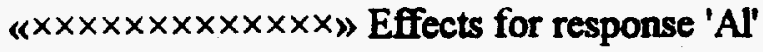

EFFECTS RESLTN SIG TERM

$\begin{array}{ccc}0.514 & & 0 \text { CONSTANT } \\ -0.652 & 10.538 & 1 \mathrm{pH} \\ -18.939 & * * & 2 \text { logferrate } \\ 1.210 & 7.605 & 3 \text { alum } \\ 0.543 & 6.249 & 4 \text { Polymer }\end{array}$

Residual SD $=1.820774$

Replicate SD $=0.000000$

N terms $\quad=5$

$N$ unique trials $=7$

$\mathrm{N}$ replicates $=1$ 
$N$ total thals $=8$

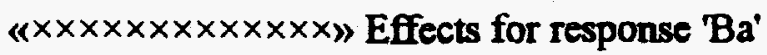

EFFECTS RESLTN SIG TERM
0.0386
$-0.1131$
CONSTANT
$-0.1111$
*** $1 \mathrm{pH}$
$\begin{array}{lll}-0.0157 & 0.0322\end{array}$
*** 2 logferrate
$\begin{array}{lll}-0.0026 & 0.0172\end{array}$
3 alum
4 Polymer

$\begin{array}{ll}\text { Residual SD } & =0.004670 \\ \text { Replicate SD } & =0.000000 \\ & =5 \\ N \text { terms } & =5 \\ N \text { unique trials } & =7 \\ N \text { replicates }=1 \\ N \text { total trials }=8\end{array}$

$\ll \times x \times x \times x \times x \times x \times x \times$ Effects for response ' $\mathrm{Cr}$

EFFECTS RESLTN SIG TERM

\begin{tabular}{|c|c|}
\hline 0.00019 & 0 CONSTANT \\
\hline-0.000470 .01159 & $1 \mathrm{pH}$ \\
\hline-0.02123 & 2 logferrate \\
\hline 0.000640 .00784 & 3 alum \\
\hline 0.000620 .00705 & 4 Polymer \\
\hline
\end{tabular}

Residual SD $=0.002049$

Replicate SD $=\mathbf{0 . 0 0 0 0 0 0}$

$\mathrm{N}$ terms $\quad=5$

$\mathrm{N}$ unique trials $=7$

$N$ replicates $=1$

$\mathrm{N}$ total trials $=8$ 


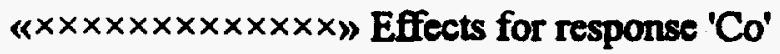

EFFECTS RESLTN SIG TERM
0.000067
$-0.0001640 .004058 \quad 1 \mathrm{pH}$
$-0.007431 \quad * * 2$ logferrate
$0.0002250 .002744 \quad 3$ alum
0.0002190 .002466 4 Polymer

Residual SD $=0.000717$

Replicate SD $=0.000000$

$\mathrm{N}$ terms $\quad=5$

$N$ unique trials $=7$

$N$ replicates $=1$

$\mathrm{N}$ total trials $=8$

« $\times x \times \times \times \times \times \times \times \times \times \times \times\rangle$ Effects for response ' $\mathrm{Cu}$ '

EFFECTS RESLTN SIG TERM
0.00028
0 CONSTANT
$-0.000680 .01681 \quad 1 \mathrm{pH}$
$-0.03079$
* 2 logferrate
$0.000930 .01137 \quad 3$ alum
0.000910 .01022 4 Polymer

Residual SD $=0.002971$

Replicate $\mathrm{SD}=0.000000$

$N$ terms $=5$

$\mathrm{N}$ unique trials $=7$

$N$ replicates $=1$

$\mathrm{N}$ total trials $=8$

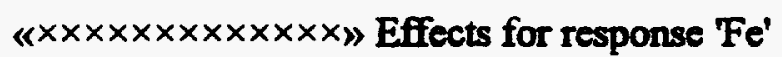


EFFECTS RESLTN SIG TERM

$\begin{array}{ccc}0.261 & & \text { O CONSTANT } \\ -0.292 & 10.957 & 1 \text { pH } \\ -20.194 & * * & 2 \text { logferrate } \\ 0.604 & 7.503 & \text { 3 alum } \\ 0.602 & 6.757 & \text { 4 Polymer }\end{array}$

Residual SD $=1.964244$

Replicate SD $=\mathbf{0 . 0 0 0 0 0 0}$

$\mathrm{N}$ terms $\quad=5$

$\mathrm{N}$ unique trials $=7$

$\mathrm{N}$ replicates $=1$

$\mathrm{N}$ total trials $=8$

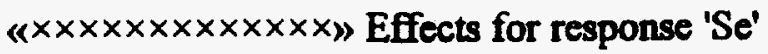

\section{LACK-OF-FIT}

EFFECTS RESLTN SIG TERM
0.1132
$-0.07171 .3587$
O CONSTANT
$0.26741 .5151 \quad 2$ logferrate
$\begin{array}{lll}-0.1506 & 0.9831 & 3 \text { alum }\end{array}$
$-0.14880 .8916 \quad 4$ Polymer

\footnotetext{
Residual SD $=0.237037$

Replicate SD $=0.002828$

$\mathrm{N}$ terms $\quad=5$

$N$ unique trials

N ramlin:en:
} 
LHFECTS RESLTN SIG TERM
0.00421
O CONSTANT
$0.007620 .03636 \quad 1 \mathrm{pH}$
$-0.03007$
* 2 logferrate
$-0.001350 .01994 \quad 3$ alum
$-0.000220 .01681 \quad 4$ Polymer

\author{
Residual SD $=0.005294$ \\ Replicate SD $=0.000000$ \\ $N$ terms $\quad=5$ \\ $\mathrm{N}$ unique trials $=7$ \\ $\mathrm{N}$ replicates $=1$ \\ $\mathrm{N}$ total trials $=8$
}

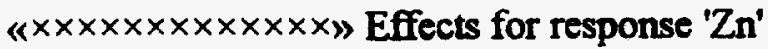

EFFECTS RESLTN SIG TERM

\begin{tabular}{|c|c|}
\hline 0.00083 & 0 CONSTANT \\
\hline-0.002020 .04985 & $1 \mathrm{pH}$ \\
\hline-0.09130 & 2 logferrate \\
\hline $\begin{array}{l}0.002770 .03371 \\
0.002680 .03029\end{array}$ & $\begin{array}{l}3 \text { alum } \\
4 \text { Polymer }\end{array}$ \\
\hline
\end{tabular}

Residual SD $=0.008810$

Replicate SD $=0.000000$

$\mathrm{N}$ terms $\quad=5$

$N$ unique trials $=7$

$\mathrm{N}$ replicates $=1$

$\mathrm{N}$ total trials $=8$ 
PROJECT NAME: ROCKYFLA.ECP

Created: Thu Nov 03 09:35:42 1994

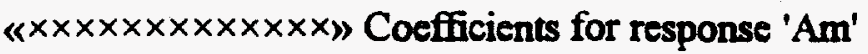

Centered continuous variables

$\begin{array}{llll}\text { COEFFICIENTS SD } & P & \text { CONDITION TERM }\end{array}$

\begin{tabular}{|c|c|c|c|}
\hline 0.00247295 & \multicolumn{3}{|c|}{0 CONSTANT } \\
\hline 0.00 & $0.06765450 .9671-$ & 0.803 & $1 \mathrm{pH}$ \\
\hline & $\begin{array}{c}0.03081810 .0095 \\
0.00201310 .8682\end{array}$ & $\begin{array}{c}0.679 \\
-\quad 0.802\end{array}$ & $\begin{array}{l}2 \text { logterrate } \\
3 \text { alum }\end{array}$ \\
\hline 2.1461 & 0.01796230 .99 & 0.835 & 4 Polyr \\
\hline
\end{tabular}

$\mathrm{N}$ trials $\quad=8$

$\mathrm{N}$ terms $\quad=5$

Residual SD $=0.091206$

Residual DF $=3$

Residual SD used for tests

Replicate SD $=0.021213$

Replicate DF $=1$

R Squared $\quad=0.963, \mathrm{P}=0.0174$ *

Adj R Squared $=0.914$

Maximum Cook-Weisberg $L D$ influence (scaled 0-1) $=1.000$

- This term may be eliminated

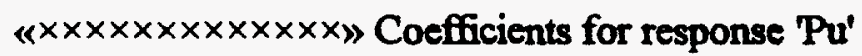

Centered continuous variables

$\begin{array}{llll}\text { COEFFICIENTS } & \text { SD } & P & \text { CONDITION TERM }\end{array}$
0.115677
0 CONST ANT
$-0.181463$
$0.6177910 .7881-0.803 \quad 1 \mathrm{pH}$
$-1.58158$
$0.2814170 .0111 \quad 0.679 \quad 2$ logferrate
0.00762947
$0.01838270 .7060-0.802 \quad 3$ alum
0.0276479
$0.1640240 .8769-0.835$
4 Polymer 
$N$ trials $\quad=8$

$\mathrm{N}$ terms $\quad=5$

Residual SD $=0.832848$, Lack-Of-Fit $\mathrm{P}=0.0316 *$

Residual DF $=3$

Residual SD used for tests

Replicate SD $=0.007071$

Replicate DF $=1$

R Squared $\quad=0.957, \mathrm{P}=0.0220 *$

Adj R Squared $=0.899$

Maximum Cook-Weisberg $L D$ influence (scaled 0-1) $=1.000$

Maximum studentized residual $=2.996 \mathrm{P}=0.0048 * *$

- This term may be eliminated

$\ll \times x \times \times \times \times \times x \times x \times x \times \gg$ Coefficients for response $U$

Centered continuous variables

$\begin{array}{llll}\text { COEFFICIENTS } & \text { SD } & P & \text { CONDITON TERM }\end{array}$

\begin{tabular}{ccccc}
0.0197023 & & \multicolumn{3}{c}{0 CONSTANT } \\
-0.0230218 & 0.00126790 .0004 & 0.803 & $1 \mathrm{pH}$ \\
0.00287712 & 0.0005775540 .0155 & 0.679 & 2 logferrate \\
$2.3051 e-005$ & $3.7727 e-0050.5844$ & 0.802 & 3 alum \\
-0.000610998 & 0.000336628 & 0.1671 & 0.835 & 4 Polymer
\end{tabular}

$N$ trials $\quad=8$

$\mathrm{N}$ terms $\quad=5$

Residual SD $=0.001709$

Residual DF $=3$

Residual SD used for tests

Replicate SD $=0.000707$

Replicate DF $=1$

R Squared $\quad=0.992, \mathrm{P}=0.0018 * *$

Adj R Squared $=0.981$

Maximum Cook-Weisberg LD influence $($ scaled $0-1)=1.000$

- This term may be eliminated 
«x $x \times x \times x \times x \times x \times x \times x »$ Coefficients for response 'Al'

Centered continuous variables

$\begin{array}{llll}\text { COEFFICIENTS } & \text { SD } & P & \text { CONDITION TERM }\end{array}$

0.513518

0 CONSTANT

$\begin{array}{lllll}-0.283369 & 1.35062 & 0.8473-0.803 & 1 \mathrm{pH}\end{array}$

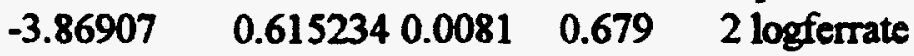

$0.0242024 \quad 0.04018830 .5895-0.802 \quad 3$ alum

$0.1086990 .358590 .7816-0.835$ 4 Polymer

$\mathrm{N}$ trials $\quad=8$

$\mathrm{N}$ terms $\quad=5$

Residual SD $=1.820774$

Residual DF $=3$

Residual SD used for tests

Replicate SD $=0.000000$

Replicate DF $=1$

R Squared $\quad=0.963, \mathrm{P}=0.0172$ *

Adj R Squared $=0.914$

Maximum Cook-Weisberg LD influence (scaled 0-1) $=1.000$

Maximum studentized residual $=3.000 \mathrm{P}=0.0000 * * *$

- This term may be eliminated

$\ll x \times x \times x \times x \times x \times x \times x \times x\rangle$ Coefficients for response 'Ba'

Centered continuous variables

$\begin{array}{llll}\text { COEFFICIENTS } & \text { SD } & P & \text { CONDITION TERM }\end{array}$

\begin{tabular}{cllll}
0.0386266 & & \multicolumn{3}{c}{0 CONSTANT } \\
-0.0491524 & 0.003464260 .0008 & 0.803 & $1 \mathrm{pH}$ \\
-0.0226995 & 0.001578050 .0007 & 0.679 & 2 logferrate \\
-0.000314993 & 0.000103081 & 0.0552 & 0.802 & 3 alum \\
-0.000520995 & 0.000919765 & 0.6107 & 0.835 & 4 Polymer
\end{tabular}

$\mathrm{N}$ trials $\quad=8$ 
$\mathrm{N}$ terms $\quad=5$

Residual SD $=0.004670$

Residual DF $=3$

Residual SD used for tests

Replicate SD $=0.000000$

Replicate DF $=1$

R Squared $\quad=0.998, \mathrm{P}=0.0003 * * *$

Adj R Squared $=0.995$

Maximum Cook-Weisberg LD influence $($ scaled 0-1) $=1.000$

Maximum studentized residual $=2.999 \mathrm{P}=0.0013$ **

- This term may be eliminated

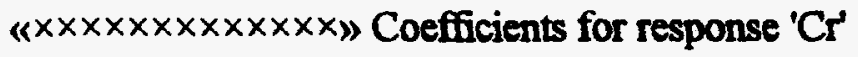

Centered continuous variables

$\begin{array}{llll}\text { COEFFICIENTS } & \text { SD } & P & \text { CONDITION TERM }\end{array}$

$0.000192196 \quad 0$ CONSTANT

$\begin{array}{lllll}-0.00020391 & 0.00151984 & 0.9018-0.803 & 1 & \mathbf{p H}\end{array}$

$\begin{array}{lllll}-0.00433739 & 0.0006923190 .0082 & 0.679 & 2 \text { logferrate }\end{array}$

$\begin{array}{lllll}1.28812 e-005 & 4.52237 e-005 & 0.7943-0.802 & 3 & \text { alum }\end{array}$

$0.0001248730 .0004035190 .7772-0.835$ 4 Polymer

$\mathrm{N}$ trials $\quad=8$

$N$ terms $=5$

Residual SD $=0.002049$

Residual DF $=3$

Residual SD used for tests

Replicate SD $=0.000000$

Replicate DF $=1$

R Squared $\quad=0.964, P=0.0167$ *

Adj R Squared $=0.916$

Maximum Cook-Weisberg $L D$ influence (scaled 0-1) $=1.000$

Maximum studentized residual $=3.000 \quad P=0.0000$ ***

- This term may be eliminated 


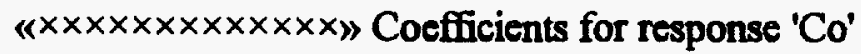

Centered continuous variables

COEFFICIENTS SD $P$ CONDITION TERM

\begin{tabular}{ccccc}
$6.72685 e-005$ & \multicolumn{3}{c}{ 0 CONSTANT } \\
$-7.13685 e-005$ & 0.000531943 & $0.9018-$ & 0.803 & 1 pH \\
-0.00151809 & 0.000242311 & 0.0082 & 0.679 & 2 logferrate \\
$4.50844 e-006$ & $1.58283 e-005$ & $0.7943-$ & 0.802 & 3 alum \\
$4.37054 e-005$ & 0.000141232 & $0.7772-$ & 0.835 & 4 Polymer
\end{tabular}

$N$ trials $\quad=8$

$N$ terms $\quad=5$

Residual SD $=0.000717$

Residual DF $=3$

Residual SD used for tests

Replicate SD $=0.000000$

Replicate DF $=1$

$\mathrm{R}$ Squared $=0.964, \mathrm{P}=0.0167 *$

Adj R Squared $=0.916$

Maximum Cook-Weisberg LD influence (scaled 0-1) $=1.000$

Maximum studentized residual $=3.000 \quad \mathrm{P}=0.0000 * * *$

- This term may be eliminated

$\ll \times x \times \times \times \times \times \times \times \times \times \times x »$ Coefficients for response ' $\mathrm{Cu}$ '

Centered continuous variables

$\begin{array}{llll}\text { COEFFICIENTS } & \text { SD } & P & \text { CONDITION TERM }\end{array}$

\begin{tabular}{|c|c|c|c|}
\hline 0.000278684 & \multicolumn{3}{|c|}{0 CONSTANT } \\
\hline-0.000295669 & 0.002203770 .9018 & 0.803 & $1 \mathrm{pH}$ \\
\hline-0.00628922 & 0.001003860 .0082 & 0.679 & 2 logferrate \\
\hline $1.86778 e-005$ & $6.55743 e-0050.7943-$ & 0.802 & 3 alum \\
\hline 0.000181065 & 0.0005851020 .7772 & 0.835 & 4 Polymer \\
\hline
\end{tabular}

$\mathrm{N}$ trials $\quad=8$

$N$ terms $\quad=5$ 
Residual SD $=0.002971$

Residual DF $=3$

Residual SD used for tests

Replicate SD $=0.000000$

Replicate DF $=1$

R Squared $\quad=0.964, P=0.0167$ *

Adj R Squared $=0.916$

Maximum Cook-Weisberg $L D$ influence (scaled 0-1) $=1.000$

Maximum studentized residual $=3.000 \quad P=0.0000$ ***

- This term may be eliminated

« $x \times x \times x \times x \times x \times x \times x \times \rrbracket$ Coefficients for response 'Fe'

Centered continuous variables

$\begin{array}{llll}\text { COEFFICIENTS } & \text { SD } & P & \text { CONDITION TERM }\end{array}$

0.261247

0 CONSTANT

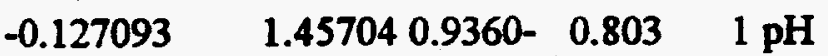

$\begin{array}{llll}-4.12549 & 0.6637120 .0084 & 0.679 & 2 \text { logferrate }\end{array}$

$0.012078 \quad 0.0433550 .7987-0.802 \quad 3$ alum

$0.1203440 .3868450 .7761-0.835$ 4 Polymer

$\mathrm{N}$ trials $\quad=8$

$\mathrm{N}$ terms $\quad=5$

Residual SD $=1.964244$

Residual DF $=3$

Residual SD used for tests

Replicate SD $=0.000000$

Replicate DF $=1$

$\mathrm{R}$ Squared $\quad=0.963, \mathrm{P}=0.0173 *$

Adj R Squared $=0.914$

Maximum Cook-Weisberg LD influence (scaled 0-1) $=1.000$

Maximum studentized residual $=3.000 \quad \mathrm{P}=0.0000 * * *$

- This term may be eliminated

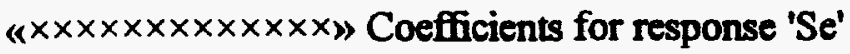


Centered continuous variables

COEFFICIENTS SD $P$ CONDITION TERM

\begin{tabular}{cccc}
0.113216 & & \multicolumn{3}{c}{0 CONSTANT } \\
-0.0311594 & $0.1758290 .8706-0.803$ & 1 pH \\
0.0546185 & $0.0800940 .5442-$ & 0.679 & 2 logferrate \\
-0.00301146 & $0.00523190 .6052-$ & 0.802 & 3 alum \\
-0.0297616 & $0.04668290 .5691-$ & 0.835 & 4 Polymer
\end{tabular}

$N$ trials $\quad=8$

$\mathrm{N}$ terms $=5$

Residual SD $=0.237037$, Lack-Of-Fit $\mathrm{P}=0.0316 *$

Residual DF $=3$

Residual SD used for tests

Replicate SD $=0.002828$

Replicate DF $=1$

$R$ Squared $\quad=0.262, P=0.8834$

Adj R Squared $=0.000$

Maximum Cook-Weisberg LD influence (scaled 0-1) $=1.000$

Maximum studentized residual $=3.000 \quad \mathrm{P}=0.0002 * * *$

- This term may be eliminated

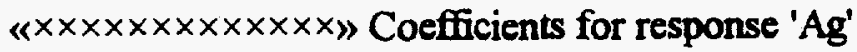

Centered continuous variables

COEFFICIENTS SD $P$ CONDITION TERM
0.00420908
0 CONSTANT
$\begin{array}{llllll}0.00331102 & 0.00392701 & 0.4611-0.803 \quad 1 \mathrm{pH}\end{array}$
$\begin{array}{lllll}-0.00614331 & 0.00178884 & 0.0414 & 0.679 & 2 \text { logferrate }\end{array}$
$\begin{array}{lllll}-2.69518 \mathrm{e}-005 & 0.00011685 & 0.8324- & 0.802 & 3 \text { alum }\end{array}$
$\begin{array}{llllll}-4.32029 e-005 & 0.00104263 & 0.9696-0.835 & 4 \\ \end{array}$

\footnotetext{
$N$ trials $\quad=8$

$\mathrm{N}$ terms $\quad=5$

Residual SD $=0.005294$

Residual DF $=3$
} 
Residual SD used for tests

Replicate SD $=0.000000$

Replicate DF $=1$

$\mathrm{R}$ Squared $\quad=0.881, \mathrm{P}=0.0956$

Adj R Squared $=0.722$

Maximum Cook-Weisberg LD influence (scaled 0-1) $=1.000$

- This term may be eliminated

« $x \times x \times x \times x \times x \times x \times x »$ Coefficients for response ' $Z \mathbf{n}$ '

Centered continuous variables

$\begin{array}{llll}\text { COEFFICIENTS } & \text { SD } & P & \text { CONDITION TERM }\end{array}$

0.000826442

0 CONSTANT

$\begin{array}{lllll}-0.000876813 & 0.0065353 & 0.9018-0.803 & 1 & \mathrm{pH}\end{array}$

$\begin{array}{llll}-0.0186508 & 0.002976970 .0082 & 0.679 & 2 \text { logferrate }\end{array}$

$5.53893 e-005 \quad 0.0001944620 .7943-0.802 \quad 3$ alum

$0.000536952 \quad 0.001735130 .7772-0.835 \quad 4$ Polymer

$\mathrm{N}$ trials $\quad=8$

$\mathrm{N}$ terms $\quad=5$

Residual SD $=0.008810$

Residual DF $=3$

Residual SD used for tests

Replicate SD $=0.000000$

Replicate DF $=1$

R Squared $\quad=0.964, \mathrm{P}=0.0167 *$

Adj R Squared $=0.916$

Maximum Cook-Weisberg LD influence (scaled 0-1) $=1.000$

Maximum studentized residual $=3.000 \quad \mathrm{P}=0.0000 * * *$

- This term may be eliminated 
PROJECT NAME: ROCKYFLA.ECP

Created: Thu Nov 03 09:36:01 1994

« $x \times x \times x \times x \times x \times x \times x \times »$ ANOVA Table for response 'Am'

Mean Squares DF P

$1.66303 \mathrm{e}-005 \quad 10.9671 \mathrm{pH}$

0.29411910 .0095 logferrate

$0.000271465 \quad 10.8682$ alum

1.18755e-008 10.9991 Polymer

$\begin{array}{lll}0.00831845 & 3 & \text { ERROR }\end{array}$

0.000451 REPLICATE ERROR

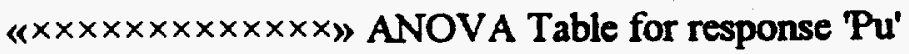

LACK-OF-FIT

Mean Squares DF P

$\begin{array}{ccc}0.0598446 & 10.7881 \mathrm{pH} \\ 21.9085 & 10.0111 \text { logferrate } \\ 0.119481 & 10.7060 \text { alum } \\ 0.0197079 & 10.8769 \text { Polymer } \\ 0.693636 & 3 \quad \text { ERROR }\end{array}$

5.00001e-005 1 REPLICATE ERROR

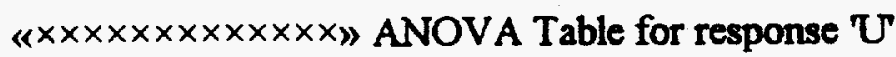

Mean Squares DF P
$0.000963222 \quad 10.0004 \mathrm{pH}$
7.25014e-005 10.0155 logferrate
$1.09066 \mathrm{e}-006 \quad 10.5844$ alum
9.62489e-006 10.1671 Polymer
2.92158e-006 3 ERROR 


\subsection{8e-007 1 REPLICATE ERROR}

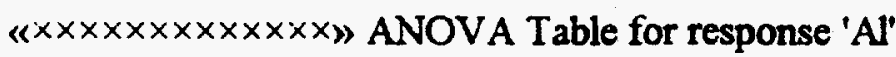

Mean Squares DF $P$

$\begin{array}{ccc}0.145933 & 10.8473 \mathrm{pH} \\ 131.113 & 10.0081 \text { logferrate } \\ 1.20235 & 10.5895 \text { alum } \\ 0.304624 & 10.7816 \text { Polymer } \\ 3.31522 & 3 & \text { ERROR }\end{array}$

$0 \quad 1$ REPLICATE ERROR

« $x \times x \times x \times x \times x \times x \times x \times x 》$ ANOVA Table for response ${ }^{\mathrm{Ba}}$

Mean Squares DF P

$$
\begin{array}{ccc}
0.00439075 & 10.0008 \mathrm{pH} \\
0.00451297 & 10.0007 \text { logferrate } \\
0.000203664 & 10.0552 \text { alum } \\
6.99816 e-006 & 10.6107 \text { Polymer } \\
2.18107 e-005 & 3 & \text { ERROR }
\end{array}
$$

$\begin{array}{lll}0 & 1 & \text { REPLICATE ERROR }\end{array}$

« $x \times x \times x \times x \times x \times x \times x \times x »$ ANOVA Table for response ' $\mathrm{Cr}$ '

Mean Squares DF P

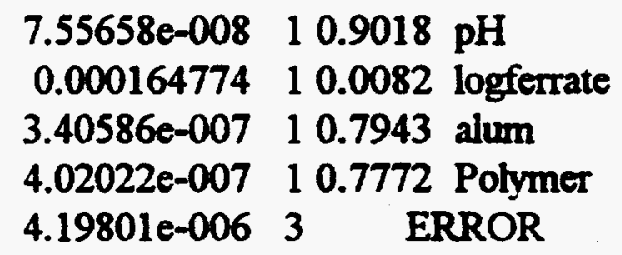

\section{$0 \quad 1$ REPLICATE ERROR}

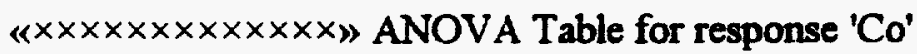


Mean Squares DF P

9.25681e-009 $10.9018 \mathrm{pH}$

$2.01848 \mathrm{e}-005 \quad 10.0082$ logferrate

$4.17218 \mathrm{e}-008 \quad 10.7943$ alum

4.92477e-008 10.7772 Polymer

5.14256e-007 $3 \quad$ ERROR

\section{$0 \quad 1$ REPLICATE ERROR}

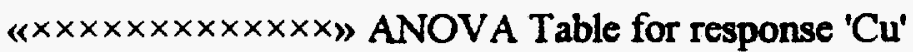

\section{Mean Squares DF P}

$\begin{array}{rll}1.58877 \mathrm{e}-007 & 10.9018 \mathrm{pH} \\ 0.000346437 & 10.0082 & \text { logferrate } \\ 7.16083 \mathrm{e}-007 & 10.7943 \text { alum } \\ 8.45251 \mathrm{e}-007 & 10.7772 \text { Polymer } \\ 8.82631 \mathrm{e}-006 & 3 & \text { ERROR }\end{array}$

$0 \quad 1$ REPLICATE ERROR

« $x \times x x x x x x x x x x x x 》$ ANOVA Table for response ' $\mathrm{Fe}$ '

Mean Squares DF P
$0.0293557 \quad 10.9360 \mathrm{pH}$
149.06810 .0084 logferrate
0.29943510 .7987 alum
0.3733910 .7761 Polymer
$\begin{array}{lll}3.85825 & 3 & \text { ERROR }\end{array}$

$\begin{array}{lll}0 & 1 & \text { REPLICATE ERROR }\end{array}$

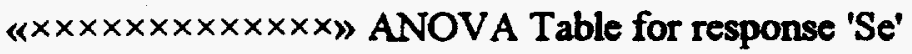

LACK-OF-FIT

Mean Squares DF P 


$$
\begin{array}{cll}
0.00176452 & 10.8706 \mathrm{pH} \\
0.0261283 & 10.5442 \text { logferrate } \\
0.0186151 & 10.6052 \text { alum } \\
0.0228365 & 10.5691 \text { Polymer } \\
0.0561864 & 3 & \text { ERROR }
\end{array}
$$

8e-006 1 REPLICATE ERROR

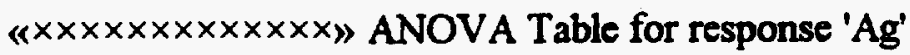

\section{Mean Squares DF $\mathbf{P}$}

$$
\begin{array}{ccc}
1.99238 \mathrm{e}-005 & 10.4611 \mathrm{pH} \\
0.00033055 & 10.0414 \text { logferrate } \\
1.49103 \mathrm{e}-006 & 10.8324 \text { alum } \\
4.81218 \mathrm{e}-008 & 10.9696 \text { Polymer } \\
2.80268 \mathrm{e}-005 & 3 & \text { ERROR }
\end{array}
$$
01
REPLICATE ERROR

« $x \times x \times x \times x \times x \times x \times x\rangle$ ANOVA Table for response ' $\mathrm{Zn}$ '

Mean Squares DF $\mathbf{P}$
$1.39721 \mathrm{e}-006 \quad 10.9018 \mathrm{pH}$
0.0030466710 .0082 logferrate
$6.29744 \mathrm{e}-006 \quad 10.7943$ alum
7.43339e-006 1 0.7772 Polymer
7.76212e-005 $3 \quad$ ERROR

\section{$\begin{array}{lll}0 & 1 & \text { REPLICATE ERROR }\end{array}$}




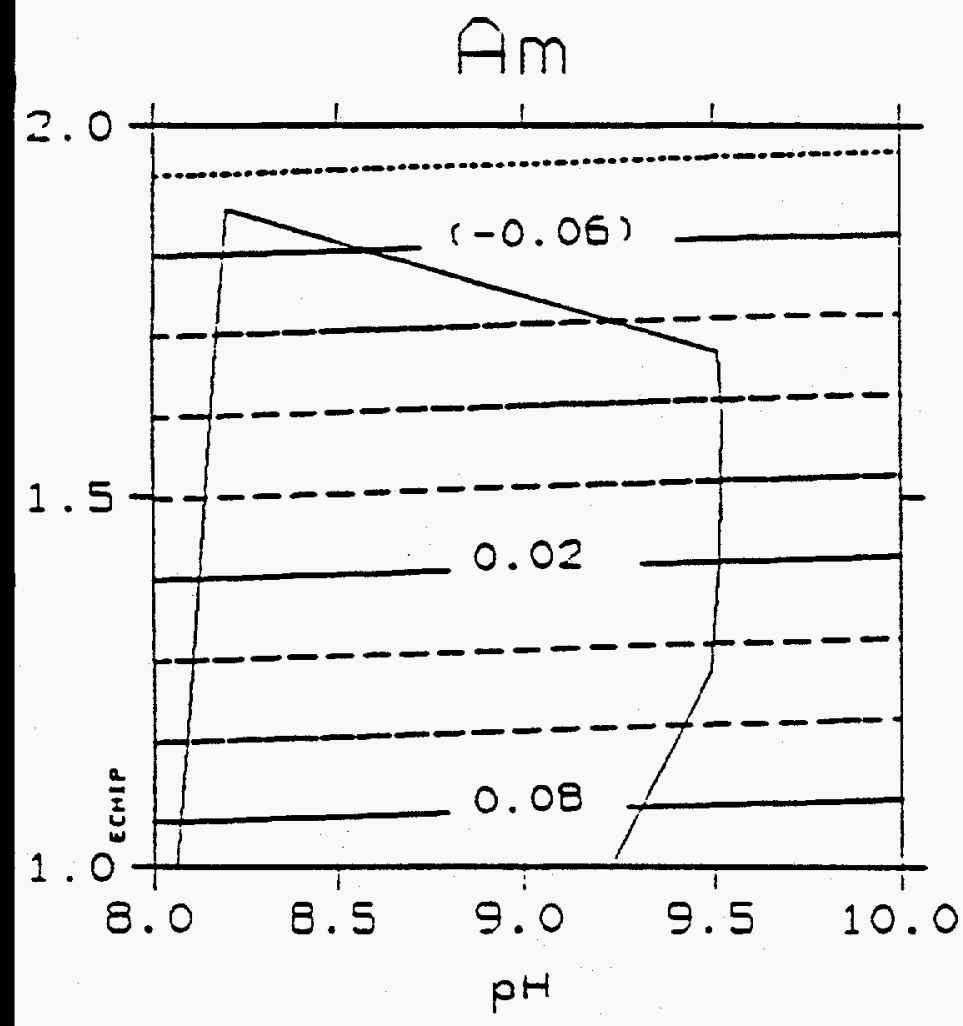

alum $=27.500000$
Polymer $=2.5000$

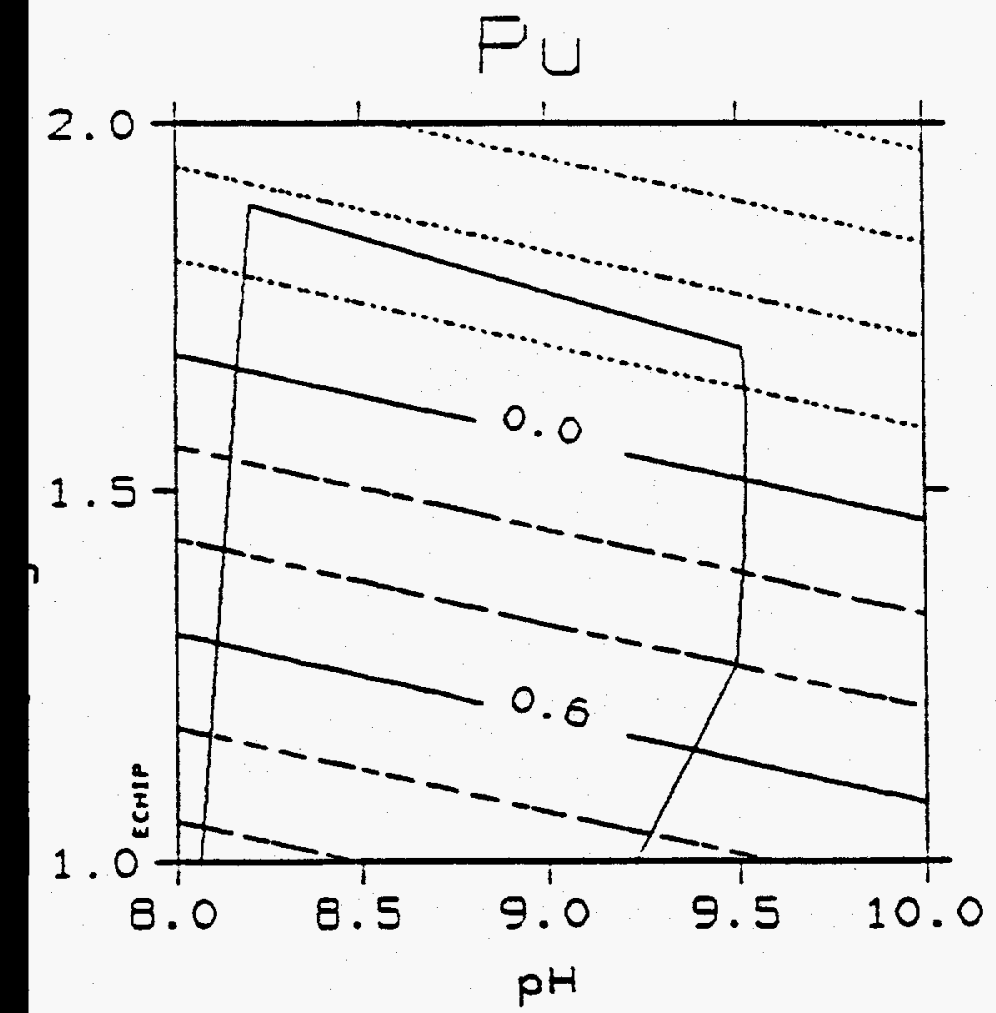

Lack of Fit

alum $=27.500000$

Polymer $=2.5000$ 


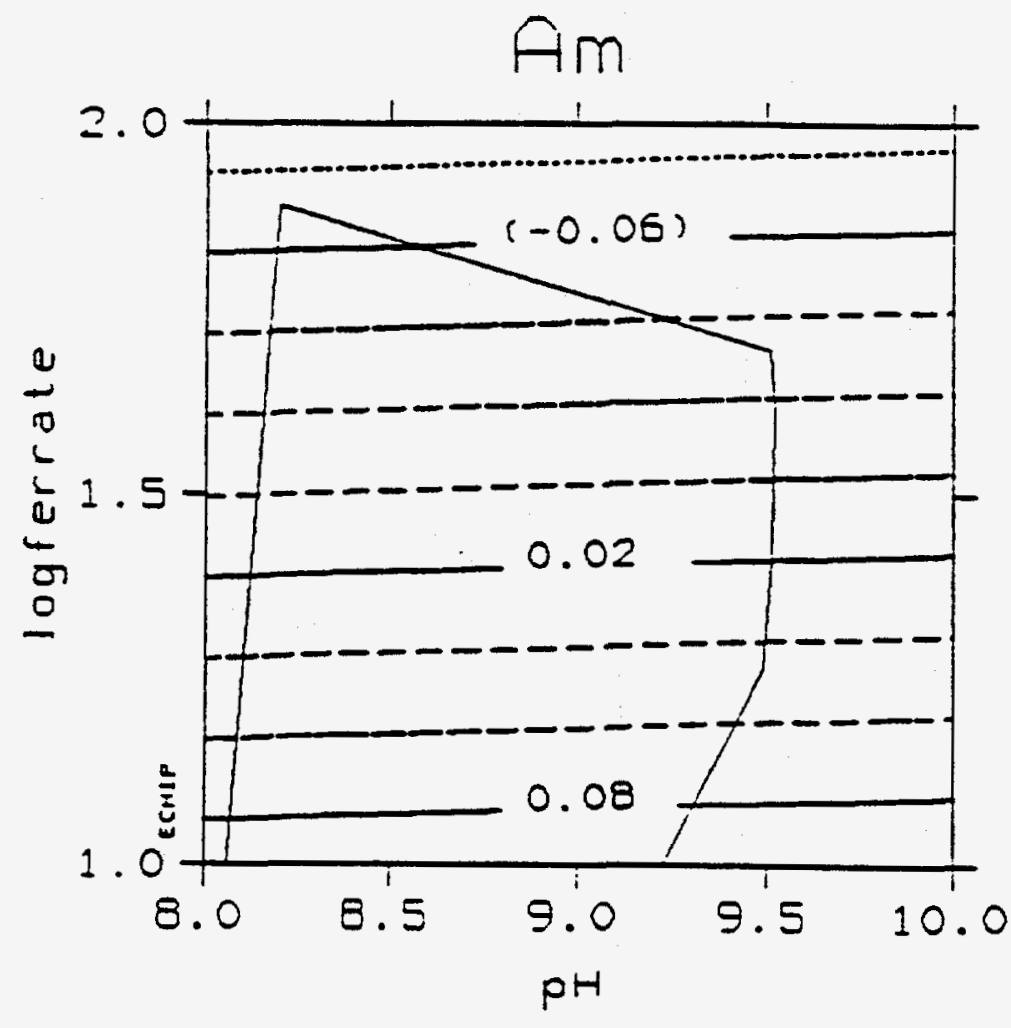

alum $=27.500000$
Polymer $=2.5000$

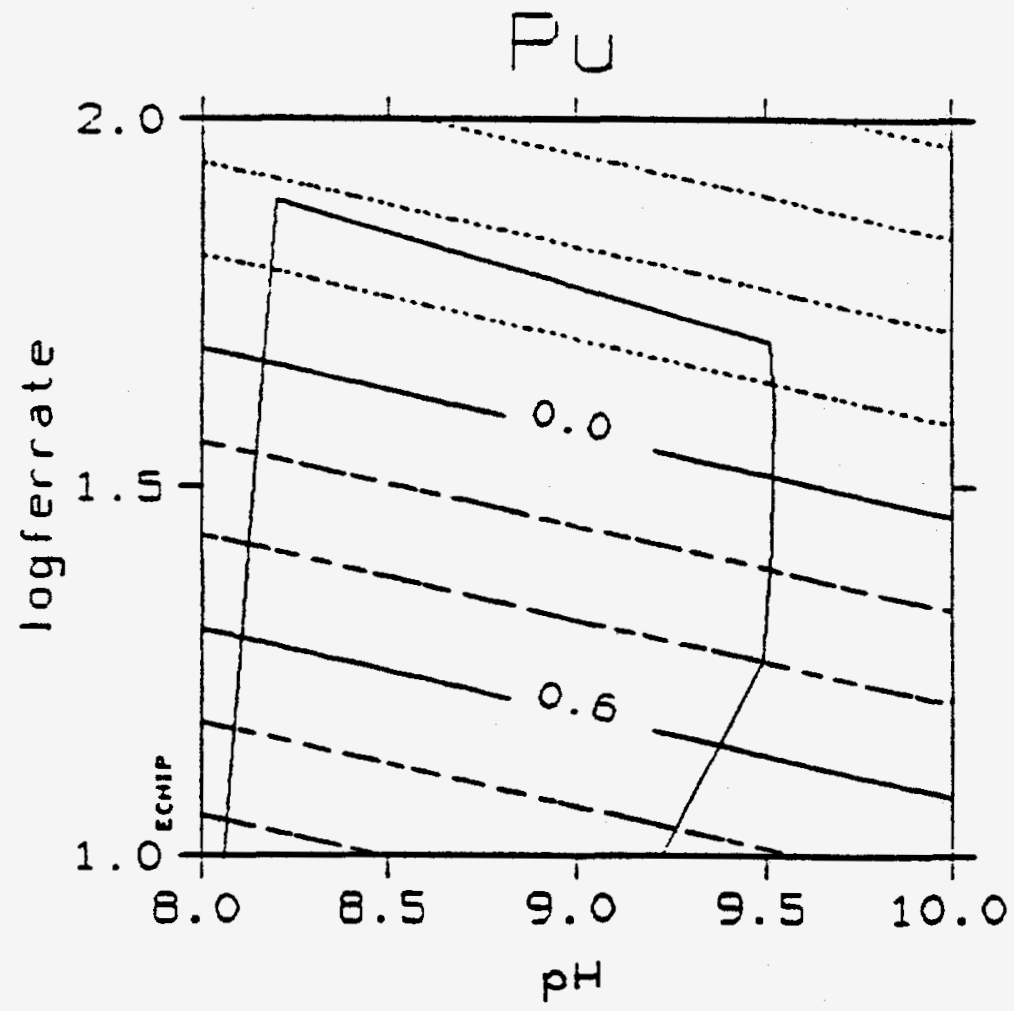

Lack of Eit

alum $=27.500000$

Polymer $=2.5000$ 


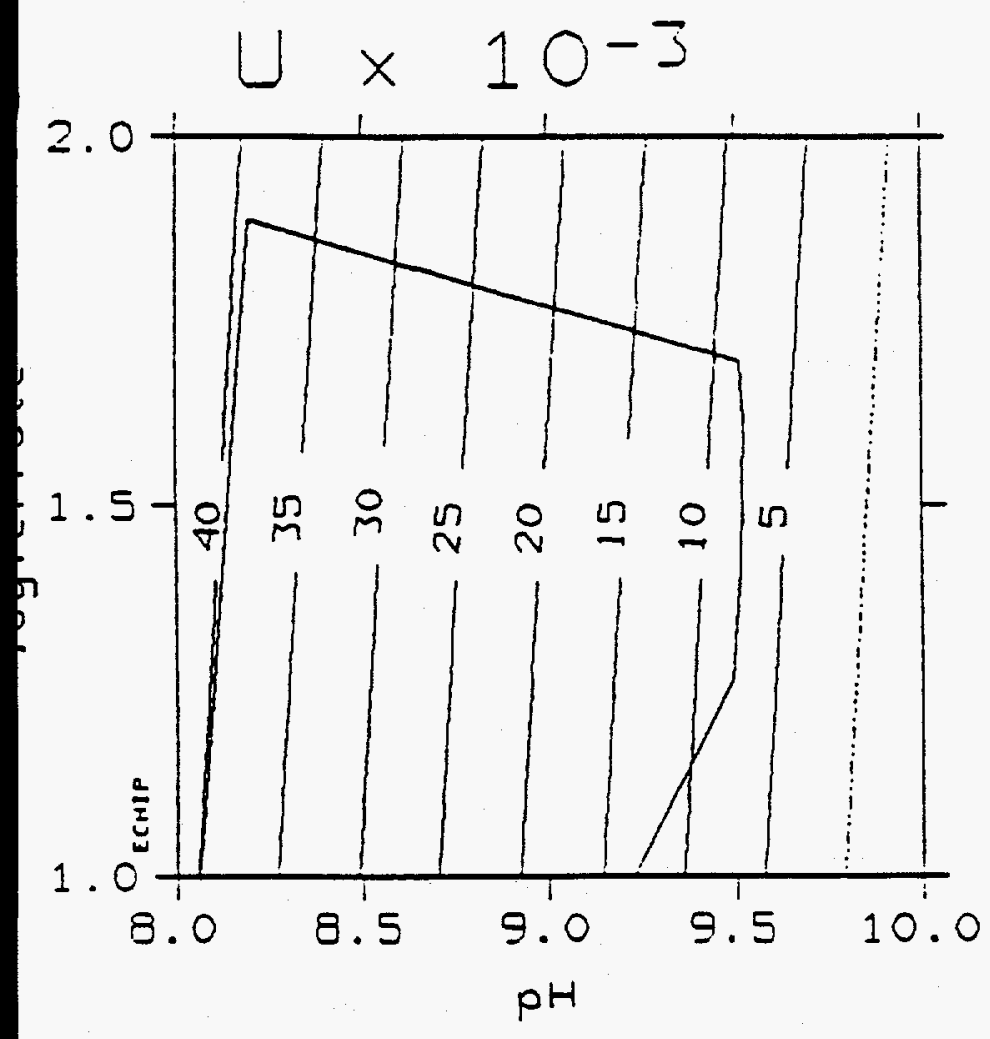

$$
\begin{aligned}
& \text { alum }=27.500000 \\
& \text { Polymer }=2.5000
\end{aligned}
$$

Al

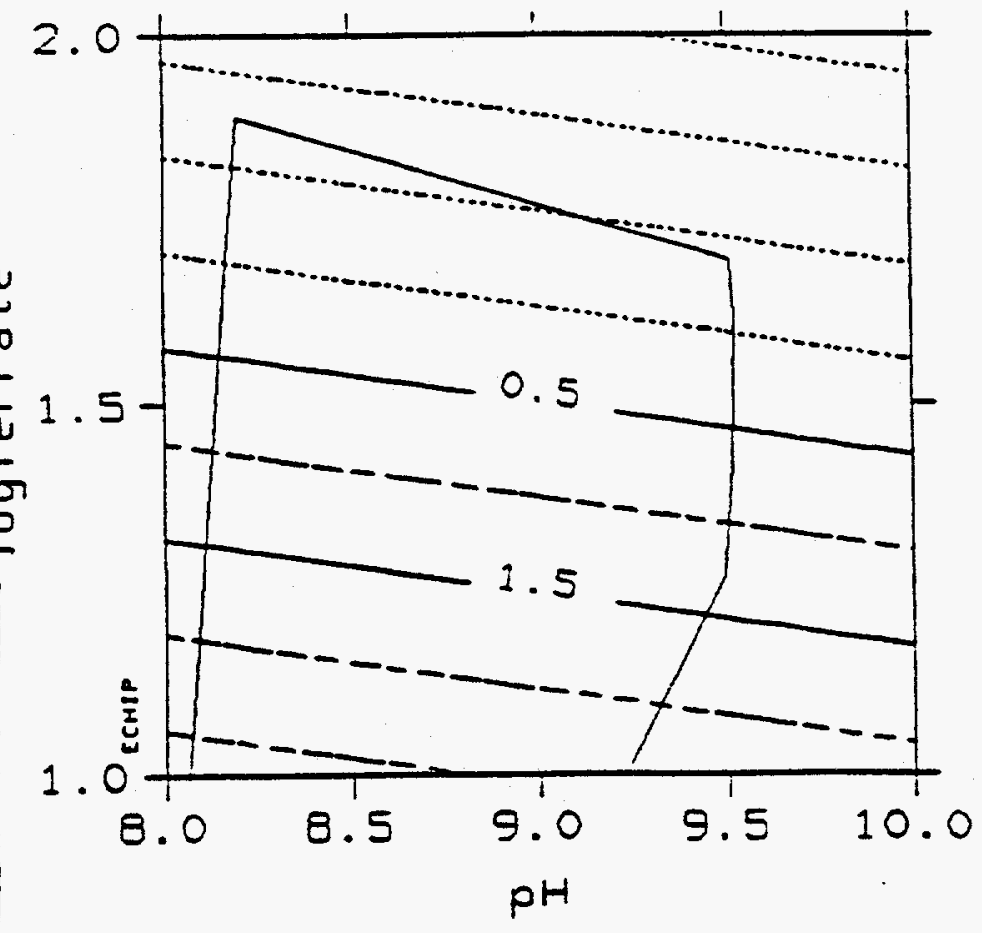

alum $=27.500000$
Polymer $=2.5000$ 


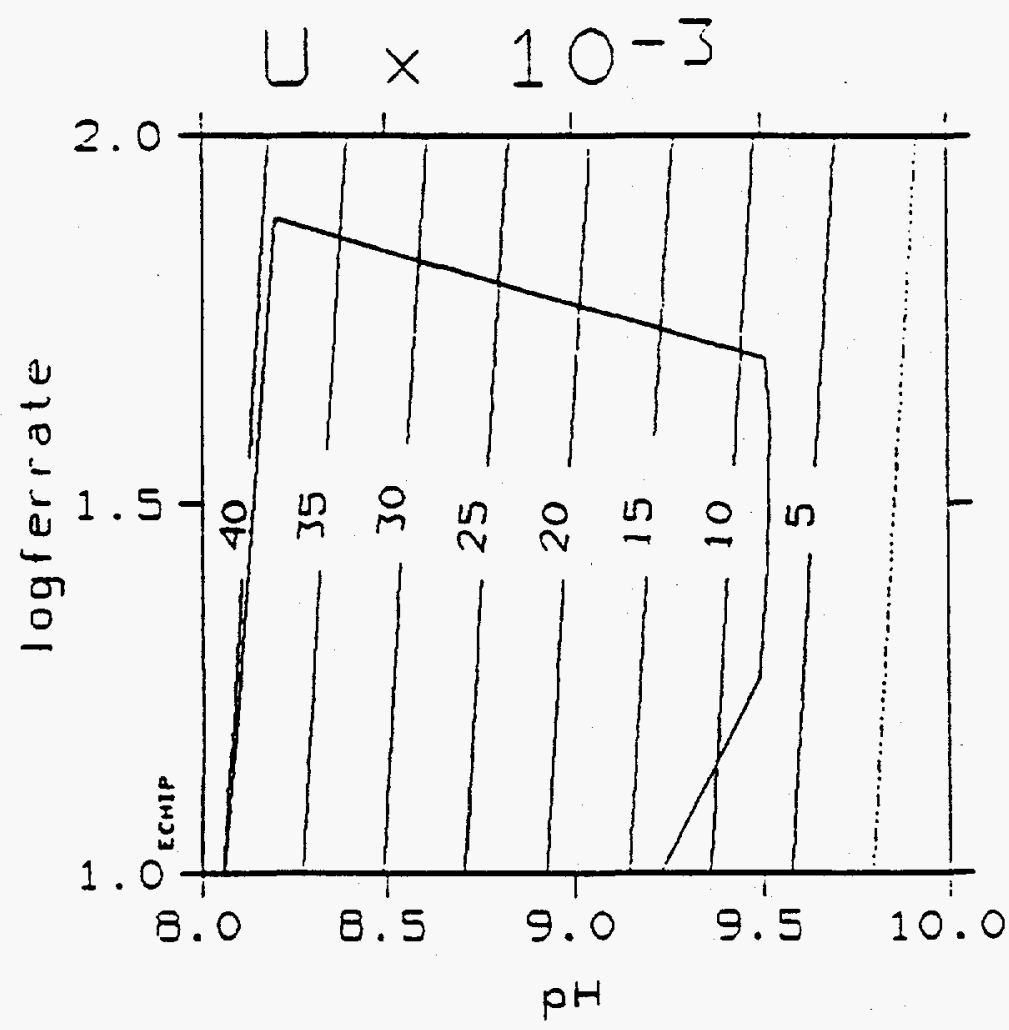

alum $=27.500000$

Polymer $=2.5000$

A 1

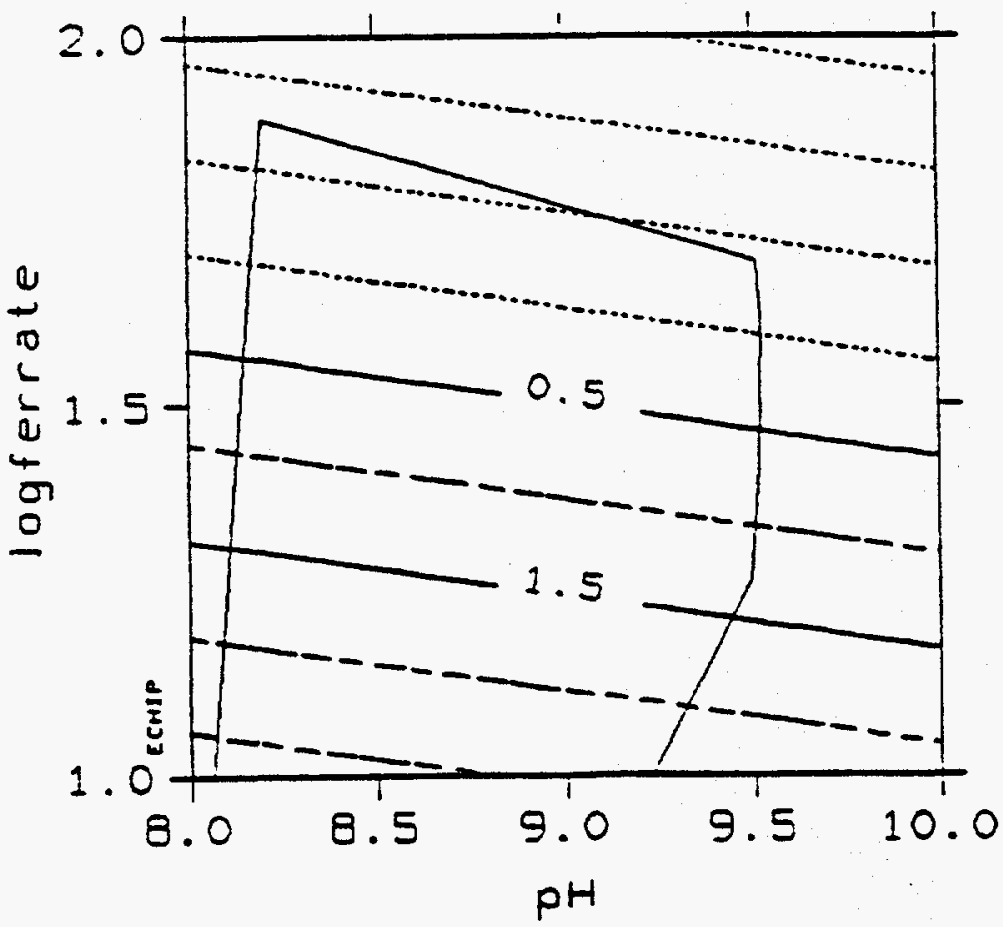

alum $=27.500000$

Polymer $=2.5000$ 

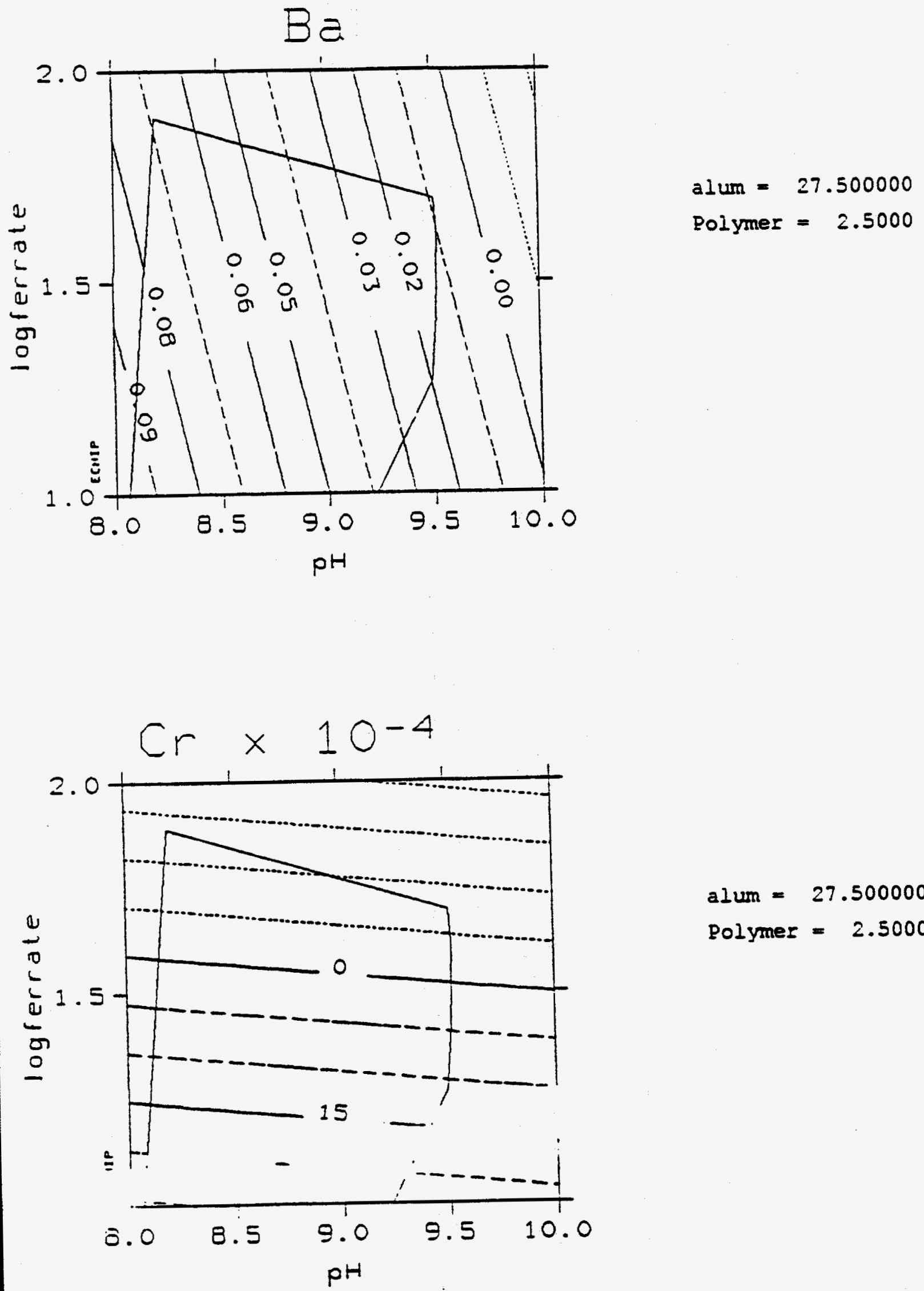

alum $=27.500000$

polymer $=2.5000$ 


\section{Co $\times 10^{-4}$}

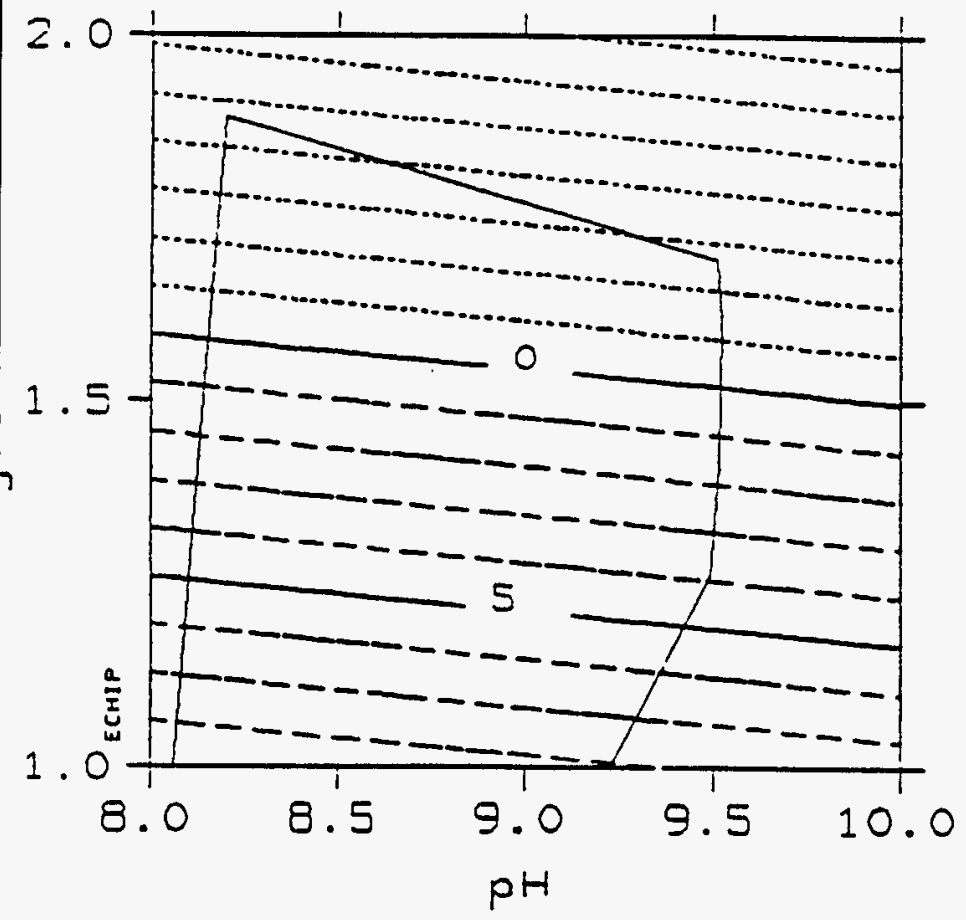

alum $=27.500000$
Polymer $=2.5000$

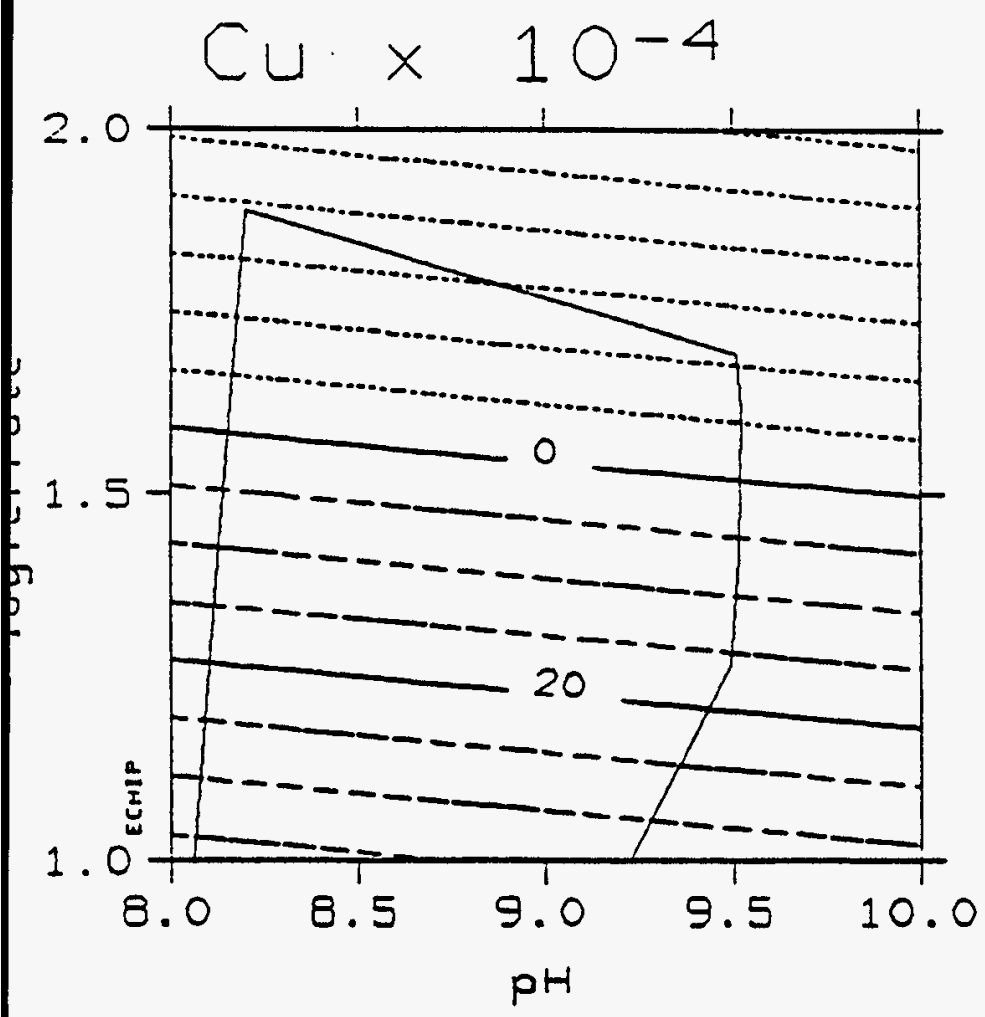

alum $=27.500000$
Polymer $=2.5000$ 

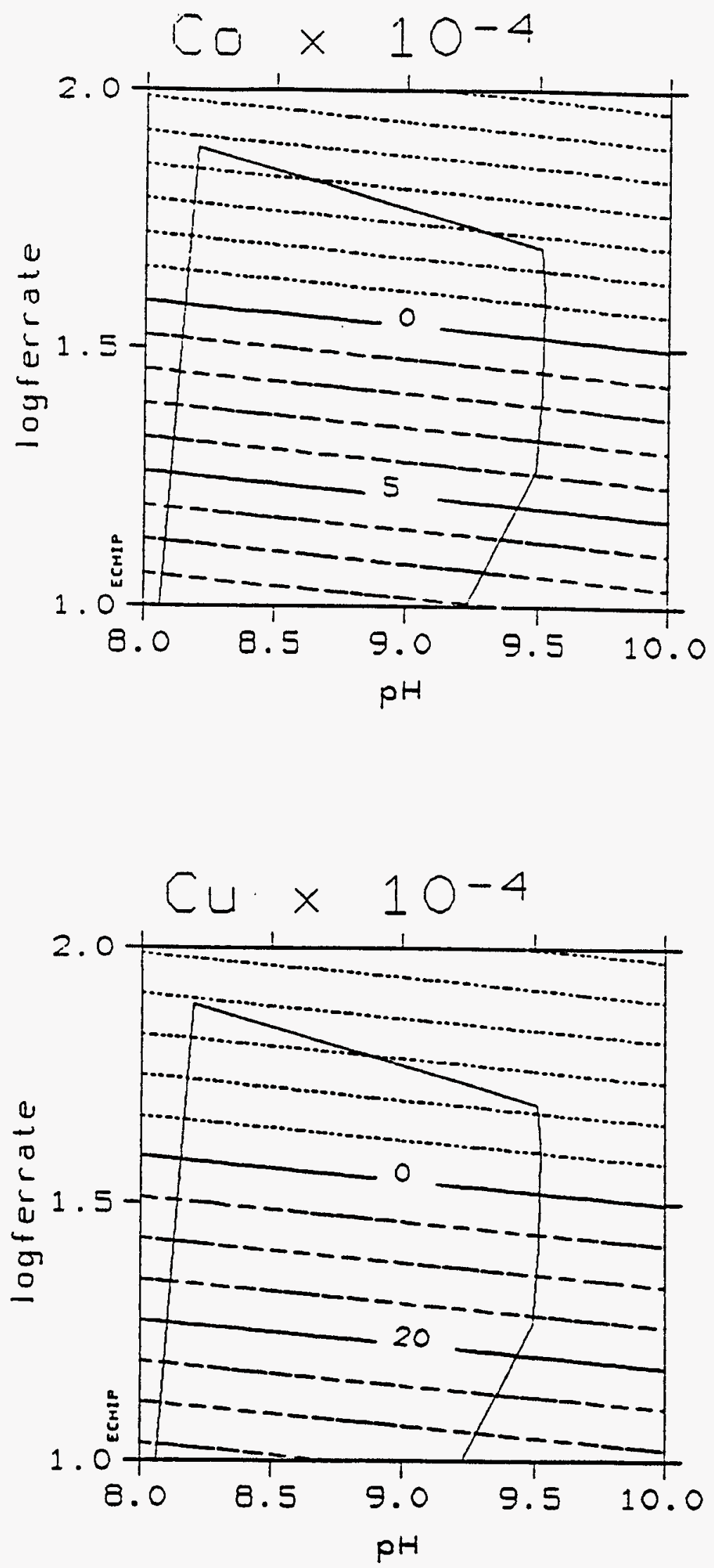

alum $=27.500000$

Polymer $=2.5000$ alum $=27.500000$
Polymer $=2.5000$ 


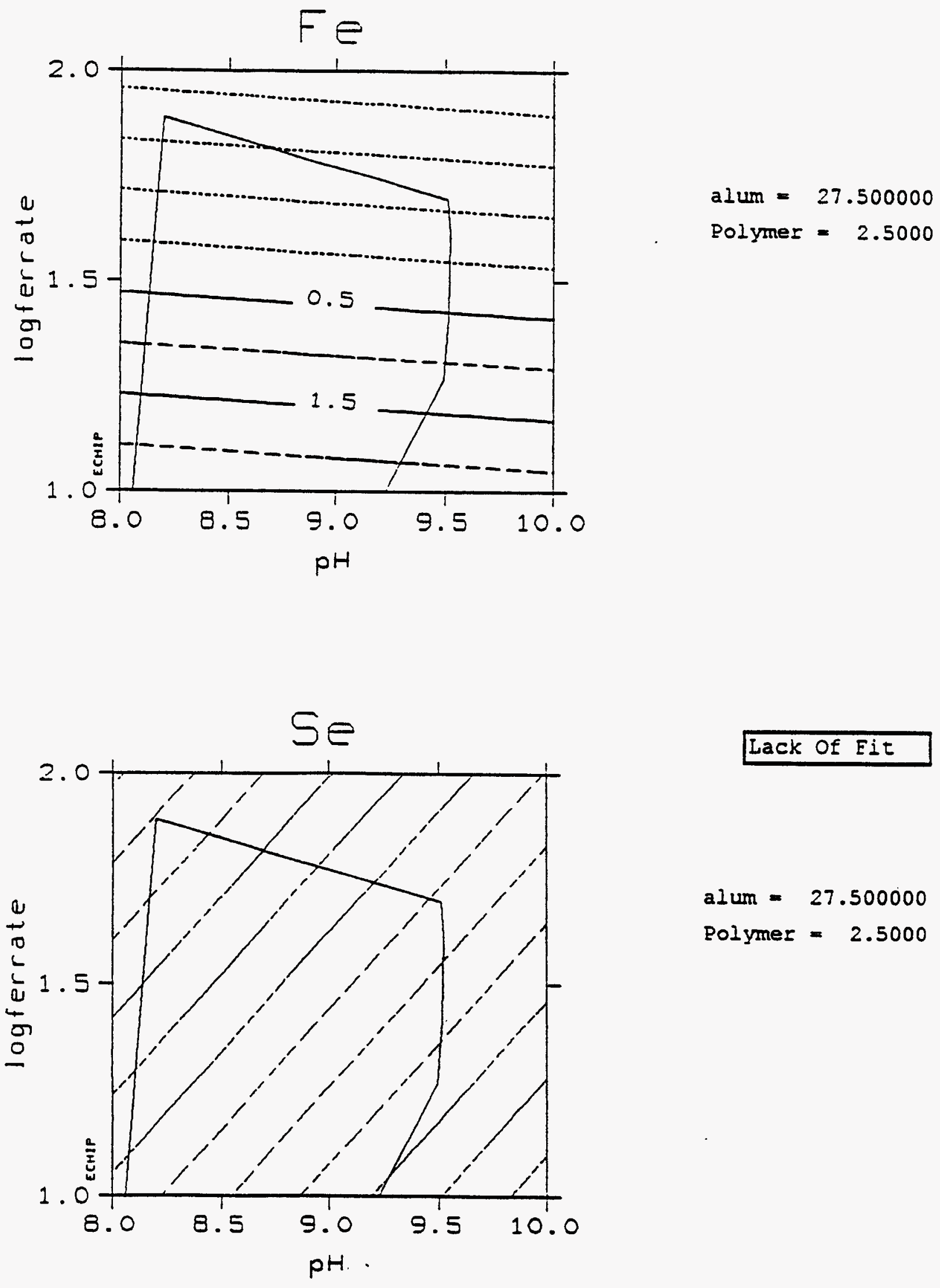


Potassium Ferrate Treatment of RFETS Groundwater
Document Number:

Section:

Page:
RF/ER-94-0028.UN

Appendix F, Rev. 0

1 of 47

\section{APPENDIX F}

ECHIP OUTPUT OF PHASE II MODIFIED TEST PLAN 
ROJECT NAME: NEWDATA.ECP

reated: Thu Dec 15 22:04:42 1994

ummary results

Am

$\begin{array}{ll}\mathrm{Pu} & \\ \cdot & \mathrm{U}\end{array}$

Al

- $\mathrm{Ba}$

. $\quad \mathrm{Cr}$

$. \quad . \quad$ Co

$\cdot \quad \cdot \quad \cdot \quad \cdot \mathrm{Cu}$

. $. \quad . \quad . \quad \mathrm{Fe}$

$\cdot \cdot \cdot \cdot \cdot \cdot \mathrm{Se}$

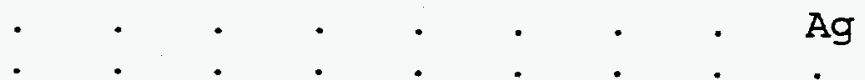

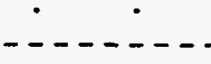

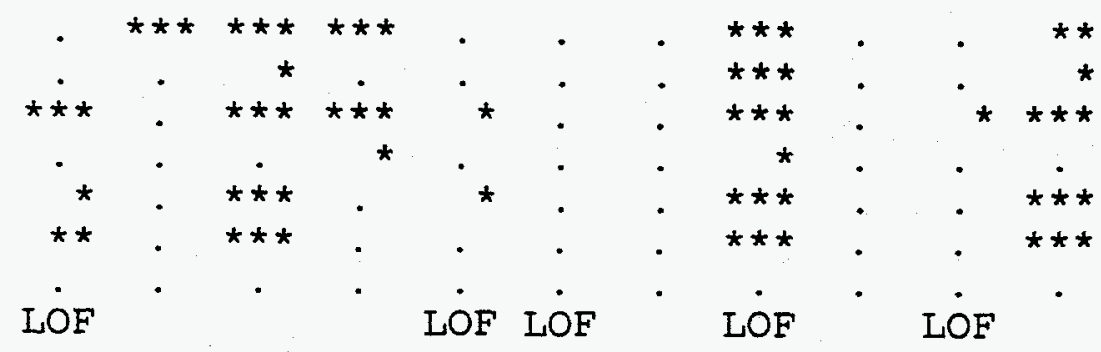

$1 \mathrm{pH}$

2 logferrate

$3 \mathrm{pH}$ *logferrate

$4 \mathrm{pH}^{\wedge} 2$

5 Iogferrate^2

$6 \mathrm{pH}^{\star}$ logferrate^ 2

$7 \mathrm{pH}^{\wedge} 2$ *logferrate 
PROJECT NAME: NEWDATA.ECP

Created: Thu Dec 15 22:04:30 1994

« $x \times x \times x \times x \times x \times x \times x \gg$ Effects graph for response 'Am'

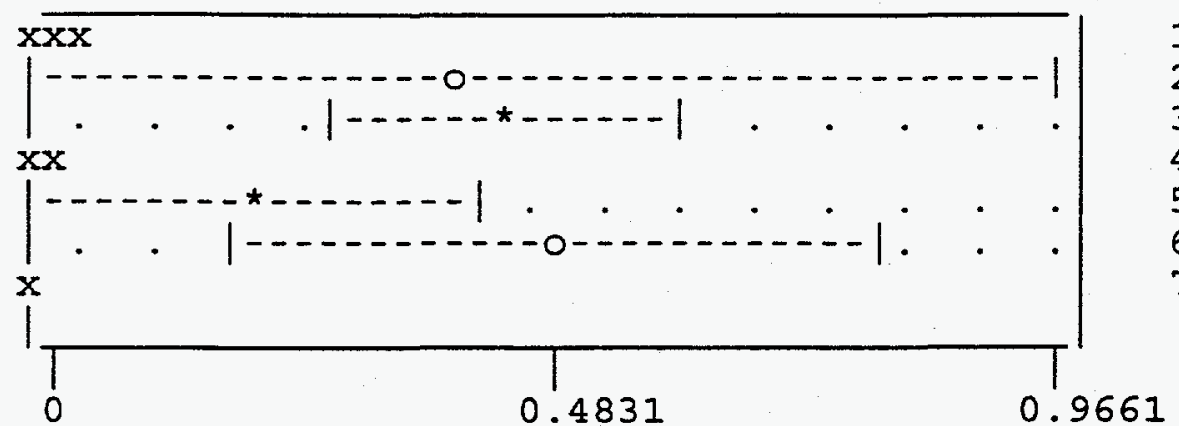

**Pareto effects graph for response 'Am'**

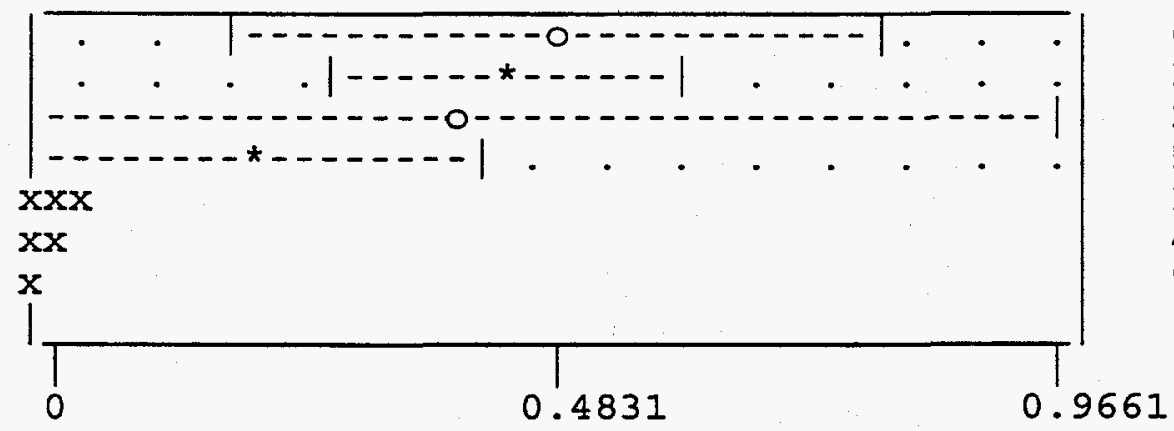

$1 \mathrm{pH}$

2 logferrate $\mathrm{pH} * \log$ ferrate $\mathrm{pH}^{\wedge} 2$ logferrate`2 $\mathrm{pH} * \log$ ferrate`2 $\mathrm{pH}^{\wedge} 2 * \log$ ferrate
$6 \mathrm{pH} *$ logferrate^2

$3 \mathrm{pH} * \log f e r r a t e$

2 logferrate

5 logferrate`2

$1 \mathrm{pH}$

$4 \mathrm{pH}^{\wedge} 2$

$7 \mathrm{pH}^{\wedge} 2$ * logferrate 
PROJECT NAME: NEWDATA.ECP

Created: Thu Dec 15 22:04:30 1994

$x \times \times \times \times \times \times \times \times \times \times \times \times \gg$ Effects graph for response 'Pu'

$\triangle A C K-O F-F I T$

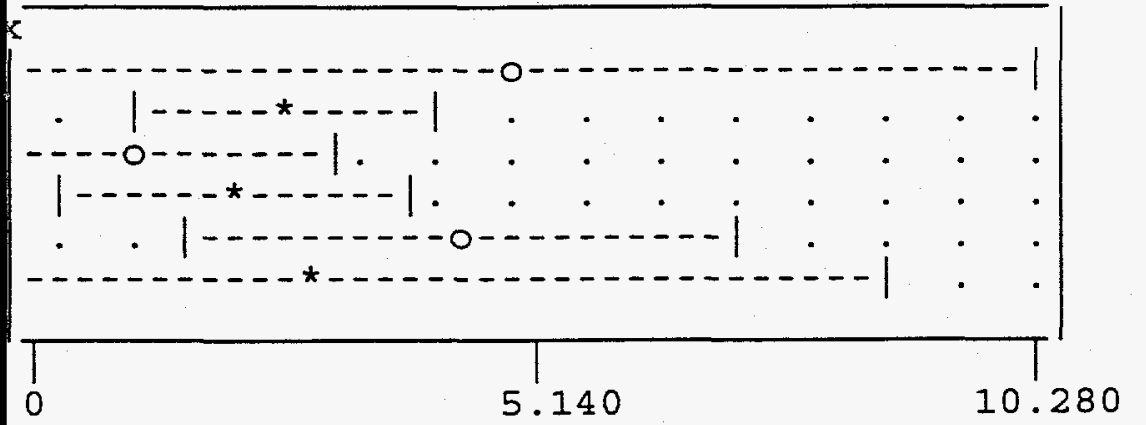

$\mathrm{pH}$

logferrate $\mathrm{pH} *$ logferrate $\mathrm{pH}^{\wedge} 2$

logferrate^2 $\mathrm{pH}^{*} \log$ ferrate 2 $\mathrm{pH}^{\wedge} 2$ *logferrate

**Pareto effects graph for response 'Pu'** ACK - OF - FIT

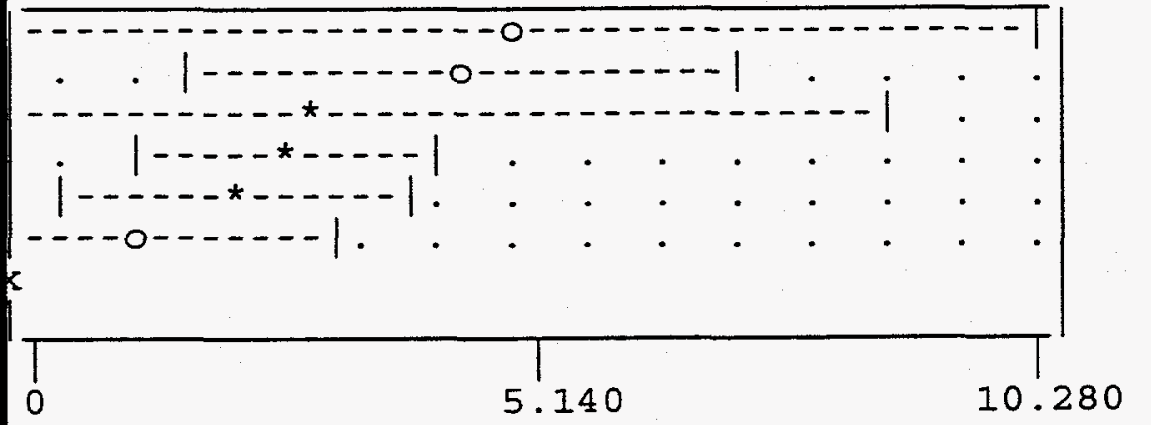

2 logferrate $6 \mathrm{pH} * \log$ ferrate`2 7 pH^2*logferrate $3 \mathrm{pH} *$ logferrate 5 logferrate^2 $4 \mathrm{pH}^{\wedge} 2$

$1 \mathrm{pH}$ 
PROJECT NAME: NEWDATA.ECP

Created: Thu Dec 15 22:04:30 1994

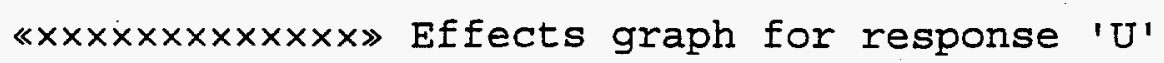

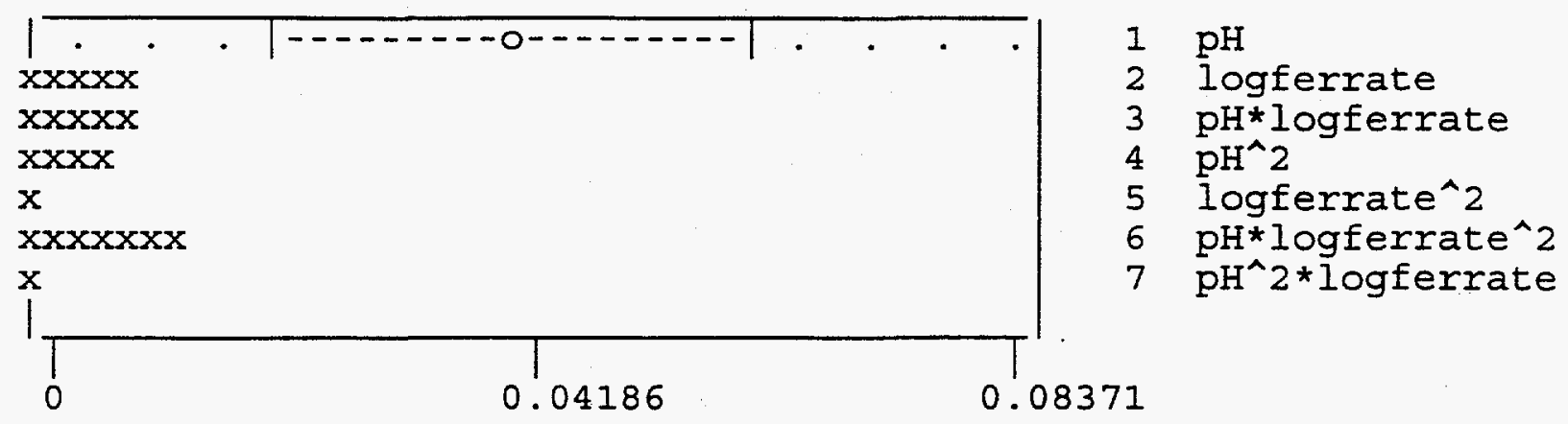

**Pareto effects graph for response ' $U$ '**

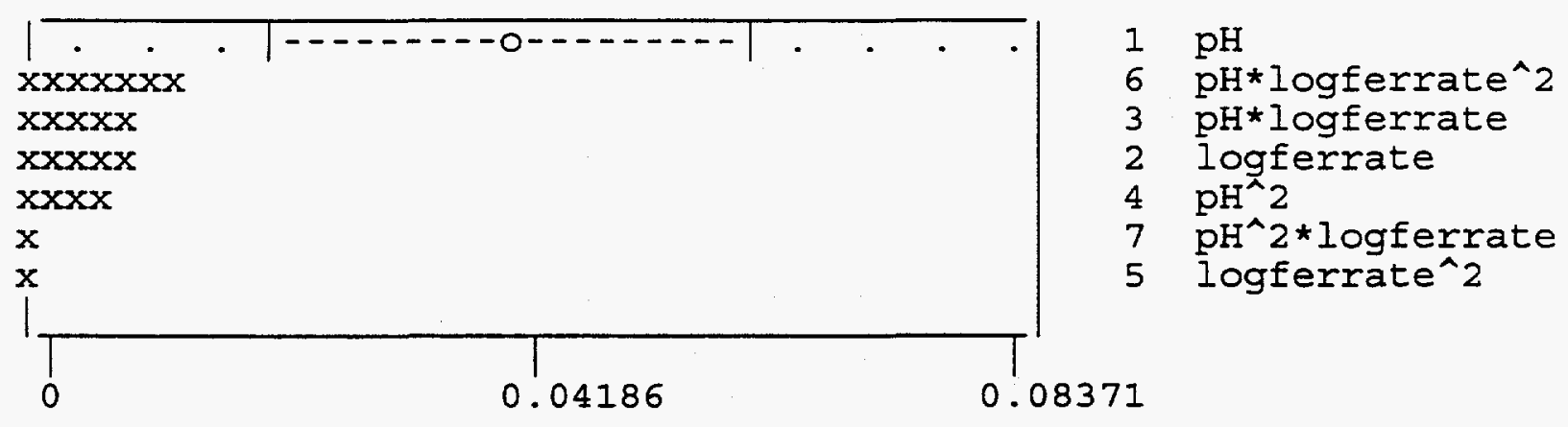


PROJECT NAME: NEWDATA.ECP

Created: Thu Dec 15 22:04:30 1994

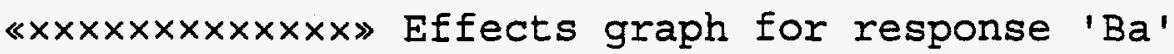

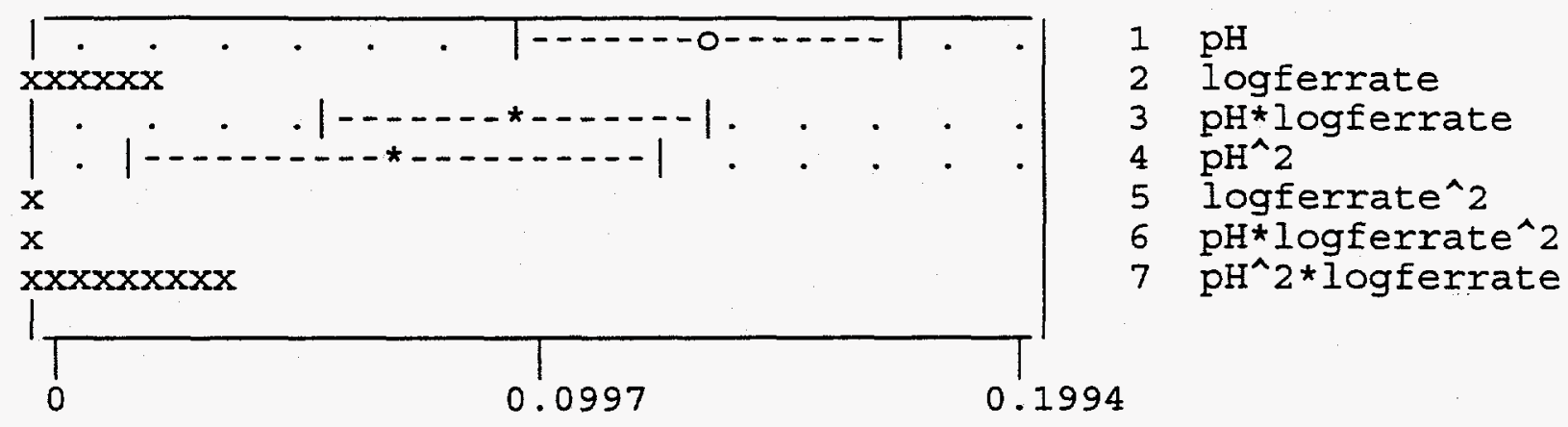

**Pareto effects graph for response ' $\mathrm{Ba}$ '**

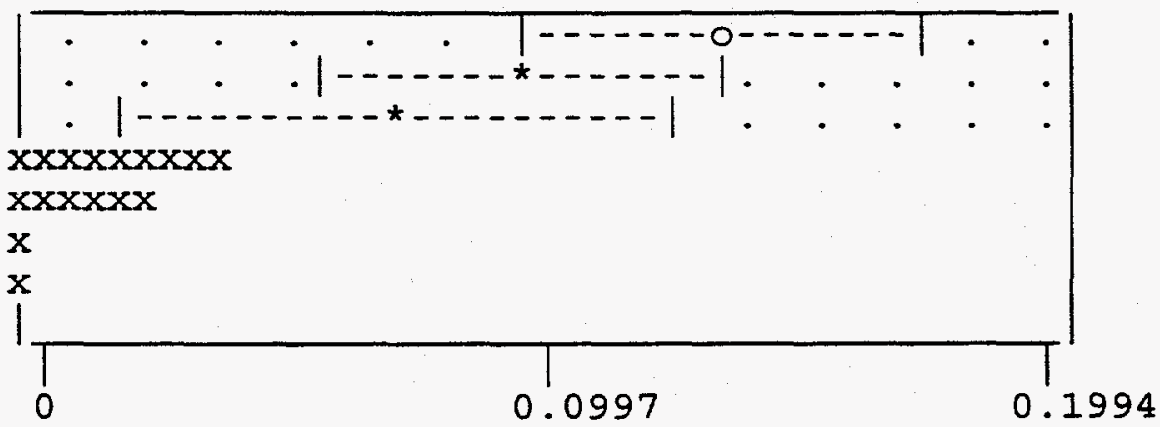

$1 \mathrm{pH}$

$3 \mathrm{pH} * \log f e r r a t e$ $4 \mathrm{pH}^{\wedge} 2$

$7 \mathrm{pH}^{\wedge} 2$ *logferrate

2 logferrate

5 logferrate`2

$6 \mathrm{pH} \star \log f e r r a t e^{\wedge} 2$ 
ROJECT NAME: 2NDRE.ECP

ceated: Tue Nov 01 13:48:27 1994

*xx $x \times x \times x \times x \times 》$ Effects graph for response 'Al'

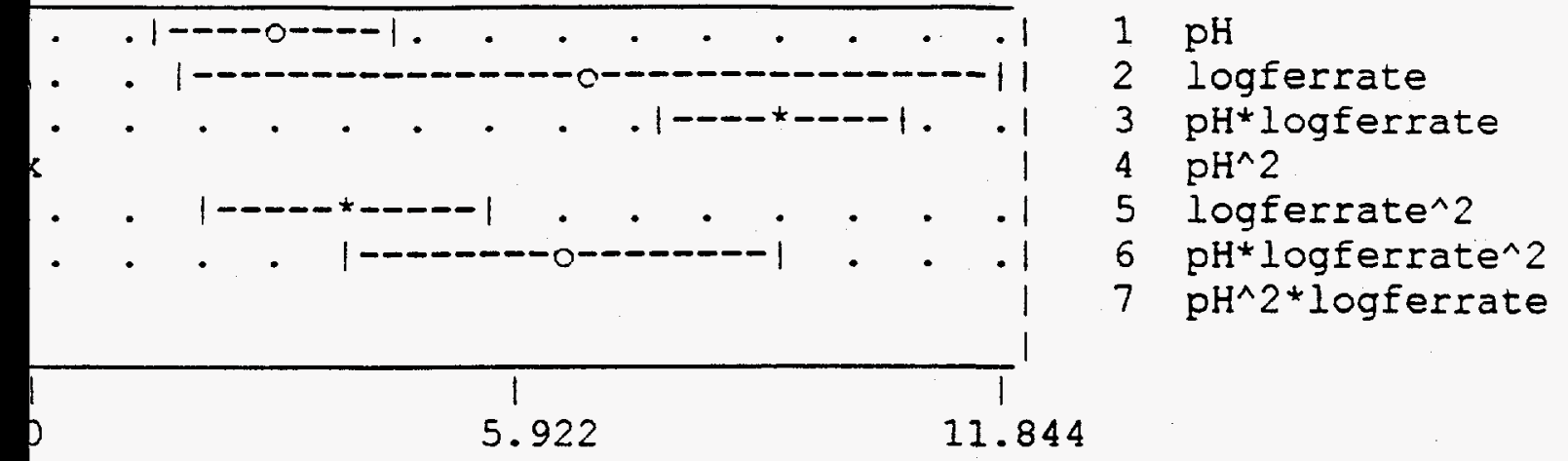

"Pareto effects graph for response 'Al'+*

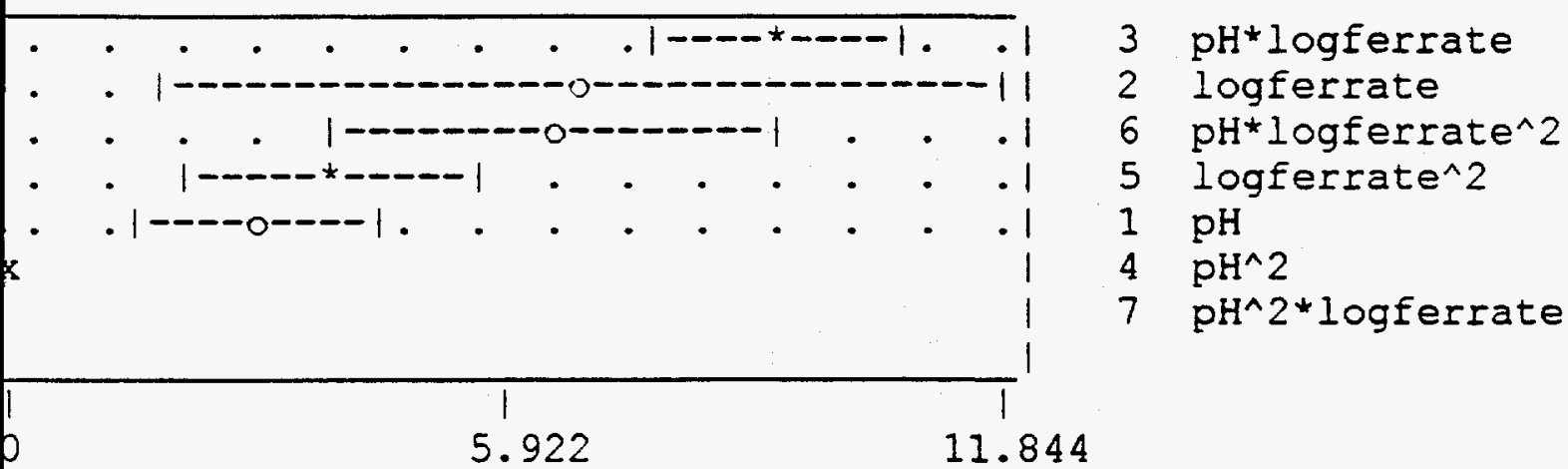


OJECT NAME: 2NDRE.ECP

eated: Tue Nov 01 13:48:27 1994

$x \times x \times x \times x \times x \times x \geqslant$ Effects graph for response ' $C r$ '

CK-OE-EIT

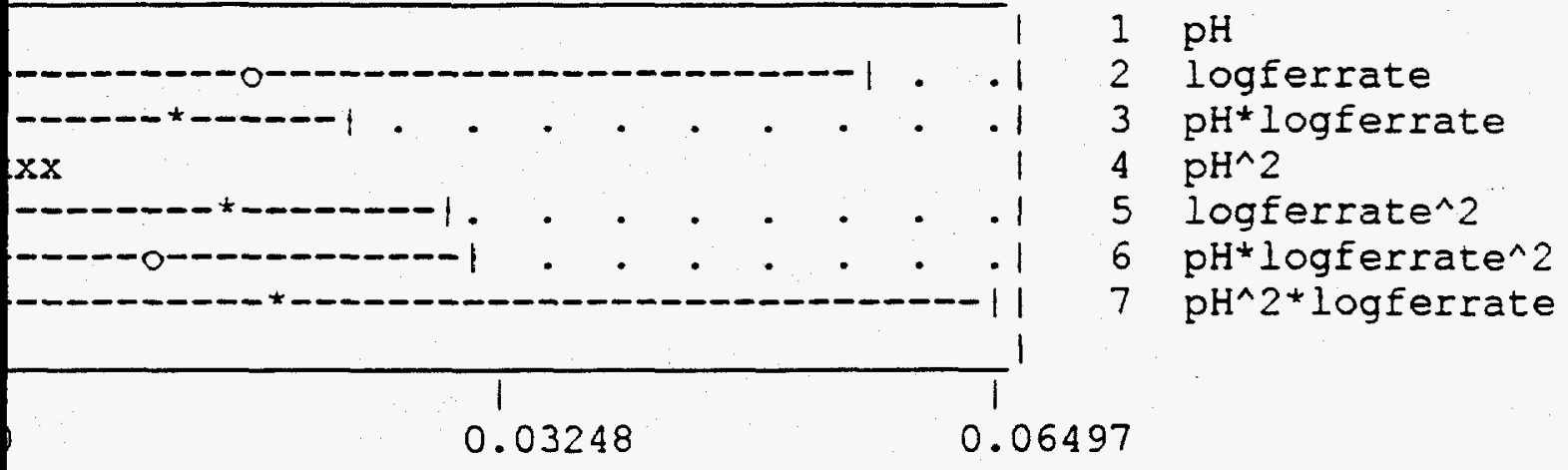

Pareto effects graph for response ' $\mathrm{Cr}$ 't*

CK-OF-EIT

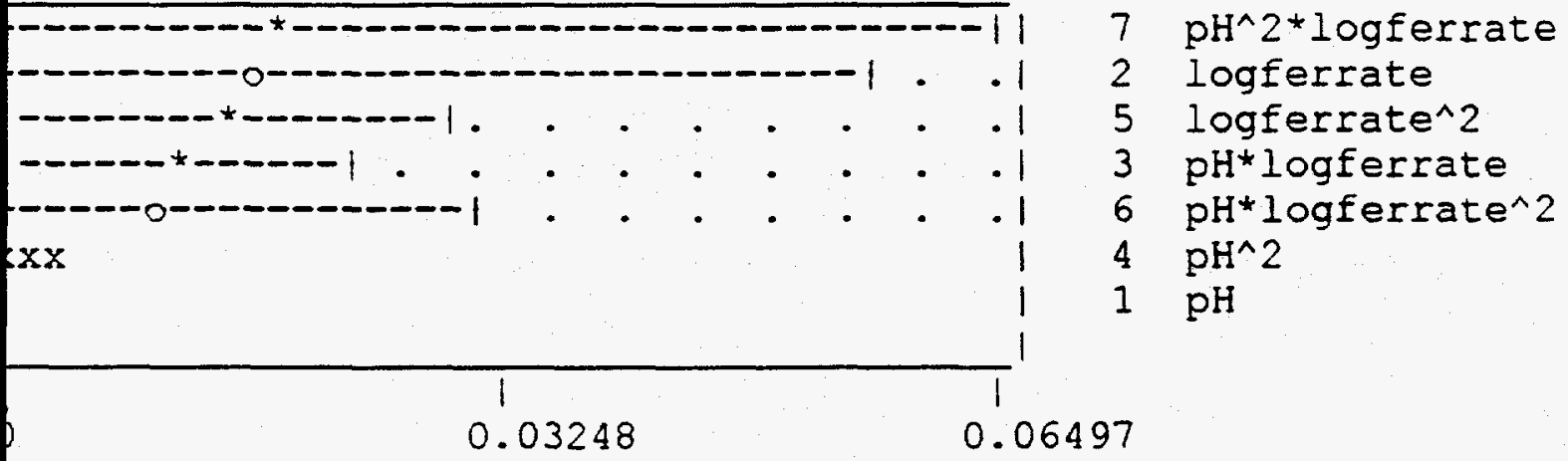


PROJECT NAME: 2NDRE.ECP

Created: Tue Nov 01 13:48:27 1994

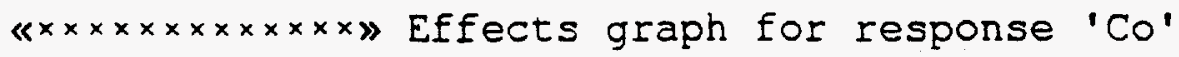

LACK-OF-FIT: Replicates too large

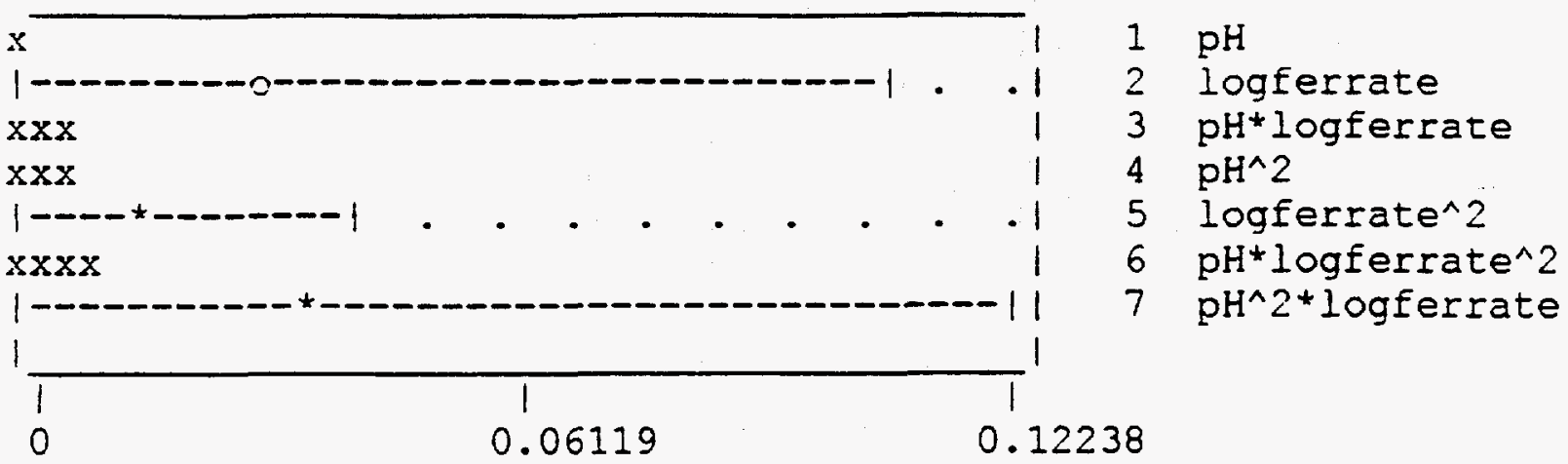

**Pareto effects graph for response 'Co'**

LACK-OF-FIT: Replicates too large

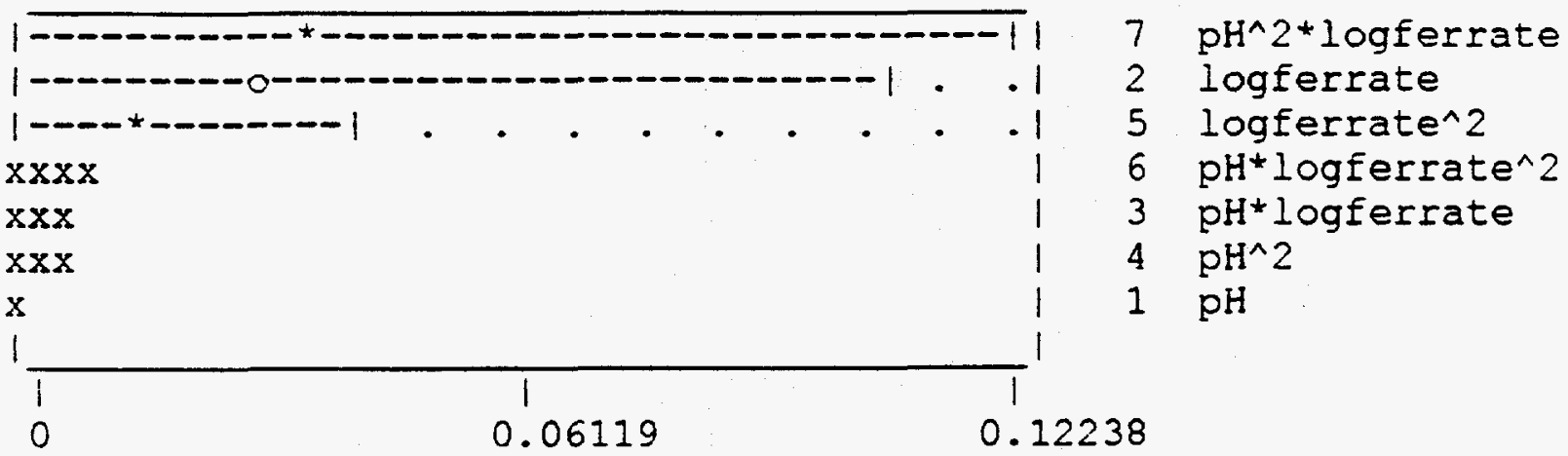


ROJECT NAME : NEWDATA.ECP

reated: Thu Dec 15 22:04:30 1994

$\times \times \times \times \times \times \times \times \times \times \times \times \gg$ Effects graph for response ' $\mathrm{Cu}$ '

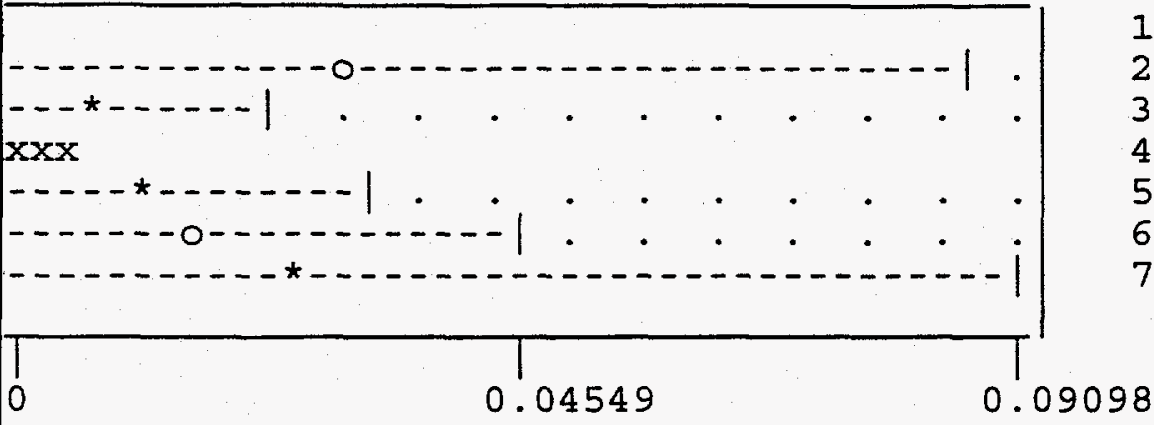

$\mathrm{pH}$

logferrate $\mathrm{pH} * \log$ ferrate $\mathrm{pH}^{\wedge} 2$

logferrate^2 $\mathrm{pH} * \log$ ferrate`2 $\mathrm{pH}^{\wedge} 2 *$ logferrate

*Pareto effects graph for response ' $\mathrm{Cu}$ '**

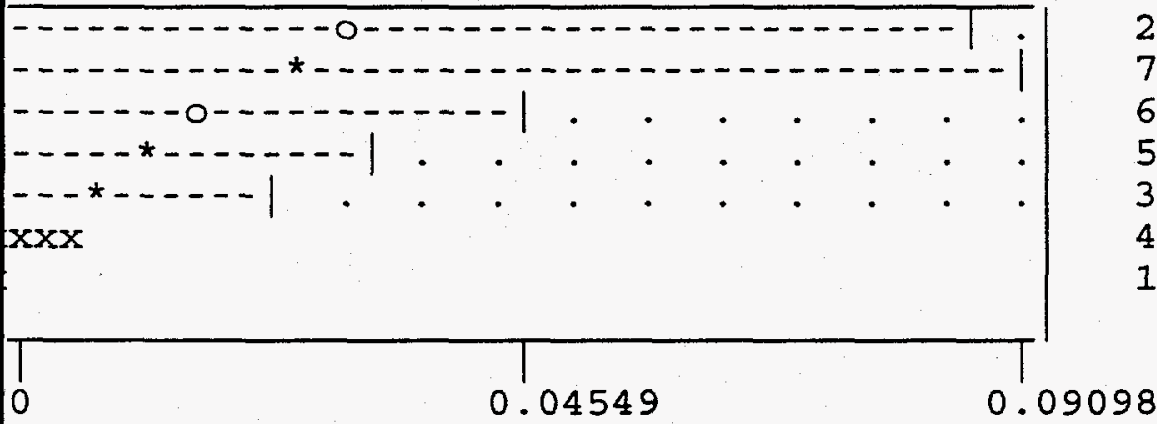

logferrate $\mathrm{pH}^{\wedge} 2 * \log$ ferrate $\mathrm{pH} * \log$ ferrate` 2 logferrate^ 2 $\mathrm{pH} * \log$ ferrate $\mathrm{pH}^{\wedge} 2$ $\mathrm{pH}$ 
PROJECT NAME: 2NDRE.ECP

Created: Tue Nov 01 13:48:27 1994

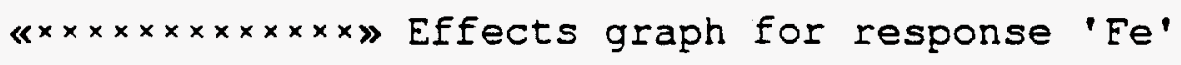

LACK-OF-EIT

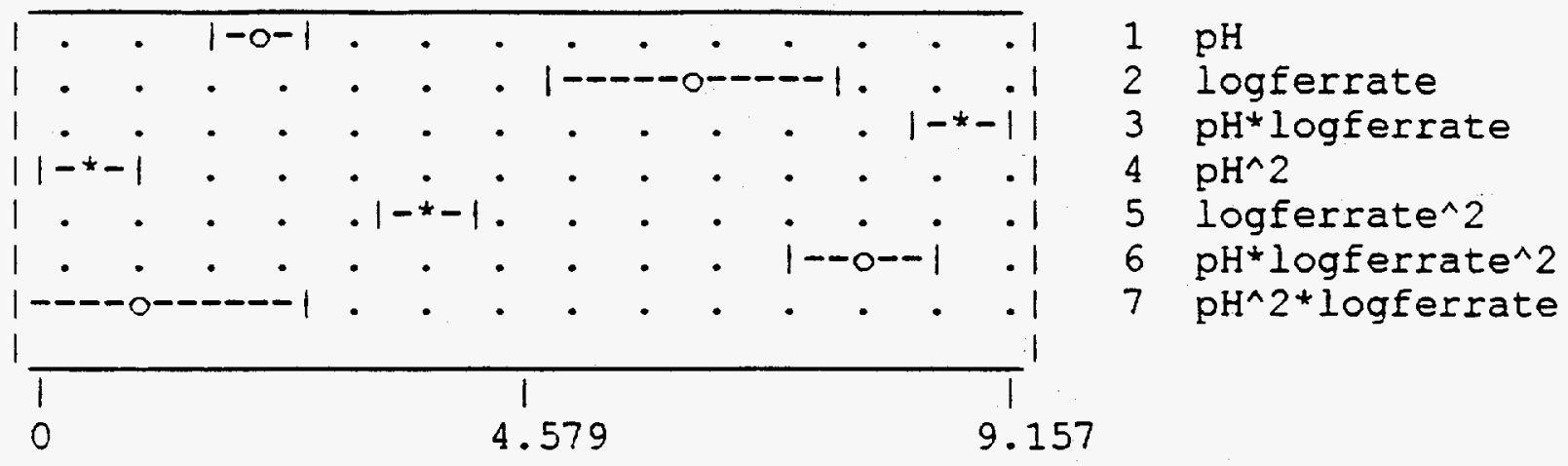

+*Pareto effects graph for response 'Fe'+*

LACK-OF-FIT

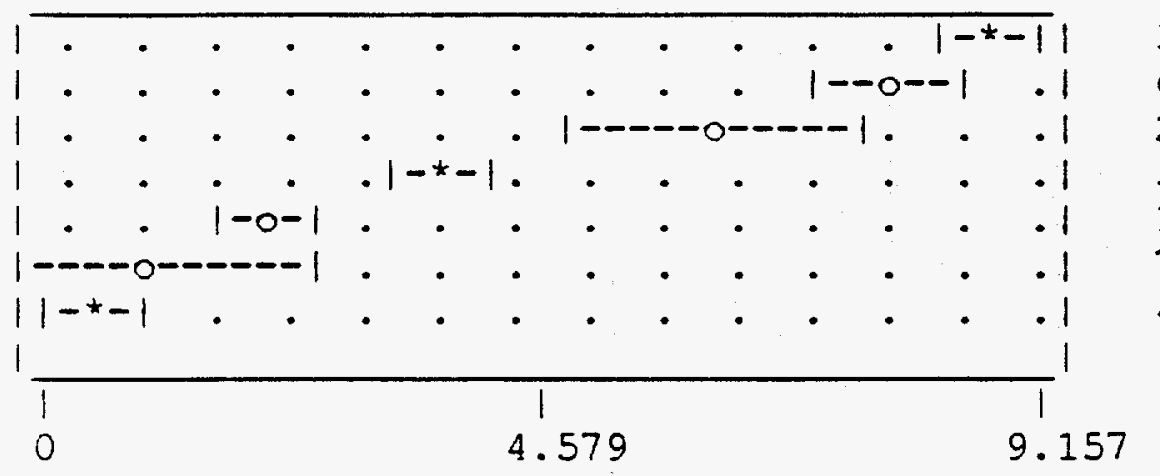

$\mathrm{pH}+\log f e r r a t e$

$\mathrm{pH}^{\star}$ logferrate^2

logferrate

logferrate^2

$\mathrm{pH}$

$\mathrm{pH}^{\wedge} 2 *$ logferrate

$\mathrm{pH}^{\wedge} 2$ 
ROJECT NAME: 2NDRF.ECP

reated: Tue Nov 01 13:48:27 1994

$x \times x \times x \times x \times x \times x \times y$ Effects graph for response 'Se'

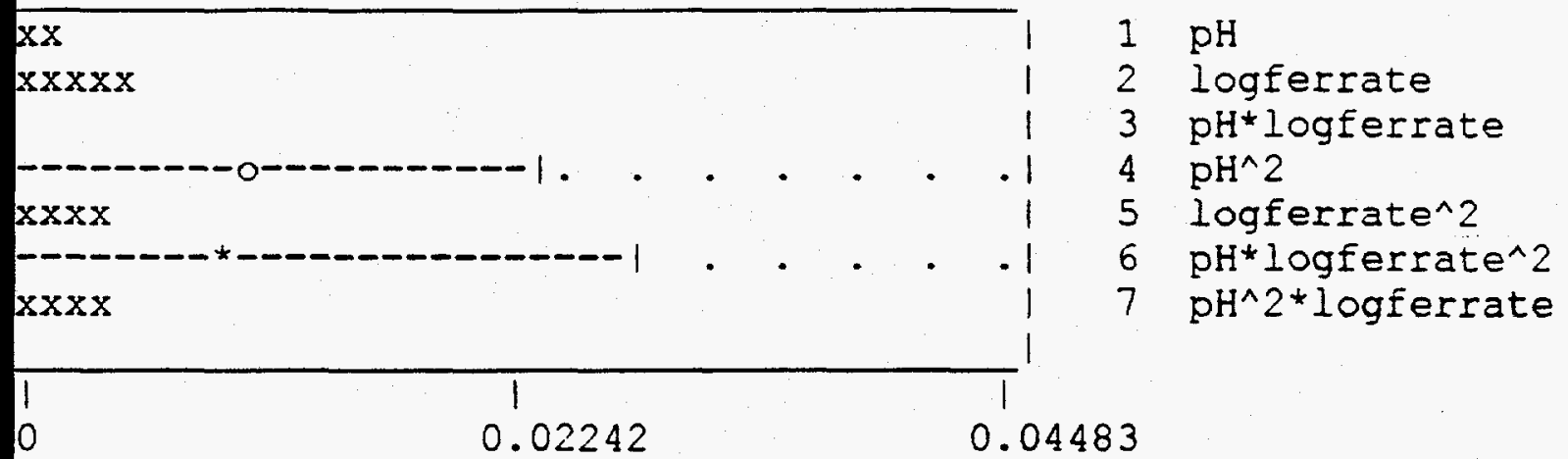

* Pareto effects graph for response 'Se'**

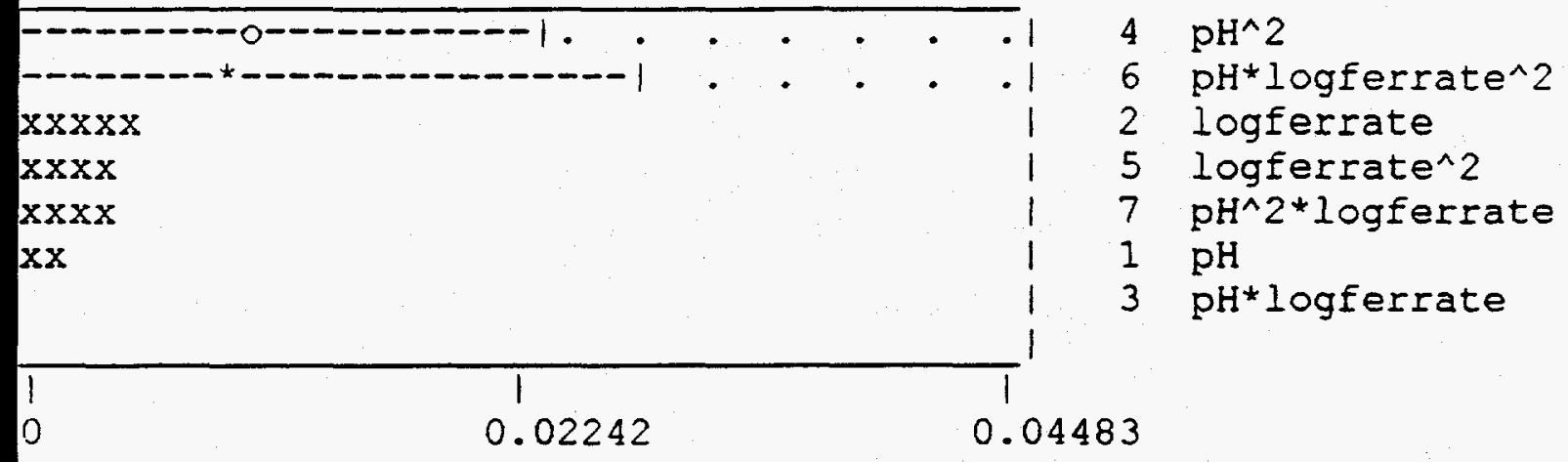


PROJECT NAME : NEWDATA.ECP

Created: Thu Dec 15 22:04:30 1994

«xx $x \times x \times x \times x \times x \times x »$ Effects graph for response 'Ag' LACK - OF - FIT

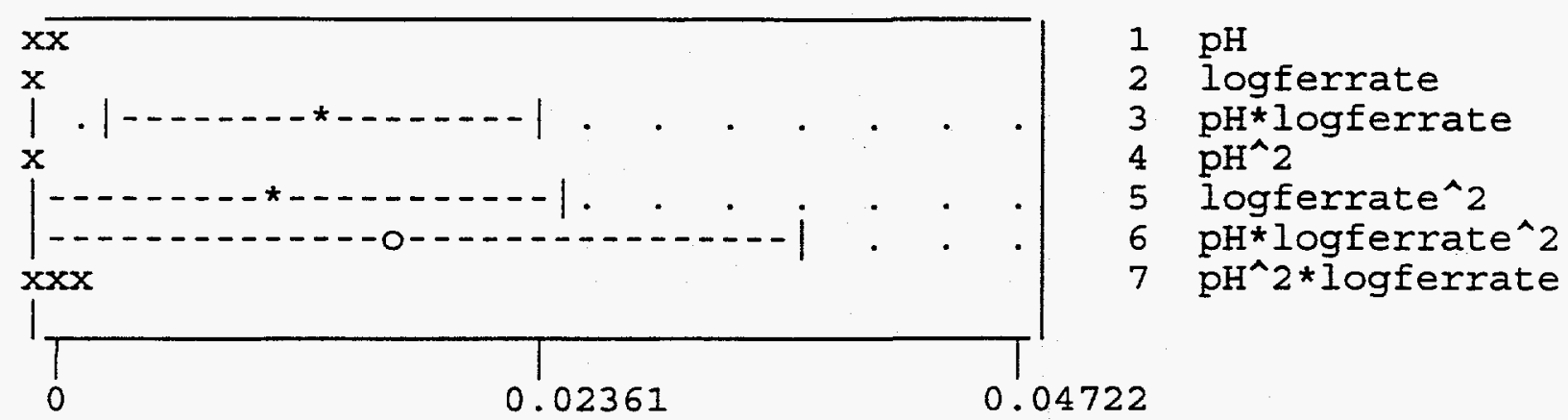

**Pareto effects graph for response 'Ag'**

LACK - OF - FIT

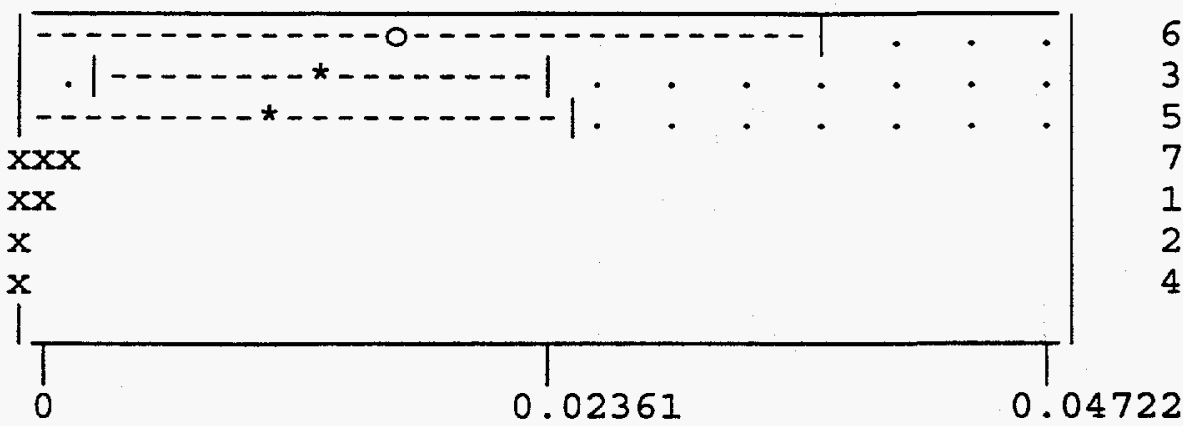


ROJECT NAME: 2NDRE.ECP

feaced: Tue Nov 01 13:48:27 1994

$x \times x \times x \times x \times x \times x \gg$ Effects graph for response ' $Z n$ '

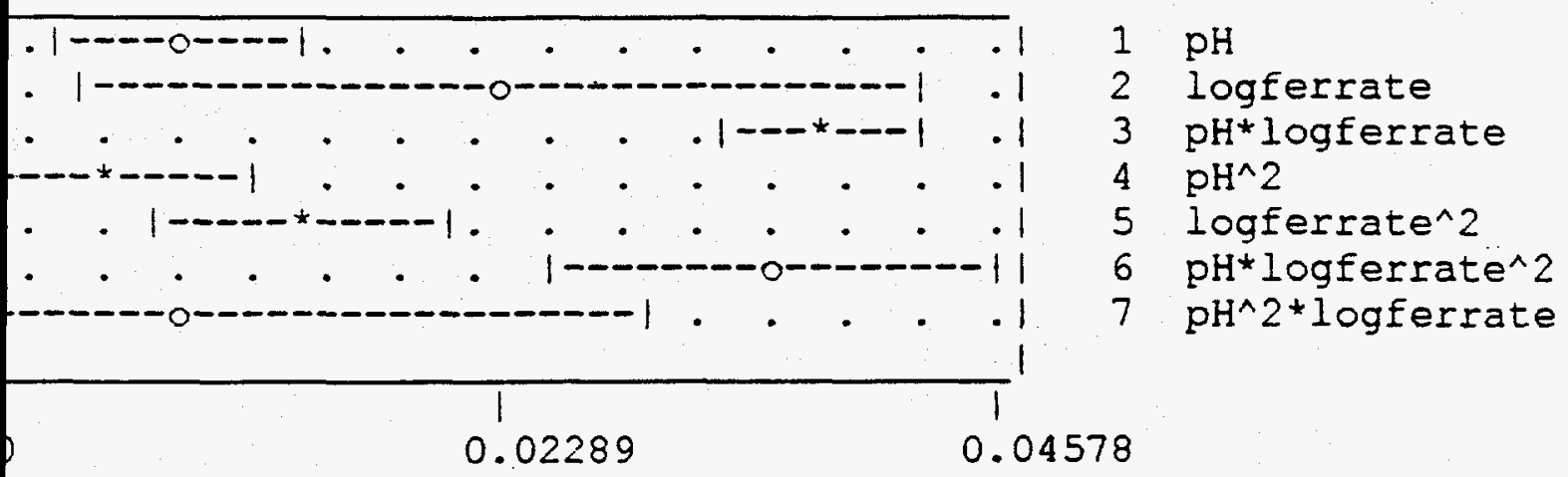

Pareto effects graph for response ' $2 n$ '**

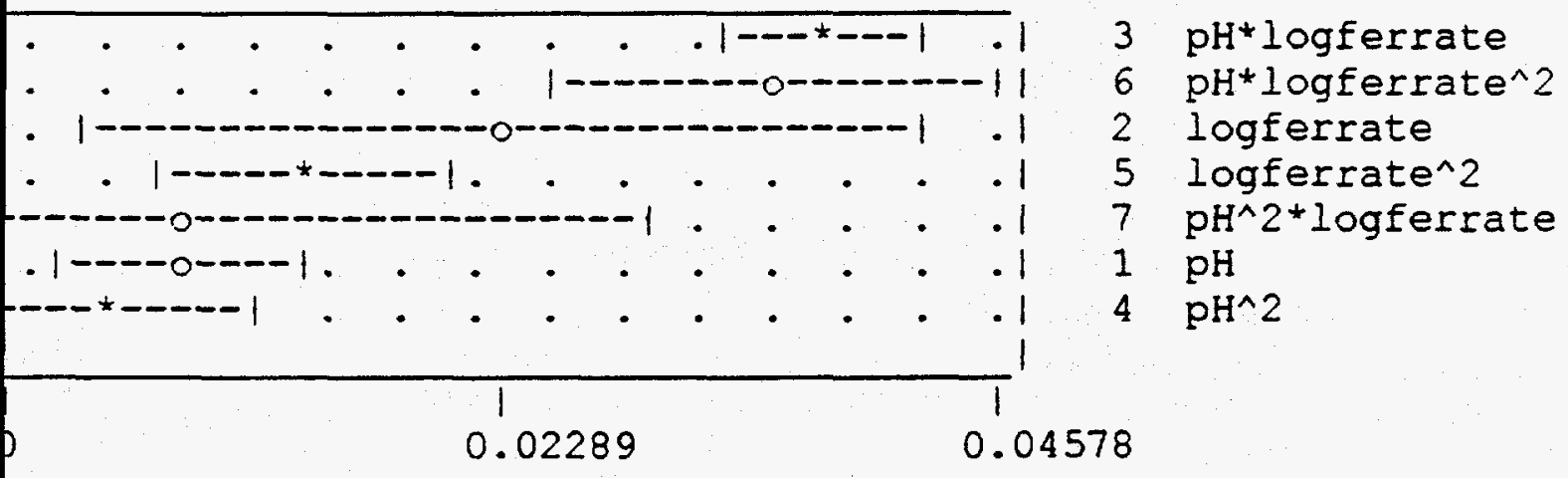


PROJECT NAME: NEWDATA.ECP

Created: Thu Dec 15 22:04:23 1994

« $x \times x \times x \times x \times x \times x \times x \times »$ Effects for response 'Am'

EFFECTS RESLTN SIG TERM
0.0827
0 CONSTANT
$\begin{array}{lll}-0.0545 & 0.2204 \quad 1 \mathrm{pH}\end{array}$
$\begin{array}{lll}-0.3867 & 0.9661 \quad 2 \text { logferrate }\end{array}$
0.4385
*** $3 \mathrm{pH}^{*} \log f e r r a t e$
$-0.03670 .2657 \quad 4 \mathrm{pH}^{\wedge} 2$
$0.2109 * 5$ logferrate ${ }^{\wedge} 2$
$-0.4909 \quad * * 6 \mathrm{pH}^{*}$ logferrate $\mathrm{e}^{\wedge} 2$
$0.00670 .66767 \mathrm{pH}^{\wedge} 2 * \log f e r r a t e$

$\begin{array}{ll}\text { Residual SD } & =0.050 \\ \text { Replicate SD } & =0.064 \\ & =8 \\ \mathrm{~N} \text { terms } \quad=8 \\ \mathrm{~N} \text { unique trials }=15 \\ \mathrm{~N} \text { replicates }=8 \\ \mathrm{~N} \text { total trials }=23\end{array}$

« $x \times x \times x \times x \times x \times x \times x \times$ » Effects for response 'Pu' LACK-OF-FIT

\section{EFFECTS RESLTN SIG TERM}

$$
\begin{array}{ccc}
1.216 & & 0 \text { CONSTANT } \\
-0.234 & 1.729 & 1 \mathrm{pH} \\
-5.059 & 10.280 & 2 \text { logferrate } \\
2.782 & * * * & 3 \mathrm{pH}^{*} \text { logferrate } \\
-1.238 & 3.300 & 4 \mathrm{pH}^{\wedge} 2 \\
2.267 & * & 5 \text { logferrate } 2 \\
-4.419 & * * & 6 \mathrm{pH}^{*} \text { logferrate } 2 \\
2.838 & 8.793 & 7 \mathrm{pH}^{\wedge} 2^{*} \text { logferrate }
\end{array}
$$

$$
\begin{aligned}
& \text { Residual SD }=0.458580 \\
& \text { Replicate SD }=0.205097 \\
& \mathrm{~N} \text { terms }=8 \\
& \mathrm{~N} \text { unique trials }=15 \\
& \mathrm{~N} \text { replicates }=8 \\
& \mathrm{~N} \text { total trials }=23
\end{aligned}
$$


《 $\times \times \times \times \times \times \times \times \times \times \times x \times \times x$ » Effects for response ' $U$ ' EFFECTS RESLTN SIG TERM
0.01581
0 CONSTANT
$-0.04025$
*** $\quad 1 \mathrm{pH}$
$-0.008680 .08082 \quad 2$ logferrate
$-0.009310 .02875 \quad 3 \mathrm{pH}^{*} \log$ ferrate
0.008320 .03682
$4 \mathrm{pH}^{\wedge} 2$
0.000950 .02586
5 logferrate $^{\wedge} 2$
0.013500 .05157
$6 \mathrm{pH}^{*} \log$ errate $^{\wedge} 2$
$-0.001430 .08371$
$7 \mathrm{pH}^{\wedge} 2 * \log f e r r a t e$
Residual SD $=0.006337$
Replicate SD $=0.004837$
$\mathrm{N}$ terms $\quad=8$
$\mathrm{N}$ unique trials $=15$
$\mathrm{N}$ replicates $=8$
$\mathrm{N}$ total trials $=23$

《 $x \times x \times x \times x \times x \times x \times x \times x$ » Effects for response 'Al'

EFFECTS RESLTN SIG TERM
0.829
$-3.030$
0 CONSTANT
$-6.870$
*** $\quad 1 \mathrm{pH}$
9.204
* 2 logferrate
$0.522 \quad 2.487$
*** $3 \mathrm{pH}$ *logferrate
4.048
$* * * \quad 5$ logferrate ${ }^{\wedge} 2$
$-6.717$
$0.130 \quad 5.804$
$6 \mathrm{pH}^{*} \log$ ferrate 2
Residual SD $=0.436947$
Replicate SD $=0.541218$
$\mathrm{N}$ terms $\quad=8$
$\mathrm{N}$ unique trials $=15$
$\mathrm{N}$ replicates $=8$
$\mathrm{N}$ total trials $=23$ 
« $x \times x \times x \times x \times x \times x \times x \times$ ) Effects for response ' $B a$ '

EFFECTS RESLTN SIG TERM

$$
\begin{aligned}
& 0.0047 \quad 0 \text { CONSTANT } \\
& -0.1371 \quad * * * \quad 1 \mathrm{pH} \\
& -0.0260 \quad 0.1651 \quad 2 \text { logferrate } \\
& 0.0957 \quad * * * \quad 3 \mathrm{pH}^{*} \text { logferrate } \\
& 0.0720 \quad * \quad 4 \mathrm{pH}^{\wedge} 2 \\
& 0.0033 \quad 0.0513 \quad 5 \text { logferrate }{ }^{\wedge} 2 \\
& 0.00290 .0763 \quad 6 \mathrm{pH}^{*} \text { logferrate } 2 \\
& -0.04080 .1994 \quad 7 \mathrm{pH}^{\wedge} 2^{*} \log \text { ferrate } \\
& \text { Residual SD }=0.012215 \\
& \text { Replicate SD }=0.009129 \\
& \mathrm{~N} \text { terms } \quad=8 \\
& \mathrm{~N} \text { unique trials }=15 \\
& \mathrm{~N} \text { replicates }=8 \\
& \mathrm{~N} \text { total trials }=23
\end{aligned}
$$

《 $x \times x \times x \times x \times x \times x \times x \times x$ " Effects for response ' $\mathrm{Cr}$ LACK-OF-FIT

\section{EFFECTS RESLTN SIG TERM}

$$
\begin{array}{lcc}
0.00193 & 0 \text { CONSTANT } \\
-0.00136 & 0.01297 & 1 \mathrm{pH} \\
-0.01665 & 0.05719 & 2 \text { logferrate } \\
0.01246 & * & 3 \mathrm{pH}^{*} \text { logferrate } \\
-0.00513 & 0.02114 & 4 \mathrm{pH}^{\wedge} 2 \\
0.01618 & * & 5 \text { logferrate } 2 \\
-0.01022 & 0.03161 & 6 \mathrm{pH}^{*} \text { logferrate } \\
0.01872 & 0.06497 & 7 \mathrm{pH}^{\wedge} 2^{*} \text { logferrate }
\end{array}
$$

$$
\begin{aligned}
& \text { Residual SD }=0.003561 \\
& \text { Replicate SD }=0.001458 \\
& \mathrm{~N} \text { terms }=8 \\
& \mathrm{~N} \text { unique trials }=15 \\
& \mathrm{~N} \text { replicates }=8 \\
& \mathrm{~N} \text { total trials }=23
\end{aligned}
$$


《 $x \times x \times x \times x \times x x \times x \times x\rangle$ Effects for response ' $C o$ '

LACK-OF-FIT: Replicates too large

EFFECTS RESLTN SIG TERM

0.00353

0 CONSTANT

$0.002850 .02498 \quad 1 \mathrm{pH}$

$-0.030160 .10743 \quad 2$ logferrate

$-0.006670 .02749 \quad 3 \mathrm{pH} * \log f e r r a t e$

$-0.006650 .03717 \quad 4 \mathrm{pH}^{\wedge} 2$

$0.014140 .04082 \quad 5$ logferrate ${ }^{\wedge} 2$

$-0.010910 .05168 \quad 6 \mathrm{pH}^{*} \log$ ferrate $^{\wedge} 2$

$0.034250 .12238 \quad 7 \mathrm{pH}^{\wedge} 2 * \log f e r r a t e$

$$
\begin{aligned}
& \text { Residual SD }=0.006787 \\
& \text { Replicate SD }=0.008664 \\
& \mathrm{~N} \text { terms } \quad=8 \\
& \mathrm{~N} \text { unique trials }=15 \\
& \mathrm{~N} \text { replicates }=8 \\
& \mathrm{~N} \text { total trials }=23
\end{aligned}
$$

« $x \times x \times x \times x \times x \times x \times x \times x\rangle$ Effects for response ' $\mathrm{Cu}$ ' EFFECTS RESLTN SIG TERM
0.00554
0 CONSTANT
$-0.001980 .01798 \quad 1 \mathrm{pH}$
$-0.031380 .08724 \quad 2$ logferrate
$0.008560 .02361 \quad 3 \mathrm{pH}^{*}$ logferrate
$-0.006920 .02899 \quad 4 \mathrm{pH}^{\wedge} 2$
$0.012690 .03198 \quad 5$ logferrate ${ }^{\wedge} 2$
$-0.017940 .04742 \quad 6 \mathrm{pH}^{*} \operatorname{logferrate}{ }^{\wedge} 2$
$0.027260 .09098 \quad 7 \mathrm{pH}^{\wedge} 2 * \log f e r r a t e$

$$
\begin{aligned}
& \text { Residual SD }=0.004907 \\
& \text { Replicate SD }=0.005965 \\
& \mathrm{~N} \text { terms } \quad=8 \\
& \mathrm{~N} \text { unique trials }=15 \\
& \mathrm{~N} \text { replicates }=8 \\
& \mathrm{~N} \text { total trials }=23
\end{aligned}
$$




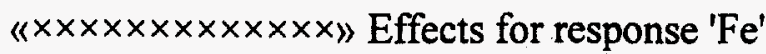
LACK-OF-FIT

EFFECTS RESLTN SIG TERM
0.736
$-2.257$
$-6.187$
8.814
0.603
3.682
$-7.793$
$-1.105$

$$
\begin{array}{cc} 
& 0 \text { CONSTANT } \\
* * * & 1 \mathrm{pH} \\
* * * & 2 \text { logferrate } \\
* * * & 3 \mathrm{pH}^{*} \text { logferrate } \\
* & 4 \mathrm{pH}^{\wedge} 2 \\
* * * & 5 \text { logferrate } 2 \\
* * * & 6 \mathrm{pH}^{*} \operatorname{logferrate}{ }^{\wedge} 2
\end{array}
$$$$
2.5617 \mathrm{pH}^{\wedge} 2 * \log f e r r a t e
$$

Residual SD $=0.112087$

Replicate SD $=0.022958$

$\mathrm{N}$ terms $\quad=8$

$\mathrm{N}$ unique trials $=15$

$\mathrm{N}$ replicates $=8$

$\mathrm{N}$ total trials $=23$

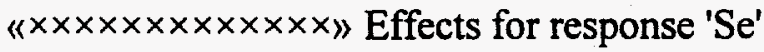

EFFECTS RESLTN SIG TERM

0.06306

0 CONSTANT

$0.002570 .01266 \quad 1 \mathrm{pH}$

$-0.006470 .04170 \quad 2$ logferrate

$0.000070 .00956 \quad 3 \mathrm{pH}^{*} \log f e r r a t e$

$-0.010420 .02433 \quad 4 \mathrm{pH}^{\wedge} 2$

$-0.004920 .01708 \quad 5$ logferrate ${ }^{\wedge} 2$

$0.009880 .02848 \quad 6 \mathrm{pH}^{*} \log$ ferrate $^{\wedge} 2$

$0.004650 .04483 \quad 7 \mathrm{pH}^{\wedge} 2 * \log f e r r a t e$

Residual SD $=0.003095$

Replicate SD $=0.002570$

$\mathrm{N}$ terms $\quad=8$

$\mathrm{N}$ unique trials $=15$

$\mathrm{N}$ replicates $=8$

$\mathrm{N}$ total trials $=23$ 
《 $x \times x \times x \times x \times x \times x \times x \times$ ) Effects for response 'Ag' LACK-OF-FIT

EFFECTS RESLTN SIG TERM

$\begin{array}{lc}0.00182 & 0 \text { CONSTANT } \\ 0.002050 .01327 & 1 \mathrm{pH} \\ 0.001170 .04034 & 2 \text { logferrate } \\ 0.01411 \quad * & 3 \mathrm{pH}^{*} \text { logferrate } \\ -0.000820 .01629 & 4 \mathrm{pH}^{\wedge} 2 \\ 0.011770 .02530 & 5 \text { logferrate } 2 \\ -0.016580 .03725 & 6 \mathrm{pH}^{*} \text { logferrate } 2 \\ -0.002550 .04722 & 7 \mathrm{pH}^{\wedge} 2^{*} \text { logferrate }\end{array}$

$$
\begin{aligned}
& \text { Residual SD }=0.003440 \\
& \text { Replicate SD }=0.001791 \\
& \mathrm{~N} \text { terms }=8 \\
& \mathrm{~N} \text { unique trials }=15 \\
& \mathrm{~N} \text { replicates }=8 \\
& \mathrm{~N} \text { total trials }=23
\end{aligned}
$$

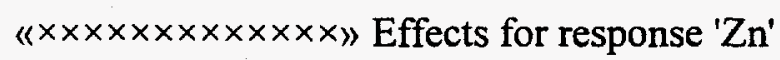

\section{EFFECTS RESLTN SIG TERM}

$$
\begin{array}{lrrl}
0.00246 & \multicolumn{3}{c}{0 \text { CONSTANT }} \\
-0.00842 & * * & 1 \mathrm{pH} \\
-0.02378 & * & 2 \text { logferrate } \\
0.03833 & * * * & 3 \mathrm{pH}^{*} \operatorname{logferrate} \\
0.00469 & 0.01206 & 4 \mathrm{pH}^{\wedge} 2 \\
0.01451 & * * * & 5 \text { logferrate } 2 \\
-0.03594 & * * * & 6 \mathrm{pH}^{*} \operatorname{logferrate}{ }^{\wedge} 2 \\
-0.00860 & 0.02986 & 7 \mathrm{pH}^{\wedge} 2^{*} \text { logferrate }
\end{array}
$$

Residual SD $=0.001638$

Replicate SD $=0.001953$

$\mathrm{N}$ terms $\quad=8$

$\mathrm{N}$ unique trials $=15$

$\mathrm{N}$ replicates $=8$

$\mathrm{N}$ total trials $=23$ 
PROJECT NAME: NEWDATA.ECP

Created: Thu Dec 15 22:04:15 1994

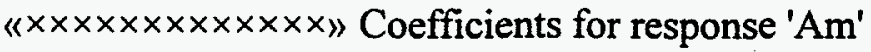

Centered continuous variables

COEFFICIENTS SD $P$ CONDITION TERM

\begin{tabular}{|c|c|c|c|}
\hline 0.0826716 & \multicolumn{3}{|c|}{0 CONSTANT } \\
\hline-0.0139783 & $0.01996160 .4945-$ & 0.386 & $1 \mathrm{pH}$ \\
\hline-0.0743695 & 0.05227820 .1753 & 0.125 & 2 logferrate \\
\hline 0.0374804 & 0.006259380 .0000 & 0.586 & $3 \mathrm{pH}^{*} \log f e r r a t e$ \\
\hline-0.00920837 & 0.02691640 .7370 & 0.283 & $4 \mathrm{pH}^{\wedge} 2$ \\
\hline 0.0234324 & 0.0104290 .0401 & 0.387 & 5 logferrate ${ }^{\wedge} 2$ \\
\hline-0.0139852 & 0.00408720 .0038 & 0.363 & $6 \mathrm{pH}^{*} \log$ ferrate ${ }^{\wedge} 2$ \\
\hline 0.0003703 & $0.01709270 .9830-$ & 0.119 & $7 \mathrm{pH}^{\wedge} 2^{*}$ logferrate \\
\hline
\end{tabular}

$\mathrm{N}$ trials $\quad=23$

$\mathrm{N}$ terms $\quad=8$

Residual SD $=0.050896$

Residual DF $=15$

Residual SD used for tests

Replicate SD $=0.064194$

Replicate DF $=8$

R Squared $\quad=0.978, \mathrm{P}=0.0000^{* * *}$

Adj R Squared $=0.968$

Maximum Cook-Weisberg LD influence (scaled 0-1) $=0.000$

- This term may be eliminated

« $x \times x \times x \times x \times x \times x \times x \times »$ Coefficients for response 'Pu'

Centered continuous variables

COEFFICIENTS SD $\quad \mathrm{P}$ CONDITION TERM 


$\begin{array}{cccc}-0.0598873 & 0.1798560 .7438- & 0.386 & 1 \mathrm{pH} \\ -0.972948 & 0.4710330 .0566 & 0.125 & 2 \text { logferrate } \\ 0.23776 & 0.05639770 .0007 & 0.586 & 3 \mathrm{pH}^{*} \operatorname{logferrate} \\ -0.310207 & 0.242520 .2203 & 0.283 & 4 \mathrm{pH}^{\wedge} 2 \\ 0.251865 & 0.09396650 .0171 & 0.387 & 5 \text { logferrate } \\ -0.125909 & 0.03682620 .0038 & 0.363 & 6 \mathrm{pH}^{*} \text { logferrate } \\ 0.156475 & 0.1540070 .3257 & 0.119 & 7 \mathrm{pH}^{\wedge} 2^{*} \text { logferrate }\end{array}$

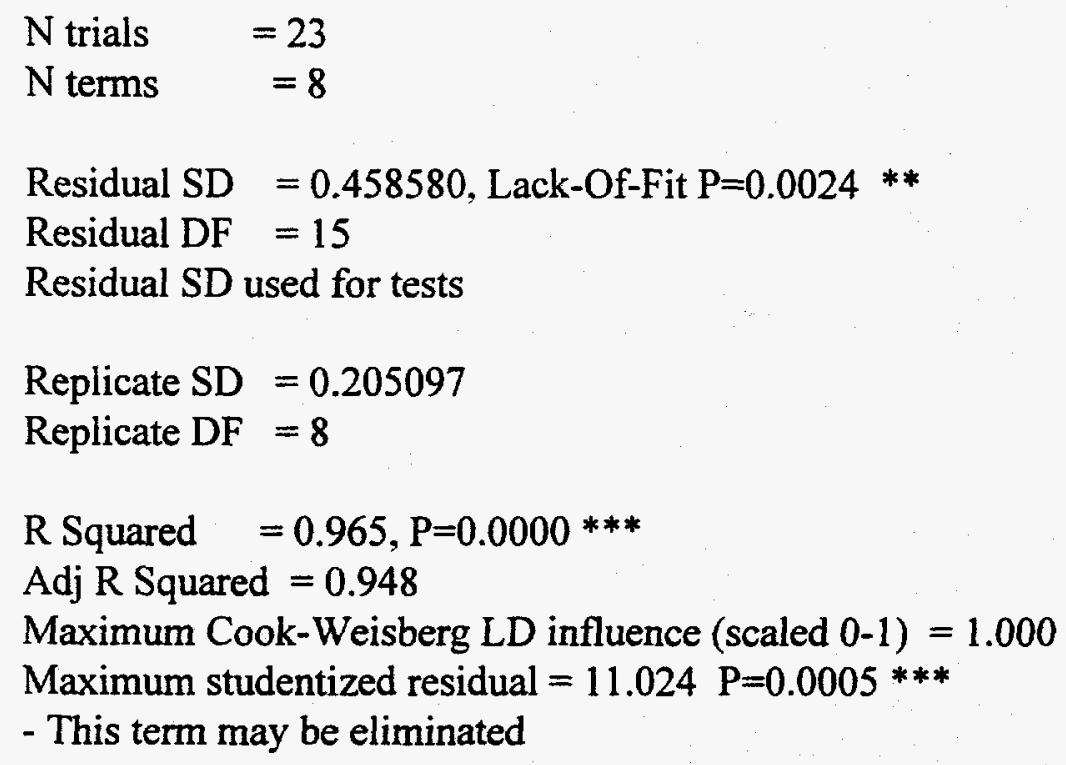

« $\times x \times x \times \times \times \times \times \times \times \times \times x »$ Coefficients for response ' $U$ '

Centered continuous variables

\section{COEFFICIENTS SD $\quad \mathrm{P}$ CONDITION TERM}

\begin{tabular}{|c|c|c|c|}
\hline 0.0158053 & \multicolumn{3}{|c|}{0 CONSTANT } \\
\hline-0.0103195 & 0.002485310 .0009 & 0.386 & $1 \mathrm{pH}$ \\
\hline-0.00166904 & $0.006508860 .8011-$ & 0.125 & 2 logferrate \\
\hline-0.000795818 & 0.000779320 .3234 & 0.586 & $3 \mathrm{pH}^{*}$ logferrate \\
\hline 0.00208594 & 0.003351210 .5430 & 0.283 & $4 \mathrm{pH}^{\wedge} 2$ \\
\hline 0.000105974 & 0.001298460 .9360 & 0.387 & $5 \operatorname{logferrate}^{\wedge} 2$ \\
\hline 0.000384568 & 0.0005088740 .4615 & 0.363 & $6 \mathrm{pH}^{*} \operatorname{logferrate}{ }^{\wedge} 2$ \\
\hline$-7.88849 e-005$ & 0.002128110 .9709 & 0.119 & $7 \mathrm{pH}^{\wedge} 2 * \log f e r r a t e$ \\
\hline
\end{tabular}

$\mathrm{N}$ trials $\quad=23$

$\mathrm{N}$ terms $\quad=8$ 
Residual SD $=0.006337$

Residual DF $=15$

Residual SD used for tests

Replicate SD $=0.004837$

Replicate DF $=8$

$\mathrm{R}$ Squared $\quad=0.882, \mathrm{P}=0.0000 * * *$

Adj R Squared $=0.827$

Maximum Cook-Weisberg LD influence (scaled 0-1) $=1.000$

- This term may be eliminated

« $x \times x \times x \times x \times x \times x \times x \times x\rangle$ Coefficients for response 'Al'

Centered continuous variables

\begin{tabular}{|c|c|c|c|}
\hline COEFFICIEN] & SD & CONDI & ION TERM \\
\hline 0.829257 & & 0 CONS & TANT \\
\hline-0.776877 & 0.1713720 .0004 & 0.386 & $1 \mathrm{pH}$ \\
\hline-1.32112 & 0.4488130 .0101 & 0.125 & 2 logferrate \\
\hline 0.786633 & 0.05373720 .0000 & 0.586 & $3 \mathrm{pH}^{*}$ logferrate \\
\hline 0.130862 & $0.231080 .5796-$ & 0.283 & $4 \mathrm{pH}^{\wedge} 2$ \\
\hline 0.449755 & 0.08953380 .0002 & 0.387 & 5 logferrate ${ }^{\wedge}$ \\
\hline-0.191373 & 0.0350890 .0001 & 0.363 & $6 \mathrm{pH}^{*} \log f e r r a t e^{\wedge} 2$ \\
\hline 0.00719295 & 0.1467420 .9616 & 0.119 & $7 \mathrm{pH}^{\wedge} 2^{*}$ logferrate \\
\hline
\end{tabular}

$\mathrm{N}$ trials $\quad=23$

$\mathrm{N}$ terms $\quad=8$

Residual SD $=0.436947$

Residual DF $=15$

Residual SD used for tests

Replicate SD $=0.541218$

Replicate DF $=8$

$\mathrm{R}$ Squared $\quad=0.996, \mathrm{P}=0.0000 * * *$

Adj R Squared $=0.994$

Maximum Cook-Weisberg LD influence (scaled 0-1) $=0.004$

- This term may be eliminated 


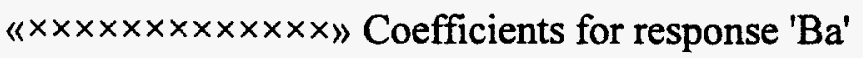

Centered continuous variables

COEFFICIENTS SD $P$ CONDITION TERM

\begin{tabular}{|c|c|c|c|}
\hline 0.00468056 & \multicolumn{3}{|c|}{0 CONSTANT } \\
\hline-0.0351515 & 0.004790760 .0000 & 0.386 & $1 \mathrm{pH}$ \\
\hline-0.0049995 & 0.01254670 .6959 & 0.125 & 2 logferrate \\
\hline 0.00817627 & 0.001502240 .0001 & 0.586 & $\mathrm{I}^{*}$ logferrate \\
\hline 0.0180554 & 0.00645990 .0136 & 0.283 & $4 \mathrm{pH}^{\wedge} 2$ \\
\hline 0.000366793 & $0.002502950 .8854-$ & -0.387 & 5 logferrate ${ }^{\wedge} 2$ \\
\hline $.37549 \mathrm{e}$ & 0.0009809230 .9331 & - 0.363 & $6 \mathrm{pH}^{*} \log f e r r a$ \\
\hline-0.00225014 & 0.004102210 .5914 & 0.119 & - Iogterra \\
\hline
\end{tabular}

$\mathrm{N}$ trials $\quad=23$

$\mathrm{N}$ terms $\quad=8$

Residual SD $=0.012215$

Residual DF $=15$

Residual SD used for tests

Replicate SD $=0.009129$

Replicate DF $=8$

R Squared $\quad=0.980, P=0.0000 * * *$

Adj R Squared $=0.970$

Maximum Cook-Weisberg LD influence (scaled 0-1) $=1.000$

- This term may be eliminated

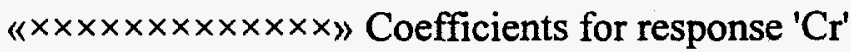

Centered continuous variables

COEFFICIENTS SD $P$ CONDITION TERM
0.00192824
0 CONSTANT
$-0.000349606$
$0.001396690 .8057-0.386 \quad 1 \mathrm{pH}$
$-0.00320234$
0.003657860 .3951
0.1252 logferrate
0.00106513
0.0004379630 .0280
0.586
$3 \mathrm{pH}^{*}$ logferrate
$-0.00128459$
$0.001883320 .5056-$
$0.283 \quad 4 \mathrm{pH}^{\wedge} 2$
0.00179797
0.0007297070 .0263
0.387
5 logferrate 2
$-0.000291075$
0.0002859780 .3249
0.363
$6 \mathrm{pH}^{*} \operatorname{logferrate}{ }^{\wedge}$ 


\section{$\begin{array}{llll}0.00103225 & 0.001195960 .4017 & 0.119 & 7 \mathrm{pH}^{\wedge} 2 * \log f e r r a t e\end{array}$}

$\mathrm{N}$ trials $\quad=23$

$\mathrm{N}$ terms $\quad=8$

Residual SD $=0.003561$, Lack-Of-Fit $\mathrm{P}=0.0012$ **

Residual DF $=15$

Residual SD used for tests

Replicate SD $=0.001458$

Replicate DF $=8$

$\mathrm{R}$ Squared $\quad=0.821, \mathrm{P}=0.0001$

Adj R Squared $=0.737$

Maximum Cook-Weisberg LD influence (scaled 0-1) $=1.000$

- This term may be eliminated

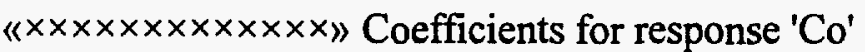

Centered continuous variables

COEFFICIENTS SD $\quad P$ CONDITION TERM

0.00353368

0 CONSTANT

$\begin{array}{lllll}0.000730427 & 0.00266198 & 0.7875- & 0.386 & 1 \mathrm{pH}\end{array}$

$\begin{array}{lllll}-0.00579985 & 0.006971560 .4185 & 0.125 & 2 \text { logferrate }\end{array}$

$\begin{array}{llll}-0.000570431 & 0.00083472 & 0.5048-0.586 \quad 3 \mathrm{pH}^{*} \log \text { ferrate }\end{array}$

$\begin{array}{llll}-0.00166572 & 0.003589440 .6493-0.283 & 4 \mathrm{pH}^{\wedge} 2\end{array}$

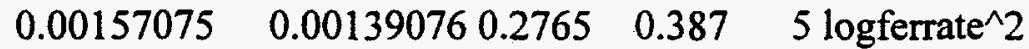

$\begin{array}{llll}-0.00031069 & 0.0005450490 .5771-0.363 \quad 6 \mathrm{pH}^{*} \operatorname{logferrate}{ }^{\wedge} 2\end{array}$

$0.00188815 \quad 0.002279390 .4205 \quad 0.119 \quad 7 \mathrm{pH}^{\wedge} 2 *$ logferrate

$\mathrm{N}$ trials $\quad=23$

$\mathrm{N}$ terms $\quad=8$

Residual SD $=0.006787$, Lack-Of-Fit (Residual SD too small) $\mathrm{P}=0.9842$

Residual DF $=15$

Residual SD used for tests

Replicate SD $=0.008664$

Replicate DF $=8$ 
$\mathrm{R}$ Squared $\quad=0.262, \mathrm{P}=0.6286$

Adj R Squared $=0.000$

Maximum Cook-Weisberg LD influence (scaled 0-1) $=0.114$

- This term may be eliminated

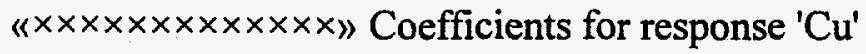

Centered continuous variables

$\begin{array}{llll}\text { COEFFICIENTS SD } & P & \text { CONDITION TERM }\end{array}$

\begin{tabular}{|c|c|c|c|}
\hline 0.00553942 & \multicolumn{3}{|c|}{0 CONSTANT } \\
\hline-0.00050666 & 0.001924670 .7959 & 0.386 & $1 \mathrm{pH}$ \\
\hline-0.00603385 & 0.005040590 .2499 & 0.125 & 2 logferrate \\
\hline 0.000731448 & 0.0006035210 .2443 & 0.586 & $3 \mathrm{pH}^{*}$ logferrate \\
\hline-0.0017336 & $0.002595250 .5143-$ & 0.283 & $4 \mathrm{pH}^{\wedge} 2$ \\
\hline 0.00140995 & 0.001005550 .1812 & 0.387 & 5 logferrate ${ }^{\wedge}$ \\
\hline-0.000511024 & $0.000394082 \quad 0.2143$ & 0.363 & $6 \mathrm{pH}^{*} \log$ ferrate ${ }^{\wedge}$ \\
\hline 0.001503 & 0.001648050 .3762 & 0.119 & $7 \mathrm{pH}^{\wedge} 2 * \log f e r r a t e$ \\
\hline
\end{tabular}

$\mathrm{N}$ trials $\quad=23$

$\mathrm{N}$ terms $\quad=8$

Residual SD $=0.004907$

Residual DF $=15$

Residual SD used for tests

Replicate SD $=0.005965$

Replicate DF $=8$

$\mathrm{R}$ Squared $\quad=0.766, \mathrm{P}=0.0008 * * *$

Adj R Squared $=0.656$

Maximum Cook-Weisberg LD influence (scaled 0-1) $=0.733$

- This term may be eliminated

« $x \times x \times x \times x \times x \times x \times x \times \rrbracket$ Coefficients for response ' $\mathrm{Fe}$ '

Centered continuous variables

COEFFICIENTS SD $P$ CONDITION TERM

0.73601

0 CONSTANT 


\begin{tabular}{|c|c|c|c|}
\hline-0.578731 & 0.04396090 .0000 & 0.386 & $1 \mathrm{pH}$ \\
\hline-1.18978 & 0.1151310 .0000 & 0.125 & 2 logferrate \\
\hline 0.7533 & 0.01378490 .0000 & 0.586 & $3 \mathrm{pH}^{*}$ logferrate \\
\hline 0.15101 & 0.05927730 .0223 & 0.283 & $4 \mathrm{pH}^{\wedge} 2$ \\
\hline 0.409111 & 0.02296750 .0000 & 0.387 & 5 logferrate ${ }^{\wedge} 2$ \\
\hline-0.222022 & 0.009001140 .0000 & 0.363 & $6 \mathrm{pH}^{*} \log$ ferrate ${ }^{\wedge}$ \\
\hline-0.0609325 & 0.03764270 .1263 & 0.119 & $7 \mathrm{pH}^{\wedge} 2^{*} \log f e r r a t e$ \\
\hline
\end{tabular}

$\mathrm{N}$ trials $\quad=23$

$\mathrm{N}$ terms $\quad=8$

Residual SD $=0.112087$, Lack-Of-Fit $\mathrm{P}=0.0000 * * *$

Residual DF $=15$

Residual SD used for tests

Replicate SD $=0.022958$

Replicate DF $=8$

R Squared $\quad=1.000, \mathrm{P}=0.0000 * * *$

Adj R Squared $=1.000$

Maximum Cook-Weisberg LD influence (scaled 0-1) $=1.000$

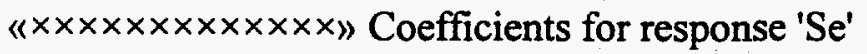

Centered continuous variables

COEFFICIENTS SD $\quad P \quad$ CONDITION TERM

\begin{tabular}{|c|c|c|c|}
\hline 0.063064 & \multicolumn{3}{|c|}{0 CONSTANT } \\
\hline 0.000660229 & $0.001213690 .5944-$ & 0.386 & $1 \mathrm{pH}$ \\
\hline-0.00124334 & 0.003178570 .7012 & 0.125 & 2 logferrate \\
\hline $6.10894 \mathrm{e}-006$ & 0.0003805770 .9874 & 0.586 & $3 \mathrm{pH}^{*}$ logferrate \\
\hline-0.00261039 & 0.001636550 .1315 & 0.283 & $4 \mathrm{pH}^{\wedge} 2$ \\
\hline-0.000546443 & 0.0006340940 .4024 & 0.387 & $5 \operatorname{logferrate}^{\wedge} 2$ \\
\hline 0.000281589 & 0.0002485060 .2749 & 0.363 & $6 \mathrm{pH}^{*} \log$ ferrate $^{\wedge} 2$ \\
\hline 0.000256357 & $0.001039250 .8085-$ & 0.119 & $2 *$ logferrate \\
\hline
\end{tabular}

$\begin{array}{ll}N \text { trials } & =23 \\ & =8\end{array}$

Residual SD $=0.003095$

Residual DF $=15$ 
Residual SD used for tests

Replicate SD $=0.002570$

Replicate DF $=8$

$R$ Squared $\quad=0.812, P=0.0002$

Adj $\mathrm{R}$ Squared $=0.725$

Maximum Cook-Weisberg LD influence (scaled 0-1) $=1.000$

- This term may be eliminated

« $\times x \times x \times x \times x \times x \times \times \times x \times)$ Coefficients for response 'Ag'

Centered continuous variables

COEFFICIENTS SD $P$ CONDITION TERM

\begin{tabular}{|c|c|c|c|}
\hline 0.00182398 & \multicolumn{3}{|c|}{0 CONSTANT } \\
\hline 0.000525543 & 0.001349340 .7024 & 0.386 & $1 \mathrm{pH}$ \\
\hline 0.00022520 & 0.003533850 .9500 & 0.125 & 2 logferrate \\
\hline 0.00120628 & 0.0004231150 .0121 & 0.586 & $3 \mathrm{pH}^{*}$ logferrate \\
\hline-0.000204527 & $0.001819470 .9120-$ & 0.283 & $4 \mathrm{pH}^{\wedge} 2$ \\
\hline 0.00130797 & 0.0007049680 .0833 & 0.387 & $5 \operatorname{logferrate}^{\wedge} 2$ \\
\hline-0.000472437 & 0.0002762820 .1079 & 0.363 & $6 \mathrm{pH}^{*} \log$ ferrate ${ }^{\wedge} 2$ \\
\hline 0.00014 & 0.001155410 .9049 & 0.119 & $7 \mathrm{pH}^{\wedge} 2 * \operatorname{logferra}$ \\
\hline
\end{tabular}

$\mathrm{N}$ trials $\quad=23$

$\mathrm{N}$ terms $\quad=8$

Residual SD $=0.003440$, Lack-Of-Fit $\mathrm{P}=0.0075 * *$

Residual DF $=15$

Residual SD used for tests

Replicate SD $=0.001791$

Replicate DF $=8$

$\mathrm{R}$ Squared $\quad=0.874, \mathrm{P}=0.0000 * * *$

Adj R Squared $=0.815$

Maximum Cook-Weisberg LD influence (scaled 0-1) $=1.000$

- This term may be eliminated

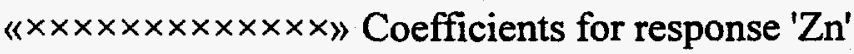


Centered continuous variables

COEFFICIENTS SD $P$ CONDITION TERM

0.00245686

0 CONSTANT

$-0.00215909$

0.0006423320 .0043

$0.386 \quad 1 \mathrm{pH}$

$-0.00457306$

0.001682230 .0159

0.1252 logferrate

0.00327574

0.0002014170 .0000

0.586

$3 \mathrm{pH}^{*}$ logferrate

0.0011765

0.0008661270 .1944

0.283

$4 \mathrm{pH}^{\wedge} 2$

0.00161198

0.0003355880 .0002

0.387

5 logferrate 2

$-0.00102404$

0.000131520 .0000

0.363

$6 \mathrm{pH}^{*} \log$ ferrate 2

$-0.00047393$

0.0005500140 .4024

0.119

$7 \mathrm{pH}^{\wedge} 2^{*} \log$ ferrate

$\mathrm{N}$ trials $\quad=23$

$\mathrm{N}$ terms $\quad=8$

Residual SD $=0.001638$

Residual DF $=15$

Residual SD used for tests

Replicate SD $=0.001953$

Replicate DF $=8$

$\mathrm{R}$ Squared $\quad=0.997, \mathrm{P}=0.0000 * * *$

Adj R Squared $=0.995$

Maximum Cook-Weisberg LD influence (scaled 0-1) $=1.000$

- This term may be eliminated 
PROJECT NAME: NEWDATA.ECP

Created: Thu Dec 15 22:04:40 1994

« $x \times x \times x \times x \times x \times x \times x \times$ ANOVA Table for response 'Am'

\author{
Mean Squares DF P \\ $0.00092455120 .7056 \mathrm{pH}$ \\ 0.007293120 .0916 logferrate \\ $0.169553 \quad 30.0000 \mathrm{pH}^{*}$ logferrate \\ $0.0025904215 \quad$ ERROR \\ 0.004120838 REPLICATE ERROR
}

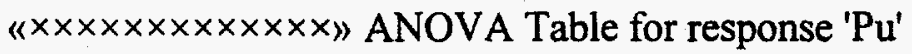

\title{
LACK-OF-FIT
}

Mean Squares DF P

$0.20582620 .3985 \mathrm{pH}$

0.76243620 .0519 logferrate

$8.2556430 .0000 \mathrm{pH}^{*}$ logferrate

$0.21029615 \quad$ ERROR

0.04206468 REPLICATE ERROR

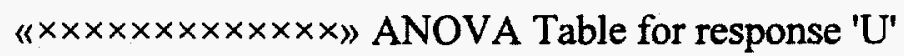

Mean Squares DF P

$0.00034639420 .0032 \mathrm{pH}$

$2.38225 \mathrm{e}-00620.9426$ logferrate

9.20154e-005 $30.1198 \mathrm{pH}^{*} \log$ ferrate

4.01549e-005 15 ERROR

2.33996e-005 8 REPLICATE ERROR 


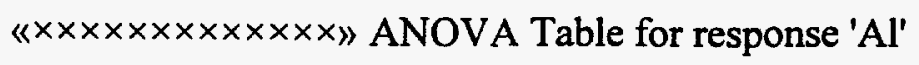

\author{
Mean Squares DF P \\ $1.9670720 .0015 \mathrm{pH}$ \\ 2.8401320 .0003 logferrate \\ $57.853530 .0000 \mathrm{pH}^{*}$ logferrate \\ $0.19092315 \quad$ ERROR \\ $0.2929178 \quad$ REPLICATE ERROR
}

« $\times x \times x \times x \times x \times x \times \times \times x$ ) ANOVA Table for response ' $\mathrm{Ba}$ '

Mean Squares DF P

$0.0041904920 .0000 \mathrm{pH}$

$1.96049 \mathrm{e}-00520.8779$ logferrate

$0.0037978730 .0000 \mathrm{pH}^{*}$ logferrate

$0.00014920615 \quad$ ERROR

8.33333e-005 8 REPLICATE ERROR

« $x \times x \times x \times x \times x \times x \times x \times x 》$ ANOVA Table for response ' $\mathrm{Cr}$ '

LACK-OF-FIT

Mean Squares DF P

$3.84755 \mathrm{e}-006 \quad 20.7427 \mathrm{pH}$

$6.51058 \mathrm{e}-00520.0200$ logferrate

9.73178e-005 $30.0024 \mathrm{pH}^{*}$ logferrate

$1.26818 \mathrm{e}-00515 \quad$ ERROR

2.125e-006 8 REPLICATE ERROR

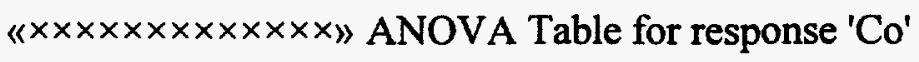

LACK-OF-FIT: Replicates too large 
Mean Squares DF P

$5.84316 \mathrm{e}-006 \quad 20.8818 \mathrm{pH}$

$3.01016 \mathrm{e}-005 \quad 20.5344$ logferrate

$2.25227 \mathrm{e}-005 \quad 30.6952 \mathrm{pH}^{*} \operatorname{logferrate}$

$4.60669 \mathrm{e}-00515 \quad$ ERROR

7.50625e-005 8 REPLICATE ERROR

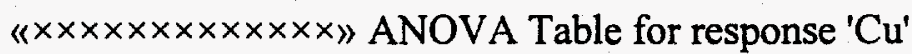

Mean Squares DF P

7.17466e-006 $20.7466 \mathrm{pH}$

$2.37343 \mathrm{e}-00520.3961$ logferrate

9.10799e-005 $30.0334 \mathrm{pH}^{*}$ logferrate

2.40819e-005 15 ERROR

3.55833e-005 8 REPLICATE ERROR

« $x \times x \times x \times x \times x \times x \times x \times$ \# ANOVA Table for response ' $\mathrm{Fe}$ '

LACK-OF-FIT

Mean Squares DF P

$1.0890320 .0000 \mathrm{pH}$

2.3676220 .0000 logferrate

$59.82530 .0000 \mathrm{pH}^{*} \log$ ferrate

$0.012563515 \quad$ ERROR

$\begin{array}{lll}0.000527083 & 8 & \text { REPLICATE ERROR }\end{array}$

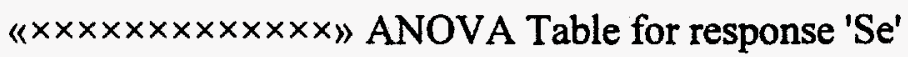

Mean Squares DF P

$1.25244 \mathrm{e}-005 \quad 20.2995 \mathrm{pH}$

$2.17754 \mathrm{e}-00520.1372$ logferrate

$1.18247 \mathrm{e}-005 \quad 30.3318 \mathrm{pH}^{*} \log$ ferrate 
9.57617e-006 $15 \quad$ ERROR

6.60417e-006 $8 \quad$ REPLICATE ERROR

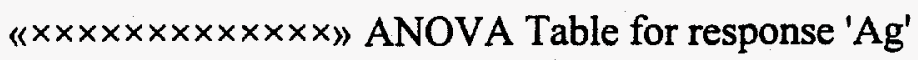

LACK-OF-FIT

Mean Squares DF P

9.09522e-007 $20.9264 \mathrm{pH}$

$6.75063 \mathrm{e}-00520.0144$ logferrate

$0.00018559630 .0001 \mathrm{pH}^{*} \log$ ferrate

1.18365e-005 15 ERROR

3.20833e-006 8 REPLICATE ERROR

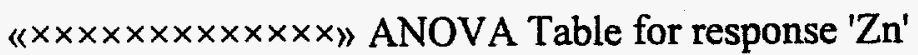

Mean Squares DF P

$1.59665 \mathrm{e}-005 \quad 20.0125 \mathrm{pH}$

$3.74525 \mathrm{e}-00520.0004$ logferrate

$0.0011849730 .0000 \mathrm{pH}^{*} \log f e r r a t e$

$2.68224 \mathrm{e}-00615 \quad$ ERROR

3.8125e-006 8 REPLICATE ERROR 


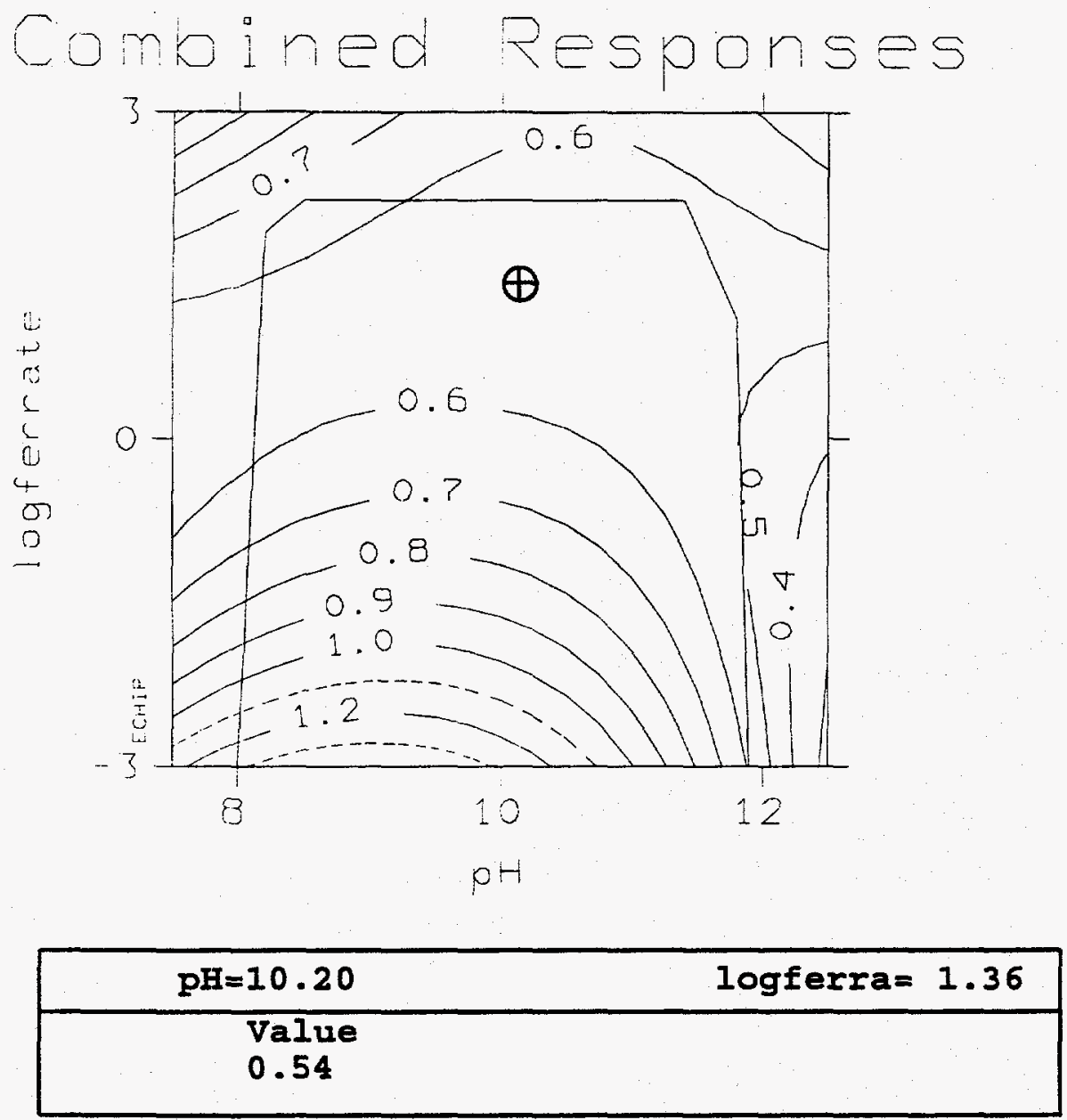




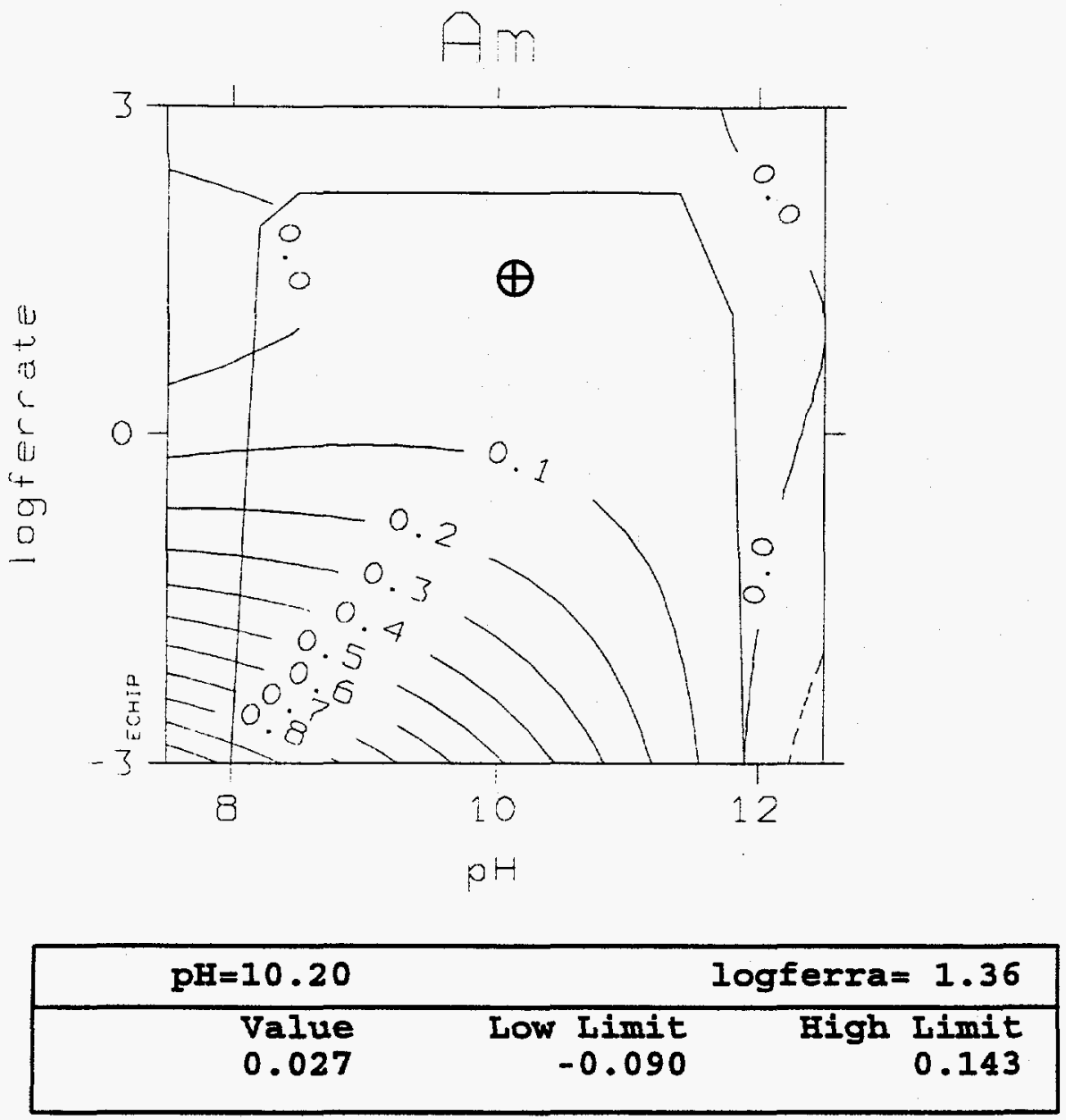




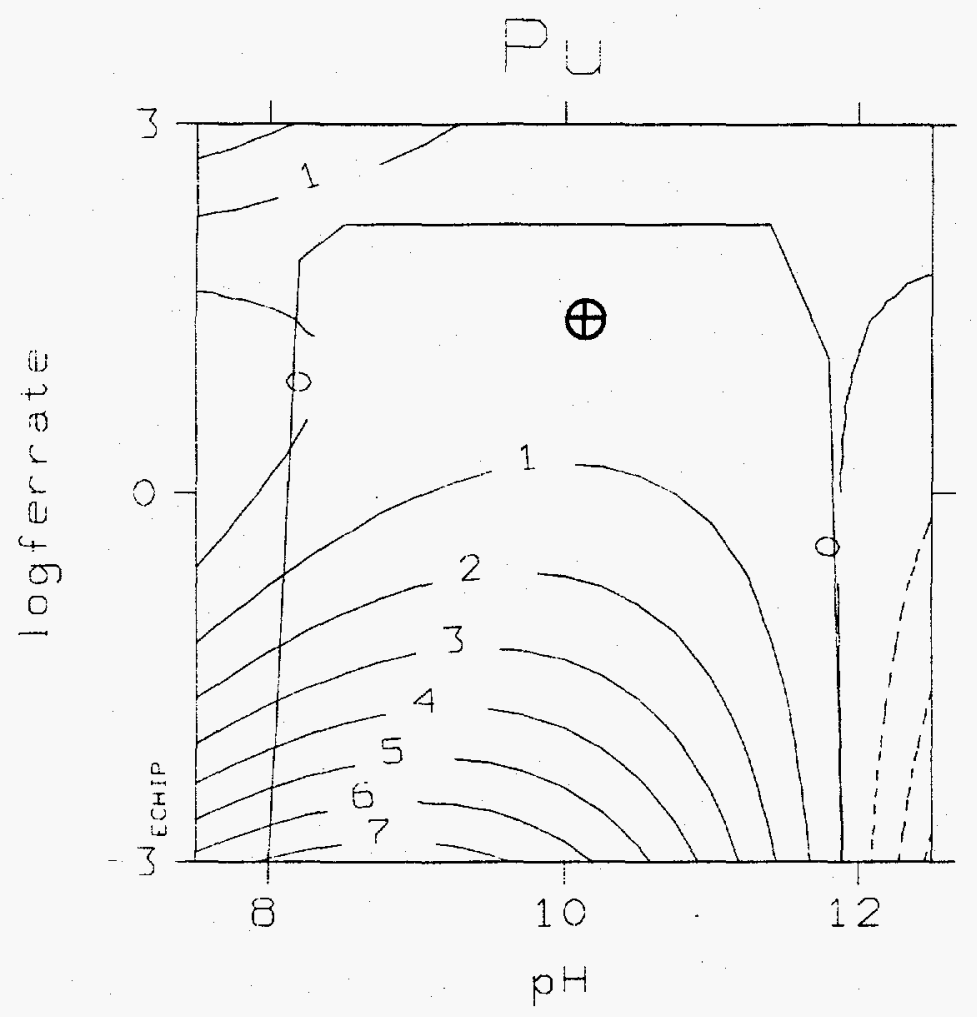

Lack OE FIE

\begin{tabular}{|rrr|}
\hline $\mathrm{pH}=10.20$ & & logferra= 1.36 \\
\hline Value & Low & Limit \\
0.36 & -0.69 & High Iimit \\
& & 1.41 \\
\hline
\end{tabular}




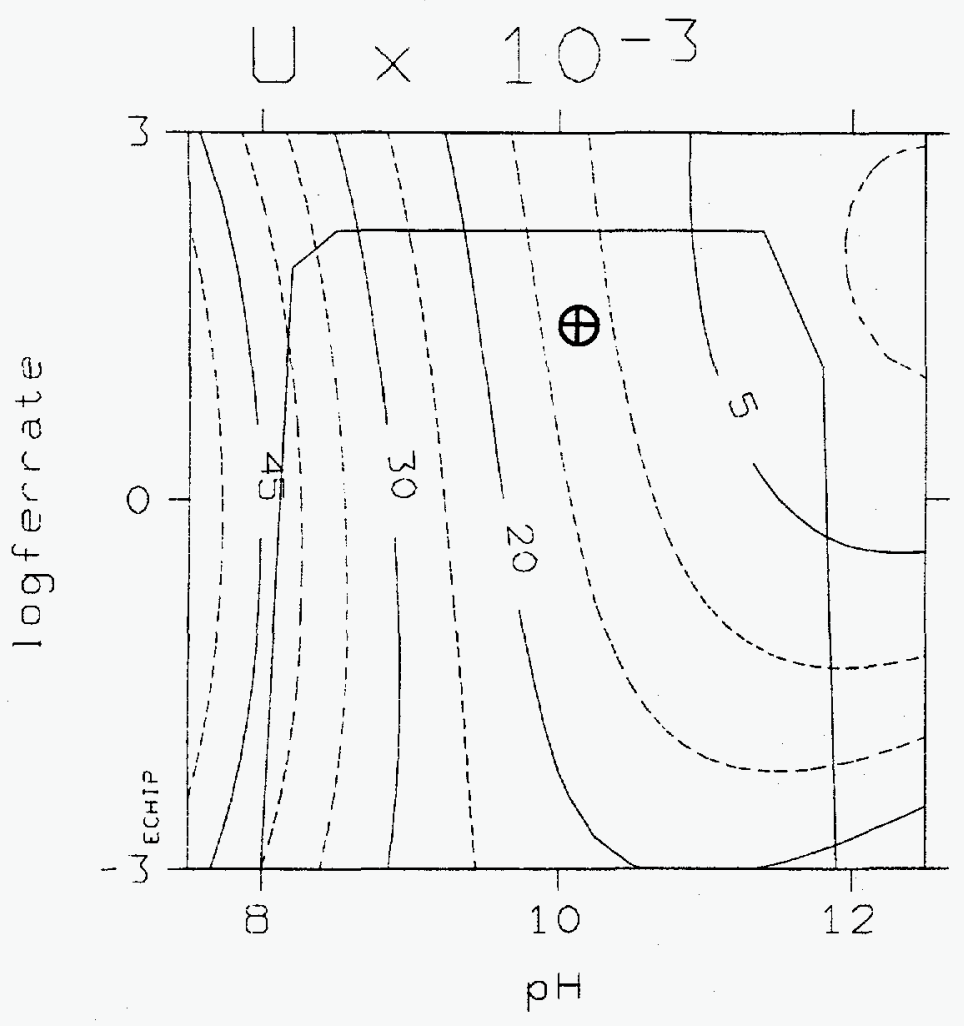

\begin{tabular}{|rrr|}
\hline $\mathrm{pH}=10.20$ & & Logferra= 1.36 \\
\hline Value & Low Limit & High Limit \\
0.0117 & -0.0029 & 0.0262 \\
\hline
\end{tabular}




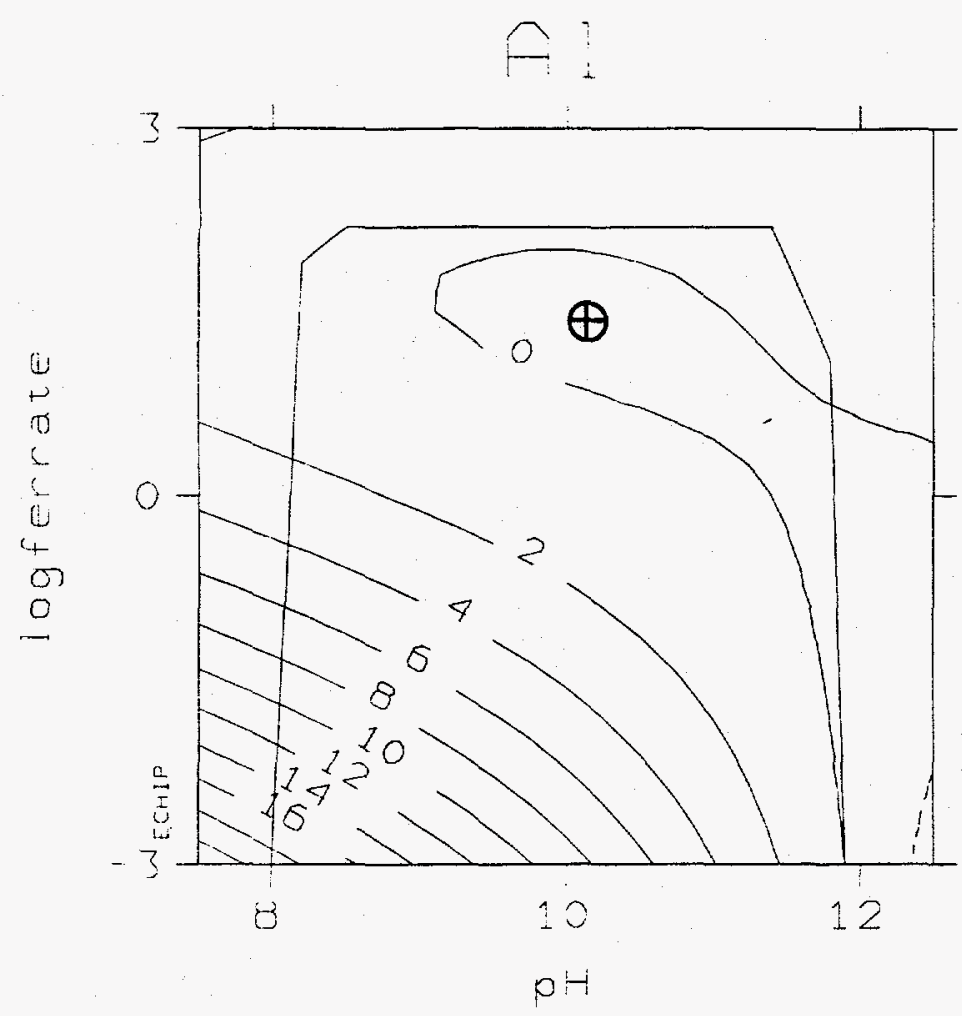

\begin{tabular}{|rrr|}
\hline $\mathrm{pH}=10.20$ & \multicolumn{2}{c|}{ logferra= 1.36} \\
\hline Value & Low Limit & High Limit \\
-0.14 & -1.14 & 0.86 \\
\hline
\end{tabular}




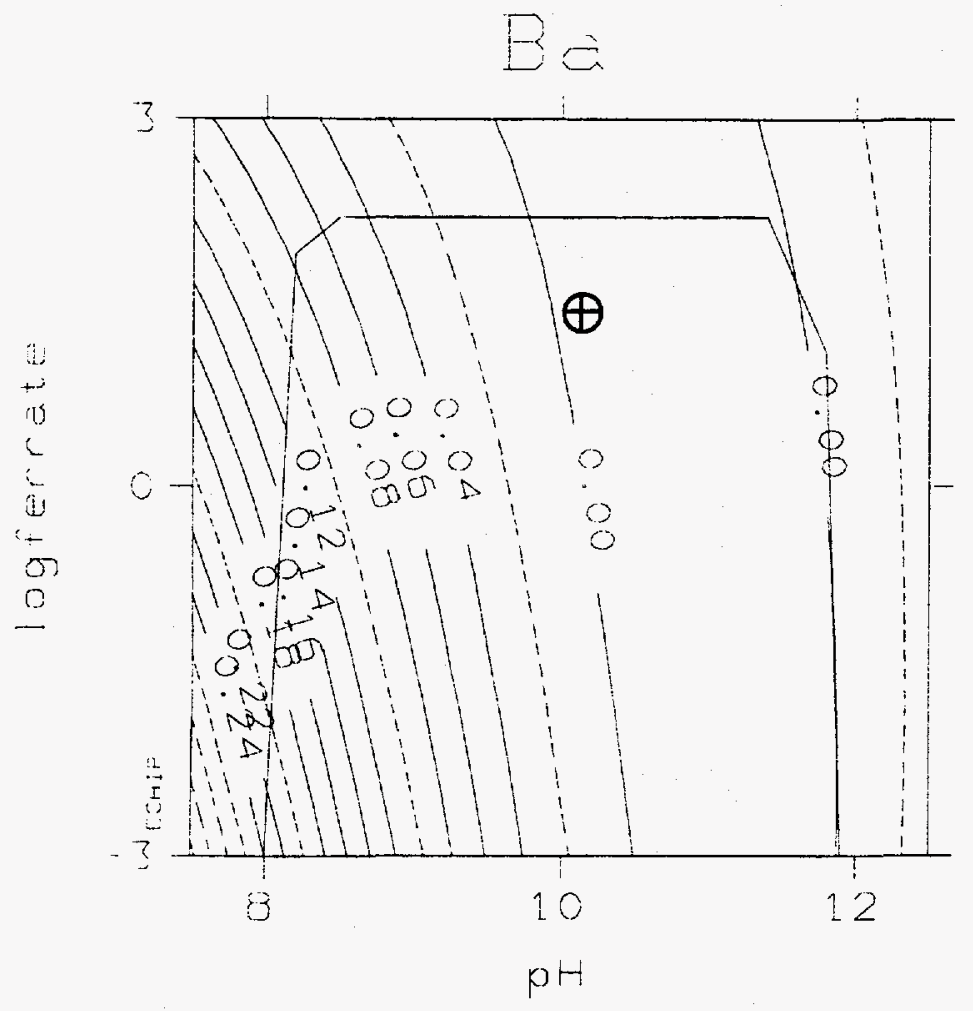

\begin{tabular}{|rrr|}
\hline pH=10.20 & & logferra= 1.36 \\
\hline Value & Low Limit & High Limit \\
-0.006 & -0.034 & 0.022 \\
\hline
\end{tabular}




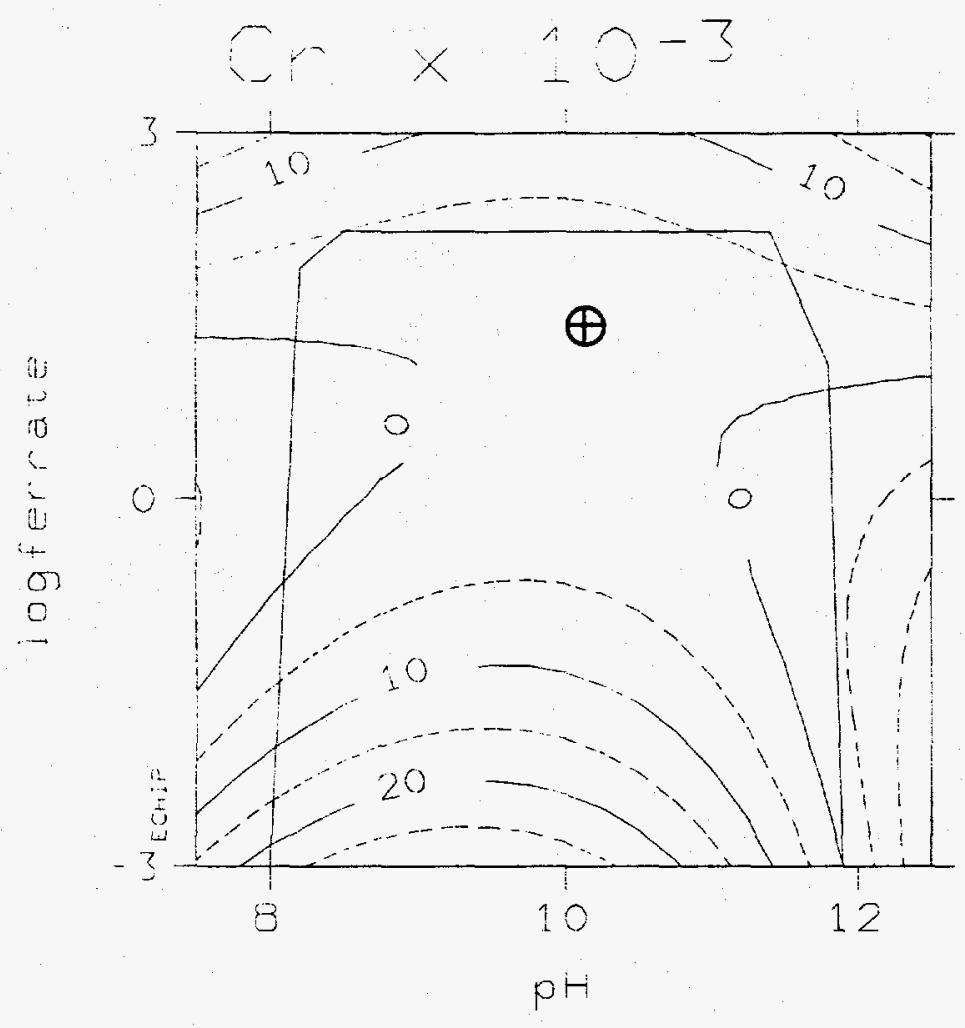

Lack Of Fit

\begin{tabular}{|rrr|}
\hline $\mathrm{pH}=10.20$ & & logferra= 1.36 \\
\hline Value & Low Limit & High Limit \\
0.0010 & -0.0071 & 0.0092 \\
\hline
\end{tabular}




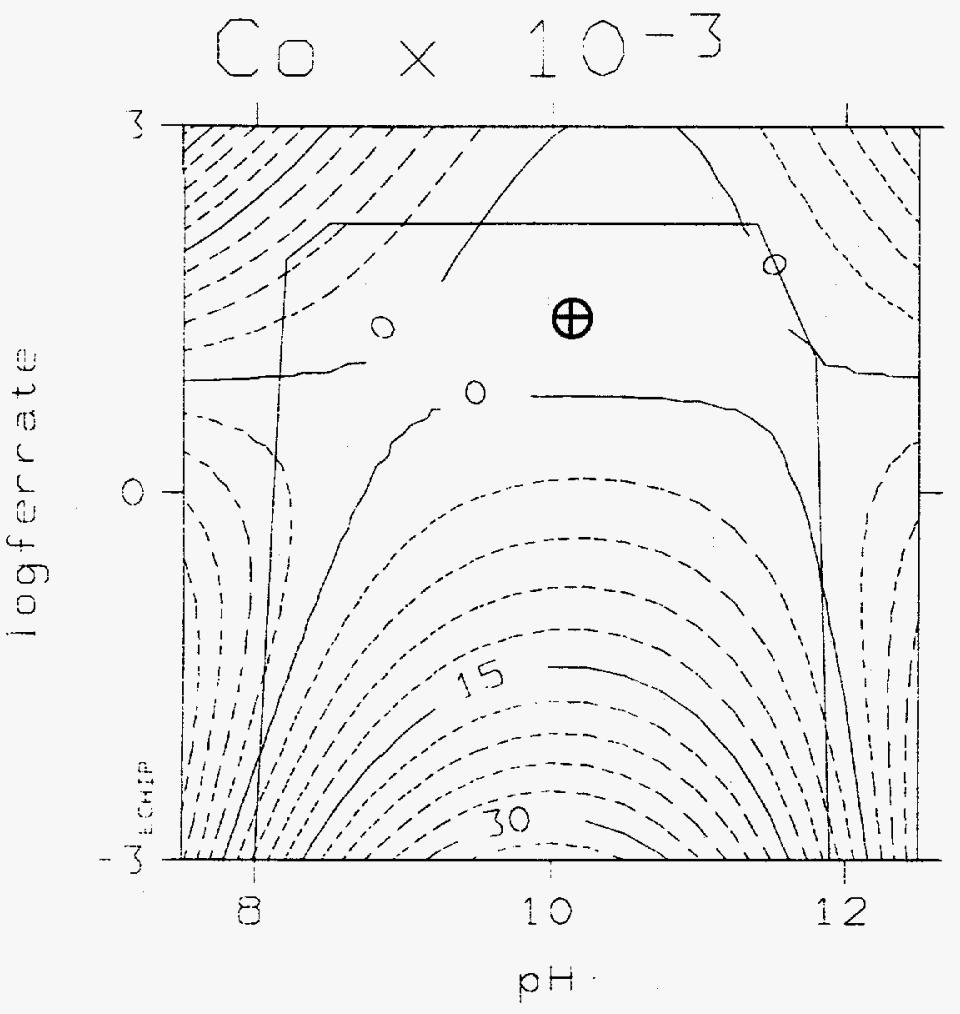

Lack of Fit

\begin{tabular}{|rrr|}
\hline $\mathrm{pH}=10.20$ & & logferra= 1.36 \\
\hline Value & Low Limit & High Limit \\
-0.0015 & -0.0171 & 0.0140 \\
\hline
\end{tabular}




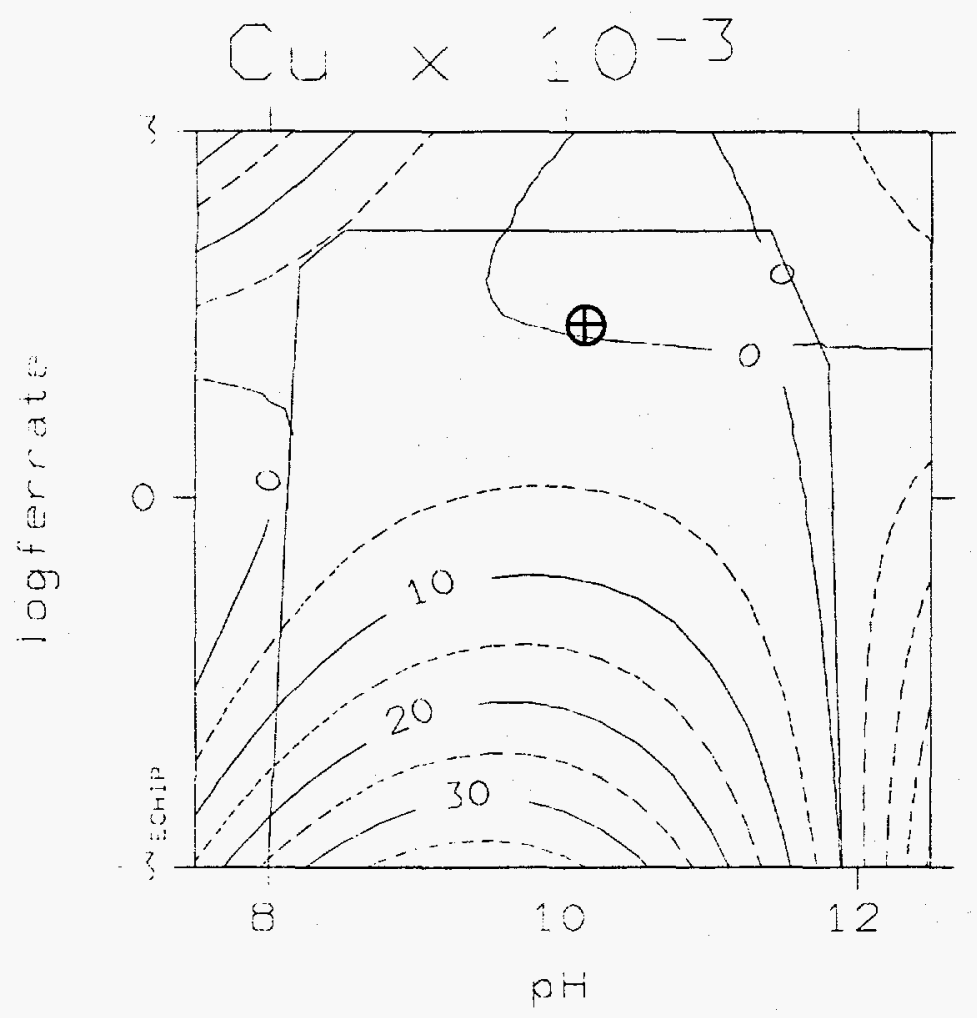

\begin{tabular}{|rrr|}
\hline $\mathrm{pH}=10.20$ & & logferra= 1.36 \\
\hline Value & Low Limit & High Limit \\
-0.0001 & -0.0114 & 0.0111 \\
\hline
\end{tabular}




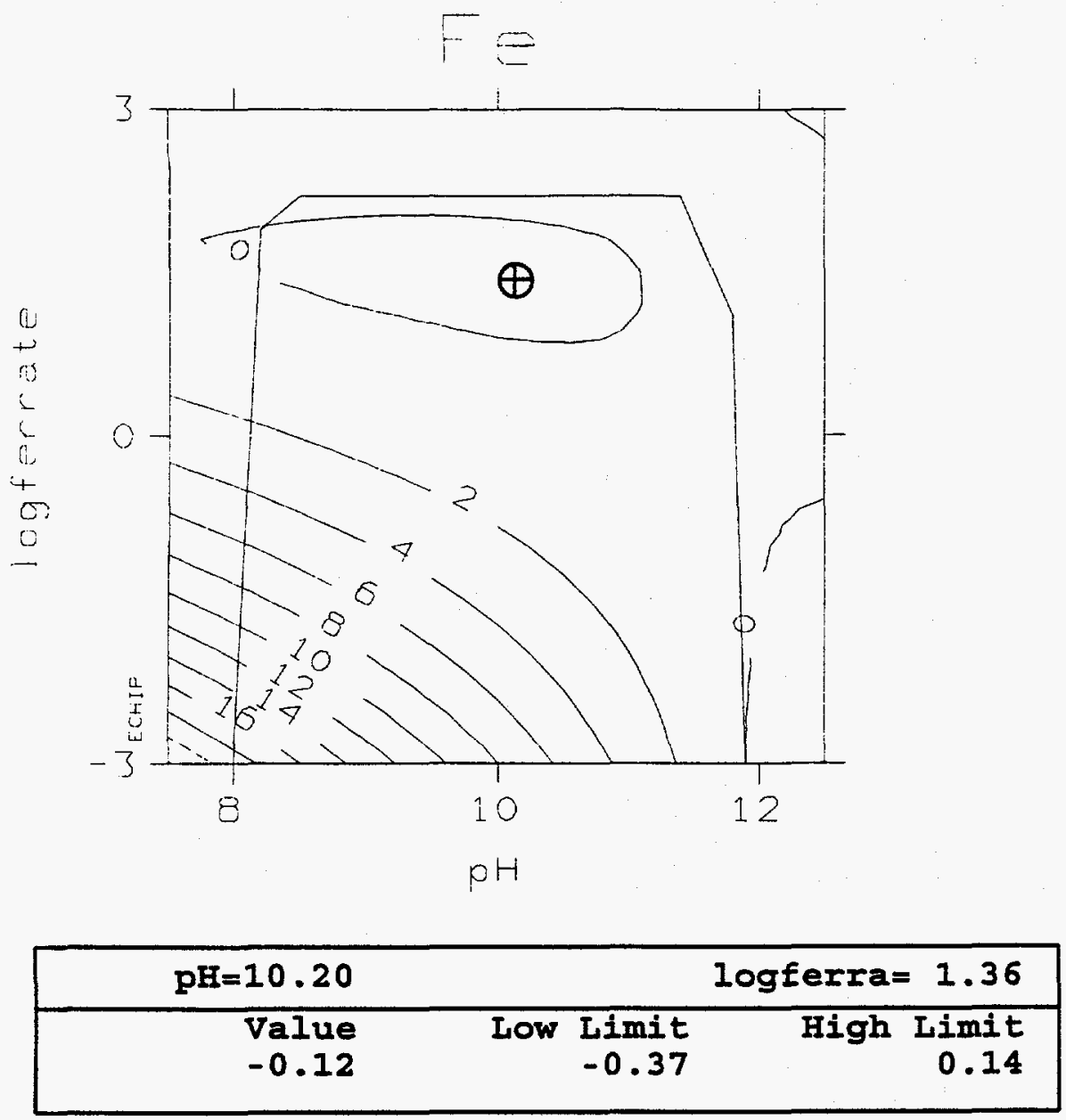

Lack OE Fit 


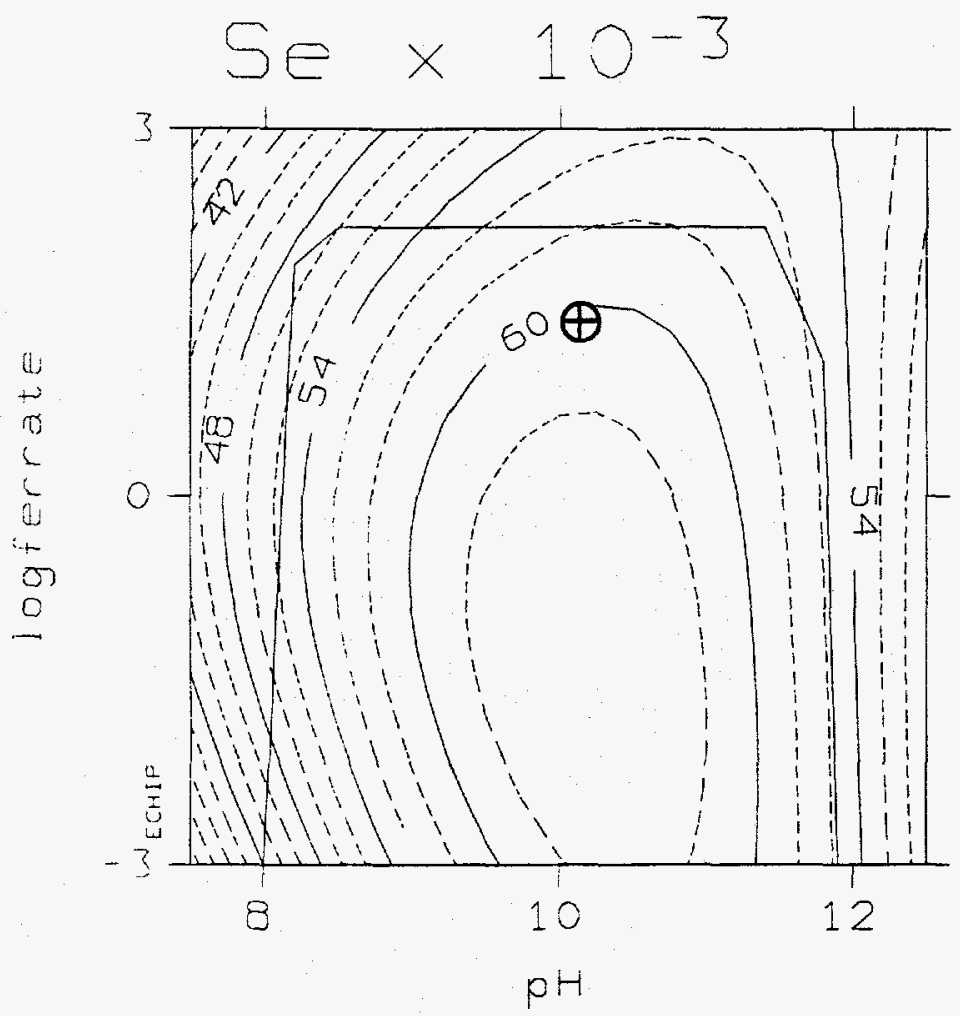

\begin{tabular}{|rrr|}
\hline $\mathrm{pH}=10.20$ & & logferra= 1.36 \\
\hline Value & Low Limit & High Limit \\
0.0605 & 0.0534 & 0.0676 \\
\hline
\end{tabular}




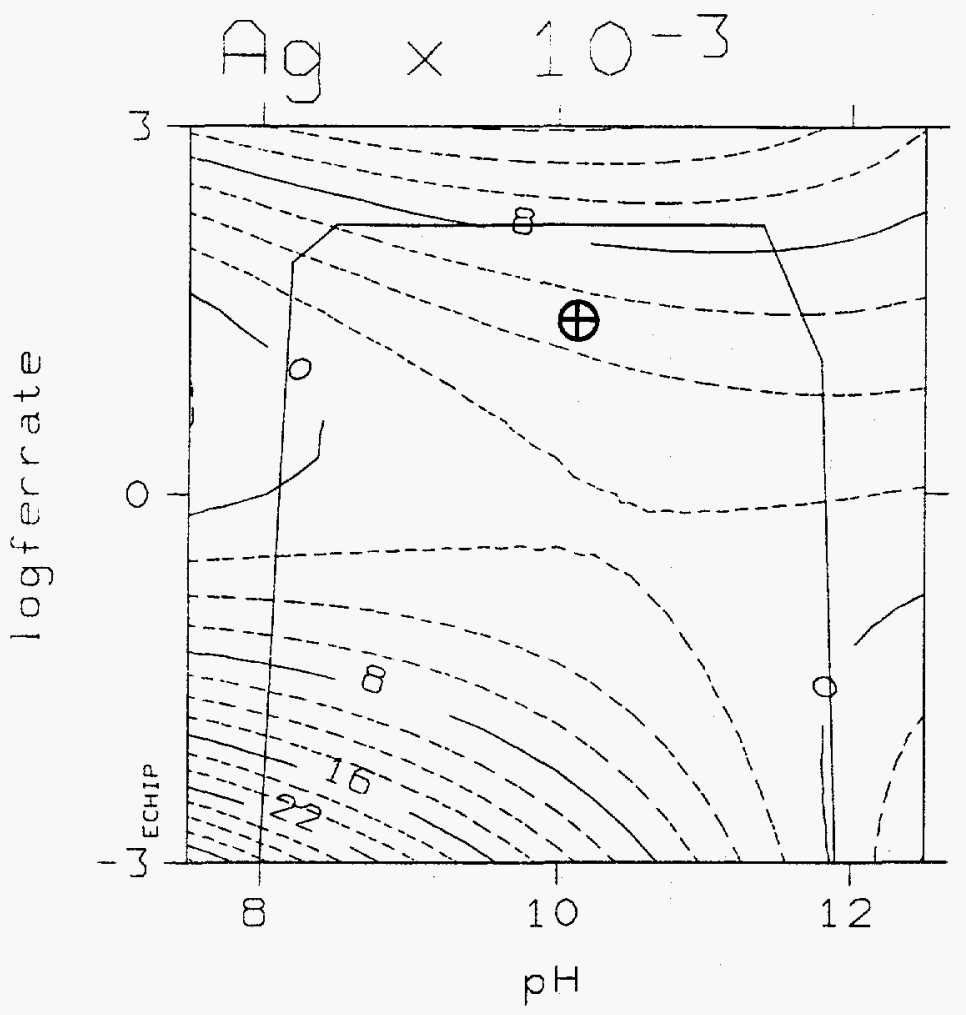

Lack of Fit

\begin{tabular}{|rrr|}
\hline $\mathrm{pH}=10.20$ & & logferra= 1.36 \\
\hline Value & Low Limit & High Limit \\
0.0048 & -0.0031 & 0.0127 \\
\hline
\end{tabular}




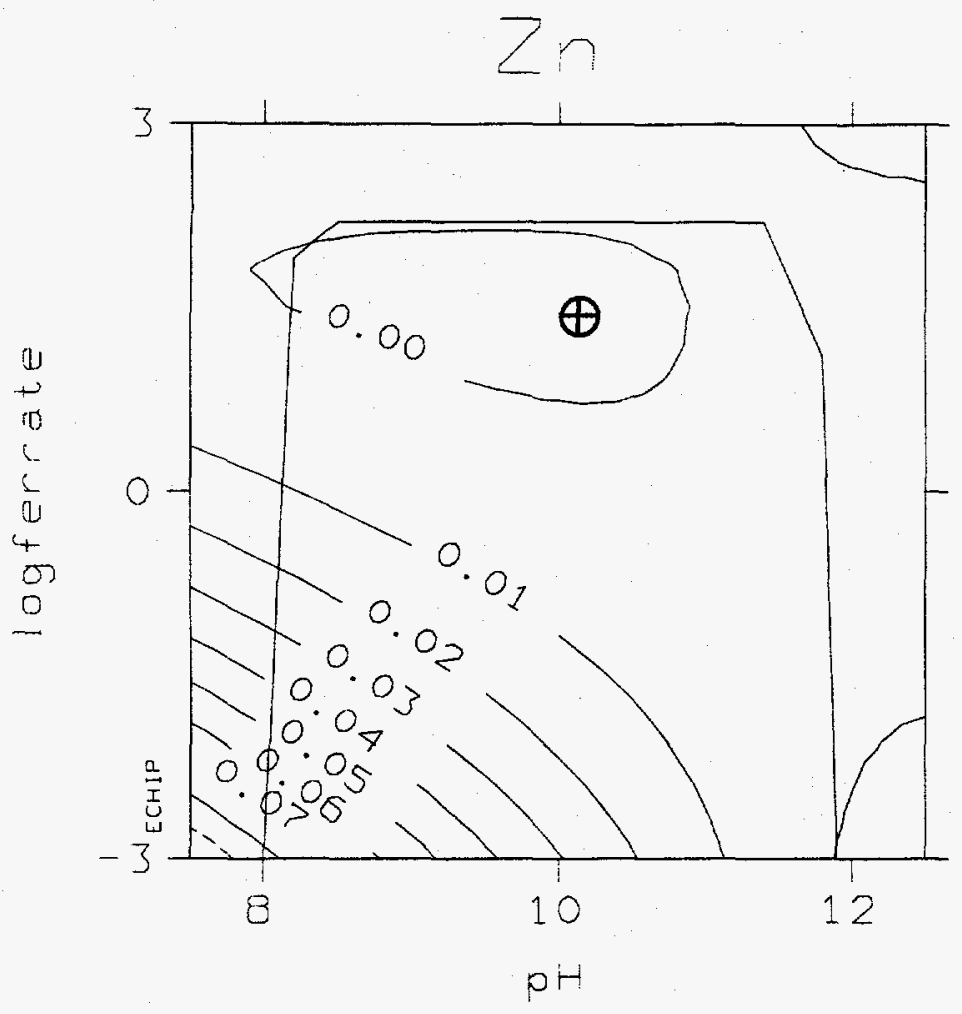

\begin{tabular}{|rrr|}
\hline $\mathrm{pH}=10.20$ & & logferra= 1.36 \\
\hline Value & Low Limit & High Limit \\
-0.0007 & -0.0044 & 0.0031 \\
& & \\
\hline
\end{tabular}


Potassium Ferrate Treatment of RFETS Groundwater

\section{APPENDIX G}

ACRONYM LIST
Document Number:

Section:

Page:
RF/ER-94-0028.UN

Appendix G, Rev. 0 1 of 3 
Potassium Ferrate Treatment of RFETS Groundwater
Document Number:

Section:
RF/ER-94-0028.UN

Appendix G, Rev. 0
$\%$

$<$

$>$

$\mathrm{ADL}$

$\mathrm{Ag}$

Al

$\mathrm{Al}_{2} \mathrm{SO}_{4}$

Am

$\mathrm{B}-\mathrm{Ker}^{2} \mathrm{TM}$

$\mathrm{Ba}$

CDPHE

Co

COCs

$\mathrm{Cr}$

$\mathrm{Cu}$

CWQCC

DE

DOE

ECHIP

EPA

ERPD

$\mathrm{Fe}$

$\mathrm{Fe}(\mathrm{OH})_{3}$

$\mathrm{Fe}_{2} \mathrm{O}_{3}$

gal

GFAA

gm

$\mathrm{H}_{2} \mathrm{O}$

ICP

$\mathrm{K}_{2} \mathrm{FeO}_{4}$

Kacl

Kass

$\mathrm{KOH}$

$\mathrm{lb}$

$\log$

$\mathrm{Mb}$
Percent

Less Than

Greater Than

Analytical Detection Limits

Silver

Aluminum

Alum

Americium

Beaker Used in Water Treatment Tests (registered Trade Mark)

Barium

Colorado Department of Public Health and Environment

Cobalt

Contaminants of Concern

Chromium

Copper

Colorado Water Quality Control Commision

Deleware

Department of Energy

Computer Software Used in This Study

U. S. Environmental Protection Agency

Environmeental Restoration Program Division

Iron

Iron (III) Hydroxide

Iron Oxide or Ferric Oxide

Gallon

Graphite Furnace Atomic Adsorption, an Analytical

Method

Gram

Water

Inductive Coupled Plasma, an Analytical Method

Potassium Ferrate

Weathered Claystone

Unweathered Sandstone

Potassium Hydroxide

Pound

Logarithm base 10

Megabyte 


\begin{tabular}{|c|c|}
\hline $\begin{array}{l}\text { Potassium Ferrate Treatment } \\
\text { of RFETS Groundwater }\end{array}$ & $\begin{array}{l}\text { Document Number: } \\
\text { Section: } \\
\text { Page: }\end{array}$ \\
\hline $\mathrm{mg}$ & Milligram \\
\hline $\mathrm{mg} / 1$ & Milligram per Liter \\
\hline $\mathrm{ml}$ & Milliter \\
\hline $\mathrm{N}$ & Normal, Chemical Equivelents per Liter of Water \\
\hline $\mathrm{Na}_{2} \mathrm{~S}_{2} \mathrm{O}_{3}$ & Sodium Thiosulfate \\
\hline $\mathrm{NaOH}$ & Sodium Hydroxide \\
\hline $\mathrm{pCi} / 1$ & Picocuries per Liter \\
\hline pH & Measure of Water Acidity \\
\hline $\mathrm{Pu}$ & Plutonium \\
\hline QA/QC & Quality Assurance / Quality Control \\
\hline RAM & Random Access Memory \\
\hline RFETS & Rocky Flats Environmental Technology Site \\
\hline $\mathrm{rpm}$ & Revolutions per Minute \\
\hline S. D. & Standard Deviation \\
\hline $\mathrm{Se}$ & Selenium \\
\hline SEPs & Solar Evaporation Ponds \\
\hline STSP & Sitewide Treatability Studies Program \\
\hline TRU/Clear ${ }^{\mathrm{TM}}$ & $\begin{array}{l}\text { Potassium Ferrate Based Water Treatment Chemical } \\
\text { (Registered Trade Mark) }\end{array}$ \\
\hline TSS & Total Suspended Solids \\
\hline $\mathrm{U}$ & Uranium \\
\hline $\mathrm{ug} / \mathrm{Kg}$ & Microgram per Kilogram \\
\hline $\mathrm{V}$ & Vanadium \\
\hline VGA & Visual Graphic Ability \\
\hline $\mathrm{Zn}$ & Zinc \\
\hline
\end{tabular}

